\title{
THE NON-ADOPTION OF XBRL BY PROFESSIONAL AND GOVERNMENT \\ ORGANISATIONS IN NEW ZEALAND AND ITS \\ IMPLICATIONS FOR STAKEHOLDERS
}

\section{BY \\ JASMINE DAVID}

\begin{abstract}
A thesis
submitted to the Victoria University of Wellington

in fulfilment of the requirements for the degree of

Doctor of Philosophy
\end{abstract}

Victoria University of Wellington

2016 



\begin{abstract}
Technology adoption plays a significant role in changing the way business communicates its financial information. One recently developed, technology-based language that can be used for financial reporting is eXtensible Business Reporting Language (XBRL). Fisher (2008) believes that XBRL is the future of business reporting and various XBRL stakeholders internationally have been promoting the use of XBRL for almost two decades. However, the widespread adoption of XBRL for business reporting has not happened in New Zealand.

Thus, the aim of this thesis is to investigate why business and professional organisations and the New Zealand Government have decided not to adopt XBRL for use in business reporting and the implications of that decision for XBRL stakeholders. The following research questions are addressed:

a) What factors influenced the organisations' decisions not to adopt XBRL for use in business reporting?

b) What are the implications of the government decision regarding XBRL use in business reporting for XBRL stakeholders?
\end{abstract}

To achieve the research aim and answer the research questions, this study developed a research framework that utilizes the Technological, Organisational, and Environmental (TOE) model of technology adoption developed by DePietro, Wiarda, and Fleischer (1990). A longitudinal multiple-case study approach that analyses interview and documentary data related to four key XBRL projects: LEAP+, Project First Step, e-GIF, and SBR, was employed.

The results suggest the non-adoption decision by New Zealand's private and public sector organisations was influenced by a combination of factors from the technological, organisational, and environmental contexts. Twelve predicted and fourteen unpredicted factors have a different degree of influence on the non-adoption decision. The factors of no relative advantage, not being perceived as a problem solver, a lack of human capability, no real championship, ineffective promotion, and communication, over-enthusiasm among experts, a lack of stakeholder involvement and a knowledge gap are the critical influencing factors and are common to all four XBRL projects. One-off factors in particular projects also had a significant influence. These were the copyright issue in the LEAP+ project; a change of laws, rules and regulations in Project First Step; a change of programme sponsor in the e-GIF 
project; and a change of government and the global financial crisis in the SBR programme. For the earlier projects, under the auspices of professional organisations, the technological and organisational contexts were the most important. However, the organisational and environmental contexts were most significant during projects under the auspices of government organisations.

The non-adoption of XBRL had different short-term and long-term implications for the XBRL stakeholders. In the short-term, the government agencies are potentially unable to perform specific reporting-related data analysis and have limited their ability to share data and improve the efficiency of their processes. In long-term the government agencies have lost an opportunity to detect more errors in financial statements, to get data and information for policy-making purposes and to work in a connected manner. Accounting firms face a lack of XBRL skill development in the short and long-term and have missed the opportunity to freeup time for other purposes. Business organisations have lost the opportunity to improve access and connections with government agencies or other businesses, to reduce their compliance costs and potentially increase their long-term effectiveness. 
DEDICATION

To

Mom and Dad;

My daughters. Ann, Anna and Adeny; and

My husband, Zimran

Thank you so much and I Love You All... 


\section{ACKNOWLEDGEMENTS}

Alhamdulillah means thanks be to God for letting me go on in this amazing journey. This has been the most challenging journey I have ever experienced, from the top of the mountain to the depths of the sea and yet, I survived. That was because I am in a circle of motivated and supportive people with the genuine intention to help me complete my intellectual adventure.

Firstly, I owe an enormous debt of gratitude to my supervisors, Associate Professor Carolyn Fowler, and Dr. David Johnstone. Their excellent supervision styles are like flying a kite, simple yet effective. They gave me the freedom to explore my ideas, then they pulled me back to provide guidance and show me the right direction. Their broad knowledge, experience and expertise in research have developed my research skills. Their encouragement and sympathy keep me going, even though I thought it almost impossible. Thank you for being there from the beginning to the end of this journey.

I have benefited from a generous scholarship from Universiti Teknologi MARA and Ministry of Higher Learning of Malaysia. They provided me with financial and administrative support during my study leave. Without this support, the journey would not have been possible.

I am indebted to the academic and administration staff of the School of Accounting and Commercial Law, Victoria University of Wellington, who provided on-going support. My particular thanks to Professor Rachel Baskerville for her encouragement and moral support; Associate Professor Carolyn Cordery for her input, inspiration and guidance; and to the late Adjunct Professor Kevin Simpkins for his input and support of my research.

I am especially appreciative of the individuals that participated in interviews. As these people were assured of anonymity for their contributions, they cannot be named and perhaps more appropriately acknowledged. They were incredibly generous with their time and provided extensive and in-depth information so this thesis could be completed.

My heartfelt gratitude to my family and friends. My husband, Zimran has been very supportive. His patience, understanding, companionship, and commitment throughout this journey have been key to its achievement. My special thanks to my wonderful daughters: Ann, Anna, and Adeny. They are great children, they pray for Mummy. The best advice was from Anna "Mummy, there is always a rainbow at the end of the corner." It kept me going 
and made me smile, though it was hard. My profound thanks to my parents, David, and Emeliah, for their unconditional love, support, and prayers that encouraged me to make this journey. To my PhD colleagues, Arifatul Husna, Hien Hoang, and Francesca Lim; thanks for your time and support during the course of the PhD. Finally, thanks to every person, who prayed, gave me inspiration, or loved to see my achievement, God bless all of them. 


\section{TABLE OF CONTENTS}

\section{CHAPTER 1: INTRODUCTION}

1.0 RESEARCH BACKGROUND

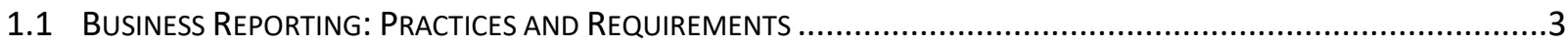

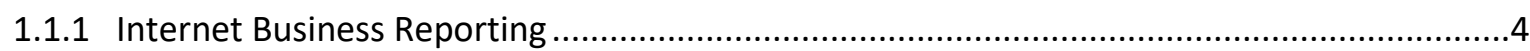

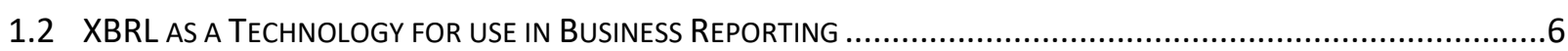

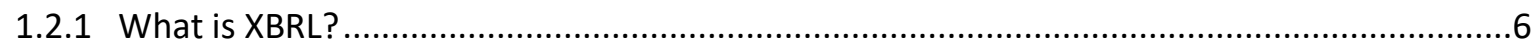

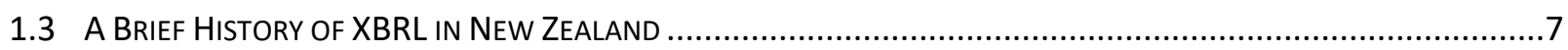

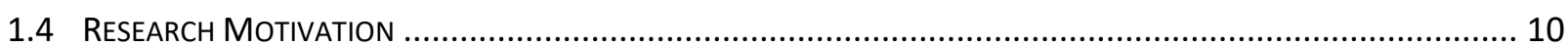

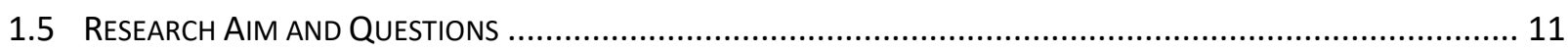

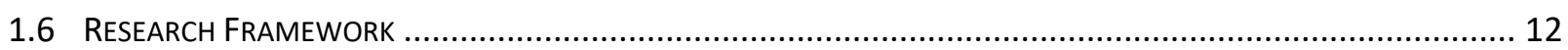

1.6.1 The Technological, Organisational and Environmental (TOE) Framework ........................ 12

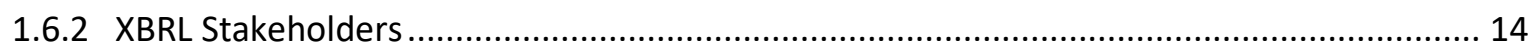

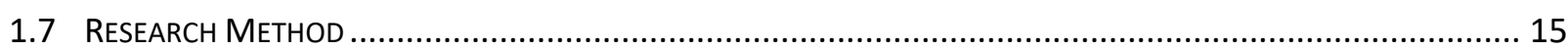

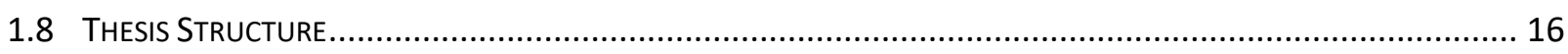

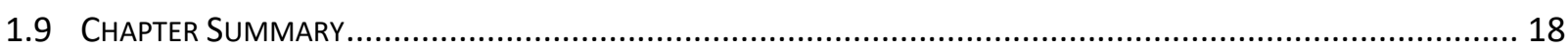

\section{CHAPTER 2: HISTORIES, STUDIES, AND ISSUES OF XBRL}

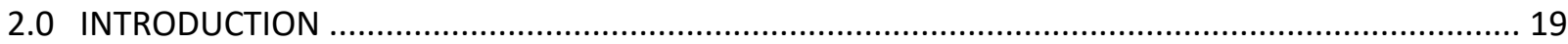

2.1 XBRL DEVELOPMENT AND USE AT THE INTERNATIONAL LEVEL (1998-2010) .............................................. 19

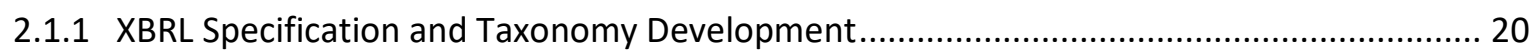

2.1.2 XBRL Jurisdictions and the Spread of XBRL Worldwide ..................................................... 21

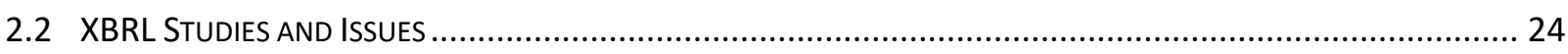

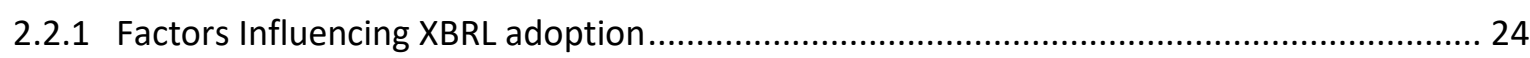

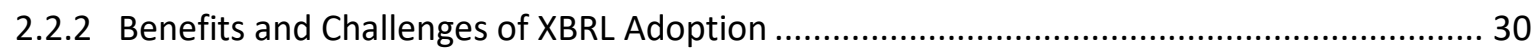

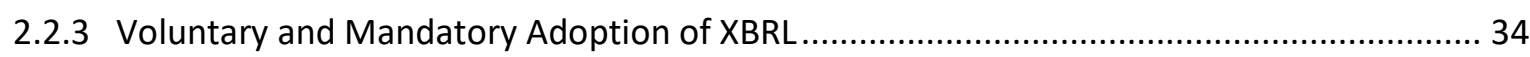

2.2.4 XBRL Awareness among Adopter and Non-Adopter Countries .......................................... 38

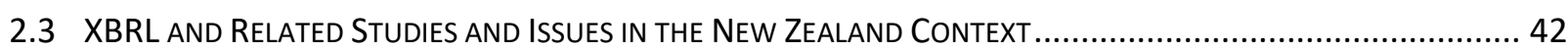

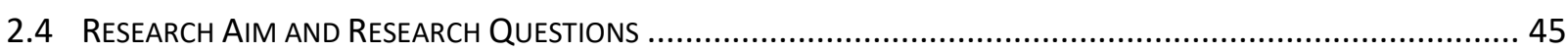

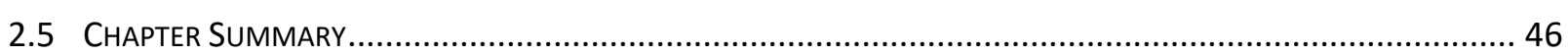

\section{CHAPTER 3: RESEARCH FRAMEWORK}

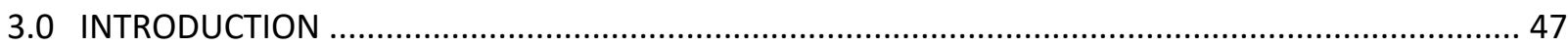

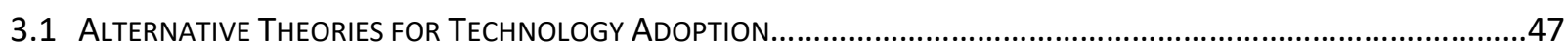

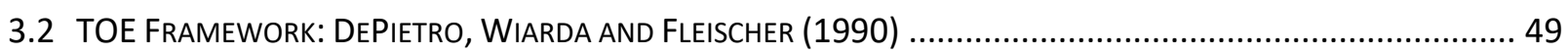

3.2.1 Application of TOE framework for Technology Adoption in IS studies ................................ 50

3.2.2 Relevance of the TOE Framework for XBRL and Adoption Decisions .................................. 54

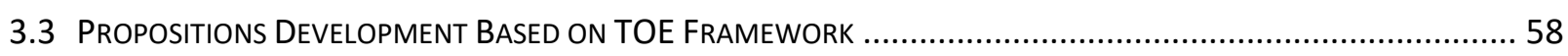

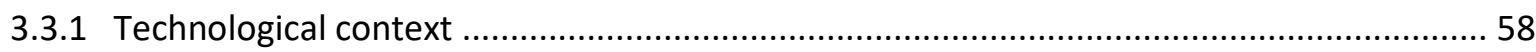

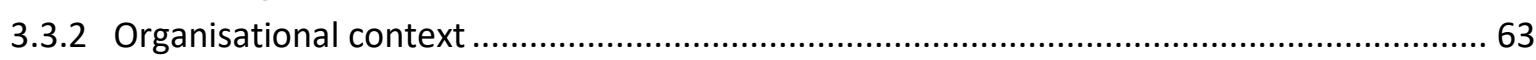

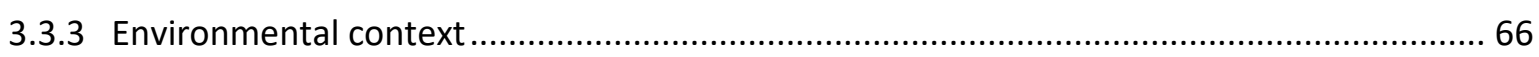

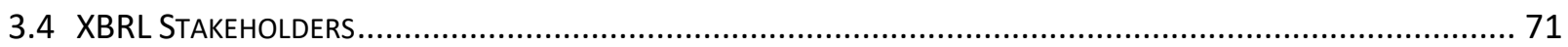

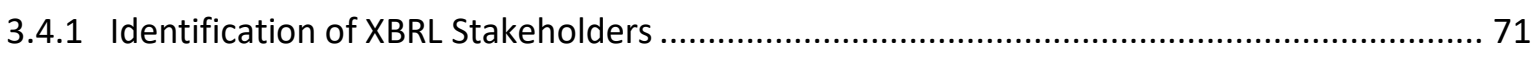

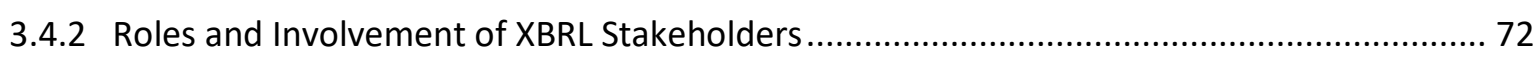




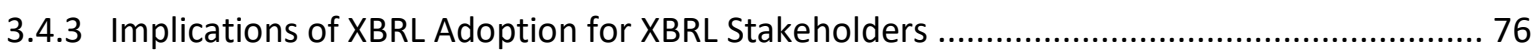

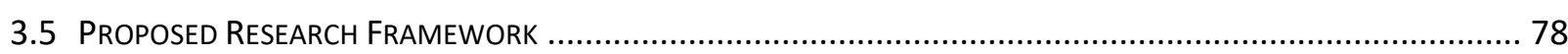

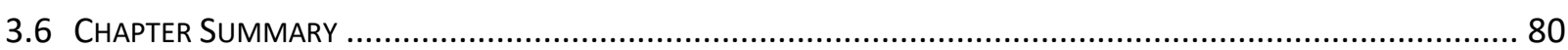

\section{CHAPTER 4: RESEARCH METHODOLOGY}

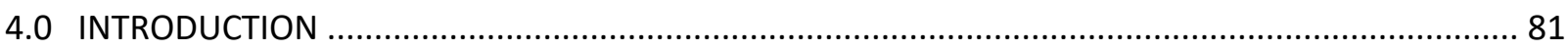

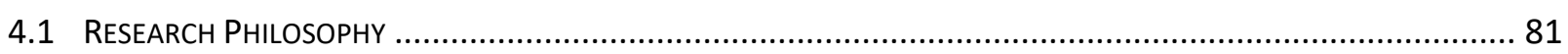

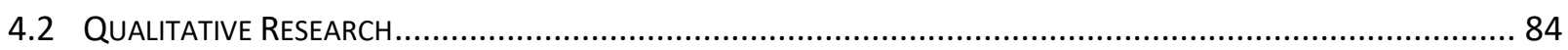

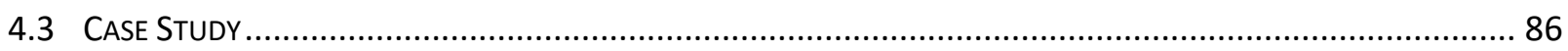

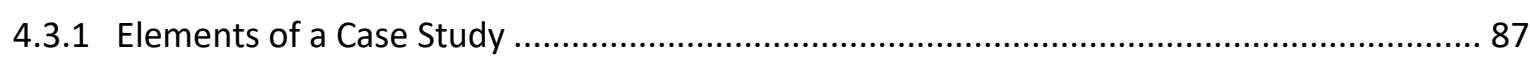

4.3.2 The Justification for and Relevance of Using a Case Study ............................................. 89

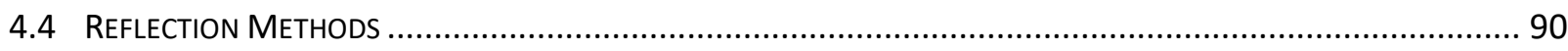

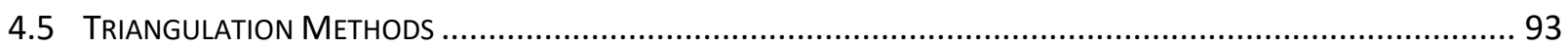

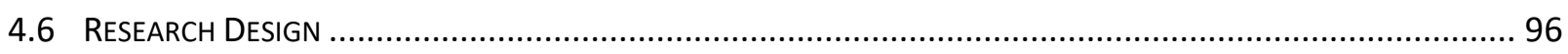

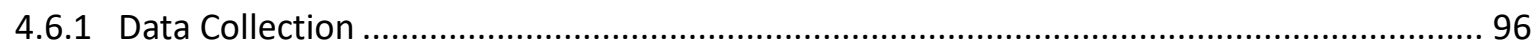

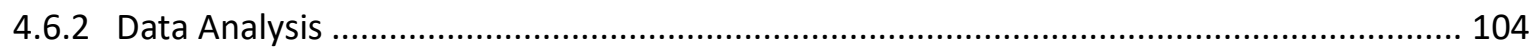

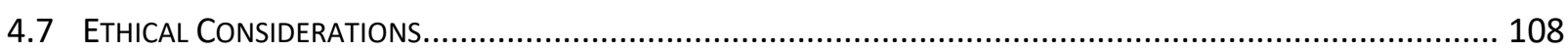

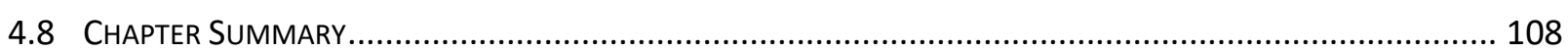

CHAPTER 5: XBRL INITIATIVES IN NEW ZEALAND: A HISTORICAL OVERVIEW

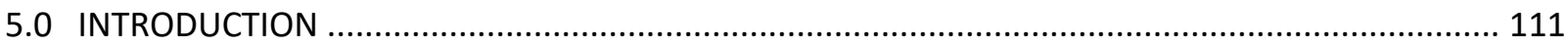

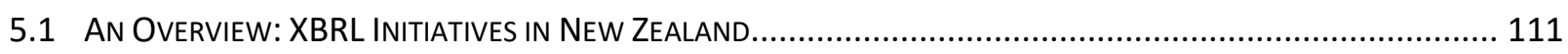

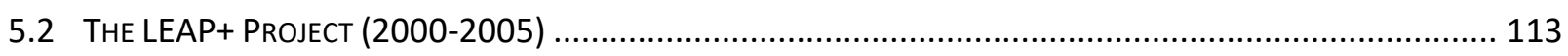

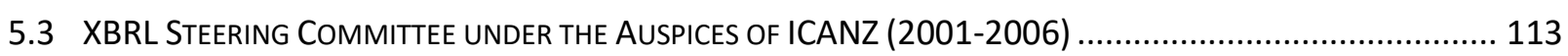

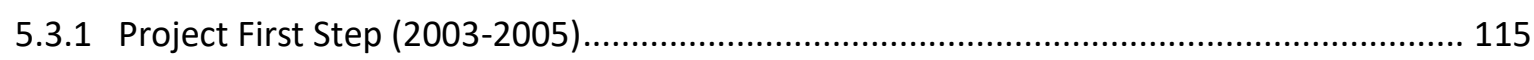

5.3.2 New Zealand's Hosting of the $9^{\text {th }}$ XBRL International Conference (2004) .......................... 116

5.3.3 Increasing Awareness in the New Zealand Business Community (2003-2004) ................ 116

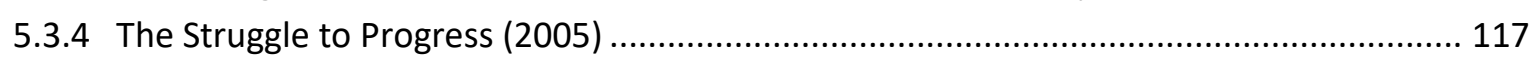

5.4 ShIFTING THE INITIATIVE FROM THE PRofESSIONAL TO GoVERNMENT AuSPICES (2006)............................... 117

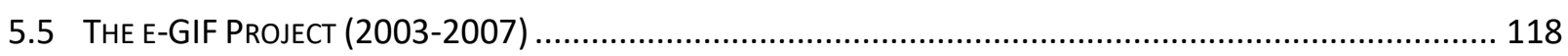

5.5.1 The Quality Regulation Review (QRR) and Financial Reporting Amendment Act 2006.... 119

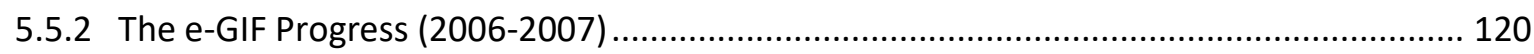

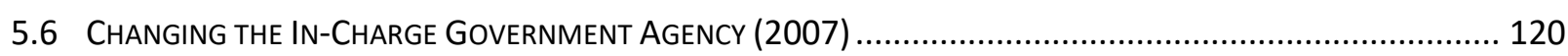

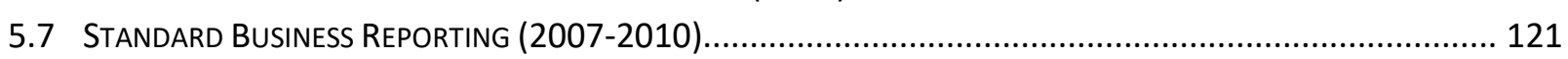

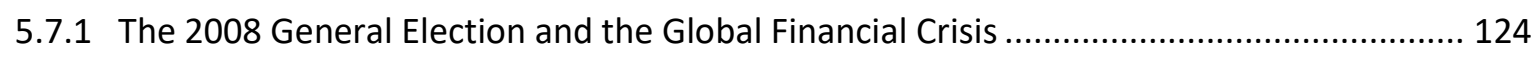

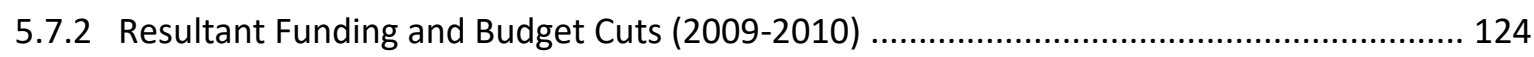

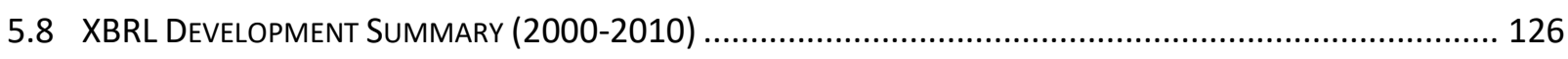

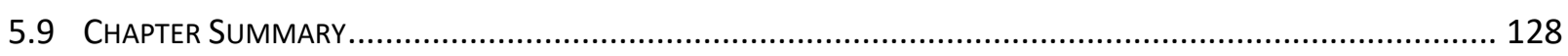

CHAPTER 6: XBRL INITIATIVES UNDER THE AUSPICES OF PROFESSIONAL ORGANISATIONS

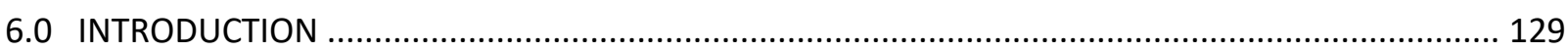

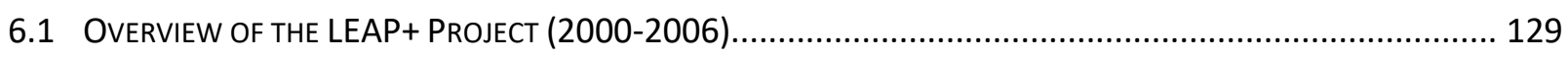

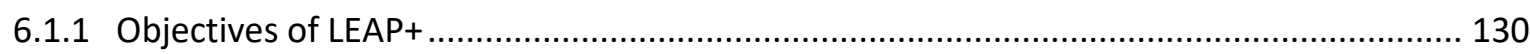

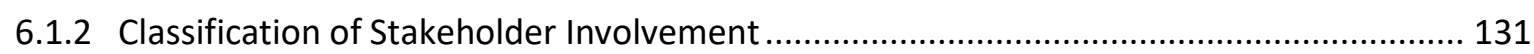

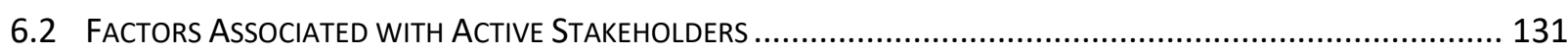

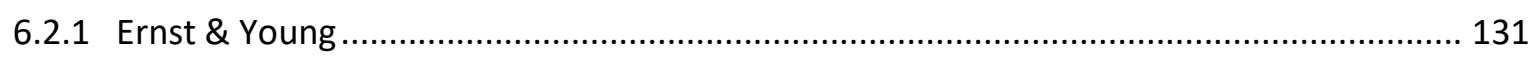




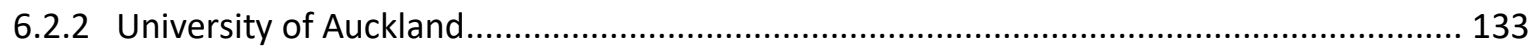

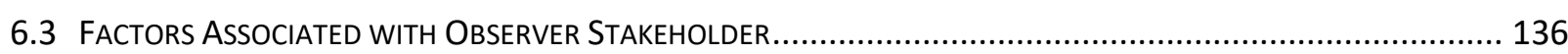

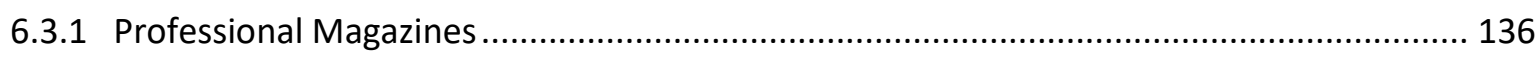

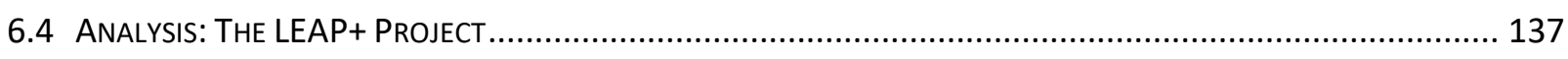

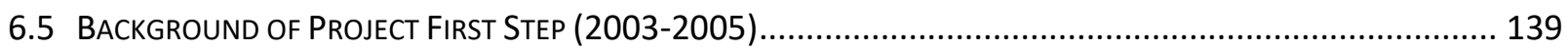

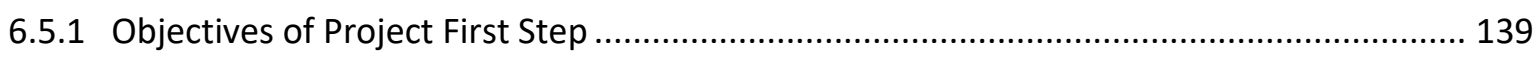

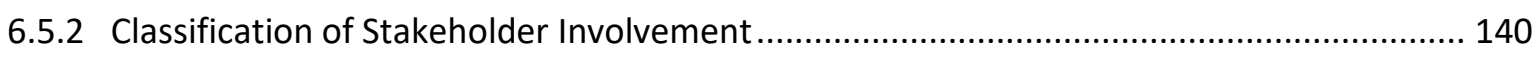

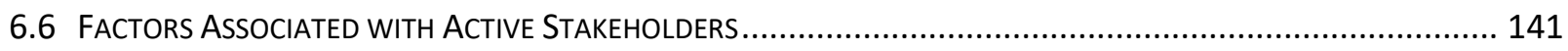

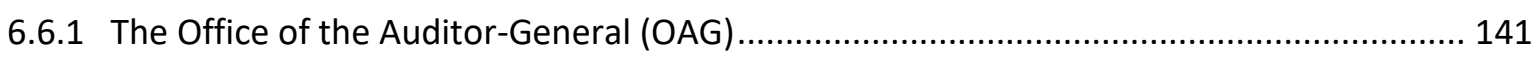

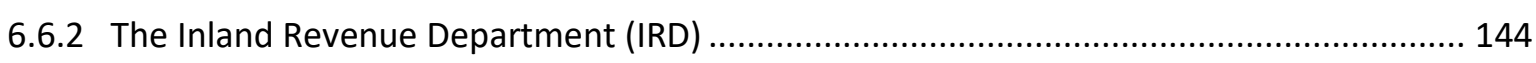

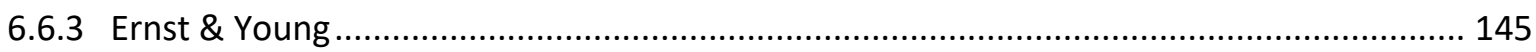

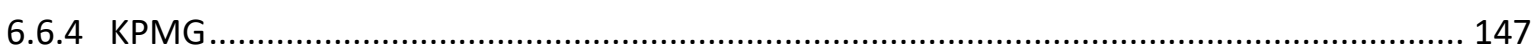

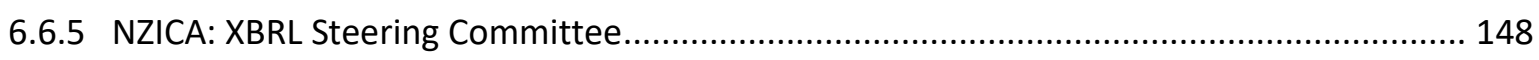

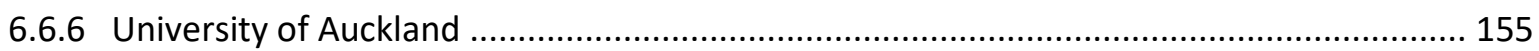

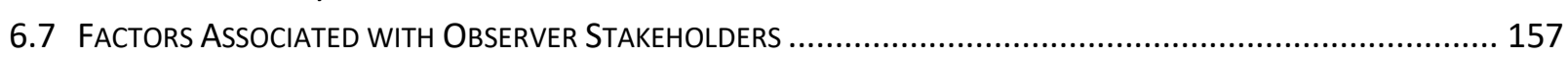

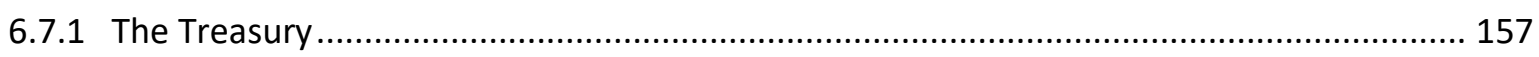

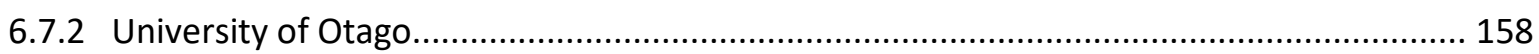

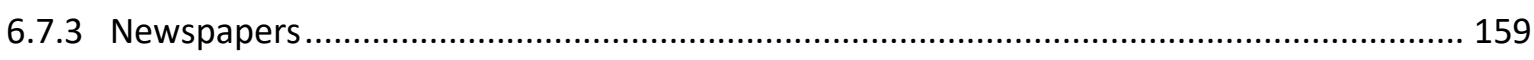

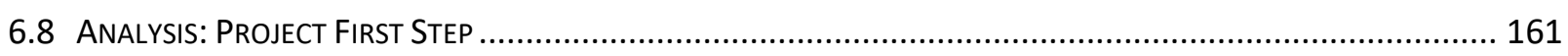

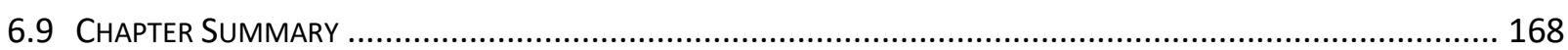

\section{CHAPTER 7: XBRL INITIATIVES UNDER THE AUSPICES OF GOVERNMENT ORGANISATIONS}

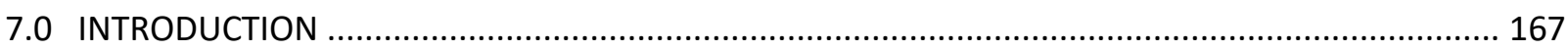

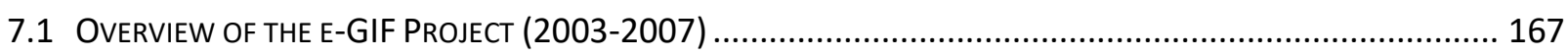

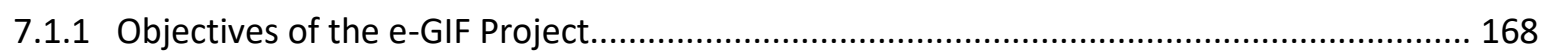

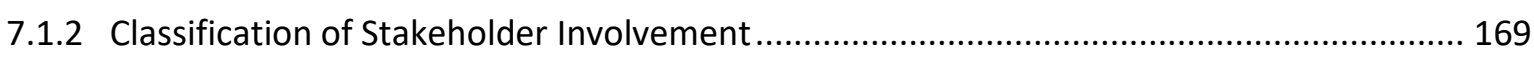

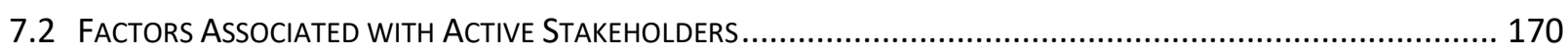

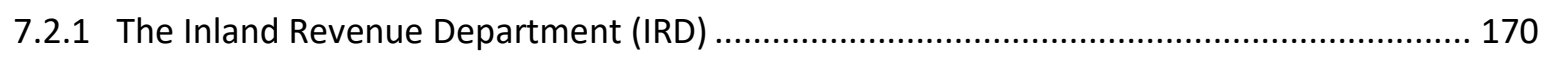

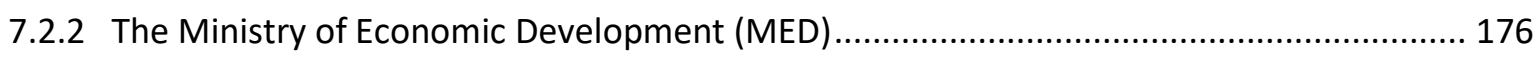

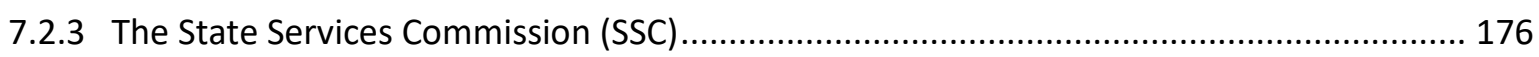

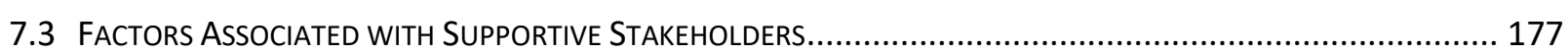

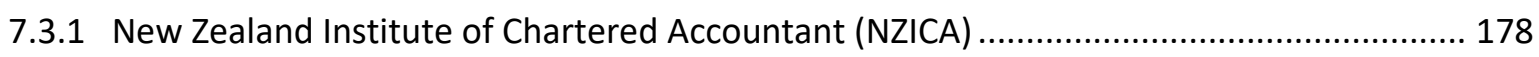

7.3.2 Tax Management Consulting Firm ............................................................................... 180

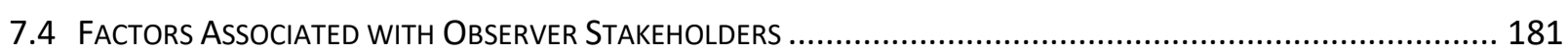

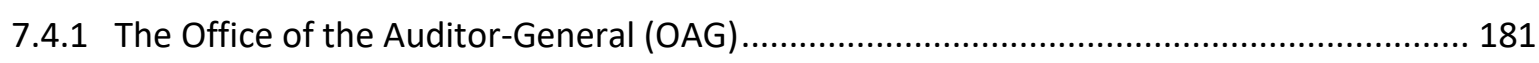

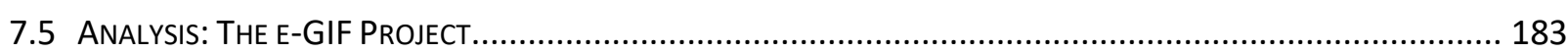

7.6 OVERVIEW OF THE StANDARd BUSINESS REPORTING (SBR) PROGRAMME (2007-2010) ............................. 186

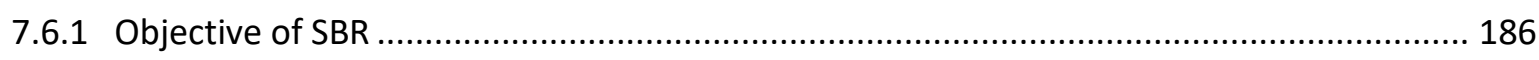

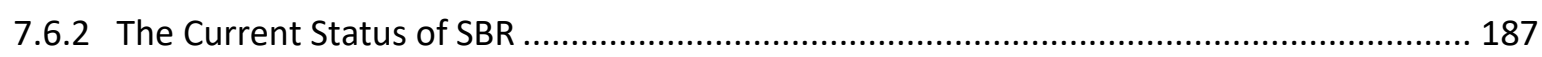

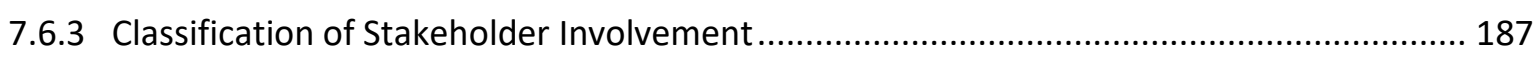

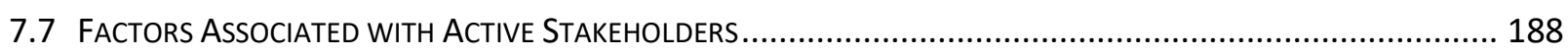

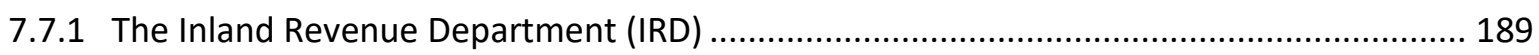

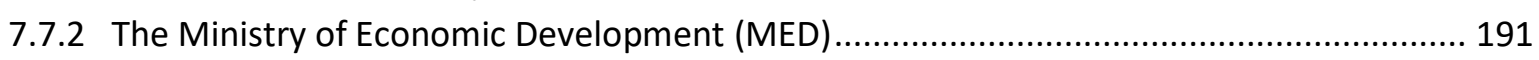

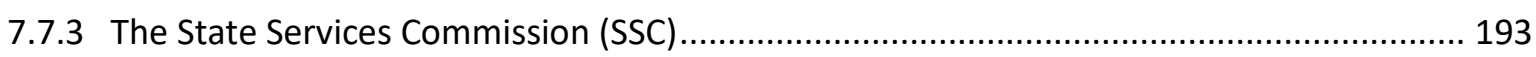

7.7.4 New Zealand Institute of Chartered Accounting (NZICA) ................................................ 196

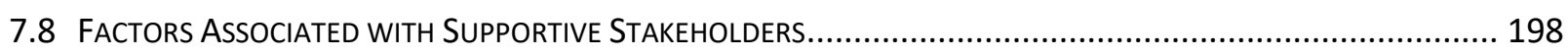




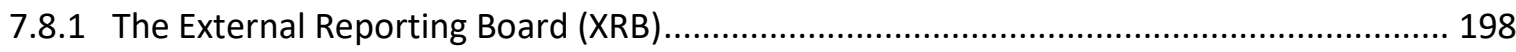

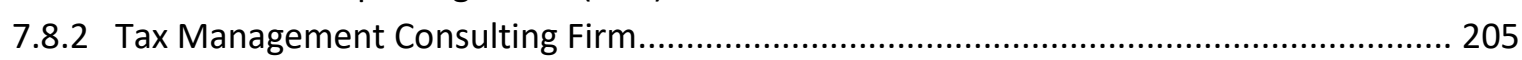

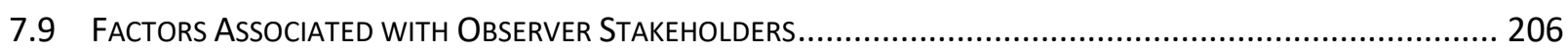

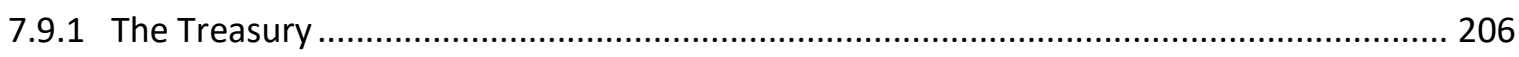

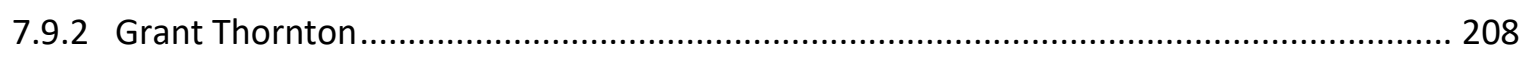

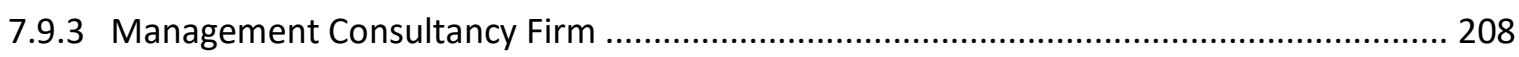

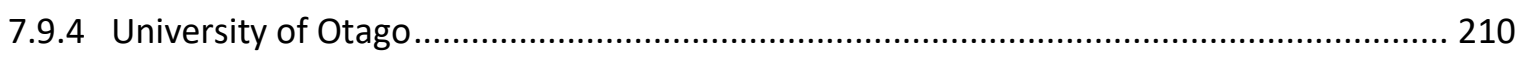

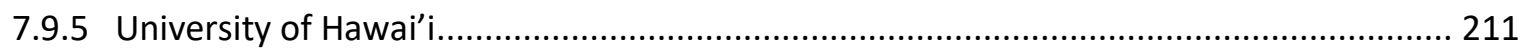

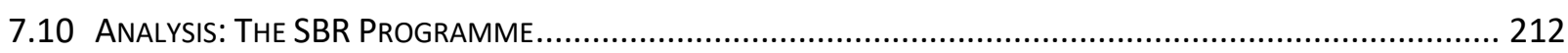

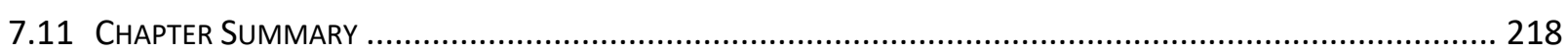

\section{CHAPTER 8: IMPLICATIONS OF THE GOVERNMENT DECISION REGARDING XBRL}

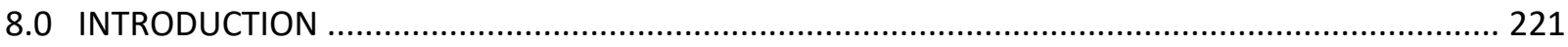

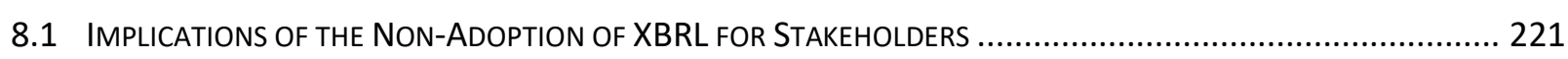

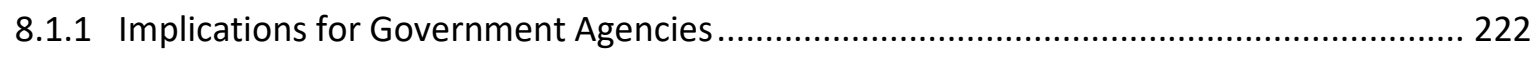

8.1.2 Implications for Accounting Firms and the Accounting Professional Bodies ..................... 226

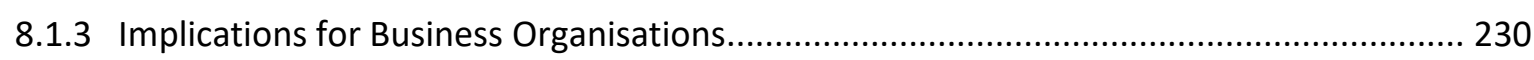

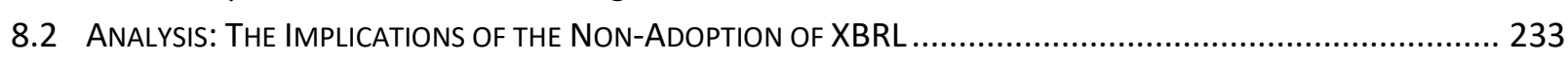

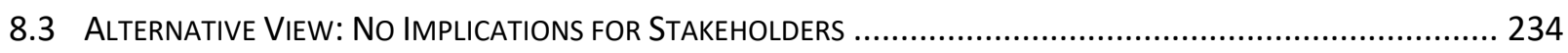

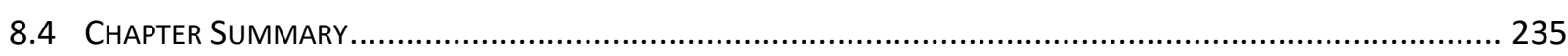

\section{CHAPTER 9: DISCUSSION AND CONCLUSION}

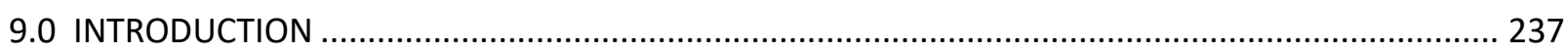

9.1 FACTORS INFLUENCED ORGANISATIONS DECISION ON NON-ADOPTION OF XBRL ....................................... 238

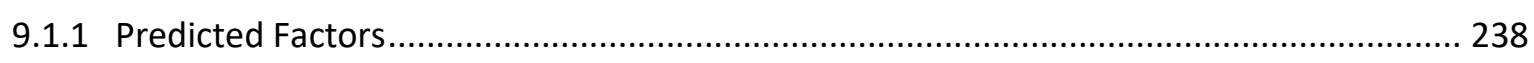

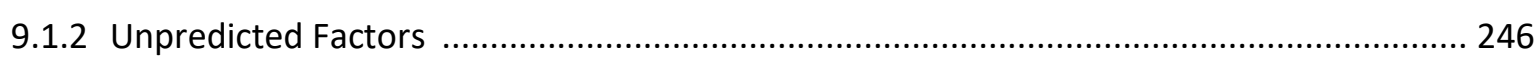

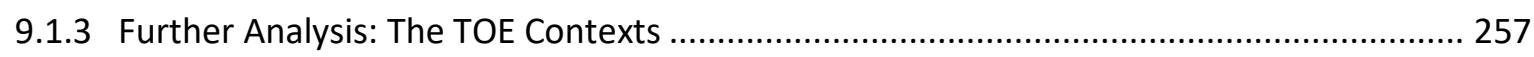

9.1.4 Further Analysis: The Stakeholder Involvements............................................................ 259

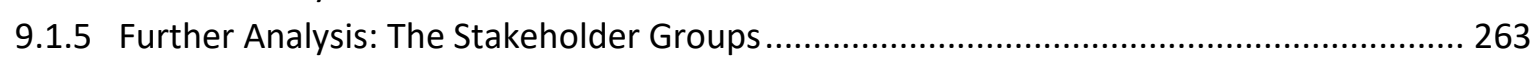

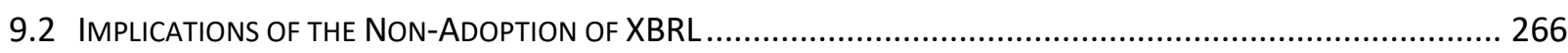

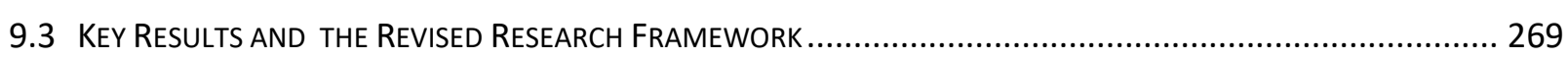

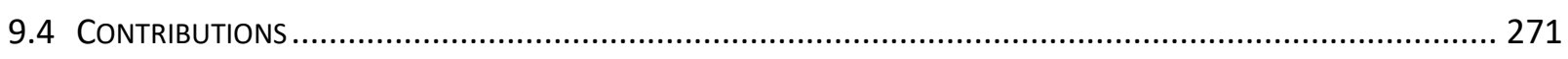

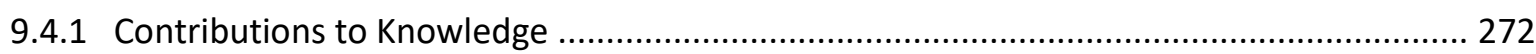

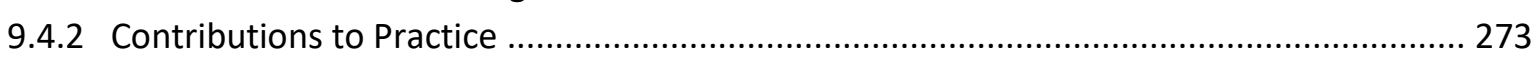

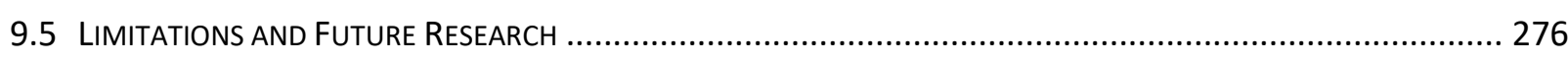

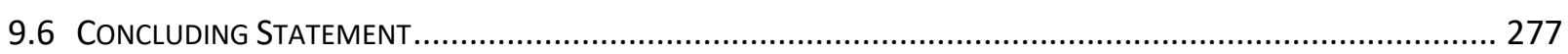

\section{APPENDICES}

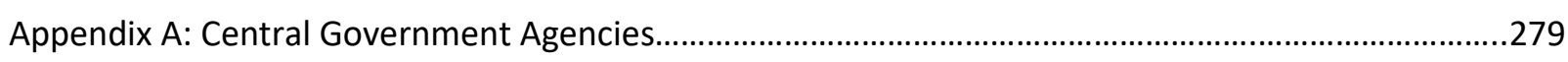

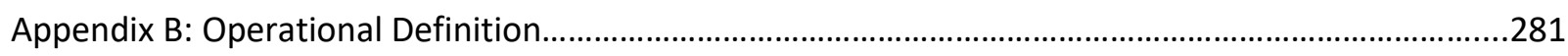

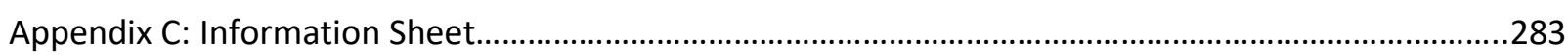

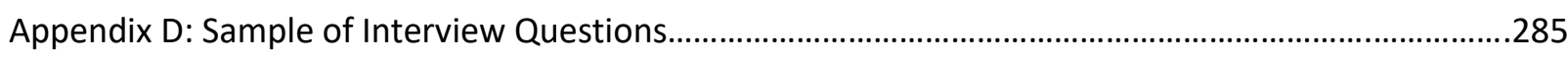

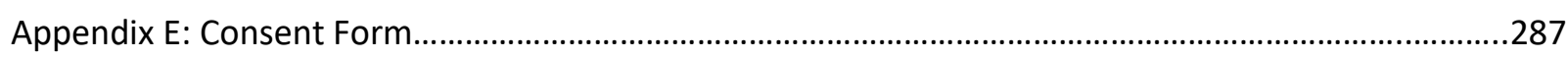

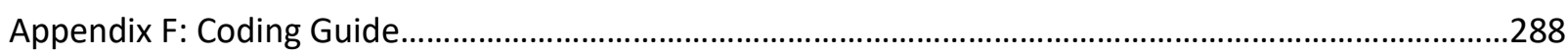

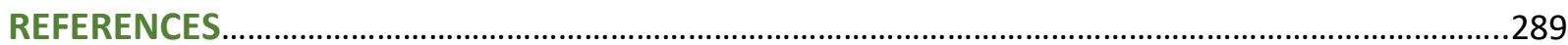




\section{LIST OF TABLES}

Table 2.1: List of XBRL Country Jurisdictions (2000-2009)

Table 2.2: XBRL Project Numbers, Based on Project Type and Status (2000-2009)

Table 2.3: XBRL Projects, Based on Entity Type and Status (2000-2009)

Table 2.4: Factors Influencing XBRL Adoption

Table 2.5: New Zealand: XBRL and Related Studies and Issues 44

Table 3.1: Technology Adoption Based on TOE Framework by Business Organisations 51

Table 3.2: Technology Adoption Based on TOE Framework by Government Organisations 52

Table 3.3: XBRL Adoption Studies Based on TOE Framework 56

Table 3.4: List of Propositions Under the TOE Framework 69

Table 3.5: Implication of XBRL Adoption for Stakeholders 78

Table 4.1: Comparison of Positivism and Post-Positivism 83

Table 4.2: Strengths of Qualitative Research 85

Table 4.3: Weaknesses of Qualitative Research 85

Table 4.4: Usage of a Case Study to Investigate XBRL Adoption 89

Table 4.5: Data Collection Method: Strengths, Weaknesses, and Sources Used 97

Table 4.6: Summary of Interviewees' Details 102

Table 5.1: The Development of XBRL in New Zealand from 2000 - 2010 126

Table 6.1: Overall Summary of TOE Context Factors in the LEAP+ Project 138

Table 6.2: Overall Summary of TOE Context Factors in Project First Step 165

Table 7.1: Overall Summary of TOE Context Factors in the e-GIF Project 185

Table 7.2: Overall Summary of TOE Context Factors in the SBR Programme 218

Table 8.1: Summary of Short-term and Long-term Implications of the Government's Decision 233

Table 9.1: Summary of Predicted TOE Context Factors for XBRL Initiatives 245

Table 9.2: Summary of Unpredicted TOE Context Factors for XBRL Initiatives 256

Table 9.3: Existence of the Influencing Factors Based on XBRL Initiatives 257

Table 9.4: Comparisons of Findings with Existing Literature on Implications for Stakeholders 


\section{LIST OF FIGURES}

Figure 1.1: A Stakeholder View of the XBRL Decision 15

Figure 2.1: Mousa's (2011) Conceptual Framework 27

Figure 2.2: Result of Studies on Level of Awareness 40

Figure 3.1: TOE Framework 49

Figure 3.2: TOE Framework in XBRL: the New Zealand Case 71

Figure 3.3: Roles and Involvement of XBRL Stakeholders in Business Reporting 76

Figure 3.4: Proposed Research Framework 79

Figure 4.1: Phases in the Reflection Method 93

Figure 4.2: Level of Triangulation 95

Figure 4.3: Breakdown of Collected Documents 99

Figure 4.4: Interviewee Involvement in XBRL Initiatives 103

Figure 5.1: XBRL Initiatives in New Zealand 112

Figure 5.2: Current Reporting Channels 122

Figure 5.3: Proposed Cluster Reporting 123

Figure 5.4: Business Reporting Burden 123

Figure 9.1: Influence of TOE Context on XBRL Initiatives 259

Figure 9.2: Views of Active Stakeholder Involved in XBRL Projects 260

Figure 9.3: Views of Supportive Stakeholder Involved in XBRL Projects 261

Figure 9.4: Views of Observer Stakeholder Involved in XBRL Projects 261

Figure 9.5: Views of Government Agencies in XBRL Projects 263

Figure 9.6: Views of Accounting Firms in XBEL Projects 264

Figure 9.7: Views of Professional Bodies in XBRL Projects 264

Figure 9.8: Views of Business Organisation in XBRL Projects 265

Figure 9.9: Views of Other Stakeholders in XBRL Projects 265

Figure 9.10: Views of All Stakeholders in XBRL Projects 266

Figure 9.11: Revised Research Framework 
LIST OF ABBREVIATIONS

\begin{tabular}{|c|c|}
\hline AARF & Australian Accounting Research Foundation \\
\hline AASB & Auditing and Assurance Standard Board \\
\hline ABS & Australian Bureau of Statistics \\
\hline ACC & Accident Compensation Corporation \\
\hline ACRA & Accounting and Corporate Regulatory Authority \\
\hline AGS & Auditing Guidance Statement \\
\hline AICPA & American Institute of Certified Public Accountants \\
\hline AIS & Accounting Information Systems \\
\hline ASIC & Australian Securities and Investment Commission \\
\hline ATO & Australian Taxation Office \\
\hline B2G & Business-to-Government \\
\hline CFA & Chartered Financial Analyst \\
\hline CFO & Chief Financial Officer \\
\hline CFIS & Crown Financial Information Systems \\
\hline CPA & Certified Public Accountant \\
\hline COREP & Common Reporting \\
\hline DART & Data Analysis, Retrieval, and Transfer System \\
\hline DOI & Diffusion Of Innovation Theory \\
\hline DWG & Domain Working Group \\
\hline EDGAR & Electronic Data-Gathering, Analysis, and Retrieval \\
\hline EDI & Electronic Data Interchange \\
\hline e-GIF & Electronic-Government Interoperability Framework \\
\hline ERP & Enterprise Resource Planning \\
\hline GAAP & General Accepted Accounting Principles/Practices \\
\hline GL & General Ledger \\
\hline GNI & Gross National Income \\
\hline GPFR & General Purpose Financial Reports \\
\hline HMRC & Her Majesty's Revenue and Customs \\
\hline HTML & Hyper Text Mark-Up Language \\
\hline IAS & International Accounting Standards \\
\hline
\end{tabular}




\begin{tabular}{|c|c|}
\hline ICANZ & Institute of Chartered Accountant of New Zealand \\
\hline ICT & Information and Communication Technology \\
\hline IFR & Internet Financial Reporting \\
\hline IFRS & International Financial Reporting Standard \\
\hline IRD & Inland Revenue Department \\
\hline IS & Information System \\
\hline HRIS & Human Resources Information Systems \\
\hline LEAP+ & Leading Edge Accounting Product \\
\hline MED & Ministry of Economic Development \\
\hline MSD & Ministry of Social Development \\
\hline NZX & New Zealand Stock Exchange \\
\hline OAG & Office of the Auditor-General \\
\hline PDF & Portable Document Format \\
\hline PwC & PricewaterhouseCoopers (Audit firm) \\
\hline QRR & Quality Regulation Review \\
\hline SBR & Standard Business Reporting \\
\hline SEC & Securities Exchange Commission \\
\hline SIG & Special Interest Group \\
\hline SMES & Small Medium Enterprises \\
\hline SSC & State Services Commission \\
\hline TAM & Technology Acceptance Model \\
\hline TOE & Technological, Organisational and Environmental Model \\
\hline VFP & Voluntary Filing Programme \\
\hline XBRL & eXtensible Business Reporting Language \\
\hline XFRML & eXtensible Financial Reporting Mark-Up Language \\
\hline XML & eXtensible Mark-Up Language \\
\hline XRB & External Reporting Board \\
\hline
\end{tabular}




\section{Chapter 1: Introduction}

\subsection{Research Background}

Technology adoptions are necessary and play a significant role in changing the way businesses communicate financial information. A recent language developed for financial reporting is eXtensible Business Reporting Language (XBRL), which is based on eXtensible Mark-up Language (XML). Fisher (2008) believes that XBRL is the future of business reporting. XBRL was developed in 1998 by an international non-profit consortium of major organisations including the American Institute of Certified Public Accountants (AICPA), the five largest accounting firms ${ }^{1}$, financial service providers, government agencies and six information technology companies as a freely available, open standard for communicating financial and business information (Boritz and No, 2005; XBRL, 2009).

By improving access to financial information, $X B R L$ has the potential to benefit many stakeholder groups including: government agencies and regulatory authorities, business organisations, accounting firms, professional bodies and other stakeholders. The potential benefits for stakeholders of adopting XBRL include: improved financial reporting, transparency, more efficient and accurate data handling, cost reductions, improved analysis, real-time internet-based reporting and assistance with regulatory filing compliance (Coffin, 2001; Hannon, 2002; McGuire, Okesson, and Watson, 2006; XBRL International, 2009).

Over the last ten years, government and regulatory entities internationally have developed programmes to allow the submission of regulatory reports using the XBRL standard (Baldwin, Brown and Trinkle, 2006; Fisher, 2008; Kernan, 2008; XBRL International, 2009). Despite the widely promoted benefits and adoption driven globally by government and regulatory-support entities, XBRL adoption by companies has been slow. In addition, while government and regulatory authorities in countries like the UK, the US, Japan, South Korea, China, India, Germany and Italy have decided to mandate the use of XBRL, the New Zealand government has not. The key New Zealand XBRL initiatives: the Leading Edge Accounting Product (LEAP)+ project; Project First Step; the e-Government Interoperability Framework

\footnotetext{
${ }^{1}$ Also known as the Big Five, which in 2002 consisted of Arthur Anderson, Deloitte \& Touche, Ernst \& Young, KPMG and PWCoopers.
} 
(e-GIF); and the Standard Business Reporting (SBR) programme have failed to promote the benefits of XBRL to their governmental, accounting, business and other stakeholders.

In New Zealand, only a few studies related to XBRL adoption have been carried out (see Section 2.3). These studies have examined the awareness of chartered accountants regarding XBRL, users' perceptions of digital reporting formats and factors influencing XBRL adoption by a small number of business organisations. Although at an international level, a variety of research with regard to XBRL adoption and diffusion has been conducted, there is limited research into XBRL adoption and implementation that includes a government perspective (see Section 2.2). The paucity of research into a government perspective can create misunderstandings among XBRL stakeholders, especially when a government does not mandate XBRL. That is because government has the power to decide to adopt XBRL voluntarily, make it mandatory or not to adopt it. In New Zealand's case, the government and private organisation has decided not to adopt XBRL for business reporting. Thus, conducting research that explores the factors influencing a government's as well as an organisation's decision not to adopt XBRL for business reporting purposes, will bridge that gap and aid understanding. Therefore, this research contributes to the existing body of knowledge by investigating the factors that influenced governmental, professional and business organisational decisions related to XBRL adoption, and by identifying the implications of the government's decision not to require XBRL for business reporting for XBRL stakeholders in New Zealand. Research into this non-adoption will be useful for other countries that choose not or are considering whether to adopt XBRL for business reporting use.

The rest of this chapter is organized as follows. The next section provides an outline of business reporting practices and requirements. The discussion will include the need for internet business reporting and the role of XBRL as an enabler of internet business reporting. An overview of XBRL is presented before the research motivation is discussed. The research aim and questions are then presented. This is followed by a discussion of the research framework and method. Finally, the structure of the thesis is presented. 


\subsection{Business Reporting: Practices and Requirements}

In this thesis, business reporting refers to reports of operating and financial data that are prepared by an organisation and are given to others such as government agencies, potential investors, and shareholders as required. The practice of business reporting and required disclosures varies across countries. Adhikari and Tondkar (1992) explore the business reporting disclosure practices and requirements of various countries by studying 35 stock exchanges located in different countries. They found there was no relationship between economy type and the level of disclosure requirements. Instead, they found that larger stock exchanges have more rigorous financial reporting disclosure requirements.

Khan (2006) also studied business reporting disclosure requirements from an international perspective. She divided countries into four groups; high income, upper-middle income, lower-middle income and low income, based on the 2004 Gross National Income (GNI) per capita by the World Bank. Her study found most countries require the same basic elements of financial reporting, the balance sheet, and income statements. The cash flow statement was not a basic requirement for most countries, especially those within the European Union. In terms of the accounting standards adopted, most countries either have adopted International Financial Reporting Standards (IFRS) directly or have incorporated the IFRS into their national General Accepted Accounting Principles (GAAP). Further investigation on the medium used to disseminate the information revealed most companies used their websites to present business information. In addition, high income countries appear to have better disclosure practices when compared to other groups of countries.

In New Zealand, business-reporting practices are primarily governed by New Zealand IFRS (NZ-IFRS). An announcement on 19 December 2002, by the Accounting Standard Review Board (ASRB) stated New Zealand reporting entities were required to apply IFRS for a period starting on or after 1 January 2007. However, reporting entities had the option to apply IFRS voluntarily from 1 January 2005 (Bradbury and van Zijl, 2006). The NZ IFRS are not directly comparable to original IFRS or international standards because extra paragraphs are added to suit the New Zealand reporting environment (Devonport and van Zijl, 2010). After considering factors, such as public sector differences and different sized entities (Devonport and van Zijl, 2010), the Ministry of Economic Development (MED) ${ }^{2}$,

\footnotetext{
${ }^{2}$ MED became part of MBIE or the Ministry of Business, Information \& Employment from 1 July 2012
} 
released a financial reporting discussion document in September 2009. The document proposed three tiers of financial reporting; the private sector, public sector, and non-profit entities. After a series of discussions, the following was implemented.

The ASRB was renamed the External Reporting Board (XRB) and it introduced a multistandards framework, requiring issuer companies to apply full IFRS and therefore their reporting has not changed. The Financial Reporting Act (2013) removed the statutory obligation for small and medium (SMEs) non-issuer companies to prepare General Purpose Financial Reports (GPFR) from 2014. Additionally, the act clarified the reporting requirements for registered charities and the public sector, which are to apply to adapted International Public Sector Accounting Standards (NZ PBE Standards) for the financial years beginning 1 July 2015. The XRB is further required to harmonize New Zealand for-profit entities financial reporting with international standards as much as possible, in particular Australia. This is to facilitate inter-country comparisons and international trade.

\subsubsection{Internet Business Reporting}

The recent moves from distributing business information using traditional media such as paper-based annual reports to the internet, suggests that information users demand fast and reliable information in a timely manner. The demand for and future of the internet as a tool to disseminate business information was first explored by Louwers, Pasewark and Typpo (1998). They argue the future of online business reporting may involve extending business disclosures beyond the reproduction of a hard copy annual report. This will enable an organisation to expand its scope, improve reporting timeliness, and increase the retrieval of business information. In addition, Lymer (1999) suggests that by using the internet, cost reductions and widely available data are made possible, which will encourage demand for its use to fulfil statutory or reporting requirements. The Auditing and Assurance Standard Board (AASB) of the Australian Accounting Research Foundation (AARF) was the first professional body to announce guidelines relating to internet financial reporting (IFR) ${ }^{3}$ (Lymer, 1999; Oyelere, Laswad and Fisher, 2003). The Auditing Guidance Statement (AGS 1050) "Audit Issues Relating to the Electronic Presentation of Financial Reports", aimed to provide guidance for auditors when a company uses information technology for presenting

\footnotetext{
${ }^{3}$ https://www.accountancylive.com/e-commerce-whats-risk
} 
audited financial information on the internet (AASB, 1999). The primary responsibility for reporting remained with management, however AGS 1050 suggested that releasing financial reports electronically might change the auditor's approach to their audit procedures and the communication of the audit report (AASB, 1999). Additionally, the guidelines identified specific matters the auditor can address with management, to raise awareness of the risks arising and to ensure the audit report presented on the company's web site adequately scopes the information that is audited.

Further, Oyelere et al. (2003) examined the extent of IFR by New Zealand companies and the determinants of IFR practices. Their results indicate that size, spread of shareholding and efficiency are the primary determinants of IFR practices among New Zealand companies. They also suggest reporting practices by New Zealand companies are influenced by the reporting environment of their foreign affiliation (if any). New Zealand companies with foreign affiliates have a tendency to use the internet as a tool to disseminate their business reporting information.

Slightly different, Allam and Lymer (2003) examined the general online reporting practices of 250 companies in the US, the UK, Canada, Australia and Hong Kong. Their findings demonstrate how newer, more interactive, aspects of internet technologies are being exploited to enable companies to benchmark online reporting activities now and into the near future. In addition, they also address the relationship between the size of companies and their level of reporting practices, and the differences between reporting practices of large companies listed primarily in the different countries. Their results suggest that reporting practices differ significantly between companies in different domains.

A company may choose to use XBRL, Hyper Text Mark-up Language (HTML) or a Portable Document Format (PDF) format to present their business information on the internet (Ghani, Laswad and Tooley, 2009). XBRL was found to be the best method in terms of time, cost and quality; however, it is not being used on a wide scale. However, even though it is a high income country, New Zealand companies predominately disclose their business information through the internet using either HTML or a PDF format (Ghani et al., 2009). At the moment, the XBRL format for business reporting purposes is required in other high income countries such as Germany, Japan, Netherlands, the UK and the US, but not in New 
Zealand. The following section discusses how XBRL technology can be used for business reporting.

\subsection{XBRL as a Technology for use in Business Reporting}

The XBRL consortium believes that XBRL is a technology that will prove useful for business reporting (XBRL, 2009). It was developed in the late 1990s and has slowly been accepted by XBRL stakeholders worldwide (Kernan, 2009). This section provides an overview of basic XBRL concepts and explains how it is closely related to accounting and information system (IS) areas.

\subsubsection{What is XBRL?}

XBRL was developed by an international non-profit consortium of major organisations, known as XBRL International. Nowadays, XBRL is used in over 50 countries and is supported by more than 650 international member organisations from either the private or public sectors (XBRL, 2015).

During the early development of XBRL, many scholars tried to promote XBRL by providing a simple and precise definition of the XBRL concept. For example Cohen, Schiavina and Servais (2005), state that XBRL is a standard for the exchange of business reporting information both within and across organisations. It blends internet-based technology standards with business reporting knowledge expertise to provide new consistent machinereadable business reports (Cohen et al., 2005). Based on this definition, Richards, Smith and Saeedi (2006) stress that two elements of XBRL; the taxonomy and the instance document, are key in understanding its functions. The taxonomy acts like a dictionary. Every item of financial information is classified according to a particular taxonomy. Once the taxonomy has been designed and reviewed, then it is mapped to an instance document. A set of instance documents is needed to present the financial information in a variety of formats (Richards et al., 2006).

Later, Plumlee and Plumlee (2008), Debreceny, Felden, Ochocki, Piechocki and Piechocki (2009a) and Garbellotto (2009) state that XBRL is about interactive data; which is used in a new and innovative way and has the ability to improve the way data is processed and exchanged. Alternatively, Savage (2009), define XBRL as a royalty-free, open specification 
for software that uses XML data tags to describe the business and financial information for public and private companies and other organisations. In response to the various definitions of XBRL concepts, $X B R L$ International suggests that XBRL is a language for the electronic communication of business and financial data that can revolutionize business reporting around the world. Additionally, XBRL has the potential to provide major benefits, for instance in the preparation, communication, and analysis of business information, as it offers cost savings, greater efficiency and improved accuracy and reliability of financial data (Coffin, 2001; Alles, Kogan and Vasarhelyi, 2002; Rezaee and Turner, 2002; Pinsker and Li, 2008; Vasarhelyi, Chan and Krahel, 2012; Wang and Goa, 2012). The benefits of XBRL will be discussed in Chapter 2 (Section 2.2.2) and Chapter 3 (Section 3.3.3).

$\mathrm{XBRL}$ is thus a language that is used to present and communicate business and financial information via a digital platform. Through the use of data tags, the specific software can automatically process business information, thereby reducing labour costs and eliminating manual data entry and analysis (Debreceny, Felden, Ochocki and Piechocki, 2009c). This is possible because the data tag feature is similar to bar coding for physical products. Each item in a financial statement has a 'unique data tag'. This data tag enables the computer to recognize every single data point in the financial reports. In addition, the use of software can recognize, select, analyze, exchange or translate the data into different formats and automatically reproduce it in the form that suits user preferences (Debreceny et al., 2009c).

Since Charles Hoffman, successfully introduced the XBRL concept in the late 1990s, there has been growing interest among XBRL stakeholders regarding its potential uses. XBRL International organizes a yearly conference to exchange and share knowledge as well as experiences about XBRL matters (XBRL, 2009). Additionally, this community also arranges for seminars and workshops to educate its members and potential members. These activities encourage private and public sector organisations to adopt XBRL technology in their own organisations.

\subsection{A Brief History of XBRL in New Zealand}

As noted, commitment from AICPA and other interested stakeholders led to the formation of XBRL International in 2000 (Kernan, 2008). At that point, the name of eXtensible Financial Reporting Mark-up Language or XFRML changed to XBRL (Bergeron, 2003). Under XBRL 
International, XBRL was developed as a viable means of communicating business information. This was possible because interested stakeholders such as accounting firms, software developers, information intermediaries, regulators, standard-setters, professional bodies, academics and business organisations worked together to develop and promote XBRL technology (XBRL, 2009).

Among the achievements of XBRL International were the production of an XBRL specification and taxonomy, the formation of national jurisdictions, and the organizing of XBRL international conferences. Stakeholder involvement, especially from governments and regulators, suggested continuous development and support for XBRL worldwide. However, this was not the case for XBRL in New Zealand.

In New Zealand, a few individuals with an accounting background monitored XBRL developments from as early as 1998 . However, serious commitment to XBRL only started in 2000. Individuals, particularly from Ernst \& Young and the Auckland University Business School, worked together on a project named LEAP+ (Hucklesby and Macdonald, 2001c). About the same time, interested people attended an XBRL International conference and formed a group named the XBRL Special Interest Group (XBRL SIG) under the Institute of Chartered Accountant of New Zealand (ICANZ) ${ }^{4}$. This group became known as the XBRL Steering Committee. The main goal of this Steering Committee was to bring about XBRL adoption and implementation in New Zealand; both in private and public sector organisations. Other objectives included: providing liaison and facilitation for XBRL within New Zealand; maintaining contact with and staying updated on international developments; educating members, government and business about XBRL by being an enabler for digital business reporting; producing an education programme for members and business entities and determining a universal taxonomy for New Zealand in the most efficient and effective way possible $e^{5}$. In order to achieve these objectives, the committee strategized their efforts. Among the achievements of the committee included becoming the sixth jurisdiction of XBRL International, drafting the New Zealand Taxonomy, hosting the

\footnotetext{
4 NZSA (New Zealand Society of Accountant) (1908-1995),

ICANZ (Institute of Chartered Accountants of New Zealand (1996-2004),

NZICA (New Zealand Institute of Chartered Accountants) (2005-2014)

Between 1908 and 2014, the chartered accounting professional body has had three name changes as detailed above. In this thesis, these terms will be used inter-changeably in a manner that relates to the appropriate time period. In 2014 the New Zealand professional body merged with the Institute of Chartered Accountants in Australia to become Chartered Accountants, Australia and New Zealand (CAANZ).

${ }^{5}$ http://www.xbrlcentral.com/countries/NewZealand.html
} 
ninth XBRL International Conference, and conducting Project First Step (Hucklesby, 2002; Boyd, 2003).

After Project First Step, XBRL initiatives in New Zealand shifted to the government auspices headed first by the Inland Revenue Department (IRD) ${ }^{6}$ under a project named e-GIF ${ }^{7}$. Later, this project was absorbed into the SBR programme under the MED. While under the SBR programme, the SBR Working Group prepared a business case for consideration by relevant Ministers in the Labour Government's Cabinet. Once the business case was completed and presented to the cabinet, the Ministers asked for more details. However, the follow-up information was only completed and re-presented once a new government, the National Government was in power in 2008. At that point, the new government asked the SBR Working Group to look for lower-cost alternatives because the programme required a considerable amount of money (NZD150 million) (Hughes, 2009). However, at the same time the government was facing the global financial crisis.

The above history shows that XBRL initiatives in New Zealand were started by individuals from private or professional organisations. They formed a collaborative group that was interested in XBRL development. The XBRL initiatives then shifted to the government arena, but the government agencies involved failed to obtain funding for XBRL adoption and implementation, particularly for investment in XBRL use for business reporting. Although using XBRL for business reporting has been accepted by many countries, it has been rejected in New Zealand.

Up to this point, this thesis has briefly explained business reporting practices and requirements, viewed $\mathrm{XBRL}$ as a technology that can be used for business reporting and overviewed the history of XBRL in New Zealand. A more detailed discussion on the history of XBRL will be presented in Chapter 5. The next section presents the research motivations.

\footnotetext{
6 Inland Revenue started out as the Land Tax Department (1878-1892)

Land and Income Tax Department (1892-1952)

Inland Revenue Department (IRD) (1952-2013)

Between 1878 and 2013, the tax department has had three name changes as detailed above. In this thesis, these terms will be used inter-changeably in a manner that relates to the appropriate time period. In 1952, the organisation joined with the Stamp Duties Department, and became the Inland Revenue Department. In 2013 the organisation became Inland Revenue (IR).

7 http://www.e.govt.nz/standards/eXtensible-business-reporting-language/current-projects
} 


\subsection{Research Motivation}

Three issues motivate this research. The first motivation is derived from the prediction that XBRL is going to be a "universal standard for business reporting" (Pinsker, 2003, p. 732). However, New Zealand has acted differently from other countries, including its major trading and business partners by rejecting XBRL as a technology for business reporting. Internationally, XBRL jurisdictions, regulators and various industries ${ }^{8}$ have been involved in promoting and implementing XBRL at various levels. By 2009, there were 25 governments and regulators in 16 countries involved in mandatory XBRL filing projects and a further 25 governments and regulators in 20 countries involved in voluntary filing projects (XBRL, 2009). In addition, the Netherlands required XBRL-based SBR for companies filing regulatory reports with government from 2004 and Australia began to introduce SBR in 2006 (van Burg, Madden, van Hilvoorde and Farkas, 2010). However, the SBR/XBRL program in New Zealand was put on hold in 2010.

Secondly, there has been limited research either internationally or in New Zealand that includes non-adoption of XBRL and from a government' perspective. Even though, Cordery, Fowler and Mustafa (2011) investigated the non-adoption scenario in New Zealand their study is focused at one point of time and based on only six interviews. Furthermore, their study did not distinguish between the four different XBRL projects or outline the history of XBRL in New Zealand. Additionally, they did not identify the implications of the nonadoption of XBRL to stakeholders in New Zealand. At the international level, most of the XBRL research concentrates on a particular company's adoption, investor benefits, user preferences of reporting formats, taxonomy development, mandatory adoption, voluntary adoption, and disclosure (see Section 2.2). Government plays a significant role and are the most influential factor in XBRL adoption (Locke and Lowe, 2006; Abdullah, Khadroo and Shaikh, 2009; Cordery et al. 2011; Lowe, Locke and Lymer, 2012; Guilloux, Locke and Lowe, 2013). Nonetheless, the above research provides little insight into why certain countries, governments and other organisations have not adopted XBRL.

Lastly, there are limited studies of XBRL development from a longitudinal or historical perspective either internationally or within the New Zealand context. Napier (2006) suggests that a historical perspective allows us to appreciate past accounting events and

\footnotetext{
${ }^{8}$ Industries such as accounting firms, bank, education, insurance and software development.
} 
contributes to our understanding of how present day accounting and related practices occurred.

Therefore, an important, interesting, and challenging research opportunity exists to investigate the factors that influenced decisions regarding the non-adoption of XBRL for use in business reporting in New Zealand. This thesis offers a comprehensive view that covers a variety of stakeholders groups and their involvement across four XBRL projects that occurred from 2000 to 2010. In addition, the application of different methods; that is a post-positivism philosophy, a longitudinal multiple case study, and reflection, and triangulation enable the researcher to explore the non-adoption scenario in detail.

\subsection{Research Aim and Questions}

As discussed in previous sections and elucidated in Chapter 2, individuals, professional organisations and government agencies made several, ultimately unsuccessful, attempts to establish the need to adopt XBRL in New Zealand. As will be discussed in Chapter 5, the first attempt was through the LEAP+ project from 2000. The second attempt was Project First Step under the New Zealand Stock Exchange (NZX). The third was the e-GIF project, which started in 2003, and the final attempt was the proposal for a SBR programme in 2008. However, these four attempts failed to succeed in promoting the benefits of XBRL use for business reporting to the potential XBRL stakeholders in the New Zealand context. Therefore, currently, XBRL has not been adopted by New Zealand organisations including the government ones. However, there will be implications for these stakeholders (as defined in Section 1.6.2) with regards to the decisions made not to adopt XBRL. Accordingly, the aim of this research is:

To investigate why business and professional organisations and the New Zealand government have decided not to adopt XBRL for use in business reporting; and the implications of that decision for XBRL stakeholders.

In order to view the non-adoption of the XBRL decision from a New Zealand viewpoint, the following research questions are addressed:

a) What factors influenced the organisations' decisions not to adopt XBRL for use in business reporting? 
b) What are the implications of the government decision regarding XBRL use in business reporting for XBRL stakeholders?

\subsection{Research Framework}

In order to achieve the above research aim and answer the two research questions, this study needs to develop a research framework. Thus, in this section the relevant theoretical model that provides the underlying background of the research framework, will be introduced and discussed. The section starts by introducing the Technological, Organisational and Environmental (TOE) model of DePietro, Wiarda, and Fleischer (1990). Then, the existing literature will be used to identify and define XBRL stakeholders that will be considered in this thesis.

\subsubsection{The TOE Framework}

Tornatzky and Fleischer (1990), in their book, Process of Technological Innovation, provide a comprehensive framework for understanding technology adoption (such as XBRL) in an organisational context. One of the chapters, by DePietro et al. (1990) developed a framework for defining a context for technological adoption, consisting of three contexts: technological, organisational, and environmental.

The technological context focuses on the manner in which technology characteristics can influence adoption (DePietro et al. 1990), and relates to the operationalization and potential realization of benefits and existing organisational adoption capability (Tan, Chong, Lin and Eze, 2009). Normally, the adopter assesses the characteristics of technology in terms of possible gains and barriers (Chau and Tam, 1997). Gains refer to the benefits an organisation expects to receive upon adoption and includes increased efficiency, quality, and reliability. In addition, relative advantage suggests that the benefits of XBRL adoption should exceed the adoption cost. In contrast, barriers refer to the problems organisations predict they will face during the adoption process, such as its complexity and its compatibility with organisational technology competency and legacy systems (Rogers, 2003). Additionally, adoption costs, including implementation, maintenance, training and transition costs, can be perceived as barriers to adopting technology (Troshani, Jerram, and Rao, 2011). 
The organisational context describes the nature of organisational characteristics that may facilitate or inhibit adoption. Technology adoption can be more easily facilitated in organisations that exhibit a high degree of centralization because top management can make and enforce adoption decisions (Yang, Lee, and Lee, 2007). Further, the greater the support from top management, the easier it will be for the adopter to overcome difficulties encountered during adoption (Premkumar and Ramamurthy, 1995). In terms of championship, this refers to the existence of a single person within the organisation who is committed to introducing and promoting the technology initiative within the organisation. The existence of a champion has been one of the most important facilitators in the adoption of technologies by government organisations (Norris, 1999). In addition, human capability, in terms of an IT skilled workforce with appropriate expertise, can be critical for successful technology adoption (Lin, 2006).

The environmental context represents the arena where organisations conduct their business, such as successful adoption stories from other entities, having a critical mass of stakeholders and the need for regulatory compliance. These factors can present opportunities to either encourage or inhibit technology adoption (Troshani et al., 2011). An environment with success stories can be conducive to technology adoption because every successful adoption leads more users to consider it strongly (Kearns \& Lederer, 2004). In addition, external support and information such as supporting infrastructure and vendor support are important for technology adoption (Chau and Hui, 2001). Government support also plays a significant role in encouraging XBRL stakeholders technology adoption by raising awareness, and through the provision of training and funding (Chong and Ooi, 2008; Troshani and Doolin, 2007). Conversely, a lack of security and diverse stakeholder involvement inhibits technology adoption in the government sector (Mousa, 2011).

According to DePietro et al. (1990), the three suggested contexts interact with each other in influencing technology adoption decisions. Further discussion and more detail on the TOE framework and it application in relation to the adoption decision of various technologies including XBRL is provided in Chapter 3, with the TOE framework assisting in identifying the factors that potentially influence the organisational decision. However, issues concerning how the factors influence the non-adoption of XBRL are yet to be investigated in any detail in the New Zealand context. Cordery et al. (2011) only considered non-adoption prior to the 
government's non-adoption decision in an exploratory manner. Thus, a proposed framework will be based on the insights gained from the existing international-focused literature. The framework will incorporate the identified potential technological, organisational, and environmental factors that might affect the organisation's decision as to whether or not to adopt XBRL technology for use in business reporting. Additionally, Chapter 3 discusses XBRL stakeholders and their role and involvement in XBRL initiatives in New Zealand. However, a brief overview of the XBRL stakeholders is provided next.

\subsubsection{XBRL Stakeholders}

Freeman (1984, p.25) defines a stakeholder as "any individual or group of individuals who can or is affected", in this case, by XBRL. Clarkson (1995) divided stakeholders into two categories, primary and secondary. Primary stakeholders such as shareholders, employees, customers, suppliers, lenders, government, and communities are given priority as their support is considered to be vital for the organisation. Consumer advocates, as well as environmentalists, are not attached to the organisation on a transactional basis and are not considered to be critical for the organisation to survive; therefore they are considered secondary stakeholders.

In a more recent study, Dunne, Helliar, Lymer and Mousa (2009) classify potential XBRL stakeholders into four groups based on their particular role in the reporting hierarchy. The groups are users (fund managers and investment analysts), business or preparer organisations (financial accountants working in private entities, IT staff, company secretaries, internal auditors and data processing managers), external auditors, and tax practitioners.

This study focuses on the primary stakeholders that are potentially involved in the XBRL decision-making process because their views are critical at the organisational level. The primary stakeholders have been classified into five groups based on their roles in business reporting and potential influence on XBRL adoption. The stakeholder groups are government, accounting firms, professional bodies, business organisations and other stakeholders. XBRL stakeholders will be discussed further in Chapter 3, Section 3.3.2. Interaction, support, and cooperation among these stakeholder groups are essential to 
promote the adoption of XBRL technology (Troshani and Doolin, 2007; Abdullah et al., 2009; Bonsón, Cortijo, and Escobar, 2009; Chen, 2012).

Therefore, this study uses a stakeholder view to analyse organisational decisions related to the non-adoption of XBRL as shown in Figure 1.1. The organisational decision will be influenced by factors such as the cost of XBRL adoption, managerial championship, and stakeholder involvement. These factors will be examined in more detail using a TOE framework (as explained in Section 1.6.1). Additionally, the implications of the government decision not to adopt XBRL for use in business reporting for XBRL stakeholders in New Zealand is considered, as the government decision potentially impacts each XBRL stakeholder differently.

Figure 1.1: A Stakeholder View of the XBRL Decision

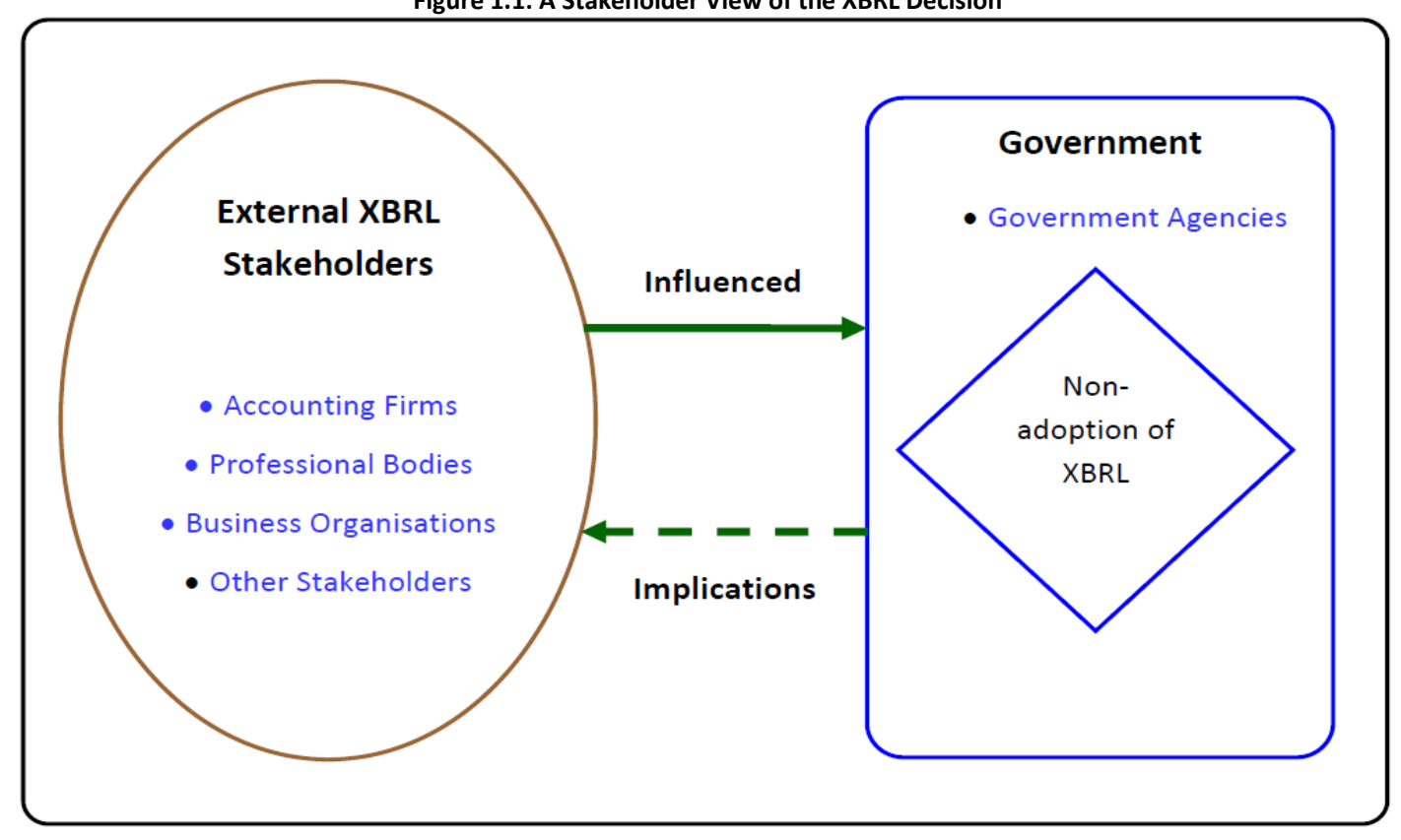

The next section briefly explains the research methods used in this study.

\subsection{Research Method}

This study applies a post-positivism research philosophy to assist in investigating the decisions related to the non-adoption of XBRL technology. Through a post-positivism philosophy, this study pursues objectivity, but accepts the theoretical perspective, background, knowledge, and values of a researcher. Additionally, a post-positivism approach enables the use of multiple observations and measures including data and method triangulation (Guba and Lincoln, 1994). 
In order to answer the research questions (as in Section 1.5), a qualitative research method is deemed appropriate. By using a qualitative method, the researcher is able to understand organisational decisions and actions within a real-life context (Strauss and Corbin, 1990; Myers and Avison, 2002). In addition, a qualitative research method enables the researcher to explore and gain a new perspective on existing issues like the non-adoption of XBRL. The use of qualitative methods also assists the researcher to present and offer a discussion on the findings.

A longitudinal multiple case study approach is employed because in order to study a reallife context such as the non-adoption of XBRL, the researcher needs to understand the phenomenon in its natural setting. Davey (1991) for example, suggests by using the case study method, the researcher can learn about a complex event through extensive description and contextual analysis. Another view from Yin (2003) indicates that the case study approach allows the researcher to identify and maintain the holistic and meaningful characteristics of real-life events.

Using a post-positivist philosophy and a longitudinal multiple case study approach, this thesis uses a combination of interviews and document analysis to obtain the data, as well as interviewing key XBRL stakeholders both locally and internationally. This thesis utilizes relevant documents such as those from government departments' websites, the Institute of Chartered Accountants archival records and other Internet-based information. In addition, reflection and triangulation methods are employed.

\subsection{Thesis Structure}

\section{Chapter 1}

The purpose of Chapter 1 is to introduce the research background relating to XBRL adoption in New Zealand. A brief discussion of the research motivation, aim, questions, and framework, as well as the research method, is included to develop an understanding of the study.

\section{Chapter 2}

The purpose of Chapter 2 is to review the literature associated with XBRL adoption including its history, current XBRL projects, and studies and issues on XBRL and related 
areas in New Zealand and internationally. The literature review reveals a gap in identifying the factors that could influence decisions on whether to adopt XBRL or not for use in business reporting.

\section{Chapter 3}

As a result of the review in Chapter 2, this chapter presents and links previous studies of XBRL and the TOE model framework developed by DePietro et al. (1990). The chapter concludes by presenting a proposed research framework suitable for investigating organisational decisions relating to the non-adoption of XBRL for business reporting and its implications for XBRL stakeholders.

\section{Chapter 4}

The research method, strategy and the rationale behind its selection are presented in this chapter. The selection of a qualitative case study research approach, the methods to collect the data and the tools used to analyse the data are explained and justified.

\section{Chapter 5}

This chapter presents research findings that provide a historical overview of XBRL development and initiatives in New Zealand. The chapter concludes with a chronology of the important XBRL events.

\section{Chapter 6}

Details and the analysis of findings for XBRL initiatives under the auspices of professional or private organisations are presented in this chapter. Based on the research framework (as given in Chapter 3), this chapter presents the drivers and inhibitors of the LEAP+ project and Project First Step. This chapter answers the first research question.

\section{Chapter 7}

This chapter provides the analysis, as well as presenting the findings for XBRL initiatives under the auspices of government agencies. By using the research framework in Chapter 3 , this chapter presents the drivers and inhibitors of the e-GIF project and SBR programme. This chapter answers the first research question. 


\section{Chapter 8}

The findings on the implications of the government decision not to adopt XBRL for business reporting for XBRL stakeholders are presented in this chapter. It answers the second research question.

\section{Chapter 9}

The final chapter discusses the findings related to the first and second research questions. In addition, the factors that influence the decisions related to XBRL adoption (or not) are presented in a revised research framework. This chapter also presents conclusions based on the empirical evidence, highlights the research's limitations and discusses the contributions of the thesis as well as suggests areas for future research.

\subsection{Chapter Summary}

Chapter 1 has provided a broad framing of the context and background of the study, which includes an overview of business reporting practices and requirements, a consideration of $X B R L$ as a technology that can be used for business reporting, and a brief outline of XBRL in New Zealand. This research is important because the government perspective and nonadoption technology phenomenon are under-researched areas. There are also limited studies providing a longitudinal or historical perspective on XBRL technology adoption. Thus, this thesis fills these gaps by investigating the factors, which influenced decisions on the non-adoption of XBRL and the implications for XBRL stakeholders in New Zealand. The chapter has also presented the research aim and questions, the research framework, and the research methods use to analyse the data, along with an outline of the thesis structure and content.

The next chapter, Chapter 2, presents and explores the development of XBRL studies and issues related to XBRL at an international and national level. 


\section{Chapter 2: Histories, Studies, and Issues of XBRL}

\subsection{Introduction}

Chapter 1 has outlined this study, which is an under-researched area, that of the nonadoption of XBRL from a multiple organisational perspective. Based on an historical approach, this thesis investigates the factors that influence organisational decisions regarding XBRL use in business reporting. Gomes, Carnegie, Napier, Parker and West (2011) suggest that accounting history does matter and contributes to our understanding of accounting's past and of contemporary practice and thought. Thus, this chapter offers a contemporary historical perspective on XBRL development at an international level. Additionally, this chapter reviews the literature on relevant studies and identifies the issues that arise.

The chapter starts by outlining the development of XBRL at the international level (between 1998 and 2010) including XBRL specification and taxonomy development, XBRL jurisdictions, and the spread of XBRL worldwide. Then, the chapter presents the issues through studies related to XBRL internationally and in New Zealand. The final section summarizes the chapter.

\subsection{XBRL Development and Use at the International Level (1998-2010)}

The development of XBRL internationally started when XML was used to resolve a product transfer pricing issue encountered by Charles Hoffman. Hoffman was a US Certified Public Accountant (CPA) who had been an auditor at Price Waterhouse, as well as working as a financial officer in several companies, and as an accounting software implementation consultant (Richards and Tibbits, 2002). Hoffman saw that XML technology could be used for other purposes, including Internet-based financial reporting. In October 1998, based on his submission, the American Institute of Certified Public Accountants (AICPA) approved a project to fund a prototype set of financial statements based on XML. The initial prototype was completed by Hoffman and Mark Jewett ${ }^{9}$ in December 1998, with help from Jeffery Ricker $^{10}$.

\footnotetext{
${ }^{9}$ Formerly a Microsoft employee

${ }^{10}$ CEO of XML Solution
} 
In January 1999, the prototype was presented to the AICPA and it was decided that XBRL was necessary for the accounting profession. Five months later, Hoffman, Wayne Harding of Great Plains Software, Eric Cohen of Cohen Computer Consulting and Louis Matherne, AICPA Director of Information Technology, created a business plan for XML-based financial statements, and it was named eXtensible Financial Reporting Mark-Up Language (XFRML) (XBRL, 2009). Again, this project received funding from AICPA, and Hoffman started to experiment with the financial statements of ten companies. In August 1999, the AICPA formed a group, known as the Steering Committee (Kernan, 2009) comprising the AICPA and twelve companies. This group was established as a not-for-profit global consortium of companies and agencies with a shared goal to develop XBRL and ensure its widespread acceptance and use (Tie, 2005). In October 1999, the first meeting of the AICPA Steering Committee took place in New York. In this session, development of the first taxonomy began (see below). This financial reporting taxonomy was named 'XFRML Financial Statements for the Commercial and Industrial Sector', and it covered the financial transactions of about eighty percent of all publicly traded US companies. Soon after, in 2000, the name XFRML was changed to XBRL (Bergeron, 2003).

\subsubsection{XBRL Specification and Taxonomy Development}

The primary components of the XBRL technology are the XBRL specification and XBRL taxonomies. The XBRL specification provides the main structure and rules of XBRL. Further, it allows software vendors, programmers, intermediaries in the preparation and distribution process, and end users to enhance the creation, exchange and comparison of business reporting information (Engel, Hamscher, Shuetrim, Kannon and Wallis, 2003). The XBRL Specification is regularly "updated to implement new [financial reporting and other] standards if they are appropriate for use within XBRL" (Saeedi, Richards and Smith, 2006, p.143). In July 2000, the first specification, known as Specification 1.0, was introduced. Eighteen months later, XBRL International published Specification 2.0. In order to have a more stable specification, XBRL International continued to improve Specification 2.0. As a result, Specification 2.1 was recommended at the end of 2003 and its stability was reaffirmed in 2008 (XBRL, 2009). With an XBRL specification, the process of developing XBRL taxonomies becomes easier. XBRL taxonomies act like dictionaries and define the specific tags for individual items of data. Different taxonomies are required for different financial 
reporting purposes and requirements. The first taxonomy was developed according to USGAAP for US commercial and industrial companies' filing and was completed for use and made available on July 1, 2000 (Cohen et al., 2005). Other countries also started to develop taxonomies to suit their own reporting requirements including country-specific GAAP.

The introduction of IFRS in early 2003 changed taxonomy development. Each country could use IFRS instead of using their own GAAP. Within European countries, the adoption of IFRS in building XBRL taxonomies is continuing to increase. In the US, a US-GAAP based financial reporting taxonomy is employed by public issuers registered with SEC (XBRL, 2009; IFRS, 2010). Additionally, the introduction of Common Reporting (COREP) for banking entities in Europe in 2006 necessitated the need for the banking industry to have its own taxonomies (Pinsker, 2003; Deshmukh, 2004).

\subsubsection{XBRL Jurisdictions and the Spread of XBRL Worldwide}

An XBRL jurisdiction is a national grouping representing a country, region or international body that focuses on the progress of XBRL in their areas, as well as contributing to the international development of XBRL. A jurisdiction's role is to promote XBRL and organize the creation of taxonomies, notably for business reporting or accounting standards, in their area. An advantage of being a jurisdiction is the opportunity to share resources and expertise from other jurisdictions. XBRL International (USA) was the first jurisdiction established. As the XBRL specification stabilized and taxonomies became well-developed, the number of XBRL jurisdictions increased. XBRL jurisdictions are distributed across the globe, including Asia, Europe, and the North America continents (Kernan, 2008). A list of country-based jurisdictions up until 2009 is given in Table 2.1. In 2006, New Zealand became the only country to withdraw as an XBRL jurisdiction (XBRL, 2009).

\begin{tabular}{|l|l|}
\hline \multicolumn{2}{|c|}{ Table 2.1: List of XBRL Country Jurisdictions (2000 -2009) } \\
\hline Year & \multicolumn{1}{c|}{ Countries } \\
\hline 2000 & XBRL International (US) \\
\hline 2001 & Australia, Canada, Germany, Japan, UK, Netherlands \\
\hline 2002 & New Zealand (withdrew in 2006) \\
\hline 2003 & No new jurisdictions \\
\hline 2004 & Belgium, Ireland, Spain \\
\hline 2005 & Denmark, France, Sweden, USA, \\
\hline 2006 & South Africa, UAE, Korea, Europe, Poland \\
\hline 2007 & Italy, Luxembourg \\
\hline 2008 & Switzerland, China, India \\
\hline 2009 & Romania (Provisional) \\
\hline & Sourced from: Baldwin et al., 2006, XBRL, 2009 and IFRS Foundation, 2011. \\
\hline
\end{tabular}


Between 2000 and 2009, there were 136 projects recorded by XBRL International. Typical XBRL project types include analysis projects, used to distribute analytical information; canonical-based exchange projects, used to transfer information relating to collections of receivables; and information supply-chain projects, used for reporting to government or collecting information from those they regulate. Other project types are initiative projects, developing XBRL-related initiatives such as open compliance and ethics projects; regulatory reporting projects, used to collect financial and non-financial information from those that are regulated, and sometimes to distribute that information to certain agencies; and taxonomy creation projects, used to develop a taxonomy, which enables companies to prepare general purpose financial statements and for reporting.

Table 2.2 outlines project numbers according to project type and their status as of 2009 . Regulatory projects make up nearly two-thirds of all XBRL projects over this period and approximately half of the completed regulatory projects required mandatory adoption. Regulatory reporting projects aim to standardize the reporting format among the regulated parties such as business organisations. In some cases, regulated parties are required to submit their report to several regulatory bodies ${ }^{11}$. Thus, by adopting $\mathrm{XBRL}$, their reporting burden is believed to be reduced.

\begin{tabular}{|c|c|c|c|c|c|c|c|c|c|c|}
\hline & & \multicolumn{8}{|c|}{ Project Type } & \multirow[b]{2}{*}{ Tota } \\
\hline & & Analysis & $\begin{array}{c}\text { Canonical } \\
\text { based } \\
\text { Exchange }\end{array}$ & $\begin{array}{l}\text { Info Supply } \\
\text { Chain }\end{array}$ & Initiative & Prototype & $\begin{array}{c}\text { Regulatory } \\
\text { reporting }\end{array}$ & $\begin{array}{l}\text { Taxonomy } \\
\text { creation }\end{array}$ & Other & \\
\hline \multirow[t]{3}{*}{ Status } & Development & 5 & 4 & 5 & 13 & 3 & 44 & 6 & 4 & 84 \\
\hline & Voluntary & 0 & 0 & 2 & 1 & 1 & 21 & 0 & 0 & 25 \\
\hline & Mandatory & 0 & 0 & 2 & 1 & 0 & 22 & 1 & 1 & 27 \\
\hline Total & & 5 & 4 & 9 & 15 & 4 & 87 & 7 & 5 & 136 \\
\hline
\end{tabular}

XBRL projects can be initiated by different bodies and sectors within a country. Table 2.3 provides a breakdown of XBRL project numbers by entity type and project status. By initiating almost $60 \%$ of all XBRL projects within this period, it is clear that governments play a significant role in the initiation and success of XBRL projects, including both voluntary and mandatory adoption of the project outcomes.

\footnotetext{
${ }^{11}$ In this thesis, regulator refers to organisations like investment and securities regulators: New Zealand Stock Exchange (NZX), Companies Office, Office of the Auditor General (OAG), and the External Reporting Board (XRB).
} 
Table 2.3: XBRL Projects, Based on Entity Type and Status (2000-2009)

\begin{tabular}{|c|c|c|c|c|c|c|c|c|c|}
\hline & & \multicolumn{7}{|c|}{ Entity Type } & \multirow[b]{2}{*}{ Total } \\
\hline & & Government & $\begin{array}{c}\text { Stock } \\
\text { Exchange }\end{array}$ & $\begin{array}{l}\text { Private } \\
\text { Sector }\end{array}$ & Consortium & Education & $\begin{array}{c}\text { Not for } \\
\text { Profit }\end{array}$ & Unknown & \\
\hline \multirow[t]{3}{*}{ Status } & Development & 40 & 9 & 12 & 6 & 2 & 10 & 5 & 84 \\
\hline & Voluntary & 17 & 8 & 0 & 0 & 0 & 0 & 0 & 25 \\
\hline & Mandatory & 23 & 2 & 0 & 0 & 0 & 1 & 1 & 27 \\
\hline Total & & 80 & 19 & 12 & 6 & 2 & 11 & 6 & 136 \\
\hline
\end{tabular}

Tables 2.2 and 2.3 demonstrate that government and regulators are the groups most involved in the development and acceptance of XBRL. For example, countries such as the US and Korea have mandated XBRL for business reporting to regulatory entities. The US Securities Exchange Commission (SEC), in December 2008, announced mandatory XBRL filings for companies listed on the US Market, effective from 2009. On-going support from the SEC has accelerated the development of XBRL in the US (Azam and Taylor, 2011b). In Korea, the Financial Supervisor Service mandated that listed companies must submit their financial statements in XBRL format on its DART (Data Analysis, Retrieval, and Transfer) system, from October 2007 (Yoon, Zo and Ciganek, 2010).

Other countries such as the Netherlands, Australia, Singapore, the UK, and Germany have also adopted XBRL based business-to-government (B2G) reporting facilities. The Netherland's government introduced a single XBRL-based SBR system in 2004, which covers all filings that business organisations are required to send to the government (van Burg et al., 2010). In Australia, the federal government started developing their SBR project in 2006 with the Australia Treasury as the lead agency and participation from the Australian Securities and Investment Commission (ASIC), the Australian Taxation Office (ATO), the Australian Bureau of Statistics (ABS) and State and Territory revenue offices (Azam and Taylor, 2011b). From 2010, companies within Australia can voluntarily use the XBRL-based SBR platform to submit their statutory reports to major participating government agencies. Incorporated companies in Singapore have been required to file financial documents in XBRL format since November 2007 unless they are exempt by the Accounting and Corporate Regulatory Authority (ACRA) (Azam and Taylor, 2011b; Raju, 2005). In the UK, Her Majesty's Revenue and Customs (HMRC) use an XBRL-based electronic reporting standard to receive company tax filings. The UK government announced that the use of XBRL was mandatory for all company tax returns from April 2011 (Lord Carter Report, 
2006). In Germany, all companies are mandated to use XBRL in the context of reporting to tax authorities from 2011 (Gräning, Felden, and Piechocki, 2011). In the next section, this thesis will consider XBRL studies and related issues.

\subsection{XBRL Studies and Issues}

In recent years, several studies have been conducted to acquire information about XBRL's utilization. That is because XBRL technology was predicted to have a profound impact on any person or organisation that creates or uses business information (Kernan, 2008). As in Chapter 1 (Section 1.6.1), this thesis uses the TOE framework. Thus, this section reviews relevant $X B R L$ studies and issues and relates them to the TOE framework. Firstly, this section introduces potential influencing factors in XBRL adoption. Then, each sub-section will present and discuss in detail potential factors within the technological (Section 2.2.2), organisational (Section 2.2.3), and environmental contexts (Section 2.2.4).

\subsubsection{Factors Influencing XBRL adoption}

In the first research question (as in Chapter 1, Section 1.5), this thesis investigates factors that influence the organisational decision not to adopt XBRL for business reporting purposes. This section examines the relevant studies that suggest factors that potentially influence XBRL adoption.

Doolin and Troshani (2007) investigated the limited organisational adoption of XBRL in Australia and provide some possible explanations. The use of the TOE framework in their study assisted them in identifying influential factors. They found factors like available information and trading partner influence to be facilitating factors. Meanwhile, complexity, market conditions, and a lack of critical mass, available support, an innovation champion, organisational readiness, relative advantage, trialability, and stability were found to be inhibitors of XBRL adoption in Australia. Troshani and Rao (2007) also explored the drivers and inhibitors of XBRL adoption in Australia. They used the TOE framework to organize their findings. Based on their findings, they found more inhibitors than drivers in XBRL adoption in Australia. The drivers were the positive impact of global pressures, and high-level education and training related to XBRL for employees. Meanwhile, the inhibitors were the instability of XBRL specification, a culture of 'wait and see', relatively small market size, other adoption priorities, a lack of managerial support resulting in limited resources, a lack 
of a local adoption strategy, and a lack of widespread awareness of XBRL benefits. Additionally, there was discussion about participation in XBRL projects. The discussions included the role of government agencies, XBRL education, and training and the readiness of XBRL as an innovation and in supporting software solutions. In these two studies, the researchers discuss XBRL adoption in a descriptive manner and do not provide empirical evidence to support their discussion. By providing empirical evidence related to $\mathrm{XBRL}$ adoption's issues, XBRL adoption and its related issues can be considered in more depth.

Mandilas, Maditinos, Pipiliagkopoulos and Passaportis (2009) examined the factors that motivated a company to adopt XBRL as part of its financial reporting tools. They used the TOE framework to determine the characteristics that influenced a company's decision to adopt XBRL. The factors were firm size, the level of technology competence, firm scope, the level of internet penetration, the national disclosure environment, and trading partner influence. Among these factors, firm size, the level of technology competence and firm scope were the most significant drivers of the XBRL adoption decision. Further analysis demonstrated a relatively low XBRL adoption level across the seven European countries examined.

Azam and Taylor (2011b) investigated the factors that drove the intentions of Chief Financial Officers (CFO) within their organisation's top management team, to adopt XBRLbased SBR for financial and compliance reporting to government agencies. They focused on the factors relating to SBR adoption from a technological perspective. However, they found the degree of intention to adopt SBR was not explained by taking a purely technological perspective. They explained that no technology attributes had an influence on CFOs, apart from the weakly significant relative advantage of SBR over existing company systems for financial and compliance reporting. However, they found strong effects for the technological perspective regarding the likelihood of a company adopting SBR in future. When the CFOs' perceive higher value from the relative advantage of SBR, the compatibility of SBR, and the lower complexity of SBR; they will encourage the company to adopt SBR.

Felden (2011) examined the influencing factors in order to present explanations for XBRL adoption in Germany. He then compared his findings to other information and communication technologies like Java, Enterprise Resource Planning (ERP), Electronic Data Interchange (EDI), and e-business. Through the application of institutional theory and the 
technology acceptance model (TAM), he found that the influence of social groups and top management leadership determined the level of XBRL adoption. The more influence social groups have on companies favoring $\mathrm{XBRL}$, the more likely a company will adopt XBRL. Further, strong encouragement or a decision by top management can lead to XBRL adoption. Additionally, he found differences in the factors that influence technology adoption. Firstly, perceived benefits have a lower impact on XBRL adoption in Germany. Secondly, no national or international leading software developer had promoted the use of XBRL. So far, only the audit firms (accounting firms) were promoting it and had become the primary drivers behind the diffusion of XBRL. Finally, the diffusion of XBRL was bound to the pressure of public or regulatory bodies.

Cordery et al. (2011) examined the factors influencing the non-adoption of XBRL technology by business organisations in New Zealand. Based on interview data obtained from key XBRL stakeholders on the relative importance of environmental, organisational, and technological context factors, they tried to ascertain why adoption had not occurred. They indicated three reasons for XBRL non-adoption. First, the lack of a government 'push' for XBRL technology resulted in organisational ignorance. Second, it appeared that organisations did not believe that XBRL would beneficially reduce compliance costs. Finally, complexity in developing the standard language (taxonomy) for XBRL use had significant budgetary implications.

Mousa (2011) investigated an e-government decision process as represented by the XBRL adoption process in the UK. Her study developed a comprehensive conceptual framework (as in Figure 2.1) to examine the XBRL adoption process and influential technological, organisational and environmental factors, as well as e-government challenges that affect the process. She found that factors such as: XBRL relative advantage and compatibility, IT skills and expertise, access to external support and information, critical mass and government support, influenced the XBRL adoption process. Besides that, she identified the e-government challenges faced including; security problems, making an XBRL business case for stakeholders, and technological complexity. Her study provides an understanding of the adoption process, identifies the technological infrastructure, emphasizes the importance of organisational readiness, and discusses the impact of the environment on the adoption process. Figure 2.1 depicts a conceptual framework, which integrated Rogers's (1983) 
adoption innovation process (or Diffusion of Innovation (DOI)), the TOE framework (of DePietro et al., 1990) and e-government challenges.

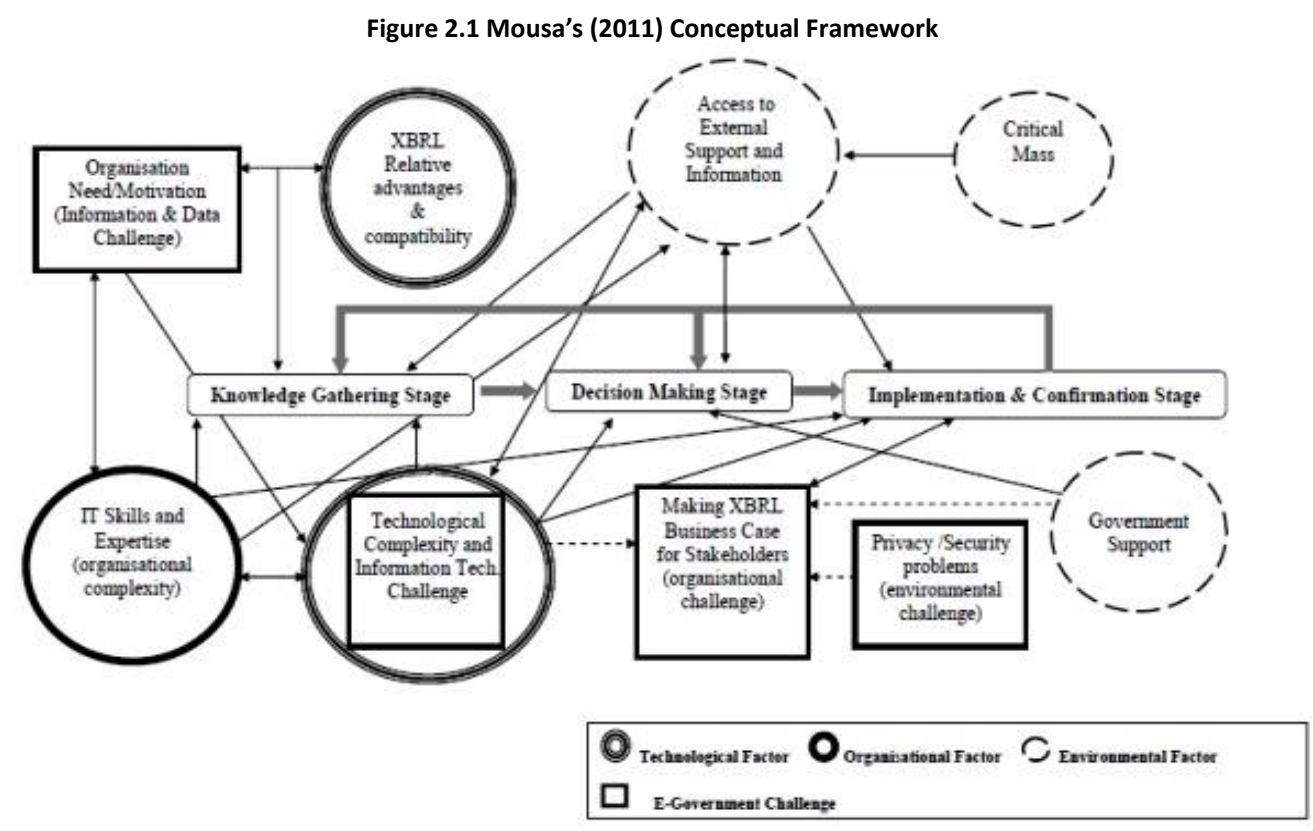

(Source: Mousa, 2011, p. 191)

Steenkamp and Nel (2012) explored the factors influencing XBRL adoption in South Africa. They found the most common reasons for not adopting XBRL were: $X B R L$ was not yet mandatory, no perceived benefits from implementing XBRL, not having sufficient technical knowledge to adopt XBRL and management not knowing what XBRL is. Additionally, their respondents also perceived that XBRL was not relevant to their organisation, had high implementation costs, management did not have the vision to adopt XBRL in their organisation, their current information system was too old to adopt XBRL, and poor economic conditions; contributed to not adopting XBRL.

Henderson, Sheetz and Trinkle (2012) investigated XBRL adoption for both internal and inter-organisational purposes. Based on their survey of 65 organisations, they found that the drivers of internal adoption differ from inter-organisational adoption. Relative advantage, compatibility, and complexity were factors that influence internal adoption, whereas, learning from external sources was the key factor for interorganisational adoption.

Researchers in this area, as summarized in Table 2.4, tend to investigate the factors influencing XBRL adoption from the private business organisation point of view. However, XBRL stakeholders are not limited to businesses, but also include: accounting firms, 
software vendors, government and regulatory authorities. More interestingly, studies by Troshani and Doolin (2007), Locke and Lowe (2006) and Cordery et al. (2011) claim that government and regulators have a significant influence on XBRL adoption. However, there has been little research to date conducted from a government or regulatory perspective regarding the factors affecting their decision to adopt XBRL. The only available research is Mousa (2011) which studies the UK context. However, there are other studies like Ebrahim and Irani (2005) from the UK context that focus on government and technology. They provide an integrated architecture framework for e-government that represents the alignment of IT infrastructure with business process management in public sector organisations, and classify the barriers that might complicate the implementation of the proposed architecture framework. Their findings suggest that organisational and technological requirements are necessary for the adoption of e-government in public sector organisations through the construction of an integrated architecture framework for egovernment. Additionally, Ebrahim and Irani (2005) identified and classified the barriers into five dimensions: IT infrastructure; security and privacy; IT skills; organisational issues; and operational costs.

\begin{tabular}{|c|c|c|c|c|}
\hline Study & Theory & Context & Findings & Relevance \\
\hline $\begin{array}{l}\text { Doolin and } \\
\text { Troshani } \\
\text { (2007) }\end{array}$ & TOE & Australia & $\begin{array}{l}\text { - Available information and trading } \\
\text { partner-influence are facilitating } \\
\text { factors. } \\
\text { - Market conditions, critical mass, } \\
\text { available support, an innovation } \\
\text { champion, organisational readiness, } \\
\text { the relative advantage (benefits), } \\
\text { complexity, trialability, and stability } \\
\text { are inhibitors. }\end{array}$ & $\begin{array}{l}\text { Potential } \\
\text { facilitating } \\
\text { and inhibiting } \\
\text { factors }\end{array}$ \\
\hline $\begin{array}{l}\text { Troshani } \\
\text { and Rao } \\
\text { (2007) }\end{array}$ & TOE & Australia & $\begin{array}{l}\text { - The drivers were the positive impact } \\
\text { of global pressures, and high-level } \\
\text { employee education and training. } \\
\text { - The inhibitors were instability of } \\
\text { XBRL specification, the culture of } \\
\text { 'wait and see', relatively small market } \\
\text { size, other adoption priorities, a lack } \\
\text { of managerial support resulting in } \\
\text { limited resources, no local adoption } \\
\text { strategy, and limited awareness of } \\
\text { XBRL benefits. }\end{array}$ & $\begin{array}{l}\text { Potential } \\
\text { driving and } \\
\text { inhibiting } \\
\text { factors }\end{array}$ \\
\hline $\begin{array}{l}\text { Mandilas et } \\
\text { al. (2009) }\end{array}$ & TOE & $\begin{array}{l}\text { UK, The } \\
\text { Netherlands, } \\
\text { Germany, } \\
\text { France, Sweden, } \\
\text { Spain, and } \\
\text { Greece }\end{array}$ & $\begin{array}{l}\text { - The factors were firm size, level of } \\
\text { technology competence, firm scope, } \\
\text { level of internet penetration, national } \\
\text { disclosure environment, and trading } \\
\text { partner influence. }\end{array}$ & $\begin{array}{l}\text { Potential } \\
\text { adopting } \\
\text { factors }\end{array}$ \\
\hline
\end{tabular}




\begin{tabular}{|c|c|c|c|c|}
\hline $\begin{array}{l}\text { Azam and } \\
\text { Taylor } \\
\text { (2011b) }\end{array}$ & TOE & Australia & $\begin{array}{l}\text { - The degree of intention to adopt SBR } \\
\text { was not explained by taking a } \\
\text { technological perspective. } \\
\text { - A weakly significant relative } \\
\text { advantage (benefits) had an } \\
\text { influence. }\end{array}$ & $\begin{array}{l}\text { Not only } \\
\text { technological } \\
\text { factors }\end{array}$ \\
\hline $\begin{array}{l}\text { Felden } \\
\text { (2011) }\end{array}$ & $\begin{array}{c}\text { Institutional } \\
\text { Theory } \\
\text { TAM }\end{array}$ & Germany & $\begin{array}{l}\text { - The influence of social groups and } \\
\text { top management leadership } \\
\text { determined the level of XBRL } \\
\text { adoption. } \\
\text { - Strong encouragement or a decision } \\
\text { by top management can lead to } \\
\text { voluntary XBRL adoption. }\end{array}$ & $\begin{array}{l}\text { Potential } \\
\text { facilitating } \\
\text { factors }\end{array}$ \\
\hline $\begin{array}{l}\text { Cordery et } \\
\text { al. (2011) }\end{array}$ & TOE & New Zealand & $\begin{array}{l}\text { - Three reasons for XBRL non- } \\
\text { adoption: } \\
\text { i) The lack of a government 'push' } \\
\text { for mandatory adoption. } \\
\text { ii) XBRL not perceived to reduce } \\
\text { compliance costs. } \\
\text { iii) Complexity in developing the } \\
\text { XBRL language (taxonomy). }\end{array}$ & $\begin{array}{l}\text { Factors that } \\
\text { influence } \\
\text { non-adoption }\end{array}$ \\
\hline $\begin{array}{l}\text { Mousa } \\
\text { (2011) }\end{array}$ & $\begin{array}{l}\text { DOI } \\
\text { TOE }\end{array}$ & UK & $\begin{array}{l}\text { - Factors such as relative advantage } \\
\text { and compatibility, IT skills and } \\
\text { expertise, access to external support } \\
\text { and information, critical mass and } \\
\text { government adoption support } \\
\text { influence the XBRL adoption process. } \\
\text { - The e-government challenges } \\
\text { include; security problems, making } \\
\text { an XBRL business case for } \\
\text { stakeholders and technological } \\
\text { complexity. }\end{array}$ & $\begin{array}{l}\text { Potential } \\
\text { influencing } \\
\text { factors in } \\
\text { government } \\
\text { adoption }\end{array}$ \\
\hline $\begin{array}{l}\text { Steenkamp } \\
\text { and Nel } \\
(2012)\end{array}$ & Exploratory & South Africa & $\begin{array}{l}\text { - A low level of awareness and slow } \\
\text { adoption of XBRL. } \\
\text { - Four main reasons for XBRL non- } \\
\text { adoption: } \\
\text { i) XBRL is not mandatory. } \\
\text { ii) No benefit in implementing XBRL. } \\
\text { iii) A lack of technical knowledge. } \\
\text { iv) Management not knowing what } \\
\text { XBRL is. }\end{array}$ & $\begin{array}{l}\text { Factors that } \\
\text { influence } \\
\text { non-adoption }\end{array}$ \\
\hline $\begin{array}{l}\text { Henderson } \\
\text { et al. (2012) }\end{array}$ & $\begin{array}{l}\text { TOE } \\
\text { (combination } \\
\text { of DOI, } \\
\text { Organisational } \\
\text { Learning \& } \\
\text { Institutional } \\
\text { Theory) }\end{array}$ & $\begin{array}{c}\text { Asia, Europe, } \\
\text { and the US }\end{array}$ & $\begin{array}{l}\text { - Relative advantage, compatibility, } \\
\text { and complexity had a strong } \\
\text { influence on the internal XBRL } \\
\text { adoption decision. }\end{array}$ & $\begin{array}{l}\text { Potential } \\
\text { influencing } \\
\text { factors }\end{array}$ \\
\hline
\end{tabular}

This thesis will investigate the factors that influence decisions made by private organisations as well as governmental organisations about the non-adoption of XBRL. Additionally, this study will focus on the New Zealand context. The relevant factors investigated in this thesis are the combination of factors that are identified here in Section 2.3, as well as in Chapter 3, Section 3.2. 


\subsubsection{Benefits and Challenges of XBRL Adoption}

This section is important for two reasons. First, the benefits of XBRL adoption are one of the key influencing factors (Table 2.4), within the technological context. Second, by considering further the benefits of $X B R L$, this thesis can link the decision not to adopt XBRL to the implications of not adopting it for business reporting. Hence, this section provides an early pre-understanding for both the first and second research questions (as in Chapter 1, Section 1.5).

Early on, during the introduction of XBRL, most scholars discussed the XBRL concept and its perceived benefits. Among the perceived benefits were: reducing costs in report dissemination (Ashbaugh, Johnstone and Warfield, 1999), the ease of generating financial reports (Coffin, 2001), continuous assurance (Alles, Kogan and Vasarhelyi, 2002), and improving efficiency, effectiveness and transparency (Rezaee and Turner, 2002).

Ashbaugh et al. (1999) examined firms' use of the Internet to enhance the relevance of their financial reporting. They defined a firm that practiced Internet Financial Reporting (IFR). Such a firm provides a comprehensive set of financial statements on their website, a link to its annual report elsewhere on the Internet or a link to the Electronic DataGathering, Analysis, and Retrieval (EDGAR) systems of the SEC. In their analysis, about 70 percent of firms engaged in IFR, but there was substantial variation in the quality of firms' IFR practices. The variations pertained to the timeliness and usefulness of firms' financial reporting on the internet. In terms of the timeliness, some firms provided more timely financial disclosure via the Internet, while other firms reported out-dated financial data. Meanwhile, the usefulness of firm's financial reporting on the Internet depended on how easy it was to access that data, the amount of data disclosed and whether users could download or analyze the data. Further analysis found that firms perceived that websites were an important medium to disseminate information to shareholders and IFR can reduce firms' information dissemination costs.

In another study, Coffin (2001) discovered XBRL benefits particularly related to the ease of generating reports. He stated that XBRL is an enabling technology in internet reporting and has an ability to cut inefficiencies. As part of his discussion, he mentioned XBRL would make it easier for companies to generate reports under different accounting standards. For example, users like analysts or investors will benefit by saving time when translating a 
financial statement from US-GAAP to IFRS, because the XBRL taxonomy will do the work for them.

Later on, Alles et al. (2002) conducted a study on the benefits of XBRL for auditors. They examined the concept of continuous assurance and the possible paths along which such services will evolve. The introduction of online reporting creates the mechanisms for continuous auditing. Continuous auditing leads to continuous reporting, which supplements and eventually replaces the annual audit report. In order to audit in a new technological environment, auditors need to use electronic sensors, software agents, or computerized audit programming models to carry out the audit work effectively. Thus, XBRL enables lowcost business information capture at the source. In addition, developments in XBRL give a strategic impetus to the development of real-time information gathering and decision support systems. XBRL has the ability to capture transactional data, monitor and analyze it and communicate the analysis. These abilities allow XBRL to deliver continuous assurance.

Different from previous studies, Rezaee and Turner (2002) investigate how an XBRL application would be useful for accountants in government agencies. They presented an overview of electronic financial reporting and examine the power of XBRL in standardizing financial reporting of government agencies. They argue that XBRL has the ability to transform government financial reporting to be more efficient, effective, and transparent. They also predict that XBRL will encourage more effective management and monitoring of government programs and lessen the possibility of mismanagement, bureaucracy, paperwork and fraud. Through greater transparency, government agencies will reduce ineffectiveness and the opportunity for inappropriate actions.

The early XBRL research, as discussed above, about the perceived benefits of $X B R L$ is considered an effort to promote the technology by creating awareness and providing insights into XBRL matters. However, the articles have weak evidence. As these studies were conducted in the US context, they have less influence on and may find it difficult to convince global stakeholders to adopt XBRL. Moreover, they provide little empirical evidence on the benefits and potential issues associated with XBRL adoption (a technological factor). Because of that, accounting and IS researchers conducted further studies on XBRL to provide stronger evidence from other countries as well as identifying the real potential benefits of XBRL. As a result, numerous studies emerged that provide 
stronger evidence of the abilities of XBRL including in facilitating investment decision making (Hodge, Kennedy, and Maines, 2004) and in making indirect cost savings in regards to financial reporting, personnel, and computer resources (Pinsker and Li, 2008).

Hodge et al.'s (2004) study investigates whether XBRL helps non-professional financial statement users to acquire and integrate the financial information while making an investment decision. Their findings reveal that most users do not access XBRL. However, for those who do use it, they are better able to acquire and integrate information, especially when stock option accounting varies between firms. The use of an XBRL-enhanced search engine increases the likelihood that users acquire information about the stock option compensation disclosed in the footnotes. They also found that XBRL helps users integrate the implications of this information, which results in different investment decisions between users and non-users. They also suggest that XBRL aids financial statement users by improving the transparency of firms' financial statement information and managers' choices for reporting that information.

From the cost-benefit perspective, Pinsker and Li (2008) investigate the cost and benefits of XBRL adoption. They interviewed four business managers that were involved in XBRL adoption in Canada, Germany, South Africa, and the US. Their findings indicate XBRL adoption may reflect the diversity of international corporate culture. The three non-US companies mention that the anticipated adoption benefits and the actual benefits involved cost savings through a variety of sources such as increased processing capability and decreased data redundancy or increased efficiency and decreased bookkeeping costs. However, in the US, XBRL adoption was considered a key marketing tool for reaching the company's potential investors. The adoption would position the company as a 'thought leader' or innovator in the equity market. Additionally, more efficient marketing and a better position in the market would lead to a broader base of potential investors and a lower cost of capital. They also found that XBRL adoption gave a competitive advantage to the adopter and increased data transparency in the marketplace.

As research evidence began to show the real potential benefits of XBRL for stakeholders, XBRL adoption rates started to increase internationally. However, stakeholders began to demand more detailed information and knowledge related to XBRL adoption especially based on different countries adoption experiences. XBRL researchers, therefore, began to 
investigate more specific matters related to XBRL practices, usefulness, and implications. Among these later studies are Vasarhelyi, Chan, and Krahel (2012); Blankespoor (2012); Wang and Goa (2012) and Hutton, Goldstein and Piemonte (2013).

Vasarhelyi et al. (2012) discussed how XBRL enhanced the usefulness of financial reporting, data analysis, and decision-making. Their study has two important findings. First, XBRL increases the usefulness of financial statement information by improving the relevance, faithful representation, comparability and consistency, and understandability of information. Second, XBRL enables machines to aid users in data retrieval, data analysis, and decision-making by improving data control and providing support for dynamic reporting, the taxonomy standardization, and improved transparency of footnote disclosures through formalization.

In an effort to encourage more investors to use XBRL, Blankespoor (2012a) examined the effect of investor information processing costs on firms' disclosure choice. She found firms increased their quantitative footnote disclosures after the adoption of XBRL detailed tagging requirements designed to reduce investor-processing costs. The findings suggest that investor-processing costs can be significant enough to impact firms' disclosure decisions and that XBRL technology use reduces investors' processing costs.

More evidence on the quality of XBRL-based financial reports is provided in the Wang and Goa (2012) study. Their study collected data from US, China, and South Korea stock exchanges and provided a comparative assessment of the quality of data between XBRL formatted financial reports and non-XBRL financial reports. They found XBRL-formatted financial reports display a large improvement in the quality of data in almost all aspects. With XBRL, web data managing, presentation and analysis applications, XBRL formatted financial reports have much better accessibility, are more accurate and timely, and retain a consistent format.

In addition to the above studies, Hutton et al. (2013) provide more evidence on the impact of XBRL for accounting professionals and security analysts. They examine trends in the awareness and usage of XBRL within these groups and the degree to which information regarding $X B R L$ has been incorporated into the education curriculum required for professional certification in these fields. They also identify the benefits of XBRL implementation for securities analysts. The benefits include increased depth of analysis, 
fewer errors, more-timely reporting, efficient securities markets, and improved access for all investors.

Besides the above benefits, academics and practitioners have also found there are challenges faced by stakeholders in adopting XBRL technology. Pinsker and Li (2008), for instance, mention stakeholder uncertainty due to unproven XBRL technology and the complexity of the taxonomy. Further, stakeholders need to spend money, and it takes time to learn the technology. Auditors also had issues relating to XBRL instance document assurance (Srivastava and Kogan, 2010). In performing audit procedures, auditors faced challenges in understanding how to apply XBRL in auditing. They need to understand the business facts and meta-data in-and-out of the XBRL instance document.

The securities analysts had difficulties with obtaining consistent, timely, accurate, and reliable financial data (Hutton et al., 2012). Usually, securities analysts use more than one data vendor or database. Each data vendor has different reporting and interpretation methodology; some might use an XBRL format and some might not. Although XBRL helps in analyzing the data, the comparability of data is limited to a single data vendor. That means across multiple vendors; securities analysts have to apply a different method of analyzing the data.

This thesis will investigate the benefits of XBRL (relative advantage) factor under the technological context of the TOE framework. In prior studies, relative advantage is perceived as one of the main factors in XBRL adoption (Table 2.4). However, based on the previous studies, stakeholders are still not convinced how XBRL could help them, particularly in business reporting matters. This indicates that more research is required on this issue. Further, the relative advantage of XBRL is closely related to the non-adoption of XBRL. For this reason, more issues relating to XBRL adoption are explored in Chapter 3 , Section 3.3.3.

\subsubsection{Voluntary and Mandatory Adoption of XBRL}

The adoption strategy is also a key influential factor when it comes to XBRL adoption (as indicated in Table 2.4). This potential factor exists in the organisational context. The key arguments between having a voluntary or mandatory adoption strategy have been explored by researchers. 
Several studies examine voluntary XBRL adoption. Mostly, these studies suggest there have been low rates of voluntary adoption by stakeholders. Callaghan and Nehmer (2009) examined a US SEC sample of voluntary XBRL adopters and compared them to pair-matched companies based on industry, size and governance rating availability. They also explored the internal and external characteristics of the sample to determine whether there are systematic differences between voluntary filers and the control sample. Their result shows that early XBRL adopters are bigger, less financially leveraged, and have a lower corporate governance rating. In addition, they conclude that larger and more visible companies that are intrinsically riskier, seek to improve their corporate governance appearance by voluntarily adopting XBRL in the US regulatory and corporate environments.

Gray and Miller (2009) identified that a high-priority in solving accounting, financial reporting, and internal audit problems would encourage US organisations to adopt XBRL voluntarily. Using four focus groups, they found that XBRL can fulfill the organisations' needs related to financial reporting. Further, Gray and Miller (2009) suggest awareness within organisations is needed before there will be widespread adoption of XBRL in the absence of a regulatory requirement to use it.

Both these studies are conducted in the US. While, Callahan and Nehmer (2009) focus on the characteristics of voluntary XBRL adopters, Gray and Miller (2009) promote XBRL adoption on a voluntary basis. Although Gray and Miller (2009) indicate there was a low rate of XBRL filing under the SEC's voluntary filing programme (VFP), this finding is consistent with Rogers (2003) in that getting a technology widely adopted is particularly challenging. Even when the technology has obvious advantages, it may be many years from the time the technology is available until it is widely adopted. Thus, the challenge is how to speed up the rate of XBRL adoption. Rogers (2003), Troshani and Rao (2007) and Gray and Miller (2009) further suggest that although some regulators are now mandating that XBRL is to be used for filings, widespread diffusion is not assured beyond the minimum filing requirements. They argue that widespread adoption of XBRL will depend largely on documenting the application of and advantages offered by XBRL in the required and other domains versus the associated costs, as well as communicating this knowledge to potential adopters. They emphasize that increasing awareness among XBRL stakeholders will result in achieving its benefits rather than forcing XBRL adoption. 
Nonetheless, recent studies by Azam and Taylor (2011a) and Efendi, Smith and Wong (2011) still find the rate of voluntary XBRL adoption is low. Azam and Taylor (2011a) assessed the Australian SBR's prospects of widespread adoption by business, users, and regulators. Although there are many benefits espoused through SBR, businesses either refused or were slow in the voluntary take-up of the online reporting facility. This occurred for two reasons. First, the issue of costs. Although applying XBRL would reduce information processing costs in the long run, there would be short-term costs such as installing the SBR platform, the potential disruption to vital information processing and reporting systems, and staff training. Second, there would be a risk of hostile takeover. Businesses perceived there were weaknesses in the transmission design of the SBR programme in Australia. They sought to ensure their data was routed to the relevant regulatory agencies in limited information packages and that more comprehensive information was not centrally stored by the government or shared between regulators. Therefore, businesses carefully assessed the situation before making a final decision to adopt XBRL. Additionally, the global financial crisis prompted business managers to 'wait and see' the future developments in XBRL at the international level. Thus, regulators needed to instill confidence among businesses the data transmitted to government electronically would remain under the participating businesses' control.

The Efendi et al. (2011) study provides an overview of the benefits of XBRL and its global development. They also evaluate the extent of XBRL adoption following the implementation of the voluntary filing programme in the US where their results show the quantity of voluntary reporting was relatively low, but reporting increased significantly over time. Moreover, voluntary adopters were larger and the most innovative firms in their industries. They found the time lag between filing reports in an XBRL format and the end of the fiscal year and quarter decreased. This finding suggests there was an XBRL learning curve that voluntary adopters experienced, and thus, the adoption rate of XBRL may increase in the future.

As discussed above, voluntary adopters have adopted XBRL technology for a variety of reasons and purposes. Even though the voluntary adoption rate is low, there is potentially a learning curve and a need for awareness. 
In contrast, recent studies on mandatory XBRL adoption argue the use of XBRL in reporting will give benefits to XBRL stakeholders and thus, it should be mandated. Debreceny, Farewell, Piechocki, Felden and Gräning (2010) investigate the extent of, and reasons for, calculation errors in the first round of filings of quarterly reports (10-Q) made in XBRL format under the SEC mandate. They suggest the data quality of the information filed by corporations can be improved. This is because; the identification of computational errors in XBRL filings is readily traceable with automated tools, unlike other formats such as HTML or PDF, which do not provide sufficient semantics to detect errors and improve the data quality. By improving the data quality, there are immediate benefits for XBRL stakeholders.

Another study by Gräning, Felden, and Piechocki (2011) explores the progress of research conducted in the XBRL domain. Their study shows the majority of the 57 analyzed XBRLrelated academic papers adopt an empirical research design, with researchers using methods such as descriptive statistical analysis, interviews and case studies to analyze the international acceptance and adoption of XBRL as a financial reporting language. They also argue there are low rates of voluntary XBRL adoption. They question whether low adoption is related to the nature of XBRL or whether it is due to a weakness in XBRL implementation. They suggest enforcement by regulators is necessary, and that future research should involve XBRL stakeholders in order to use their previous experience (voluntary adoption) to identify factors that accelerate or decelerate the mandatory adoption of XBRL.

Research by Kim, Lim and No (2012) examines the effect of mandatory XBRL disclosure across various aspects of the financial information environment. Their findings show an increase in information efficiency, a decrease in event return volatility and a reduction of change in stock returns volatility for 425 firms (1,159 firm-quarters) in the post-XBRL, adoption period. Their findings suggest mandatory XBRL disclosure decreases information risk and information asymmetry in both general and uncertain information environments. Here, XBRL stakeholders, such as investors and investment analysts, will benefit from using $X B R L$, if $X B R L$ use is mandated.

Based on the studies, there is a possibility that mandating XBRL use in business reporting offers benefits to XBRL stakeholders that they would not realise under a voluntary strategy. Thus, a voluntary or mandatory adoption strategy (an organisational factor) is a key influential factor because the decision to adopt XBRL voluntarily depends on organisations' 
intentions, whereas they must adopt under a mandatory adoption strategy. Although previous studies explore and discuss the impact of voluntary and mandatory adoption, they do not explicitly argue that the adoption strategy is an influential factor in XBRL adoption.

\subsubsection{XBRL Awareness among Adopter and Non-Adopter Countries}

XBRL awareness is a key influencing factor (as shown in Table 2.4) under the environmental context. A lack of stakeholder awareness about XBRL can influence XBRL development and adoption in organisations. However, there are limited studies that investigate stakeholder awareness on a longitudinal basis, and relate this awareness to XBRL development or adoption.

In the US, Pinsker (2003) was among the earliest studies to identify the level of awareness among accountants and auditors. Despite the dissemination of XBRL information via business magazines and widely read newspapers, his findings indicate a lack of knowledge of and experience with XBRL by the majority of accountants and auditors. Further, respondents did not perceive that XBRL use would increase the efficiency and effectiveness of job-related performance.

As an example of later studies on XBRL awareness among accountants and auditors in the US, Venkatesh and Armitage (2012) gathered information about these stakeholders' levels of XBRL knowledge and awareness. Their study also investigated the stakeholders' perceptions about the importance of providing assurance and the level of assurance needed. They suggest that accountants and auditors believe that assurance on XBRL financial statements is important, and must adjust their auditing methods. The results also show that auditors have limited knowledge, received below average training in XBRL and did not have the skills, expertise, and training to provide assurance on XBRL produced statements.

Hutton et al. (2012) provided three possible explanations for low awareness of XBRL among securities analysts in the US. Firstly, most of the sell-side analysts use data compiled by third party data providers. There are several available data providers, and each provider collects data differently, for example through proprietary data tagging or structured XBRL tagging. Secondly, there are limited data available on $10-Q$ and $10-K$ reports (filed in $X B R L$ ) that are useful to analysts. While the SEC reporting is backward looking, securities analysis 
is forward looking. Companies are required to disclose material information as soon as it is available. Hence, timeliness is important, but XBRL is not being used to report that data. Finally, there is a low level of confidence in XBRL data. Companies have established safeguards such as robust checks on data integrity. However, Hutton et al. (2012) notes those safeguards do not yet extend to XBRL data.

Two Australian studies investigate the level of awareness among the XBRL stakeholders. However, these studies do not focus on specific stakeholders as the US studies did. Troshani and Doolin (2005) conducted in-depth interviews to explore a range of issues surrounding the adoption of XBRL in Australia. They found that a lack of awareness of XBRL benefits inhibited and slowed XBRL adoption. This finding was consistent with Troshani and Rao (2007), where a lack of awareness existed because stakeholders were unable to experience XBRL benefits.

$\mathrm{Nel}$ and Steenkamp (2008) investigated the levels of awareness and understanding of XBRL in South Africa among chartered accountants. The majority of chartered accountants were unaware, and only a few fully understood XBRL. Later Steenkamp and Nel (2012) repeated the study. As with the US findings, Steenkamp and Nel (2012) found the level of awareness among South African chartered accountants still low.

From the securities analysts' perspective, the Chartered Financial Analyst (CFA) Institute ${ }^{12}$ conducted regular surveys of its members in 2007, 2009 and 2011, in regions such as Asia/Pacific, Canada, Europe, the Middle East, and Africa, Latin America, and the United States. In 2007, the CFA Institute found low awareness among financial analysts. They also revealed XBRL tagged interactive data has the potential to make the largest possible improvement on uploading company data into financial analysis models and making comparisons between companies and industries. The survey in 2009 still showed a low awareness among its members particularly among new members and those from the AsiaPacific, Europe, the Middle East, and Africa. Among members that were aware of XBRL, they did not use information from an XBRL instance document and only a few of them extracted or imported XBRL tagged data directly into financial analysis models. This situation continued in 2011, where there was still low awareness with a small number of members

\footnotetext{
12 This Institute is the most widely recognized professional credential for a securities analyst not only in the US but also in most other regions.
} 
using XBRL tagged information. The CFA surveys indicate there has been continuing low awareness of XBRL among securities analysts. Figure 2.2 shows the results of the surveys.

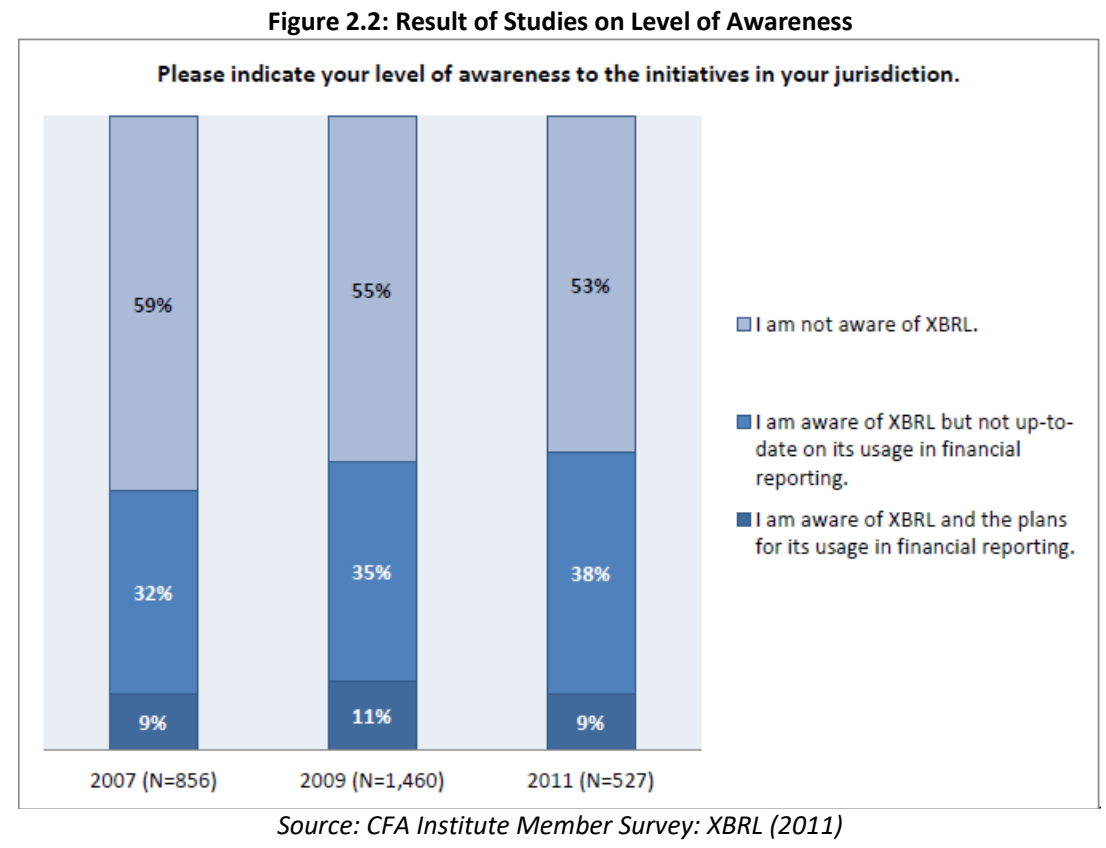

In Germany, Felden (2011) explored XBRL adoption. His findings indicate that the perceived benefits of XBRL usage do not provide a reason to adopt the technology. Only a few participants knew about XBRL, which meant they had limited knowledge about XBRL's potential benefits. Moreover, the participants had little experience in using XBRL. Felden mentioned that most companies did not know they were obliged to file their tax balance return in XBRL format.

In the UK, Theresa Dunne, Helliar, Lymer, and Mousa (2013) examined corporate stakeholders' awareness of the benefits of XBRL. They found the majority of the respondents did not know about XBRL, which suggests there were low awareness and little knowledge about XBRL among UK stakeholders. However, those familiar with XBRL were also aware of the reported benefits, such as that XBRL eliminated the need to re-key information, it enabled greater data comparability, was inter-operable and sped up and improved data analysis.

Rosa and Caserio (2013) focused their study on the auditors' perspective. They examined whether independent auditors in Italy were convinced of the utility and practicality of XBRL in their work. They revealed that independent auditors' knowledge about XBRL remains low and that auditors are not influenced by the benefits of XBRL. They suggest that XBRL 
benefits are not a driver for interest in XBRL. Instead, the main cause of the low XBRL interest was connected with culture. Rosa and Caserio (2013) also provide explanations for the low interest, knowledge, and experience in XBRL, based on other perspectives: regulatory, economic, and procedure or technical. Independent auditors were expecting legislative intervention to promote their interest or awareness of XBRL. Rosa and Caserio (2013) suggest auditing firms would have a greater interest in XBRL if the benefits exceeded costs in relation to its implementation, adoption, and successive assurance activity. The auditors' interest in XBRL could be further stimulated if information on XBRL was widely available and complete. This information would overcome the culture of resistance to the technology.

XBRL adopter countries like the US, Australia, South Africa, UK and Italy show a low level of awareness among its stakeholders. Even though, in some countries like the US and the UK, XBRL adoption for some organisations is mandatory. This suggests that it does not matter if a mandatory or voluntary adoption strategy is used by government organisations or private industry groups (like banks); the level of stakeholders' awareness is low.

Moving into the countries where there is little voluntary adoption and no mandatory adoption, studies from New Zealand and Malaysia also indicate a low awareness of XBRL. In New Zealand, Davidson, Robinson, and Malthus (2006) examined the knowledge and use of XBRL by chartered accountants. Their findings reveal the majority of chartered accountants were aware of $\mathrm{XBRL}$, but only $1 \%$ was using XBRL. Although there was an awareness of XBRL, most chartered accountants and the organisations they worked for were committed to their existing accounting information system and not intended to adopt XBRL in the future. Thus, the challenge identified was to improve knowledge about how XBRL works and the benefits of its implementation.

Meanwhile, in Malaysia, Ilias, Razak and Razak (2014) explored the readiness for and awareness of XBRL in Malaysian organisations. They found there was low awareness of XBRL among stakeholders, with only a small percentage that could understand the XBRL concept. However, more than half of stakeholders intended to investigate XBRL further. Additionally, the study suggests that more training related to XBRL should be conducted to improve the awareness and understanding of XBRL. 
As can be seen from the above literature, regardless of whether the research participants and/or organisations were in countries that encouraged or mandated adoption (or not), awareness among XBRL stakeholders was low (an environmental factor). This indicates the level of awareness among the wider XBRL stakeholders is not directly influenced by being encouraged to voluntarily adopt XBRL or adopt it on a mandatory basis. However, through mandatory adoption, the stakeholders that are directly impacted will learn about and accept XBRL for use in their business reporting.

Exploring XBRL issues and studies at the international level provides a wider picture of what is happening around the world. The US as a context dominated most of the XBRL studies above, as well as developments in XBRL. Nonetheless, there are some New Zealand-based studies related to IFR as well as XBRL. In the next section, XBRL-related issues and studies in New Zealand are presented.

\subsection{XBRL and Related Studies and Issues in the New Zealand Context}

There were several studies related to XBRL that have a New Zealand focus. Among those are Oyelere et al. (2003), Davidson et al. (2006) as discussed in Section 2.2.4, Locke and Lowe (2006), Chatterjee \& Hawkes (2008), Ghani et al. (2009), Ghani and Jusoff (2009), Cordery et al. (2011) as discussed in Section 2.2.1 and Ghani, Laswad and Tooley (2011).

Oyelere et al. (2003) examines the determinants of voluntary financial reporting through traditional media like print-based annual reports. They extend the literature by examining the voluntary adoption of the Internet as a medium for transmitting financial reports and determinants of such voluntary practice by New Zealand companies. Their results indicate that determinants of traditional financial reporting were also the determinants of voluntary adoption of IFR: firm size, liquidity, industrial sector, and spread of shareholding. However, other firm characteristics, such as leverage, profitability, and internationalization do not explain the choice to use the Internet as a medium for corporate financial reporting.

Locke and Lowe (2006) examine the continuing development and promotion of XBRL in the light of issues that may arise in implementation. They applied a framework that has been developed in the management and IS literature to analyze the implementation of complex technologies. Their results found four general concerns related to XBRL. Firstly, regulator 'push' is essential at the beginning of technology adoption. Secondly, support from IT and 
accounting professionals is needed during the implementation stage. Thirdly, there is a need to identify the stability of XBRL technology and to define the scope of implementation. Finally, the need to determine the trade-off between achieving greater infusion of XBRL in the organisation against the potential risks inherent in XBRL-General Ledger (GL).

Chatterjee \& Hawkes (2008) investigate the difference that occurred in website organisation as a way of considering the accessibility of information between New Zealand and Indian companies, both across countries and within the same reporting structure. Their results show that a wide range of information does not necessarily enhance the usefulness of websites if the required information cannot be accessed in an easy manner. Further, they suggest that IFR provides the illusion of comparability. However, without a more sustained focus on the harmonisation of terminology and attributes included in Internet reporting, the potential for comparison is reduced by the variation in levels at which information items are disclosed, the terminology that is used on websites and the information items provided on company websites.

Ghani et al. (2009) examine users' perceptions of three digital reporting formats: PDF, HTML, and XBRL. Public accounting practitioners were employed to examine users' perceptions of different reporting formats used in disseminating financial information. Their findings revealed that most participants agreed that reporting formats in the digital environment are useful and easy to use. Users' perceptions were also found to influence their preferred reporting format. The findings also showed that users' perceptions of usefulness are analogous to their decision accuracy for HTML and XBRL formats but not for the PDF format.

Ghani and Jusoff (2009) examined two factors that influence the preference for a particular digital presentation format. They used a questionnaire to examine two possible factors: public accounting practitioners' work experience and familiarity with a presentation format (HTML, PDF, or XBRL). Their findings reveal that work experience was not an important determinant of users' preferred presentation format. However, public accountants preferred to use HTML as their digital presentation format, which meant familiarity with types of presentation formats was an important factor. Further, they suggest that more promotion should be undertaken to increase users' awareness and understanding towards the presentation formats in the digital reporting environment. 
Ghani et al. (2011) examine whether the presentation of financial information in digital formats, addressed the concerns over users' functional fixation. Public accountants were involved in their experimental design research. Their key findings suggest the use of digital formats to present financial reports did not fully overcome the issue of functional fixation in the processing of financial information. However, public accountants were able to identify and extract relevant information, regardless of whether or not the information was presented in the financial statements or in the notes to the accounts. The evidence indicates that functional fixation remained when the accountants made final decisions based on available information. This shows that functional fixation may not be caused by access to or extraction of information, but by the level of perceived significance based on where the information is reported in the financial statements. Thus, they stated that current technology might not be able to reduce fully, functional fixation in the evaluation of financial information prepared by different accounting policies and methods.

Table 2.5 summarizes the New Zealand studies that have examined XBRL either separately or as part of the wider IFR arena. Researchers in New Zealand have conducted two IFR, three digital financial reporting, and three XBRL studies. In IFR and digital reporting studies, researchers investigated the determinants of IFR, the usefulness of IFR, user's perception of digital reporting format, determinants of the preferred digital presentation format, and the use of digital formats. Meanwhile in the XBRL studies, New Zealand researchers examined XBRL awareness among chartered accountants, the development and promotion of XBRL, and factors influencing the non-adoption of XBRL. This means only one study on XBRL has considered the factors influencing the adoption of XBRL by New Zealand organisations, and this data was collected before the governmental decision not to adopt XBRL for business reporting use was made.

Table 2.5: New Zealand: XBRL and Related Studies and Issues

\begin{tabular}{|l|l|l|}
\hline \multicolumn{1}{|c|}{ Study } & \multicolumn{1}{c|}{ Findings } & Focus \& Relevance \\
\hline $\begin{array}{l}\text { Oyelere et } \\
\text { al. (2003) }\end{array}$ & $\begin{array}{l}\text { - Size, the spread of shareholding and efficiency are primary } \\
\text { determinants of IFR. } \\
\text { - Industries' groups and foreign affiliation are not significantly } \\
\text { associated with the practice of IFR. }\end{array}$ & IFR \\
\hline $\begin{array}{l}\text { Davidson } \\
\text { et al. }\end{array}$ & $\begin{array}{l}\text { - The use of XBRL was very low (awareness). } \\
\text { (2006) }\end{array}$ & $\begin{array}{l}\text { - The majority of respondents were aware of XBRL, but their } \\
\text { (Section }\end{array}$ \\
$2.2 .4)$ & systems. & $\begin{array}{l}\text { XBRL: Awareness } \\
\text { Potential influencing } \\
\text { factor in the } \\
\text { environmental } \\
\text { context. }\end{array}$ \\
\hline
\end{tabular}




\begin{tabular}{|c|c|c|}
\hline $\begin{array}{l}\text { Locke \& } \\
\text { Lowe } \\
\text { (2006) }\end{array}$ & $\begin{array}{l}\text { - Four generic concerns with XBRL: } \\
\text { i) The initiation of adoption that is occurring through regulator } \\
\text { 'push' (adoption strategy). } \\
\text { ii) The ability of both IT and accounting professionals to support } \\
\text { implementation (stakeholder involvement). } \\
\text { iii) Concerns about technology stability and defining the scope of } \\
\text { the implementation (stability). } \\
\text { iv) The trade-off between achieving greater infusion of XBRL in } \\
\text { organisations against the potential risks inherent in XBRL-GL. }\end{array}$ & $\begin{array}{l}\text { XBRL: Generic } \\
\text { Potential influencing } \\
\text { factors }\end{array}$ \\
\hline $\begin{array}{l}\text { Chatterjee } \\
\text { \& Hawkes } \\
\text { (2008) }\end{array}$ & $\begin{array}{l}\text { - Disclosure of a wide range of information doesn't enhance the } \\
\text { usefulness of websites if the required information can't be } \\
\text { accessed in an easy manner. } \\
\text { - IFR provides the illusion of comparability. } \\
\text { - Needs to be more sustained focus on the harmonization of } \\
\text { terminology and attributes included in internal reporting. }\end{array}$ & IFR \\
\hline $\begin{array}{l}\text { Ghani et } \\
\text { al. (2009) }\end{array}$ & $\begin{array}{l}\text { - All reporting formats in the digital environment are useful and easy } \\
\text { to use. }\end{array}$ & $\begin{array}{l}\text { Digital Financial } \\
\text { Reporting }\end{array}$ \\
\hline $\begin{array}{l}\text { Ghani and } \\
\text { Jusoff } \\
\text { (2009) }\end{array}$ & $\begin{array}{l}\text { - Experience was not an important determinant of users' preferred } \\
\text { presentation format. } \\
\text { - Public accountants preferred to use HTML as their digital } \\
\text { presentation format. } \\
\text { - More promotion should be undertaken to increase users' } \\
\text { awareness and understanding of presentation formats. }\end{array}$ & $\begin{array}{l}\text { Digital Financial } \\
\text { Reporting }\end{array}$ \\
\hline $\begin{array}{l}\text { Cordery } \\
\text { et al. } \\
\text { (2011) } \\
\text { (Section } \\
\text { 2.2.1) }\end{array}$ & $\begin{array}{l}\text { - Three reasons for the non-adoption of XBRL: } \\
\text { i) The lack of a government 'push' for XBRL technology } \\
\text { (mandatory adoption). } \\
\text { ii) Organisations do not believe that XBRL will reduce compliance } \\
\text { costs (no relative advantage). } \\
\text { iii) Complexity in developing the taxonomy for XBRL use } \\
\text { (complexity). }\end{array}$ & $\begin{array}{l}\text { XBRL: Adoption } \\
\text { Potential influencing } \\
\text { factors in the } \\
\text { technological and } \\
\text { environmental } \\
\text { contexts. }\end{array}$ \\
\hline $\begin{array}{l}\text { Ghani et } \\
\text { al. (2011) }\end{array}$ & $\begin{array}{l}\text { - Using digital formats to present financial reports did not fully } \\
\text { overcome the issue of functional fixation. } \\
\text { - Functional fixation may be caused by the level of perceived } \\
\text { significance based on where the information is reported in the } \\
\text { financial statements }\end{array}$ & $\begin{array}{l}\text { Digital Financial } \\
\text { Reporting }\end{array}$ \\
\hline
\end{tabular}

\subsection{Research Aim and Research Questions}

Based on the previous studies and issues related to XBRL, a specific research gap can be identified. None of these studies has conducted a longitudinal study of XBRL, or investigated the implications of the non-adoption of XBRL for stakeholders. Although, there are studies that investigate the non-adoption of XBRL like Cordery et al. (2011) in New Zealand and Steenkamp and Nel (2012) in South Africa, they do investigate different types of stakeholder involvement. There are also limited studies that examine XBRL adoption from the government perspective except for Mouse (2011). However, Mousa (2011) only considers a single perspective, that of government, and focuses solely on the UK context.

Thus, this thesis will address the above gaps by conducting research which aims: 
To investigate why business and professional organisations and the New Zealand government have decided not to adopt XBRL for use in business reporting; and the implications of that decision for XBRL stakeholders.

Further, the following research questions have been developed to explore the nonadoption of the XBRL decision in the New Zealand context:

a) What factors influenced the organisations' decisions not to adopt XBRL for use in business reporting?

b) What are the implications of the government decision regarding XBRL use in business reporting for XBRL stakeholders?

Thus, conducting a study that investigates why New Zealand, particularly XBRL stakeholders in private sector and governmental organisations, decided not to adopt XBRL for use in business reporting will address the gaps identified in the prior literature. This motivation is consistent with the suggestion by Perdana, Robb and Rohde (2015), which proposes XBRL adoption issues as one of four current XBRL research streams. Additionally, the identification of the implications of non-adoption of XBRL will provide understanding to stakeholders at large.

\subsection{Chapter Summary}

This chapter explored the history of XBRL at the international level and its development and relevant issues. This exercise enabled the identification of patterns and stages in introducing and adopting a new technology like XBRL. In addition, the researcher began to understand the key issues related to XBRL, and was able to determine the level of stakeholders' interest, and explore the ability of XBRL to support business reporting. More importantly, this chapter assisted in the identification of the gaps in the literature related to XBRL adoption. This was done by evaluating relevant XBRL studies that had different contexts, perspectives, and focuses. By using prior research related to adoption, including: the factors influencing adoption; the benefits and challenges of XBRL adoption; voluntary versus mandatory adoption; and XBRL awareness among adopter and non-adopter countries, as well as prior New Zealand-related studies; this thesis has established a link between the topics, identified the gaps, and developed the research questions.

In the next chapter, the research framework used will be introduced and explained. 


\section{Chapter 3: Research Framework}

\subsection{Introduction}

In Chapter 2, the history of and research into XBRL internationally and New Zealand was outlined. The related discussion on the issues and studies of XBRL identified that nonadoption XBRL studies from a public sector perspective are under-researched areas. As explained in Chapter 1, the motivations for this thesis relate to the different direction the New Zealand government took when compared to its trading partners regarding XBRL adoption, as well as the lack of research on XBRL that includes the governmental perspective. Thus, this thesis aims to investigate why business and professional organisations and the New Zealand government have decided not to adopt XBRL for use in business reporting; and the implications of that decision for XBRL stakeholders. In order to achieve the research aim, two research questions (as identified in Section 2.4) are to be investigated.

In this chapter, the research framework used to identify and examine the 'what' factors that influenced the New Zealand professional and government organisations' decision not to adopt XBRL for use in business reporting, is introduced, and developed. Based on the review of the pertinent literature, specific propositions are then developed. The chapter starts by explaining the TOE framework. This includes the relevance of the TOE framework to private sector and governmental XBRL adoption decisions, and definitions of the factors under the technological, organisational, and environmental contexts. This chapter also explains who the XBRL stakeholders are within the context of this thesis. Following that, this chapter presents the proposed research framework. The last section summarizes the chapter.

\subsection{Alternative Theories for Investigating Technology Adoption}

There are several alternative theories that can be employed when investigating technology adoption scenarios, including the Technology Acceptance Model (TAM), Diffusion of Innovation (DOI) and Institutional Theory (IT). The relationships central to the study and the operating setting in which these relationships exist, determines the choice of theory/theories. 
TAM is an information systems theory, initially proposed by Davis (1989). Its aim is to study how individual perceptions or attitudes affect an individual's intentions to use technology and their actual usage. The model is based on the theory of reasoned action and is the most widely used theory in IS literature. Further developments in this theory have been to include social influence and the normative beliefs of others, which is known as TAM2 (Venkatesh and Davis, 2000).

DOI, as introduced by Rogers (1995), consists of four stages: invention, diffusion, (or communication) through the social system, time, and consequences. Throughout the process of diffusion, Rogers has identified five adopter categories: innovators, early adopters, early majority, late majority, and laggards. DOI is considered the process by which an innovations is communicated through certain channels over a period of time among the members of a social system (Rogers, 1995).

Institutional theory focuses on the environmental factors experienced by an organisation such as cultural-cognitive, normative and regulative elements, which together with associated activities and resources, provide stability and meaning to social life (Scott, 2004). Institutional theory depends heavily on social contracts to help define the structure and processes of an organisation providing a bridge between societal views and organisation's actions.

However, none of the above theories is employed in this study for the following reasons. First, TAM is used to analyse an intention to adopt or accept a new technology at the individual level. However, this study is interested in the technology adoption at the organisational level. Second, DOI's focus is on the innovation process, which 'an organisation passes from first knowledge of an innovation, to forming an attitude towards the innovation, to a decision to adopt or reject, to implementation of the new idea' (Rogers, 1983, p.21). In contrast, this study focuses on the influencing factors of non-adoption of XBRL. Third, IT emphasises environmental factors and explains how these environmental factors affect social contracts. This study explores and identifies the potential factors that influenced the non-adoption decision by organisations, not the social constructs that were present in this decision. Further, the potential factors are not restricted to environmental factors but also include those in technological and organisational contexts. 


\subsection{TOE Framework: DePietro, Wiarda and Fleischer $(1990)^{13}$}

DePietro et al. (1990) developed the TOE framework to evaluate technology adoption and to describe the organisational components that affect firms' adoption decisions. This framework has some similarity to the DOI developed by Rogers (1983), in terms of the technological characteristics. The DOI assumes that the decision is made to adopt technology so as to improve the operational efficiency of organisations (Teo, Wei and Benbasat, 2003). However, the organisational decision to adopt new technology may also be influenced by other contexts, such as those relating to the organisation itself and its environment, as demonstrated in Figure 3.1. This figure describes the three contexts: technological, organisational, and environmental, those influence the process by which an organisation adopts and implements a new technology like XBRL. Each of these contexts interacts with each other in influencing technology adoption decisions (DePietro et al., 1990).

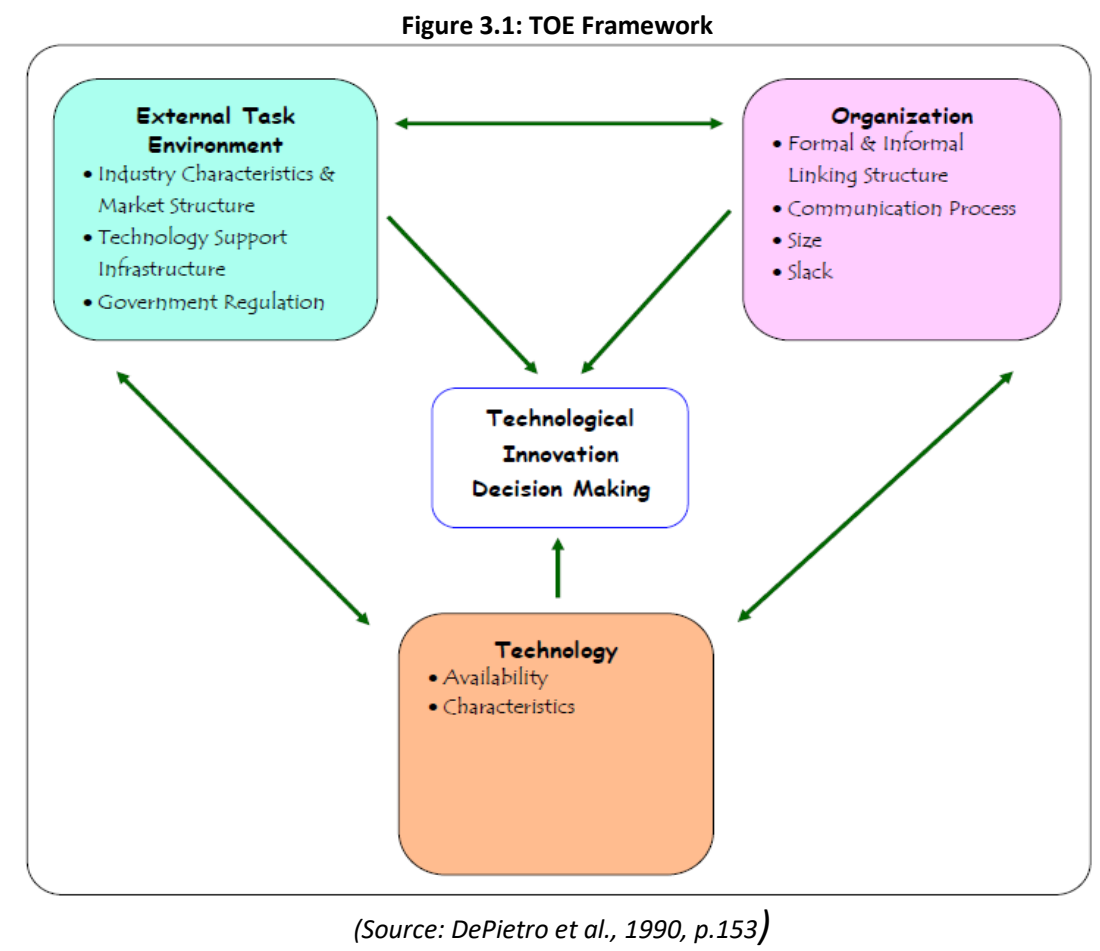

DePietro et al. (1990) describe the technological context as including the existing and new technologies available to the organisation, such as previous technology usage and the computers available in the organisation. Considering the technological context helps to determine the characteristics of the technology required and the ability of the organisation to shift from an existing technology to a new one such as XBRL. The organisational context

\footnotetext{
13 Most studies attribute the TOE Framework to Tornatzky and Fleischer (1990). However, this thesis will give the credit to the original authors, DePietro, Wiarda and Fleischer (1990).
} 
refers to specific measures about the organisation, such as the communication process, size, and organisational structure. This includes the available resources that support the acceptance of any new technology. Finally, the environmental context represents the setting in which an organisation conducts business and is influenced by the industry, competitors in the market, technology support infrastructure, and interactions with the government (DePietro et al., 1990). Further explanation about each TOE context will be presented in Sections 3.2.1, 3.2.2, and 3.2.3.

Based on the previous studies, the TOE framework provides a useful analytical tool that can be used to study the adoption and assimilation of different types of technology adoption in an organisation (Dedrick and West, 2004). The researchers listed in Tables 3.1, 3.2 and 3.3 below argue that the TOE framework has a solid theoretical basis, which can be used to provide empirical support for their studies. Further, the TOE framework has the potential to be applied in the IS domain, but specific factors need to be identified within the three contexts for each study. Nonetheless, the interaction and influence of the TOE factors leads to a decision regarding technology adoption (DePietro et al., 1990). Thus, this framework helps distinguish between intrinsic technological characteristics, organisational capabilities and motivations, and broader environmental dimensions that impact on adoption decisions (Dedrick and West, 2004).

\subsubsection{Application of TOE framework for Technology Adoption in IS studies}

The empirical studies summarized in Table 3.1, have used the TOE framework as a theoretical foundation for investigating organisational acceptance of new technology. Zhu, Kraemer and $\mathrm{Xu}$ (2003) used the TOE framework to investigate past influences on ebusiness adoption by European firms. They studied data on 3,552 firms to understand the influence of the technology, organisation, and environment contexts on adoption. Zhu, Kraemer, Xu and Dedrick (2004) also used the TOE framework as a base to develop their research model. This framework was used to evaluate and test the influence of TOE factors on business value. Zhu and Kraemer (2005) also applied the TOE framework to investigate past influences on e-business by analyzing 624 organisations across ten countries. These three studies were interested in understanding the antecedents to e-business adoption. The specific factors identified from these e-business studies are listed in Table 3.1. 
The TOE framework has also been used to validate the antecedent factors that influence EDI adoption (in Table 3.1) (lacovou, Benbasat, and Dexter, 1995; Kuan and Chau, 2001). Using a case study methodology, lacovou et al. (1995) investigated the EDI adoption influences of seven firms that were suppliers to the British Columbia provincial government. Another study of EDI adoption by Kuan and Chau (2001), used the TOE framework to investigate the different antecedents within the three contexts. In their study, they demonstrate similar support for the utility of the TOE framework in determining technology adoption and acceptance.

The TOE framework has also been used to investigate the factors that influence web service adoption. Ciganek, Haines and Haseman (2006) applied the TOE framework to organize their findings and to identify the antecedents and challenges of the adoption of web services including the perceived characteristics of technology. They also extended the TOE framework by distinguishing factors in the environment category based on horizontal and vertical factors. Slightly differently, Lippert and Govindarajulu (2006) used the TOE framework to explain the main organisational view that a firm adopts when implementing technology. They suggest that the TOE framework enables further investigations through the empirical testing of hypotheses to confirm both the direction and intensity of the relationships. Additionally, the TOE framework could be used to further validate, enhance, and support the understanding of factors affecting any technology adoption using propositions.

Table 3.1: Technology Adoption Based on TOE Framework by Business Organisations

\begin{tabular}{|c|c|c|c|c|}
\hline \multirow[t]{2}{*}{ Study } & \multirow{2}{*}{$\begin{array}{l}\text { Technology } \\
\text { adoption }\end{array}$} & \multicolumn{3}{|c|}{ Analysed variables } \\
\hline & & Technological & Organisational & Environmental \\
\hline $\begin{array}{l}\text { Zhu et al. } \\
\text { (2003) }\end{array}$ & e-business & $\begin{array}{l}\text { - IT infrastructure } \\
\text { - E-business know-how }\end{array}$ & $\begin{array}{l}\text { - Firm scope } \\
\text { - Firm size }\end{array}$ & $\begin{array}{l}\text { - Consumer readiness } \\
\text { - Competitive pressure } \\
\text { - Trading partner readiness }\end{array}$ \\
\hline $\begin{array}{l}\text { Zhu et al. } \\
\text { (2004) }\end{array}$ & $\begin{array}{l}\text { e-business } \\
\text { value }\end{array}$ & - Technology readiness & $\begin{array}{l}\text { - Firm size } \\
\text { - Global scope } \\
\text { - Financial resources }\end{array}$ & $\begin{array}{l}\text { - Competition intensity } \\
\text { - Regulatory environment }\end{array}$ \\
\hline $\begin{array}{l}\text { Zhu and } \\
\text { Kraemer } \\
(2005)\end{array}$ & $\begin{array}{l}\text { e-business } \\
\text { usage }\end{array}$ & $\begin{array}{r}\text { - Technology } \\
\text { competence }\end{array}$ & $\begin{array}{l}\text { - Size } \\
\text { - International scope } \\
\text { - Financial } \\
\text { commitment }\end{array}$ & $\begin{array}{l}\text { - Competitive pressure } \\
\text { - Regulatory support }\end{array}$ \\
\hline $\begin{array}{l}\text { Kuan and } \\
\text { Chau (2001) }\end{array}$ & EDI & $\begin{array}{l}\text { - } \text { Perceived direct } \\
\text { benefits } \\
\text { - Perceived indirect } \\
\text { benefits }\end{array}$ & $\begin{array}{l}\text { - Perceived financial } \\
\text { cost } \\
\text { - Perceived technical } \\
\text { competence }\end{array}$ & $\begin{array}{l}\text { - Perceived industry } \\
\text { pressure } \\
\text { - Perceived government } \\
\text { pressure }\end{array}$ \\
\hline $\begin{array}{l}\text { Ciganek et al. } \\
(2006)\end{array}$ & $\begin{array}{c}\text { Web } \\
\text { service }\end{array}$ & - Performance & $\begin{array}{l}\text { - Justification \& ROI } \\
\text { - Management support } \\
\text { - Expertise }\end{array}$ & $\begin{array}{l}\text { - Industry leadership } \\
\text { - Industry fragmentation } \\
\text { - Vertical standards }\end{array}$ \\
\hline
\end{tabular}




\begin{tabular}{|l|c|l|l|l|}
\hline & & & $\begin{array}{l}\text { - Partner demand } \\
\text { - Alternative technologies } \\
\text { - Vendor support } \\
\text { - Security }\end{array}$ \\
\hline $\begin{array}{l}\text { Lippert and } \\
\text { Govindarajulu } \\
(2006)\end{array}$ & Web & service & - Security concerns & - Reliability \\
& & - Deployability & $\begin{array}{l}\text { - Firm size } \\
\text { - Firm scope } \\
\text { - Perceived benefit } \\
\text { - Technology } \\
\text { knowledge }\end{array}$ & $\begin{array}{l}\text { - Regulatory influence } \\
\text { - Dependent partner } \\
\text { readiness } \\
\text { - Trust }\end{array}$ \\
\hline
\end{tabular}

Through the above discussion, it is apparent the TOE framework can be used to investigate and explain a business or professional organisation's decision to adopt new technology. Additionally, government agencies or public sector organisations can use this framework as a tool for understanding factors affecting the acceptance of new technology (Srivastava and Teo, 2007; Pudjianto, Zo, Ciganek, and Rho, 2011; Troshani, Jerram and Rao, 2011). Table 3.2 presents government-focused organisational studies that have applied the TOE framework as their theoretical framework.

\begin{tabular}{|c|c|c|c|c|}
\hline \multirow[t]{2}{*}{ Study } & \multirow{2}{*}{$\begin{array}{l}\text { Technology } \\
\text { adoption }\end{array}$} & \multicolumn{3}{|c|}{ Analysed variables } \\
\hline & & Technological & Organisational & Environmental \\
\hline $\begin{array}{l}\text { Srivastava and } \\
\text { Teo (2007) }\end{array}$ & e-government & $\begin{array}{l}\text { - ICT infrastructure } \\
\text { - Technology } \\
\text { development }\end{array}$ & - Human capital & $\begin{array}{l}\text { - Public institution } \\
\text { - Macro-economy }\end{array}$ \\
\hline $\begin{array}{l}\text { Srivastava and } \\
\text { Teo (2010) }\end{array}$ & $\begin{array}{c}\text { e-business, } \\
\text { e-government }\end{array}$ & - ICT infrastructure & - Human capital & $\begin{array}{l}\text { - Public institution } \\
\text { - Macro-economy }\end{array}$ \\
\hline $\begin{array}{l}\text { Pudjianto et al. } \\
\text { (2011) }\end{array}$ & e-government & $\begin{array}{ll}- & \text { ICT expertise } \\
\text { - } & \text { ICT infrastructure }\end{array}$ & $\begin{array}{l}\text { - Top management } \\
\text { support } \\
\text { - Organisation } \\
\text { compatibility } \\
\text { - Extent of coordination }\end{array}$ & $\begin{array}{l}\text { - Regulatory } \\
\text { environment } \\
\text { - Competitive } \\
\text { environment }\end{array}$ \\
\hline $\begin{array}{l}\text { Troshani et al. } \\
\text { (2011) }\end{array}$ & HRIS & $\begin{array}{l}\text { - Adoption cost } \\
\text { - Vendor support }\end{array}$ & $\begin{array}{l}\text { - Championship } \\
\text { - Human capability } \\
\text { - Management } \\
\text { commitment } \\
\end{array}$ & $\begin{array}{l}\text { - Successful } \\
\text { adoptions } \\
\text { - Regulatory } \\
\text { compliance } \\
\end{array}$ \\
\hline
\end{tabular}

Srivastava and Teo (2007) used the TOE framework as the guiding theoretical lens to analyze the factors that facilitate e-government development. They indicated that the TOE framework served as a useful theoretical framework for understanding the adoption and performance of technological innovations and IS in the organisational context. Further, Srivastava and Teo (2010) proved the TOE framework can assess both e-government and ebusiness technology adoption. They examined the facilitators of e-government and ebusiness development, the relationship between e-government and e-business, and their 
collective impact on national economic performance. Their results showed there were different factors related to the development of e-government and e-business, which can be used by national policy makers for designing relevant, effective policies. Among the significant findings were that information and communication technology (ICT) infrastructure (technological) appeared to be important for e-government and e-business; human capital (organisational) was an important facilitator for e-government, but not ebusiness, and the institutional and macroeconomic environment (environmental) appeared to be the key enabler for e-business but not for e-government. Their findings suggest significant and intertwined roles for e-government and e-business in enhancing national economic performance.

Pudjianto et al. (2011) agreed the TOE framework serves as a useful theoretical lens for understanding technology adoption. Their study employed the TOE framework to develop a comprehensive framework to examine factors for e-government assimilation in Indonesia, and identified and examined factors that influence the assimilation process. In contrast, in Troshani et al. (2011), the TOE framework was employed as an analytical tool to confirm that the adoption of Human Resources Information Systems (HRIS) in the public sector depends on environmental, organisational, and technological context factors being used in certain ways. First, adoption champions in public sector organisations need to demonstrate the benefits that HRIS can introduce to their organisations. This includes integration, accessibility, operational efficiency and the extent to which the benefits can justify adoption costs and inherent HRIS complexity. Second, organisational context factors like management commitment and human capability are crucial for both supporting adoption initiatives and ensuring that resources are made available for sustaining adoption efforts. Finally, environmental context factors such as regulatory compliance and successful adoptions can have a profound impact on HRIS adoption success.

In terms of the existing or important factors that are examined in the above studies, each researcher used different factors for the technological, organisational, and environmental contexts. Although, DePietro et al. (1990) suggests that the three contexts influence adoption, the researchers believe there is a unique set of factors or measures for their study's technology adoption context. For example, Zhu et al. (2003) argue that two important factors in the technological context, which influence e-business adoption are 'IT 
infrastructure' and 'e-business know-how'. The authors also argue that 'firm scope' and 'firm size' are the significant factors under the organisational context. Finally, the 'consumer 'readiness, competitive pressure and trading partner readiness' are pertinent factors that affects the e-business adoption. In short, different types of technologies have different factors that influence their adoption. Similarly, different national, cultural or industries potentially have differing factors. Therefore, other studies identify and use different factors within the technological, organisational, and environmental contexts. As XBRL is considered a recent technology in business reporting, then the TOE framework can be applied in XBRL related studies. In the next subsection, this thesis will present the XBRL studies that applied the TOE framework to study adoption.

\subsubsection{Relevance and Justification of the TOE Framework for XBRL and Adoption Decisions}

The TOE framework is useful for investigating the adoption of new technology such as XBRL at the organisational level (DePietro et al., 1990). As mentioned, the interactions of three context factors influence an organisation's decision to adopt a technology (DePietro et al., 1990). As discussed in the previous section, researchers have applied the TOE framework to explore a variety of technologies such as e-business, EDI, web services, e-government, and HRIS (as given in Table 3.1 and 3.2). In the Accounting Information Systems (AIS) literatures, Doolin and Troshani (2007), Troshani and Rao (2007), Mandilas et al. (2009), Azam and Taylor (2011b), Cordery et al. (2011) and Mousa (2011) have applied the TOE framework in their studies on XBRL adoption.

Doolin and Troshani (2007) used the TOE framework to organize their exploratory study of the factors that facilitate or inhibit XBRL adoption by Australian organisations as shown in Table 3.3. These findings have implications for policy as well as the adoption strategies of government and other decision makers such as regulators. For example, if regulatory bodies such as stock exchanges and other adopters were to adopt XBRL, many of their employees potentially become redundant. Regulatory bodies can also force adoption or mandate XBRL for their reporting needs, which may result in its widespread adoption. In this case, XBRL adoption might be labour intensive and complex as it requires specific procedures to be followed and amendments to be made to relevant legislation. 
Troshani and Rao (2007) also applied the TOE framework in order to identify the potential drivers and inhibitors of XBRL adoption in Australia. Their findings show there are more inhibitors than drivers in XBRL adoption, which is consistent with Doolin and Troshani (2007). In addition, they evaluated certain factors such as the role of government, XBRL education and training, the readiness of XBRL as an innovation and its supporting software solutions.

Mandilas et al. (2009) used the TOE framework as a useful analytical tool to distinguish the inherent characteristics of technology, for example as facilitators, inhibitors, and motivators, affecting adopting organisations' decisions. They believed that XBRL has all the characteristics of a technology, therefore they employed the TOE theoretical framework to investigate it. They identified six determinants and examined whether and to what extent they affect the XBRL adoption decision.

Different from the previous studies, Azam and Taylor (2011b) applied the TOE framework, but focused on the technology perspective as the main predictor of the intention to adopt SBR. They utilized TOE to analyse the organisational-level adoption of XBRL technology. The selection of factors was made according to the DOI theory, which are: relative advantage, compatibility, and complexity.

Similarly, Cordery et al. (2011) used the TOE framework to assist them in examining the factors that influence organisations' decisions to adopt XBRL. By using the framework, they identified the factors that influence organisations to adopt XBRL, which included the influence of trading partners, relative advantage (benefits versus costs), and compatibility. At the same time, they also determined the factors that contributed to the stagnation of the XBRL project in New Zealand. These were the lack of government 'push' for XBRL technology, misunderstandings about compliance costs and the complexity of developing the XBRL taxonomy. They argued that the TOE framework could be used to identify the key factors for non-adoption of XBRL in New Zealand.

A recent study of XBRL by Mousa (2011) employed the TOE framework to test the relationships between the TOE factors and the adoption process. Mousa's study aimed to develop a framework that outlined the different stages of the XBRL adoption process, the influential factors that could affect the process and the challenges that could restrict the progress of the process. In order to develop a comprehensive conceptual framework, 
Mousa (2011) integrates Rogers's adoption process (1983 and 1995) and the TOE framework of DePietro et al. (1990).

Based on the above evidence, the TOE framework is appropriate as the theoretical basis for investigating XBRL adoption in organisations. Table 3.3 summaries XBRL studies that applied the TOE framework as their theoretical framework and includes the TOE variables examined.

Table 3.3: XBRL Adoption Studies Based on TOE Framework

\begin{tabular}{|c|c|c|c|c|c|}
\hline \multirow[t]{2}{*}{ Study } & \multirow[t]{2}{*}{ Perspective } & \multirow[t]{2}{*}{ Context } & \multicolumn{3}{|c|}{ Analysed variables } \\
\hline & & & Technological & Organisational & Environmental \\
\hline $\begin{array}{l}\text { Doolin } \\
\text { and } \\
\text { Troshani } \\
\text { (2007) }\end{array}$ & $\begin{array}{l}\text { Stakeholder } \\
\text { organisation }\end{array}$ & Australia & $\begin{array}{l}\text { - Complexity } \\
\text { - Stability } \\
\text { - Relative } \\
\text { advantage } \\
\text { - Trialability/ } \\
\text { Observability }\end{array}$ & $\begin{array}{l}\text { - Innovation } \\
\text { champion } \\
\text { - Organisation } \\
\text { readiness }\end{array}$ & $\begin{array}{l}\text { - Market conditions } \\
\text { - Trading partner } \\
\text { influence } \\
\text { - Available } \\
\text { information } \\
\text { - Critical mass } \\
\text { - Available support }\end{array}$ \\
\hline $\begin{array}{l}\text { Troshani } \\
\text { and Rao } \\
\text { (2007) }\end{array}$ & $\begin{array}{l}\text { Stakeholder } \\
\text { organisation }\end{array}$ & Australia & $\begin{array}{l}\text { - Perceived relative } \\
\text { advantage and } \\
\text { benefits } \\
\text { - Perceived cost } \\
\text { - Compatibility } \\
\text { - Trialability } \\
\text { - Observability } \\
\text { - Complexity } \\
\text { - Associated costs }\end{array}$ & $\begin{array}{l}\text { - Human capital } \\
\text { and employee } \\
\text { education } \\
\text { - Management } \\
\text { attitudes } \\
\text { - Resources }\end{array}$ & $\begin{array}{l}\text { - External pressure } \\
\text { - Culture } \\
\text { - Legal issues } \\
\text { - Government } \\
\text { - Industry } \\
\text { associations } \\
\text { - Successful adoption }\end{array}$ \\
\hline $\begin{array}{l}\text { Mandilas } \\
\text { et al. } \\
\text { (2009) }\end{array}$ & $\begin{array}{c}\text { Business } \\
\text { organisation }\end{array}$ & $\begin{array}{l}\text { UK, The } \\
\text { Netherlands, } \\
\text { Germany, } \\
\text { France, } \\
\text { Sweden, } \\
\text { Spain and } \\
\text { Greece }\end{array}$ & $\begin{array}{l}\text { - Level of } \\
\text { technology } \\
\text { competence }\end{array}$ & $\begin{array}{l}\text { - Firm size } \\
\text { - Firm scope }\end{array}$ & $\begin{array}{l}\text { - Internet penetration } \\
\text { - Trading partner } \\
\text { influence } \\
\text { - National disclosure } \\
\text { environment }\end{array}$ \\
\hline $\begin{array}{l}\text { Azam and } \\
\text { Taylor } \\
\text { (2011b) }\end{array}$ & $\begin{array}{l}\text { Business } \\
\text { organisation }\end{array}$ & Australia & $\begin{array}{l}\text { - Relative } \\
\text { advantage } \\
\text { - Compatibility } \\
\text { - Complexity }\end{array}$ & - None & - None \\
\hline $\begin{array}{l}\text { Cordery } \\
\text { et al. } \\
(2011)\end{array}$ & $\begin{array}{l}\text { Stakeholder } \\
\text { organisation }\end{array}$ & $\begin{array}{c}\text { New } \\
\text { Zealand }\end{array}$ & $\begin{array}{l}\text { - Relative } \\
\text { advantage } \\
\text { - Compatibility } \\
\text { - Complexity } \\
\text { - Trialability }\end{array}$ & $\begin{array}{l}\text { - Top management } \\
\text { support } \\
\text { - Organisation } \\
\text { champion } \\
\text { - Organisational } \\
\text { size and } \\
\text { resources }\end{array}$ & $\begin{array}{l}\text { - Market competition } \\
\text { - Trading partner } \\
\text { influence } \\
\text { - Regulator/ } \\
\text { Government } \\
\text { influence } \\
\text { - Available } \\
\text { information and } \\
\text { support }\end{array}$ \\
\hline $\begin{array}{l}\text { Mousa } \\
(2011)\end{array}$ & $\begin{array}{c}\text { Government } \\
\text { agencies }\end{array}$ & UK & $\begin{array}{l}\text { - Complexity } \\
\text { - Compatibility } \\
\text { - Relative } \\
\text { advantage }\end{array}$ & $\begin{array}{l}\text { IT skills \& } \\
\text { expertise }\end{array}$ & $\begin{array}{l}\text { - Security } \\
\text { - Critical mass } \\
\text { - Government } \\
\text { support and } \\
\text { influence }\end{array}$ \\
\hline
\end{tabular}




\begin{tabular}{|l|l|l|l|l|}
\hline & & & & $\begin{array}{l}\text { - External support } \\
\text { information } \\
- \text { Making business } \\
\text { case for } \\
\text { stakeholders }\end{array}$ \\
\hline
\end{tabular}

Therefore, in XBRL studies, the TOE framework has been used to determine the influential or facilitating factors and the inhibitors or barriers to XBRL adoption. Most of these studies highlighted similar factors under each context, which could be drivers or inhibitors in XBRL adoption. Among the studies in Table 3.3, only Cordery et al. (2011) considers non-adoption of XBRL and only Mousa (2011) incorporates the government perspective. In brief, the above studies, as outlined in Sections 3.1.1 and 3.1.2, suggest the use of the TOE framework to examine XBRL adoption has consistent empirical support for the following reasons. Firstly, the TOE framework has broad applicability and possesses explanatory power across a number of technological, industrial, national/cultural contexts and a broad spectrum of general IS. Secondly, the TOE framework has been tested in European, American and Asian contexts, as well as in developed and developing countries. Finally, in each study, the three TOE contexts have been shown to influence the way a firm identifies the need for, searches for and adopts new technology.

Therefore, this thesis employs the TOE framework because:

i) The framework helps distinguish between intrinsic technological characteristics, organisational capabilities and motivations, and broader environmental dimensions that impact on adoption decisions (Dedrick and West, 2004).

ii) The framework can be used as a theoretical framework for understanding the adoption and performance of technological innovations and IS in an organisational context (Srivastava and Teo, 2007).

iii) The framework can be applied in both business and government organisations to evaluate new technology adoption, or in this research, technology non-adoption.

A part of that, the TOE framework in the following ways:

i) As a theoretical foundation to develop the research model. This framework will be used as a guideline while exploring potential factors that influence the non-adoption of XBRL in New Zealand. 
ii) To develop, validate and support the understanding of factors affecting non-adoption of XBRL using propositions.

iii) To investigate and analyse the factors that influence the XBRL adoption decision in private or public sector organisations.

iv) To identify and classify the potential drivers or inhibitors of XBRL adoption in the technological, organisational and environmental contexts.

v) To explain the organisational decision relating to the non-adoption of XBRL by providing evidence that supports the relevant factors from the technological, organisational and environmental contexts.

At the same time, the researcher is aware of the weaknesses or critiques of the TOE framework. These include that there has been limited enumerating of the different factors that are relevant in various adoption contexts. That means very little theoretical synthesis has occurred (Baker, 2012). Further researchers like Lai and Guynes (1997); Zhu, Kreamer and $\mathrm{Xu}$ (2006) and Lee and Shim (2007) argue that using a single theoretical lens limits the explanations surrounding the adoption and diffusion of all types of innovations.

\subsection{Proposition Development Based on TOE Framework}

The use of the TOE framework in this study will allow the identification of factors that potentially influence the non-adoption of XBRL by the New Zealand government. Thus, the proposed framework will be based on the insights gained from the prior literature. In the next subsection, this thesis will discuss the TOE framework, which comprises technological, organisational and environmental contexts. In each context, the factors will be explained and followed by propositions for study.

\subsubsection{Technological Context}

The technological context focuses on the manner in which technology characteristics can influence adoption (DePietro et al., 1990). This includes its relevance and ' $\mathrm{fit}^{\prime}$ to an organisation's internal landscape (Tornatzky and Fleischer, 1990). It is important for successful IT adoption that the organisation has access to its internal technology resources such as infrastructure, technical skills and user time (Kwon and Zmud, 1987). Later, Rogers (1995) found that perceived attributes of the technology are the major factors that determine the speed of technology adoption. That means, the decision to adopt a new 
technology depends on what functionality it can provide and how it will fit into the organisation.

Normally, the potential adopter assesses the characteristics of technology in terms of possible gains and barriers (Chau and Tam, 1997). Here, gains refer to the benefits that an organisation expects to receive upon adoption and includes increased efficiency, quality and reliability. In contrast, barriers refer to the problems organisations predict they will face during the adoption process, such as its complexity and its compatibility with organisational technology (competency and legacy systems) (Rogers, 2003). Additionally, adoption costs, including implementation, maintenance, training and transition costs can be perceived to be barriers to adopting technology (Troshani et al, 2011).

Within government organisations, Srivastava and Teo (2007) and Pudjianto et al. (2011) examined ICT infrastructure as one of the factors related to e-government adoption under the technological context. Mousa (2011) focused on complexity, compatibility, and relative advantage, as these factors were considered to be the major technological factor that influence the XBRL technology adoption in government organisations. Doolin and Troshani (2007), Troshani and Rao (2007) and Cordery et al. (2011) examined trialability as one of influential factors under the technological context. Since this thesis is focusing on private and public sector organisations, it will investigate the following technology factors: relative advantage, compatibility, complexity, and trialability. In addition, it will also examine security as one of the influential factors in the adoption decision. Security has been chosen for two reasons. First, Lippert and Govindarajulu (2006) highlight this factor as one of the possible influencing factors under the technological context. However, there have been few studies that examine security as an influencing factor in XBRL adoption (Alles and Debreceny, 2012). Second, Mousa (2011) highlight security as a potential influencing factor under the environmental context. However, Ebrahim and Irani (2005) identified and suggested that security and privacy should be investigated under the technological context. Therefore, this thesis chooses to examine security as a potential influencing factor under the technological context. 


\subsubsection{Relative Advantage}

Relative advantage refers to the perceived costs and benefits involved in the adoption of a technology (Rogers, 1995). This includes the adoption cost of XBRL. Boyd (2004a) suggests that XBRL can improve the efficiency of a government's reporting process by facilitating the processing of information received from companies filing their regulatory information. This is supported by Cordery et al. (2011) who argue that XBRL can reduce organisations' compliance costs as they only file once, which results in increased accuracy and efficiency of data exchange and analysis. Further, XBRL is flexible enough to accommodate existing accounting standards (Willis, 2007) and is able to facilitate further standardization of international reporting standards (Premuroso and Bhattacharya, 2008), which are identified as potential benefits of XBRL that could be realised by governments and other organisations. Moreover, XBRL allows government agencies and business organisations to establish their own websites that contain financial data and performance measures that can be used for business reporting (Abdolmohammadi, Harris and Smith, 2002). Organisations are more likely to adopt XBRL when the advantages are available and realizable; at the same time, these advantages must exceed the adoption costs. Thus, this thesis proposes that:

P1: If the adoption costs are perceived to exceed the benefits, then the organisation is less likely to adopt XBRL for use in business reporting.

\subsubsection{Compatibility}

Compatibility is defined as the degree to which XBRL adoption is perceived as being consistent with existing information systems, tasks, and the current needs and objectives of organisations, including government (Moore and Benbasat, 1991). Tornatzky and Klein (1982) give a more detailed definition by suggesting two types of compatibility; normative and operational compatibility. Normative compatibility refers to compatibility that deals with what humans feel or think about an innovation. Meanwhile, operational compatibility reflects the extent to which a technology 'fits' with an adopting organisation's current work process.

Later, DePietro et al. (1990) stated the ' $\mathrm{fit}^{\prime}$ ' between the available technology and the organisation's current technology is essential in technology adoption decisions. Research by Dawes (1996), Dawes, Pardo, Connelly, Green and Mclnerney (1997) and Landsbergen and 
Wolken (2001) show that incompatibility of the hardware, software and telecommunication networks negatively affect organisations' technology adoption decisions. This is supported by Cordery et al. (2011). They found that the user organisations were concerned about compatibility issues surrounding XBRL's integration with their existing systems. This is especially a concern when XBRL might be incompatible with an organisation's current process and legacy systems including accounting information systems. Further, Mousa (2011) discovered that XBRL's interoperability feature was an indication of its compatibility with Her Majesty Revenue and Custom's (HRMC) existing electronic filing system. This resulted in HRMC deciding to adopt XBRL. Thus, this thesis proposes that:

P2: If the XBRL technology is perceived to be inconsistent with an organisations existing information systems, tasks, the current needs and objectives, then the organisation is less likely to adopt XBRL for use in business reporting.

\subsubsection{Complexity}

Complexity refers to the degree to which technology is perceived as relatively difficult to understand and use (Rogers, 1995). There are two levels of complexity that have been identified by Zaltman, Duncan and Holbek (1973). In relation to XBRL; first, XBRL technology may contain complex ideas and second, the implementation of XBRL may be complex. In addition, technology complexity includes the current knowledge and skills of the employees in the organisation. For example, the continuous proliferation of XBRL taxonomy versions and the availability of XBRL compatible software are among the barriers that could affect the XBRL adoption decision (Vun Kannon and Hannon, 2004; Dunne et al., 2009; Cordery et al., 2011). In New Zealand, Davidson et al. (2006) found that the availability of XBRL software was limited and lack of knowledge and skills hindered the adoption of XBRL by organisations' accountants. In the UK, Mousa (2011) indicated that developing an appropriate XBRL taxonomy was the most difficult technical task experienced by the XBRL project team. Moreover, the difficulty of creating XBRL compatible software has been perceived as a costly reporting technology, which results in an additional administrative burden on users without additional benefits to business (Mousa, 2011). This is consistent with Cordery et al. (2011) where the different versions of the XBRL taxonomy and the contextual mix of regulators and government became hurdles to XBRL adoption. Although 
complexity might not be as important as compatibility and relative advantage factors, it has the potential to be a barrier to XBRL adoption. Therefore, this thesis proposes that:

P3: If the XBRL technology is perceived to be relatively difficult to understand and use, then the organisation is less likely to adopt XBRL for use in business reporting.

\subsubsection{Security}

Security is defined as both the perception or judgement and fear of safeguarding mechanisms for the movement and storage of data and information through systems (Lippert and Govindarajulu, 2006). This also includes the concerns with the security risk associated with XBRL use. Nowadays, most organisations including government agencies are dependent upon databases for day-to-day operations (Lippert and Govindarajulu, 2006). This means that government and business organisations' IS databases hold a large amount of crucial data about the individuals they deal with such as government agencies, other business organisations, accounting firms and other stakeholders. Compromising the security could be costly to private and public sector organisations in terms of dissatisfied stakeholders resulting in a loss of goodwill and a likely reduction in trust and possible litigation. Some researchers argue that public users of online government services are sometimes sceptical of using these services because of the potential sharing and disclosure of their information (Milner, 2002; Joshi, Ghafor, Aref and Spafford, 2001). In the UK, for example, data protection and privacy laws could hamper the progress of any online government initiatives as many regulatory authorities struggle to comply with these laws (Mousa, 2011). In New Zealand, security is shown in the governmental e-GIF project as spanning throughout the layers to reflect the fact that security must be designed into a system. This means that the security factor has the potential to be barrier to XBRL adoption. Therefore, this thesis proposes that:

P4: If there is perceived to be a lack of safeguarding mechanisms for the movement and storage of data and information through $X B R L$, then the organisation is less likely to adopt XBRL for use in business reporting. 


\subsubsection{Trialability}

Trialability refers to the degree to which organisations can test the technology before deciding whether to adopt it (Rogers, 2003). According to Rogers (1995) the greater the opportunity to try a new technology, the easier it is for organisations to evaluate it and ultimately adopt it. In certain conditions, trialability can be a challenge since the technology may require organisations to make substantial investments of time and effort before they can begin to experiment. Regardless, it is essential for organisations to be given the opportunity to try the technology, whether it is a software package like an accounting program or hardware like interactive tools and equipment. The ability to test and experience the benefits of XBRL is an important factor in adoption decisions (Doolin and Troshani, 2007; Troshani and Rao, 2007; Cordery et al., 2011). Thus, this thesis proposes that:

P5: If there is perceived to be limited opportunity to test the XBRL technology, then the organisation is less likely to adopt XBRL for use in business reporting.

\subsubsection{Organisational Context}

The organisational context refers to the internal characteristics of the organisation that might impact on the decision to adopt XBRL technology. Thong (1999) highlights the need to consider organisational characteristics in technology adoption or acceptance research. Among the factors, which are important to assess are organisation size and scope, (Tornatzky and Fleischer, 1990; Rogers, 1995). Other organisation characteristics studied in the IS literature include IT infrastructure, financial commitment, IT skills, organisational readiness and management commitment (Zhu and Kraemer, 2005; Doolin and Troshani, 2007; Troshani et al.; 2011; Mousa, 2011).

The nature of the organisational characteristics can facilitate or inhibit technology adoption. There are connections between the technological and organisational context factors. For example, if the relative advantage of a technological factor cannot be realised due to lack of organisational resources such as IT skills, the adoption decision will be inhibited, regardless of how significant the benefits are. In other words, when sufficient organisational resources are available within the organisation, the decision to adopt a particular technology is facilitated (Tornatzky and Fleischer, 1990). In addition, the technology adoption is more easily facilitated if an organisation has support from top management including the 
provision of expertise and financial support as well as there being an organisational champion (Zhu and Kraemer, 2005; Pudjianto et al., 2011; Troshani et al., 2011; Mousa, 2011).

This thesis focuses on human capability, championship and financial support because these factors represent the ability and readiness of organisations to adopt new technology. Moreover, these factors are also highlighted as critical by Doolin and Troshani (2007), Cordery et al. (2011) and Troshani et al. (2011).

\subsubsection{Human Capability}

Human capability refers to the degree to which the organisation perceives that staff possess a relatively high level of knowledge and expertise related to technology (Rogers, 1995). One of the most important factors in technology adoption is staff competence in IT (Perry and Danziger, 1980). This is supported by DePietro et al. (1990) who state that to adopt new technology such as XBRL, an organisation needs to equip its IT staff with relevant skills and knowledge. Later, Srivastava and Teo (2010) suggest that human capability is an important requirement for e-government but not for e-business development.

As inter-organisational information systems become more complex and composed of databases, hardware and telecommunication technologies, the need for knowledgeable and expert staff increases (Premkumar and Ramamurthy, 1995). The lack of sufficient human capability is thus an important barrier and affects technology adoption. In order to have sufficient human capability, an organisation has two options. First, organisations can employ well-trained and experienced employees, which will result in a lower cost in terms of training and equipment when adopting new technology. Second, the organisation can provide relevant training to its existing staff, which increases training costs as well as equipment expenses. The second suggestion is consistent with Troshani and Rao (2007); if the strategy of mandating XBRL is taken, then the organisation needs to provide high-level education and training about XBRL to staff. On the other hand, if staff are not well-trained in particular technologies such as XBRL, it can result in redundancies, resistance to change, and the inability to utilize information technology to its fullest capacity (Norris, 1999; Troshani and Rao, 2007). Thus, this thesis proposes that: 
P6: If it is perceived that staff has a low level of knowledge and expertise in XBRL, then the organisation is less likely to adopt XBRL for use in business reporting.

\subsubsection{Championship}

Championship is defined as a single person at decision making levels within an organisation, who is committed to introducing a new technology into its processes, requirements and laws (Norris, 1999). The appointment of the person that fulfils the above criteria is often made based on the amount of personal contact or communication with other employees they have to enable the exchanging of information about a particular technology (DePietro et al., 1990). Championship is important because champions provide a communication function, and provide energy and labour for adoption and implementation stages (DePietro et al., 1990; Norris, 1999). Krishna and Walsham (2005) emphasise that the presence of an internal individual is a very important factor in the successful adoption of technology. This is because of the complexity and scale of change that will take place during the adoption of XBRL (Burn and Robins, 2003). However, research by Cordery et al. (2011) indicates that the existence of an organisational champion appears to influence XBRL adoption only when top management supports the decision.

There are five key elements of effective championship (Krishna and Walsham, 2005). First, the champion must be knowledgeable and enthusiastic about the new technology. Second, the person should be prepared to make a long-term commitment to the change process that is needed to introduce the new technology successfully. Third, the champion must be willing to take a detailed interest in the actual adoption process and encourage subordinates to do the same. Fourth, the champion must respond and be willing to learn from mistakes. Finally, the person needs to have ability to utilize power and political skills; for instance, in recruiting and maintaining suitable staff. Additionally, Irani (2002) and Dembla, Palvia, Brooks and Krishnan (2003) note that the champion's support should result in sufficient funding being made to facilitate the adoption of new technology. From the public sector organisations view, champions need to demonstrate the benefits of a particular technology to stakeholder organisations including its ease of integration, accessibility and operational efficiency and the extent to which its benefits exceed adoption costs (Troshani et al., 2011). 
Sometimes staff perceive that new technology will be a potential threat to their power and sustainability because there is possibility that the use of new technology might reduce their authority in the organisation (Ebrahim and Irani, 2005). Thus, they become resistant to the idea of adopting new technology like XBRL. This thesis proposes that:

P7: If there is perceived to be an absence of an XBRL champion at the decision making level in the project, then the organisation is less likely to adopt XBRL for use in business reporting.

\subsubsection{Financial Support}

Financial support refers to the availability of funds to make a project possible, particularly investment to enhance or build the organisational IT-related to new technology (Rogers, 1995). Funding is required to ensure the successful adoption of new technology (Troshani and Doolin, 2005; Troshani et al., 2011). Financial support is thus considered a key driver of technology adoption in organisations as it represents a source of support and funding which are critical for adopting new technology and adapting them to suit organisational requirements (Troshani et al., 2011). Limited resources influence many potential adopters' decision to consider XBRL applications in their organisations (Troshani and Rao, 2007; Cordery et al., 2011). Therefore, this thesis proposes that:

P8: If it is perceived that funds for investing or building the organisational IT related to XBRL are unavailable, then the organisation is less likely to adopt XBRL for use in business reporting.

\subsubsection{Environmental Context}

The environmental context refers to the external characteristics of an organisation that might influence the organisation decision to adopt XBRL technology. It also represents the arena where the organisation operates. Research has shown the influence of the external environment cannot be ignored in technology adoption ( $O^{\prime}$ Callaghan, Kaufman and Konsynski, 1992). This means, that environmental context factors such as competitive pressure, trading partner influence, critical mass, regulator support, influence the decision making process regarding technology adoption (Zhu and Kraemer, 2005; Doolin and Troshani, 2007). Business organisations, accounting firms, professional bodies and other stakeholders are considered key players in the environmental context. DePietro et al. 
(1990), Doolin and Troshani (2007), Cordery et al. (2011) and Mousa (2011) argue that these key players influence technology adoption.

These external characteristics can present opportunities to either encourage or inhibit technology adoption (Troshani et al., 2011). Opportunity is when there is support and critical mass in the organisation environment during the technology adoption decisionmaking process (Doolin and Troshani, 2007). In contrast, factors like competitive pressures or impositions from business trading partners might inhibit technology adoption (Chau, 2001).

Among other factors, Doolin and Troshani (2007) examined stakeholder involvement, critical mass and trading partner influence and Troshani and Rao (2007) investigated successful adoption stories. Mandilas et al. (2009) examined trading partner influence, while Mousa (2011) examined stakeholder involvement and critical mass. Cordery et al. (2011) examined stakeholder involvement and trading partner influence in the nonadoption of XBRL. Based on these previous XBRL TOE studies, this thesis will consider the following environmental context factors: successful adoption stories, stakeholder involvement, critical mass and trading partner influence.

\subsubsection{Successful Adoption Stories}

A successful adoption story is defined as the perception of a favourable experience in adopting or implementing technology, which fulfils two criteria, sustainability and the perspective of different stakeholders (Krishna and Walsham, 2005). Here, the sustainability criterion refers to projects that have been in continuous operation and have expanded in coverage and scope. The second criterion is concerned with the evaluation of the adopted technology from different stakeholders' perspectives. An environment with a successful adoption story can be conducive to technology adoption because every successful adoption leads more users to strongly consider it (Kearns and Lederer, 2004). Based on the Australian experience with XBRL, Doolin and Troshani (2007) indicate that the lack of local XBRL success stories has been perceived to inhibit adoption. Troshani et al. (2011) also agree that a successful adoption story of any technology can have a positive impact on adoption because it allows the benefits of a particular technology to be observed in practice by its stakeholders at large. Therefore, this study proposes that: 
P9: If it is perceived that there are limited successful adoption stories of XBRL technology by stakeholders, then the organisation is less likely to adopt XBRL for use in business reporting.

\subsubsection{Stakeholder Involvement}

Stakeholder involvement refers to the degree of effectiveness of stakeholder participation, which includes encouragement, support, providing information, funding and political backing by stakeholders in the adoption decision process. DePietro et al. (1990) highlight that in order to adopt new technology, organisations require different types of support and cooperation especially from stakeholders. Heeks (1999), Norris (1999) and Krishna and Walsham (2005) argue that stakeholder involvement could be in the form of software testing, product demonstrations, IT-tailored training and consultancy to enhance the existing organisational skills of the adopting organisation's staff members. In the context of XBRL adoption, Doolin and Troshani (2007) believe that regulatory entities play their role in $X B R L$ adoption by mandating XBRL through legislative requirements. At the same time, if they do mandate it, regulatory entities need to make sure that information regarding XBRL is available (Cordery et al., 2011), and that they provide sufficient funding, create and arrange for XBRL education and training, and give encouragement to all stakeholders. This suggestion is also supported by Abdullah, Khadaroo and Shaikh (2009) where they conclude that mandating XBRL by regulators and obtaining support from stakeholders such as accounting firms, business organisations, external users and other interest groups, is essential for the future success of XBRL. This thesis proposes that:

P10: If there is perceived to be a lack of effectiveness in stakeholder participation, then the organisation is less likely to adopt XBRL for use in business reporting.

\subsubsection{Critical Mass}

The term of critical mass is borrowed from nuclear physics, and refers to the amount of a substance needed to start a chain reaction ${ }^{14}$. The Macmillan Dictionary defined it as the smallest number of people or things needed to make something happen ${ }^{15}$. In this thesis, critical mass refers to a sufficient number of organisations adopting XBRL technology so that it reaches a point where it becomes self-sustaining and creates further growth. This

\footnotetext{
${ }^{14} \mathrm{https}: / /$ en.wikipedia.org/wiki/Critical mass (sociodynamics)

${ }^{15} \mathrm{http}: / /$ www.macmillandictionary.com/dictionary/british/critical-mass
} 
definition is consistent with Rogers (2003). In addition, Locke and Lowe (2007) describe critical mass as widespread adoption, which, when it spreads, is termed diffusion. Diffusion may occur spontaneously (Hamilton, 2003) or it may require years of effort and persistence to achieve (Hamm, 2005). The diffusion of XBRL among its stakeholders is important because adoption by one side or party is unlikely to stimulate enough adoptions to reach critical mass (Locke and Lowe, 2007). Experience from Australia indicates that limited adoption of XBRL was due to the absence of critical mass of XBRL applications, software tools and users (Doolin and Troshani, 2007). Thus, this thesis proposes:

P11: If there is perceived to be an insufficient number of organisations adopting $X B R L$, then the organisation is less likely to adopt XBRL for use in business reporting.

\subsubsection{Trading Partner Influence}

This thesis defines trading partner influence as two or more participants that have business or formal relationships on regular basis ${ }^{16}$. The participants ${ }^{17}$ could be a person, company, country, or region that sells/buys goods or undertakes project collaborations with one another. Zhu et al. (2003) examined trading partner influence in adopting e-business. Their findings suggest a strong relationship between a lack of trading partner influence and ebusiness adoption. In XBRL studies, Doolin and Troshani (2007) and Cordery et al. (2011) found trading partner influence is an important factor influencing XBRL adoption. In contrast, Mandilas et al. (2009) found that trading partners' influence less significantly than affects a company's decision to adopt XBRL, but still affects the adoption decision. Thus, this thesis proposes that:

P12: If there is perceived to be a lack of trading partner influence, then the organisation is less likely to adopt XBRL for use in business reporting.

Table 3.4: List of Propositions Under the TOE Framework

\begin{tabular}{|c|l|}
\hline $\begin{array}{c}\text { Proposition } \\
\text { number }\end{array}$ & \multicolumn{1}{c|}{ Specific proposition } \\
\hline P1 & $\begin{array}{l}\text { If the adoption costs are perceived to exceed the benefits, then the organisation is less likely } \\
\text { to adopt XBRL for use in business reporting. }\end{array}$ \\
\hline P2 & $\begin{array}{l}\text { If the XBRL technology is perceived to be inconsistent with an organisations existing } \\
\text { information systems, tasks, the current needs and objectives, then the organisation is less }\end{array}$ \\
\hline
\end{tabular}

\footnotetext{
${ }^{16}$ http://thelawdictionary.org/trading-partner/; http://www.macmillandictionary.com/dictionary/british/trading-partner

17 http://www.collinsdictionary.com/dictionary/english/trading-partner
} 


\begin{tabular}{|c|c|}
\hline & likely to adopt XBRL for use in business reporting. \\
\hline P3 & $\begin{array}{l}\text { If the XBRL technology is perceived to be relatively difficult to understand and use, then the } \\
\text { organisation is less likely to adopt XBRL for use in business reporting. }\end{array}$ \\
\hline P4 & $\begin{array}{l}\text { If there is perceived to be a lack of safeguarding mechanisms for the movement and storage } \\
\text { of data and information through XBRL, then the organisation is less likely to adopt XBRL for } \\
\text { use in business reporting. }\end{array}$ \\
\hline P5 & $\begin{array}{l}\text { If there is perceived to be limited opportunity to test the XBRL technology, then the } \\
\text { organisation is less likely to adopt XBRL for use in business reporting }\end{array}$ \\
\hline P6 & $\begin{array}{l}\text { If it is perceived that staff has a low level of knowledge and expertise in } X B R L \text {, then the } \\
\text { organisation is less likely to adopt } X B R L \text { for use in business reporting. }\end{array}$ \\
\hline P7 & $\begin{array}{l}\text { If there is perceived to be an absence of an XBRL champion at the decision making level in } \\
\text { the project, then the organisation is less likely to adopt } X B R L \text { for use in business reporting. }\end{array}$ \\
\hline P8 & $\begin{array}{l}\text { If it is perceived that funds for investing or building the organisational IT related to XBRL are } \\
\text { unavailable, then the organisation is less likely to adopt XBRL for use in business reporting. }\end{array}$ \\
\hline P9 & $\begin{array}{l}\text { If it is perceived that there are limited successful adoption stories of XBRL technology by } \\
\text { stakeholders, then the organisation is less likely to adopt XBRL for use in business reporting. }\end{array}$ \\
\hline P10 & $\begin{array}{l}\text { If there is perceived to be a lack of effectiveness in stakeholder participation, then the } \\
\text { organisation is less likely to adopt XBRL for use in business reporting. }\end{array}$ \\
\hline P11 & $\begin{array}{l}\text { If there is perceived to be an insufficient number of organisations adopting } X B R L, \text { then the } \\
\text { organisation is less likely to adopt } X B R L \text { for use in business reporting. }\end{array}$ \\
\hline P12 & $\begin{array}{l}\text { If there is perceived to be a lack of trading partner influence, then the organisation is less } \\
\text { likely to adopt XBRL for use in business reporting. }\end{array}$ \\
\hline
\end{tabular}

This thesis uses the TOE framework to develop, validate, and support the examination of the factors that potentially influence the non-adoption of XBRL through the propositions developed (as listed in Table 3.4). The TOE framework has been adapted to investigate why business and professional organisations and the New Zealand government have decided not to adopt XBRL for use in business reporting. The TOE context factors are identified based on prior TOE research on XBRL adoption as shown in Table 3.3. However, if additional technological, organisational, and environmental factors become apparent during the data coding and analysis phase, the researcher will investigate and analyse those factors. Figure 3.2 depicts the predicted TOE context factors in the New Zealand case study as identified and discussed above. 
Figure 3.2: TOE Framework in XBRL: the New Zealand Case

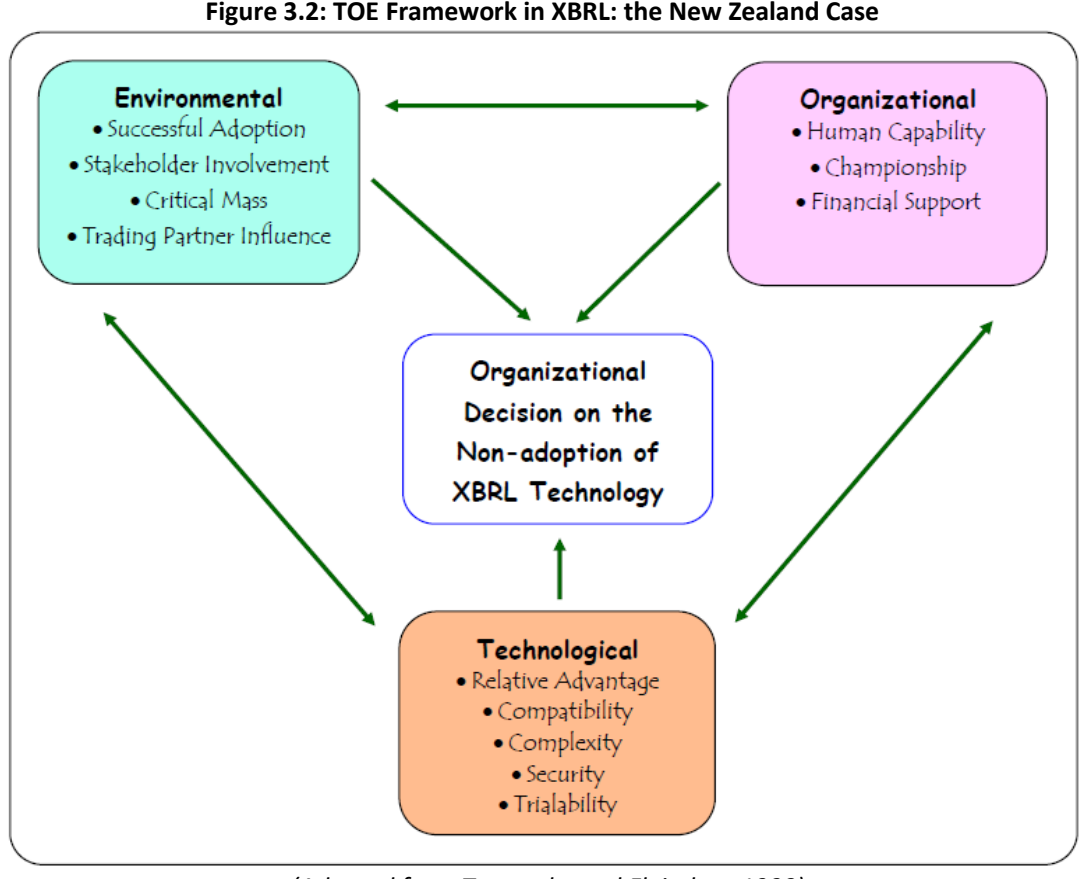

(Adapted from Tornatzky and Fleischer, 1990)

\subsection{XBRL Stakeholders}

In order to understand and establish the link between the XBRL stakeholders and the government's decision, this section develops a definition of stakeholders in the context of this study. The need to identify the stakeholder groups is important because different stakeholders will react and be impacted differently by the adoption decision. Moreover, each of the stakeholders potentially influences the business, professional and government organisational decisions regarding XBRL differently.

\subsubsection{Identification of XBRL Stakeholders}

Freeman (1984, p.25) defines a stakeholder as "any individual or group of individuals who can or is affected" in this case, by XBRL. Clarkson (1995) divided stakeholders into two categories, primary and secondary. Primary stakeholders such as shareholders, employees, customers, suppliers, lenders, government and communities; are given priority, as their support is considered to be vital for the organisation. Consumer advocates as well as environmentalists are not attached to the organisation on a transactional basis, as they are not considered to be critical for the organisation to survive; therefore they are considered secondary stakeholders.

In a more recent study, Dunne et al. (2009) classify potential XBRL stakeholders into four groups, which are based on their particular role in the reporting hierarchy. The groups are 
users (fund managers and investment analysts); business or preparer organisations (financial accountants working in private entities, IT staff, company secretaries, internal auditors and data processing mangers); external auditors; and tax practitioners.

This study will adapt Dunne et al. (2009) to classify the stakeholder groups as they are specifically related to XBRL. However, as this study incorporates public sector organisations, instead of having four groups of stakeholders, this thesis will have five groups: government, accounting firms, professional bodies, business organisations, and other stakeholders.

\subsubsection{Roles and Involvement of XBRL Stakeholders}

This study will focus on the primary stakeholders that are potentially involved in the XBRL decision making process in New Zealand. The primary stakeholders have been classified into five groups based on their roles in business reporting and their potential influence on XBRL adoption.

The first group is the government, which can be divided into initiators, decision makers, and government agency officers. The current organisational structure of government in New Zealand is given in Appendix A. As in Chapter 1, XBRL initiatives have involved two different governments, namely the Labour and National Governments. The Labour Party was in government and involved in XBRL initiatives from November 2002 up until 2008. Then, the National Party was elected as the Government from November 2008 until the present. Initiators ${ }^{18}$ refer to the person who starts and encourages the XBRL initiative. In this study, the initiators are the politicians or ministers from the Labour Party that provided support or were interested in XBRL. Meanwhile, decision makers ${ }^{19}$ refers to somebody who is authorized to make important decisions for the country, in this study, decisions related to government XBRL initiatives. In the context of this study, the decision makers are the politicians or ministers from the National Party. The Labour Government initiated and was involved in the e-GIF project and SBR programme. The National Government continued the SBR initiative on, where they acted as decision makers during 2009 and 2010. The government officers ${ }^{20}$ are attached to government agencies ${ }^{21}$ and have knowledge about specific areas. Relevant government officers are interviewed as they have experience with

\footnotetext{
${ }^{18} \mathrm{http}: / / \mathrm{www}$. thefreedictionary.com/Initiator

${ }^{19}$ http://www.qfinance.com/dictionary/decision-maker

${ }^{20}$ http://www.en.wikipedia.org/wiki/Advisor

${ }^{21}$ As most of the government officers are attached to government agencies, therefore this thesis will be use both words interchangeably.
} 
the professional and government organisational XBRL initiatives in New Zealand. For example, in Project First Step, the Office of the Auditor-General (OAG) and the IRD were actively involved; whereas, the Treasury was an observer organisation. During the e-GIF project, the IRD, the MED and the State Services Commission (SSC) were active stakeholders but the OAG was an observer stakeholder. Later on, in the SBR programme, the IRD, the MED, and the SSC were still active stakeholders, with the XRB as a supportive stakeholder and the Treasury as an observer stakeholder.

The second group is the accounting firms ${ }^{22}$. This group refers to a firm that specializes in accounting services including auditing and taxation for its clients. In this study, the accounting firms include external auditors and tax practitioners. Most of the big accounting firms in New Zealand have been involved in XBRL initiatives since 2000. This professional group supported government agencies, business organisations and other stakeholders regarding XBRL matters. For example, experts from accounting firms built the XBRL specification and taxonomy to be used by users from government agencies and preparers from business organisations. In addition, some of the external auditors and tax practitioners acted as advisors to government-decision makers when needed. Early on, the accounting firms were involved as commentators of XBRL events that happened either in New Zealand or overseas. Through this contribution, stakeholders were able to get more information about XBRL, and government agencies were exposed to XBRL. The accounting firms, thus, assisted the government-decision makers, business organisations and other stakeholders in terms of technical skills and specific knowledge of XBRL. This group was actively involved in the LEAP+ project and Project First Step, as both of these projects were under professional auspices and were professionally controlled. During the governmental e-GIF project and SBR programme, this group was involved but as an observer stakeholder.

Third, the professional bodies refer to a group of people in a learned occupation who are entrusted with maintaining control or oversight of the legitimate practice of the occupation (Harvey, 2004). In this study, the New Zealand-based professional bodies for the accounting profession have been responsible for developing and monitoring accounting educational programs, updating relevant skills and finally, conducting professional examinations to qualify a person. One accounting professional body (NZICA) was firstly involved in Project

\footnotetext{
${ }^{22}$ http://www.thefreedictionary.com/accounting+firm
} 
First Step as an active stakeholder. Throughout XBRL initiatives, the Institute's involvement has varied between being an active and supportive stakeholder, which means this group has potentially played a significant role in influencing the XBRL adoption decisions of other organisations.

Fourth, business organisations ${ }^{23}$ refer to a commercial entity, which is involved in producing goods or providing the services to public. In these organisations, staffs like financial accountants, internal auditors and IT professionals, are involved in preparing and communicating financial information to users. This group was involved actively in Project First Step as they tried the XBRL application developed in their organisations. However, their involvement in e-GIF changed to become a supportive stakeholder. Then they become an observer stakeholder in the SBR programme.

Finally, the other stakeholder groups are divided into academic, software developers/vendors, and XBRL International. An academic ${ }^{24}$ is a person who is member of a tertiary institution including scholars and educators that encourage interest and development in particular subjects like XBRL. Software developers/vendors are the provider of business accounting software to the business organisations. Meanwhile, XBRL International is an international non-profit consortium, which promotes and supports XBRL development around the world. This group's involvement varied in XBRL initiatives. Some of them were an active stakeholder like academics, in the LEAP+ project and Project First Step. However, academics became an observer stakeholder in the other two XBRL initiatives.

There are five groups of XBRL stakeholders in this study as presented in Figure 3.3. Since each of these groups comes from different background and experience, they possibly play different but significant roles in the XBRL initiatives (Krishna and Walsham, 2005). As in Figure 3.3, the first group is government agencies such as the IRD, Statistics New Zealand, the SSC and the MED. This group's role would include initiating the implementation of XBRL, introducing any required regulations, as well as enforcing the new regulations. The second group is the accounting firms like Ernst \& Young, KPMG, and PricewaterhouseCoopers (PwC). This group also includes external auditors and tax practitioners. The accounting firm assists the first group in developing and implementing the XBRL technology (Doolin and

\footnotetext{
${ }^{23} \mathrm{http}: / /$ www.thefreedictionary.com/business+organisation

${ }^{24}$ http://www.macmillandictionary.com/us/dictionary/american/academician
} 
Troshani, 2004). The third group is the professional bodies. In this study, there is only one professional body, NZICA. The fourth group is business organisations. This group needs support from accounting firms, in-terms of preparing financial reports and fulfilling the business reporting requirements. Finally, the other stakeholder group played their roles in supporting the government agencies, accounting firms and business organisations in XBRL related matters. The academics can contribute by acting as commentators, educators of future accountants and researchers. Software developers/vendors contribute through incorporating and promoting XBRL as an embedded and suitable business accounting software to business organisations and government agencies.

The key event in this thesis as outlined in Chapter 1 was the government's decision in 2010 not to support the SBR programme, which resulted in XBRL not being adopted. Although, the government had the final say as to whether to adopt or not to adopt SBR it was dependent on stakeholders' information and demands (refer to Figure 3.3). The main idea of adopting XBRL is to provide benefits not only to government and its agencies but also to other XBRL stakeholders. Therefore, before the government was able to decide on the nonadoption of XBRL, there needed to be interaction among the XBRL stakeholders. This means that stakeholder involvement during the decision making process of adopting XBRL is a crucial factor and any decision made would have implications for these stakeholders. 


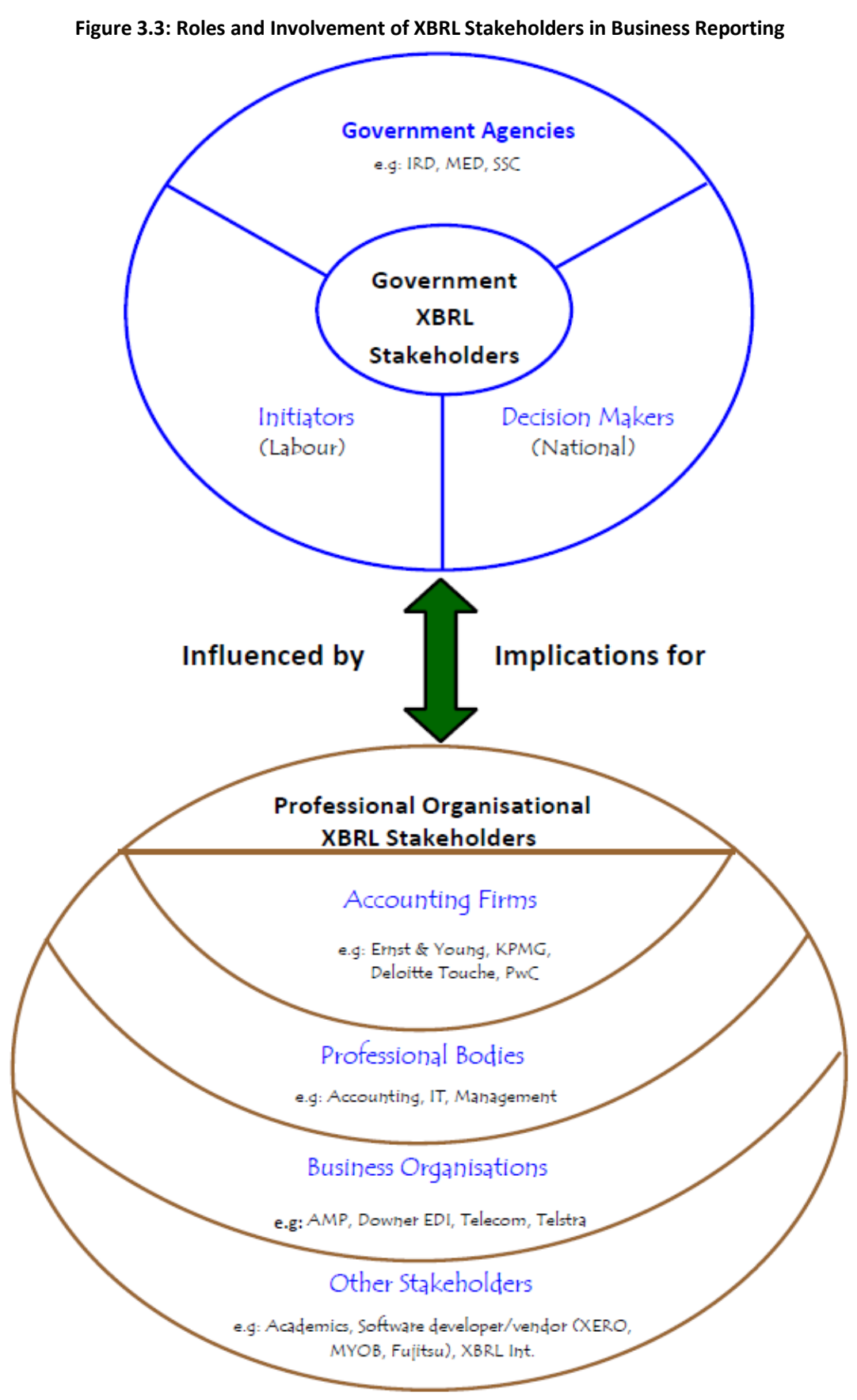

\subsubsection{Implications of XBRL Adoption for XBRL Stakeholders}

An implication is defined as the effect that an action or decision will have on something in the future ${ }^{25}$. The decision to adopt or not to adopt any kinds of technology such as XBRL will have some effect and these will be either short or long term. A limited number of studies have examined the implications of adopting XBRL as in Table 3.5. The adoption of XBRL leads to the reduction of information asymmetry especially for large-size companies. Yoon et al. (2011) studied the Korean Stock Market and suggest that XBRL improves the quality of information by facilitating a continuous flow of information. Thus, the improved,

\footnotetext{
${ }^{25}$ http://www.dictionary.cambridge.org/dictionary/english/implication
} 
transparent, and real-time financial reporting and disclosure of data in an XBRL format reduces the company's cost of capital. Chen (2012) found the implementation of XBRL increases the accountability and transparency of business and financial information, and it being gathered in an XBRL format, improved the ease of public dissemination and analysis.

A study by Bharosa, Janseen, van Wijk, de Winnie, van der Voort, Hulstijin and Tan (2013) examined two different B2G information exchange architectures that reflect continuous transformations that empowered government agencies to conduct compliance monitoring tasks with fewer resources. They revealed that pushing controls (automated checks) upstream (into company software and data sources) results in more efficiency, higher information quality and reduces redundant controls. Later, Shan and Troshani (2014) investigated the impact of XBRL on financial statement auditing by using empirical evidence from companies listed on the NYSE and NASDAQ from 2009 to 2011. Their findings suggest $X B R L$ reduces auditing costs in the business information supply chain; because XBRL adopters are likely to pay reduced audit fees. They also indicate that XBRL can enhance the credibility and reliability of financial statements, which can have important implications for all stakeholders within the business information supply chain. Umoren and Jeremiah (2015) examined the implications of XBRL adoption in Nigeria. They found that adopting XBRL enhances financial reporting comparability across companies, and increases the understandability and relevance of XBRL-based financial reports for decision-making. Further, it addresses the efficiency in respect to information generation, accurate, and reliable information, and information accessibility and security.

Table 3.5 lists the implications of adopting XBRL for various stakeholders based on the above studies. These studies all focus on the positive implications of adopting XBRL within organisations. However, this thesis investigates the implications of a decision relating to the non-adoption of XBRL for stakeholders, and thus, the implications are expected to differ from those in Table 3.5 . 
Table 3.5: Implication of XBRL Adoption for Stakeholders

\begin{tabular}{|c|c|c|c|}
\hline Study & Context & Stakeholder & Implication \\
\hline Yoon et al. (2011) & Korea & - Business organisations & - Reduced information asymmetry \\
\hline Chen (2012) & $\begin{array}{c}\text { US, The } \\
\text { Netherlands, } \\
\text { Australia } \\
\text { and } \\
\text { Singapore }\end{array}$ & - Government & $\begin{array}{l}\text { - Increased accountability and } \\
\text { transparency } \\
\text { - Improved ease of public dissemination } \\
\text { and analysis }\end{array}$ \\
\hline $\begin{array}{l}\text { Bharosa et al. } \\
(2013)\end{array}$ & $\begin{array}{c}\text { The } \\
\text { Netherlands }\end{array}$ & $\begin{array}{l}\text { - Government agencies } \\
\text { - Business organisations }\end{array}$ & $\begin{array}{l}\text { - Greater efficiency } \\
\text { - Higher information quality } \\
\text { - Reduction in redundant controls }\end{array}$ \\
\hline $\begin{array}{l}\text { Shan and } \\
\text { Troshani (2014) }\end{array}$ & US & $\begin{array}{l}\text { - Accountants } \\
\text { - Auditors }\end{array}$ & $\begin{array}{l}\text { - Reduced audit costs } \\
\text { - Enhanced credibility and reliability of } \\
\text { financial statements }\end{array}$ \\
\hline $\begin{array}{l}\text { Umoren and } \\
\text { Jeremiah (2015) }\end{array}$ & Nigeria & - Accountants & $\begin{array}{l}\text { - Enhanced financial reporting } \\
\text { comparability across companies } \\
\text { - Increased understandability and } \\
\text { relevance of XBRL-based financial reports }\end{array}$ \\
\hline
\end{tabular}

\subsection{Proposed Research Framework}

The TOE framework of DePietro et al. (1990) is used to investigate the government decision, which consists of technological, organisational, and environmental contexts as discussed in Section 3.1. Through this framework, this thesis will examine the influence of the TOE context factors on the governmental, business and professional organisations' decisions regarding XBRL adoption, and further will consider the implications of the government decision not to adopt SBR (and thus XBRL) for XBRL stakeholders.

In Figure 3.4, the research framework has been divided into three parts: I, II and II. The first part (I) of the research framework has three contexts: technological, organisational, and environmental. The operational definition of these factors as given in Appendix B and supply literature is identified. In each context, it contains several factors as proposed in Section 3.2.1 for the technological context, Section 3.2.2 for the organisational context and Section 3.2.3 for the environmental context. As mentioned by DePietro et al. (1990), there are interactions among these factors. Eventually, these interactions will influence the decision, in this case not to adopt XBRL for business reporting (Doolin and Troshani, 2007). 


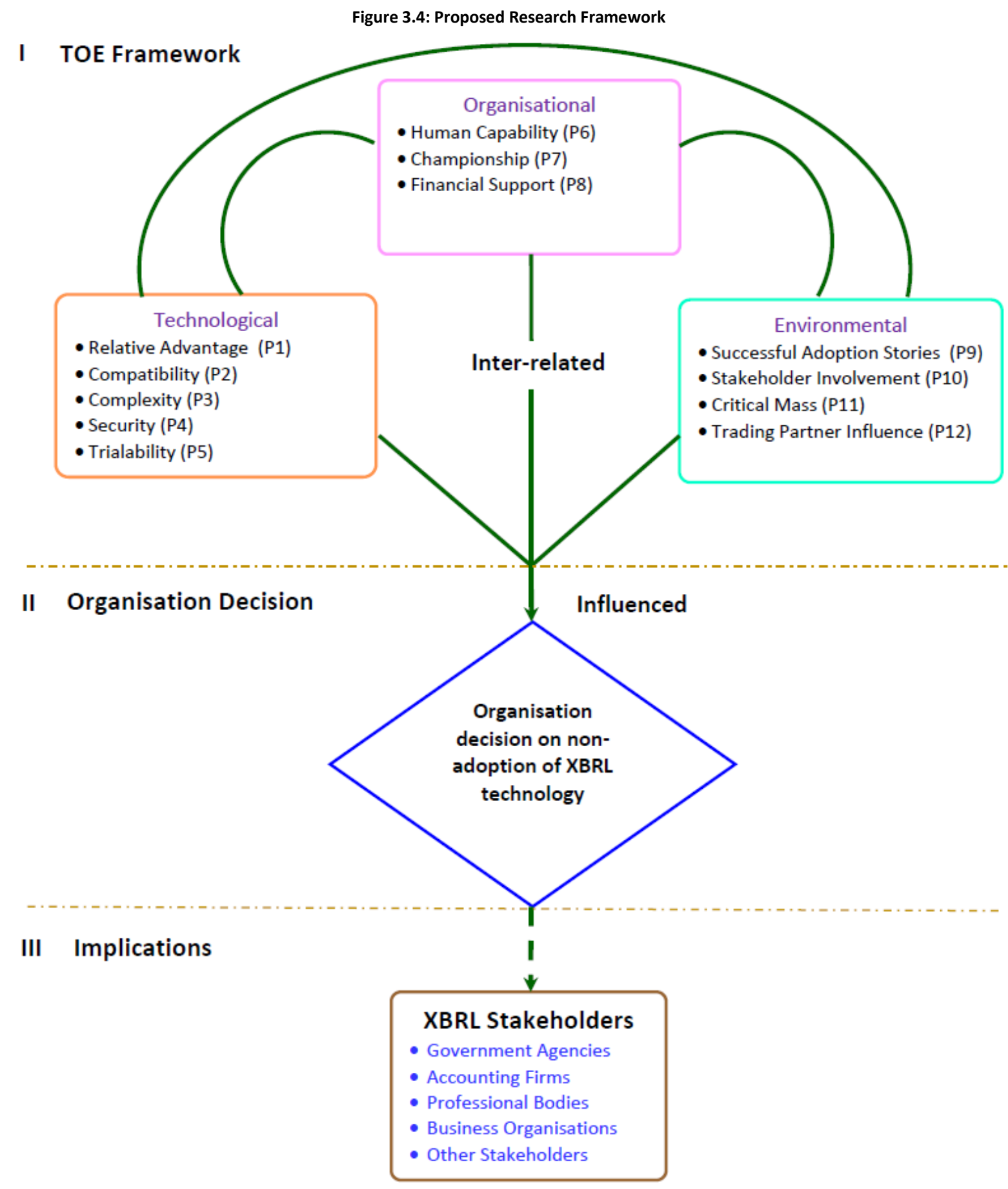

In the second part (II), this thesis will identify which of the factors in part (I) influenced the organisational decision either from businesses, professionals, or government agencies. Additionally, this part will suggest the key factors that influenced the decision, and identify which context is potentially the most critical in each XBRL initiative. This enables Research Question 1 to be answered; what factors influenced the organisations' decisions not to adopt XBRL for use in business reporting? 
In the final part (III), this thesis will identify any implications of the government decision not to adopt XBRL for each XBRL stakeholder. As presented in Section 3.3.3, it is probable that the stakeholders in Figure 3.3 would have affected this government decision. Hence, it will provide answers to Research Questions 2 as to what are the implications of the government decision regarding XBRL use in business reporting for XBRL stakeholders? This framework further provides useful insights that enable the understanding of the links between the influencing factors, organisation decisions, and implications for XBRL stakeholders.

\subsection{Chapter Summary}

This chapter reviews the literature in order to establish a research framework that utilizes the TOE framework of DePietro et al. (1990). Through the review, the TOE framework has been used to analyse various types of technology adoption by private and public sector organisations. The DePietro et al. (1990) framework has been empirically tested in prior studies and has been found to be a useful for understanding the adoption of technology by organisations.

In order to investigate further the implications of government decision for XBRL stakeholders, this thesis identifies the XBRL stakeholder groups in the New Zealand context and outlines their roles and involvement in XBRL initiatives. Later, this thesis develops a research framework that can assist in answering the research questions (Figure 3.4).

The research framework will be used in investigating and analysing the data from documents and interviews. In order to collect this data, an explanation of the research methodology is required. In the next chapter, the research methodology will be introduced and explained in the context of this study. 


\section{Chapter 4: Research Methodology}

\subsection{Introduction}

The second chapter of this thesis presented an overview of the literature concerning the developments and issues related to XBRL technology. Chapter 3 described the theoretical framework that has been adopted for the data analysis. This is based on the TOE Framework of DePietro et al. (1990). In this chapter, the research methodology underpinning the study will be explained, and the methods employed in this study will be discussed.

This chapter is organized as follows. The next section discusses the reasons for selecting the research philosophy and the epistemology underpinning this study. Then, the research method selection is explained. The following two sections discuss the use of reflection and triangulation methods to increase the reliability and rigour of the study's results. Next, the research design and data collection and analysis are addressed. The last section summarises the chapter.

\subsection{Research Philosophy}

The growing importance of accounting and IS studies in the last two decades has led to the use of different research approaches and methods originating from other disciplines like the social and natural sciences (Kock, McQueen, and Corner, 1997). As IS and accounting are multi-disciplinary fields, there are therefore several philosophical assumptions that can be used to explain the underlying nature of the phenomenon investigated by the researcher (Orlikowski and Baroudi, 1991). In addition to positivism, IS and accounting researchers can use interpretivism or the critical paradigm to inform their philosophical assumptions. This means no single philosophical assumption encompasses all the domains of knowledge needed for the study of IS and accounting (Galliers, 1992).

The most important philosophical assumptions are those that relate to the underlying epistemology that guides the research (Myers and Avison, 2002). Epistemology answers many questions concerning the nature of knowledge and how it can be acquired (Fetzer, 1993). The most common research philosophies in the IS and related fields, like accounting, 
are positivism and interpretivism (Orlikowski and Baroudi, 1991; Walsham, 1995). However, post-positivism is an alternative philosophy that can be used to view the adoption technology scenario.

Positivist studies focus on adopting an empirical epistemology, where a pre-determined set of assumptions about data gathering is established and accepted. In general, positivist research assumes that reality is objectively given and can be described by measurable properties, which are independent of the researcher and his or her instruments (Orlikowski and Baroudi, 1991; Myers, 1997). A positivist epistemology stance assists in testing or evaluating theory, to increase the predictive understanding of the phenomena under study (Orlikowski and Baroudi, 1991). Also, positivism uses deductive reasoning to postulate theories that can be tested. Based on the findings, a positivist researcher can conclude whether the theory does or does not fit the case investigated. Where the theory does not fit, it opens up another avenue to revise the theory to better predict reality (Trochim, 2006).

Scholars like Burrell and Morgan (1979), Morgan (1983), Lincoln and Guba (1985), Chua (1986) and Sobh and Perry (2006) have discussed the limitations of the positivism research philosophy. Among the limitations is that positivism is supposed to follow universal laws. The key positivism assumption is that people can best comprehend and evaluate the world by striving to escape historical and culturally constructed presuppositions. Based on this assumption, anything that is not observable such as the ethical, aesthetic, normative, philosophical, metaphysical or theological will be dismissed as meaningless for it has no valid knowledge claims (Hawkesworth, 1988). This leads to a neglect of the historical as well as environmental conditions, which potentially influence human action (Orlikowski and Baroudi, 1991). Additionally, positivism aims to view reality through a "one-way mirror" (Sobh and Perry, 2006, p.1195), which means positivists investigate a phenomenon based on one perspective. Further, a meta-analysis of positivist studies often confirms its inadequacy for or imperfect handling of investigations of social phenomena. This is because in reality the world is "imperfectly and probabilistically apprehensible", thus, various views are needed to understand social phenomena (Guba and Lincoln, 1994, p.109).

As suggested by Wildemuth (1993), positivism and interpretivism can be combined into an approach called post-positivism. Post-positivism is a contemporary philosophy developed in 
response to the limitations of positivism and can be applied when studying technology adoption in organisations, particularly when the nature of the study is embedded in the social context. The latter suggests that environmental elements such as culture, politics, and the economy as well as the point in time cannot be neglected when revealing the truth scenario (Orlikowski and Baroudi, 1991) of adoption technology phenomenon like the nonadoption of XBRL. This is in contrast to a positivism research philosophy, which ignores the historical context of adoption technology phenomena as positivist researchers are rooted in the status quo (Chua, 1986). Table 4.1 compares the positivism and post-positivism paradigm.

Table 4.1: Comparison of Positivism and Post-Positivism

\begin{tabular}{|l|l|l|}
\hline \multicolumn{1}{|c|}{ Element } & \multicolumn{2}{|c|}{ Paradigm } \\
\cline { 2 - 3 } & \multicolumn{1}{|c|}{ Positivism } & \multicolumn{1}{c|}{ Post-Positivism } \\
\hline Ontology (is 'reality') & $\begin{array}{l}\text { Reality is real and apprehensible } \\
\text { (capable of being understood) }\end{array}$ & $\begin{array}{l}\text { Reality is 'real' but only imperfectly } \\
\text { and probabilistically apprehensible } \\
\text { (understandability of desired } \\
\text { outcomes). Triangulation from many } \\
\text { sources is required to try to know it }\end{array}$ \\
\hline $\begin{array}{l}\text { Epistemology (is the } \\
\text { relationship between that } \\
\text { reality and the researcher) }\end{array}$ & $\begin{array}{l}\text { Findings true- the researcher is } \\
\text { objective by viewing reality through } \\
\text { a 'one-way mirror' }\end{array}$ & $\begin{array}{l}\text { Findings probably true- the researcher } \\
\text { is value-aware and needs to } \\
\text { triangulate any perceptions s/he is } \\
\text { collecting }\end{array}$ \\
\hline $\begin{array}{l}\text { Common methodologies } \\
\text { (methodology is the } \\
\text { technique used by the } \\
\text { researcher to discover that } \\
\text { reality) }\end{array}$ & $\begin{array}{l}\text { Mostly concerned with a testing of } \\
\text { theory. Thus, mainly quantitative } \\
\text { methods such as surveys, } \\
\text { experiments, and verification of } \\
\text { hypotheses are used }\end{array}$ & $\begin{array}{l}\text { Mainly qualitative methods such as } \\
\text { case studies and convergent } \\
\text { interviews }\end{array}$ \\
\hline
\end{tabular}

(Source: Guba and Lincoln (1994), p.109; Sobh and Perry (2006), p.1195)

While a positivist view believes that the researcher and object of inquiry are independent (Orlikowski and Baroudi, 1991), post-positivism accepts that theory, background, knowledge and the values of the researcher influence what is observed. In other words, post-positivism research pursues objectivity by recognizing the possible effects of biases (Trochim, 2006). At the same time, it emphasizes the importance of multiple observations and measures. Post-positivism encourages the use of triangulations, either of data, methods, researcher, or theories thereby reducing errors and biases in the study findings. This is consistent with the views of Morgan (1980), Polkinghorne (1983) and Hirschheim (1985) who assert there is no one correct method of science, but there are many methods or 'methodological pluralism'. Thus, post-positivism recognises that many different approaches and techniques can be applied to collect and analyse data (Ryan, 2006; Henderson, 2011). 
Based on the above discussion, a post-positivist epistemological stance will be taken in this study. A post-positivism approach will allow the empirical investigation of the non-adoption of XBRL through close investigation of documents and face-to-face contact with participants in the XBRL decision. Each of these participants has their own socially constructed realities. But by using a post-positivism approach, these realities can be combined to identify a single probable truth about an important event the non-adoption of XBRL, and the exploration of the factors that facilitate or inhibit its non-adoption in a natural setting through the application of the TOE framework. During data analysis, the researcher identified there types of stakeholder involvement: active, supportive and observer. The reality of the nonadoption phenomenon from these three types of stakeholders generates multiple realities that could be combined into single probable truth. Furthermore, the use of post-positivism enables the researcher to explore the potential non-adoption factors of XBRL, which are not included in the initial propositions. Additionally, post-positivism assists the researcher in identifying the implications of the government decision not to adopt XBRL for various stakeholders. The following section will discuss the qualitative research method and how it is appropriate for use in this thesis.

\subsection{Qualitative Research}

Quantitative and qualitative research methods encompass a variety of methods of inquiry and derive from different scientific traditions. Quantitative research methods developed in the natural sciences to study physics, chemistry, and biology phenomena. On the other hand, qualitative research methods developed in the social sciences to enable researchers to study social and cultural phenomena (Myers and Avison, 2002).

Since one of the objectives of this study is to identify and analyse the technological, organisational, and environmental factors that influence organisations' decisions relating to XBRL adoption, a qualitative research method will be more appropriate. This is because qualitative methods are designed to help researchers understand organisational decisions and actions within a real-life context, which are difficult to explain fully in quantitative terms (Strauss and Corbin, 1990; Myers and Avison, 2002). Further, according to Strauss and Corbin (1990), qualitative research methods can be used to understand better any phenomena, which have not been completely explored, and to gain new perspectives on existing issues such as XBRL adoption. XBRL adoption from the government perspective, in 
particular, is an under-researched area (Troshani and Doolin, 2007), and needs more indepth empirical information to explain it. Table 4.2 presents the strengths of qualitative research.

Table 4.2: Strengths of Qualitative Research

\begin{tabular}{|l|l|}
\hline \multicolumn{1}{|c|}{ Strength } & \multicolumn{1}{c|}{ Reference } \\
\hline The researcher can study IS phenomena in their natural setting. & $\begin{array}{l}\text { Benbasat, Goldstein and Mead (1987) } \\
\text { Silverman (2000) }\end{array}$ \\
\hline $\begin{array}{l}\text { Allows the researcher to investigate meanings given by specific } \\
\text { participants. }\end{array}$ & Silverman (2000) \\
\hline $\begin{array}{l}\text { Allows the researcher to have a thick and close description of } \\
\text { phenomena in the context-specific setting. }\end{array}$ & $\begin{array}{l}\text { Myers (1997) } \\
\text { Silverman (2000) } \\
\text { Creswell (2007) }\end{array}$ \\
\hline $\begin{array}{l}\text { Allows the researcher to gain an in-depth understanding of the } \\
\text { nature and complexities of a particular process. }\end{array}$ & $\begin{array}{l}\text { Benbasat et al. (1987) } \\
\text { Silverman (2000) }\end{array}$ \\
\hline
\end{tabular}

Meanwhile, Table 4.3 presents the weaknesses of qualitative research.

Table 4.3: Weaknesses of Qualitative Research

\begin{tabular}{|l|l|}
\hline \multicolumn{1}{|c|}{ Weakness } & \multicolumn{1}{c|}{ Reference } \\
\hline $\begin{array}{l}\text { It has a small sample size, which reduces the controllability, } \\
\text { deductibility, and generalizability of the research. }\end{array}$ & $\begin{array}{l}\text { Smithson and Cornford (1996) } \\
\text { Silverman (2000) }\end{array}$ \\
\hline $\begin{array}{l}\text { It is time-consuming because the researcher needs to spend a lengthy } \\
\text { amount of time collecting and analysing the data. }\end{array}$ & $\begin{array}{l}\text { Lee (1991) } \\
\text { Data is open to a variety of interpretations, which could reduce the } \\
\text { accuracy of interpretation results. }\end{array}$ \\
\hline $\begin{array}{l}\text { Results in the collection of a large amount of unstructured and } \\
\text { unbounded data. }\end{array}$ & See (1991) \\
\hline
\end{tabular}

Based on the above discussion and the identification of strengths as in Table 4.2 and the consideration of the weaknesses as in Table 4.3, the qualitative method is considered the most appropriate for use in this study for the following reasons:

i) One purpose of this study is to identify and analyse the factors that influence the organisations' decisions regarding XBRL adoption for business reporting. Analysing the issue requires an approach that is suitable for identifying these underlying factors. Therefore, a qualitative approach is employed in this study. This approach enables the researcher to study XBRL-related phenomena in its natural setting and gain an in-depth understanding of the nature and complexities of the issues (Benbasat et al., 1987; Silverman, 2000). Additionally, this method allows the researcher to determine the implications of the government decision for XBRL stakeholders. 
ii) Analysing the factors that facilitate and/or inhibit XBRL adoption requires building a close connection (Creswell, 2007) with the participants involved in XBRL adoption decisions. Therefore, utilizing qualitative research will support the identification of influencing adoption factors for this study (Silverman, 2000).

iii) Since the non-adoption of XBRL is a little-known phenomenon, using a qualitative method will allow the in-depth understanding and examination of decisions related to XBRL. It will also explore the history and development of XBRL in New Zealand, thus providing a better understanding of the non-adoption of XBRL in this country.

In summary, this study will employ a post-positivist epistemology approach, which entails collecting data through qualitative research methods. In the next section, the use of a case study as the research strategy will be introduced and discussed.

\subsection{Case Study}

Consistent with the principles of post-positivist approach, researchers have developed a set of research methods for conducting post-positivist case studies. In this section, an explanation of the case study elements, the justification of case study use and the relevance of a case study approach to investigating XBRL adoption will be discussed.

Understanding case study research is important in studying an event in its natural setting. According to Benbasat et al., (1987) and Yin (1994) the case study method can be used for exploring a contemporary phenomenon. Davey (1991), p.2 suggests, "the case study method involves an in-depth longitudinal examination of a single event or instance". Further, he explains, "the case study is a method of learning about multiple instances through extensive description and contextual analysis" (p.2). Later, Yin (2003, p.2) indicates that the case study is concerned with "the rigorous and fair presentation of empirical data", which allows the researcher to identify and maintain the holistic and meaningful characteristics of real-life events such as organisational and managerial processes. Dubé and Paré (2003) and Yin (2003) also believe that a case study can be used to explain the links in real-life interactions that are too complex for survey and experimental strategies. 


\subsubsection{Elements of a Case Study}

Paré (2004, p.237) suggests there are five elements necessary to guide case study decisions, namely:

i) The initial definition of research questions;

ii) A priori specification of constructs of theory;

iii) The definition of the unit of analysis;

iv) The selection of and number of cases; and

v) The use of a case study protocol.

The first element, the research questions should determine the type of research strategy. Yin (2003) explains that case study research is most likely to be appropriate for 'how' and 'why' research questions. This is because these types of questions deal with the operational links that need to be traced over time, rather than common frequencies or incidence. However, using a case study approach to 'what' questions is also applicable and justifiable when conducting an exploratory case study (Yin, 2003). This study has a two research questions that use 'what' questions:

i) What factors influenced the organisations' decisions not to adopt XBRL for use in business reporting?

ii) What are the implications of the government decision regarding $X B R L$ use in business reporting for XBRL stakeholders?

Concerning the second element relating to theory constructs, two different approaches may be taken (Anderson and Aydin, 1994). First, the researcher could work within an explicit research framework which "consists of a selection of concepts and relations among them, grouped so as to enable its users to see the major concepts easily and simultaneously in their relations to one another" (Kochen, 1985, p.93). By using this approach, the researcher can make some explicit theoretical statement (Mile and Huberman, 1994). In the second, the researcher tries not to be constrained by previous theory but sees the development of relevant theory hypotheses and concepts as the purpose of the project. However, these approaches can be combined to guide theory-building research (Paré, 2004). Both approaches are combined in this study as it explores the non-adoption of XBRL. A research framework is used to guide this study. However, at the same time, this study will 
consider potential factors that may be discovered during the data collection and analysis stages.

The third element of the case is related to the unit of analysis. Yin $(1994$, p.22) states that "the unit of analysis is related to the way the initial research questions have been defined." He believes that the unit of analysis can be an individual, a group, a city, an event, entity or an organisation. Thus, a case study may not only be concerned with a particular technology or system, but it could also investigate a strategy or an organisation that is adopting an emerging technology (Yin, 1994; Paré, 2004). In this study, the unit of analysis is the XBRL project, specifically the LEAP+, Project First Step, e-GIF and SBR projects.

The fourth element is related to the selection and number of cases. The researcher needs to decide whether to have either one or more cases in the research project. Frequently, a single case study is criticised, as it is incapable of providing a generalizable conclusion. However, Yin (2003) mentions that single case designs are appropriate when it represents a unique, revelatory, or critical case in testing a well-formulated theory. On the other hand, when adopting a multiple-case design, the researcher faces the problem of deciding the number of cases deemed necessary or sufficient for their research. Whether to use one or multiple case studies depends on researcher discretion and judgement (Paré, 2004), and the certainty a researcher wants to have in the case result (Yin, 2003). That means within single or multiple cases; the researcher must ensure the selection can maximise what can be learned in the period available for the study (Paré, 2004). For the purpose of this study, a multiple case study approach is chosen because it will help to validate internally and crosscheck findings through conducting a comparative analysis of the case findings (Eisenhardt, 1991; Yin, 2003). Further, a multiple-case study enables the identification of the difference in contexts allowing for the conducting of an informed comparative analysis of the cases (Lee, 1989; Voss, Tsikriktsis, and Frohlich, 2002). Alternatively, multiple case studies can be used in combination to investigate the historical antecedents leading up to a major event. Thus, the multiple cases are the LEAP+ project, Project First Step, e-GIF project and SBR programme. These are explained in detail in Chapter 5.

The last element is the use of a case study protocol. The main purpose of creating a case study protocol is to increase reliability (Yin, 2003). The use of a case study protocol is designed to assist another researcher to repeat the procedure and arrive at the same or 
similar conclusions (Paré, 2004). A case study protocol is essential in a multiple-case study (Paré, 2004). Yin (2003) suggests a general case protocol contains four components; an overview of the case study project, the field procedures to be used, interview guidelines and a guide for the case study report.

In brief, consistent with Paré's (2004) suggestions, this study applies an exploratory postpositivist case study approach to investigate the factors that influenced the decisions not to adopt XBRL for business reporting and to identify the implications of the government decision (in particular) for XBRL stakeholders. This research is exploratory in nature because the non-adoption XBRL is under-researched and poorly understood. An organisation is the unit of analysis and a multiple-case study strategy is applied. Finally, a case study protocol has been developed to ensure consistency in the process while performing the procedures.

\subsubsection{The Justification for and Relevance of Using a Case Study}

The case study method has been extensively applied in IS and accounting (Gable, 1994; Paré, 2004). The case study approach refers to a group of methods which emphasize qualitative analysis (Yin, 1984), seek to understand the problem being investigated, provide the opportunity to ask penetrating questions, and capture the richness of organisational behaviour. Benbasat et al. (1987) identify three strengths of a case study. Firstly, the researcher can study phenomena in its natural setting and generate theories from practice. Secondly, a case study allows the researcher to understand the nature and complexity of the organisational processes taking place. Finally, this method provides valuable insights into new topics that are emerging in rapidly changing fields.

The relevance of case study method to study XBRL adoption is supported by several researchers including Doolin and Troshani (2007), Troshani and Rao (2007) and Mousa (2011) as presented in Table 4.4.

Table 4.4: Usage of a Case Study to Investigate XBRL Adoption

\begin{tabular}{|l|l|}
\hline \multicolumn{1}{|c|}{ Study } & \multicolumn{1}{c|}{ Usage and Characteristics } \\
\hline $\begin{array}{l}\text { Doolin and } \\
\text { Troshani } \\
(2007)\end{array}$ & $\begin{array}{l}\text { - Case study based on interviews with potential organisational adopters of XBRL including } \\
\text { regulatory authorities, accounting firms and members of XBRL Australia. } \\
\text { - This explanatory qualitative case study provided the opportunity to conduct a preliminary } \\
\text { analysis of findings, for example, the implications of XBRL adoption strategies on } \\
\text { government and other adoption decision-makers in Australia. }\end{array}$ \\
\hline $\begin{array}{l}\text { Troshani } \\
\text { and Rao }\end{array}$ & $\begin{array}{l}\text { A case study to identify the contextual factors that influence XBRL adoption by } \\
\text { organisations. }\end{array}$ \\
\hline
\end{tabular}




\begin{tabular}{|l|l|}
\hline$(2007)$ & - Enabled researchers to explain the limited usage of XBRL by potential Australian adopters. \\
\hline Mousa & $\begin{array}{l}\text { - An in-depth case study to examine the adoption of XBRL, as an e-government initiative in } \\
\text { (2011) }\end{array}$ \\
& $\begin{array}{l}\text { the UK context. } \\
\text { Development of a conceptual framework based on the XBRL adoption process by two } \\
\text { major UK government bodies, HM Revenue and Customs and the Companies House. }\end{array}$ \\
\hline
\end{tabular}

Based on the above discussion, this study uses a case study method for four reasons:

i) The case study method is particularly suitable for technology-focused research. This study focuses on the non-adoption of XBRL in an organisational setting.

ii) The research objective of identifying and analysing the influential factors on decisions regarding XBRL adoption can be addressed by an in-depth understanding of the organisational setting.

iii) XBRL adoption from the governmental viewpoint is not well investigated. Therefore, the case study provides an exploratory analysis of phenomena that is not thoroughly understood.

iv) XBRL adoption by organisations can be studied in its 'natural' setting, which provides insight into the actual decision-making practices of organisations including government.

Based on the above discussion, the selection of multiple-case study has been justified. The following section will discuss the reflection and triangulation methods that are used to enhance the rigour of the research process and enrich the results.

\subsection{Reflection Methods}

A flexible and on-going thinking process when conducting research is known as reflection. Using such a method, the researcher can continuously reflect on the research at different stages of the qualitative enquiry including when defining the research problem, choosing an appropriate theory and collecting and analysing how data interacts and influences each other (Ahrens and Chapman, 2006). Using a reflection strategy has two purposes. The first is using direct reflection to cross-check and validate ideas and tentative findings from earlier data collection or analysis (Covaleski and Dirsmith, 1988). The second is comparing and validating interviewees' views to provide an assessment of theory validity in explaining the factors that influence decisions related to XBRL (Ahrens and Dent, 1998). Reflection helps the researcher to identify a possible fit between the research problem, theory, and data. This study employs a reflection method in defining the research problem, choosing an appropriate theory, developing the interview questions, collecting and analysing data and 
determining the conclusion of the research findings. Additionally, a reflection method was applied when establishing and checking the linkages between data and the research framework.

This study adopts interactive patterning in the reflection research process where the preliminary findings assist decisions about future data collection (Covaleski and Dirsmith, 1988). There are five phases of reflection in this study. Firstly, data are collected to gain a broad or general understanding of XBRL concepts and to assist in identifying the research questions. This phase informs the research context and establishes the research questions as highlighted in Chapters 1 and 2.

Secondly, the focus is on collecting the data from archival and government documents and specific literature relating to XBRL. Most of the archival and government records are available through websites (1999 to 2010). The analysis of archival and government documents provides insight into the most significant and interesting issues, which are then used to develop the interview questions (Ahrens and Dent, 1998). Additionally, in developing the interview questions, data such as the potential interviewees' background and XBRL studies relevant to research questions are also collected. From here, the researcher can customize the interview questions based on the interviewee's background. Meanwhile, the relevant XBRL literature helps the researcher to select an appropriate theory and build the research framework as discussed in Chapter 3.

Thirdly, the interview questions are asked in the interview process, where the related data are collected. In this stage, while preparing for the next interviews, the researcher selfreflects, discusses her understanding with her supervisors, and studies the next interviewee's background. Then, the researcher reflects on her understanding and reconstructs the interview questions to match the next interviewee's background and experience. Within each case, the opinions and perspectives gained from earlier interviews and documents are directly communicated to later interviewees who are asked to comment and reflect on those views and perceptions from their organisational perspectives (Covaleski and Dirsmith, 1988). This step assists the researcher to reduce bias and to obtain accurate data from the next interviewee.

Fourthly, data from the third phase are analysed to discern key characteristics and factors, and their correspondence to the proposed theory and research framework is evaluated 
(Covaleski and Dirsmith, 1988; Ahrens and Chapman, 2006). Before the transcriptions are analysed, they are labelled based on the interviewee's involvement in the four key XBRL initiatives. Thus, reflection is used while the researcher builds the research themes and applies the coding. Reflection also helps the researcher consistently code within the transcript. Again, this step helps the researcher to minimize bias while analysing the data. At the same time, reflection guides the researcher in the presentation of the findings.

In the final stage, the findings are discussed and compared with previous studies. Through these actions, the researcher provides explanations and makes logical connections between the factors. The researcher then revises the research framework and presents the overall conclusions of the study. Here, reflection is used to assist the researcher to be consistent in answering the research questions and providing explanations.

Additionally, the use of reflection methods enables the revision of the research framework, the verification of the research findings and provides additional insights and richness to the understanding of XBRL non-adoption and its implications and consequences for XBRL stakeholders (Covaleski and Dirsmith, 1988; Ahrens and Dent, 1998). Another method, triangulation is also used to increase the validity and reliability of this study's results and will be discussed in the next section.

Figure 4.1 summarizes the stages of the reflection method employed in this study. The figure shows each stage has different activities. 


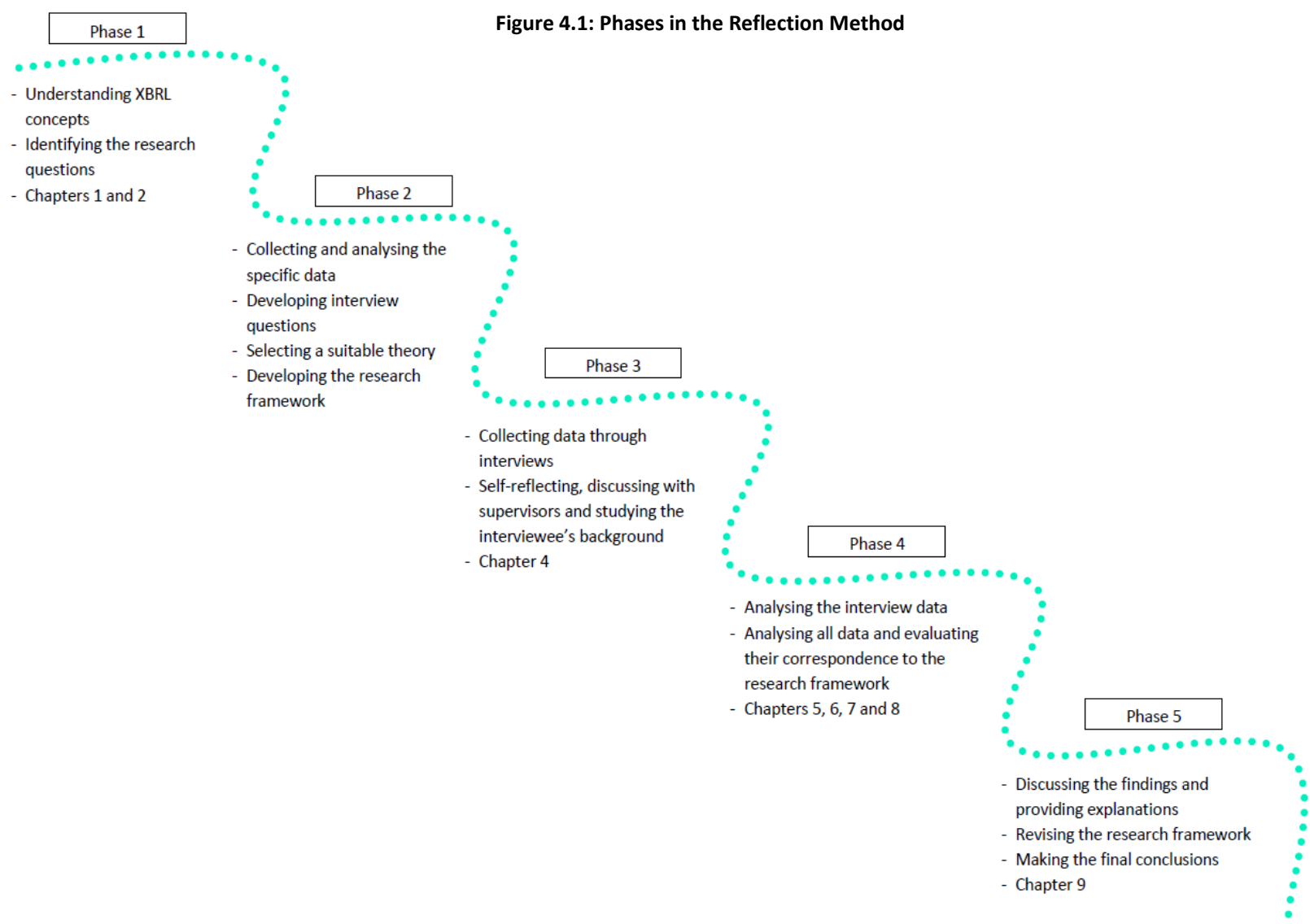

\subsection{Triangulation Methods}

An observation of research from at least two different points is known as triangulation (Flick, Kardoff and Steinke, 2004). The primary benefits are validating the findings and increasing the richness of descriptions and insights about the subjects under study (Ahrens and Chapman, 2006; Denzin, 2009). Any single method can only explain one aspect of empirical reality and, therefore, it cannot rule out rival explanations (Denzin, 2009). On the other hand, triangulation enables the assessment of these rival explanations. According to Jick (1979), triangulation can capture a more holistic and contextual picture of the subjects under study, and thus it increases the validity of interpretation (Bourgeois and Eisenhardt, 1988; Marginson, 1999).

Triangulation findings gained from different data sources, methods, theories or researchers can reveal additional insights that could be neglected by a single data source, method, theory or researcher (Denzin and Lincoln, 2003). Data triangulation means data are collected from different sources at different times, different places and from different people (Flick, 1992). The purpose of data triangulation is first to ensure the consistency of patterns and instances across different data sets and to confirm the validity or trustworthiness of the explanation, theory, or argument. The second is to provide a richer 
and more in-depth story about a particular event, people, context, or community (Flick et al., 2004). Methodological triangulation is the combination of methods in a study. It also involves "a complex process of playing each method off against the other to maximize the validity of field efforts" (Denzin, 2009, p.304). There are two types of methodological triangulation: across method and within the method. Across method means quantitative and qualitative methods of data collection are used in one study (Denzin, 1970), and it has been referred to as mixed methods (Denscombe, 2010). Within method triangulation is where more than one method of data collection from the same design is used in a study (Denzin, 1989; Kimchi, Polivka, and Stevenson, 1991). Researcher triangulation involves two or more researchers, who are directly involved in collecting and interpreting data. The purpose of doing this is to reduce, limit, and balance out the potential subjectivity of an individual researcher (Flick et al., 2004). Theoretical triangulation refers to the use of multiple theories and perspectives in an empirical analysis (Flick, 1992). More holistic understanding of the social phenomena under study can be gained using theoretical triangulation (Denzin, 2009) because new and additional meanings and definitions can be attached to the events or actions, or different behaviour can be identified.

Each type of triangulation can be used separately or in conjunction with each other. Using multiple strategies of triangulation helps propose the best line of action (Denzin, 2009). Many scholars have identified the strengths and benefits of triangulation. For instance, triangulation allows the researcher to achieve the best of each method while overcoming each methods deficiencies (Denzin, 1978). Jick (1979) suggests that triangulation offers the researcher valuable opportunities such as increased confidence in results, the potential to create new methods and the opportunity to provide an enriched explanation of the research problem. Hence, multiple data sources, methods, researchers, or theories can be combined in one study to enhance the credibility of the explanations and to capture better the richness and complexity of the phenomena (Denzin, 2009). Triangulation thus helps to overcome the bias inherent in the single-method study and increases the reliability of the data (Tellis, 1997b) and enhances the validity of a study (Silverman, 2000).

This study employs data and within method triangulation by drawing upon multiple data sources and comparing the results between these sources. Figure 4.2 illustrates the levels of triangulation used. There are two columns: document and interview, which represent the 
methods. There are three rows or levels: Level 1, Level 2, and Level 3. Level 2 and 3 represent the data. Therefore, Level 1 is the methodological triangulation, and Levels 2 and 3 are the data triangulation.

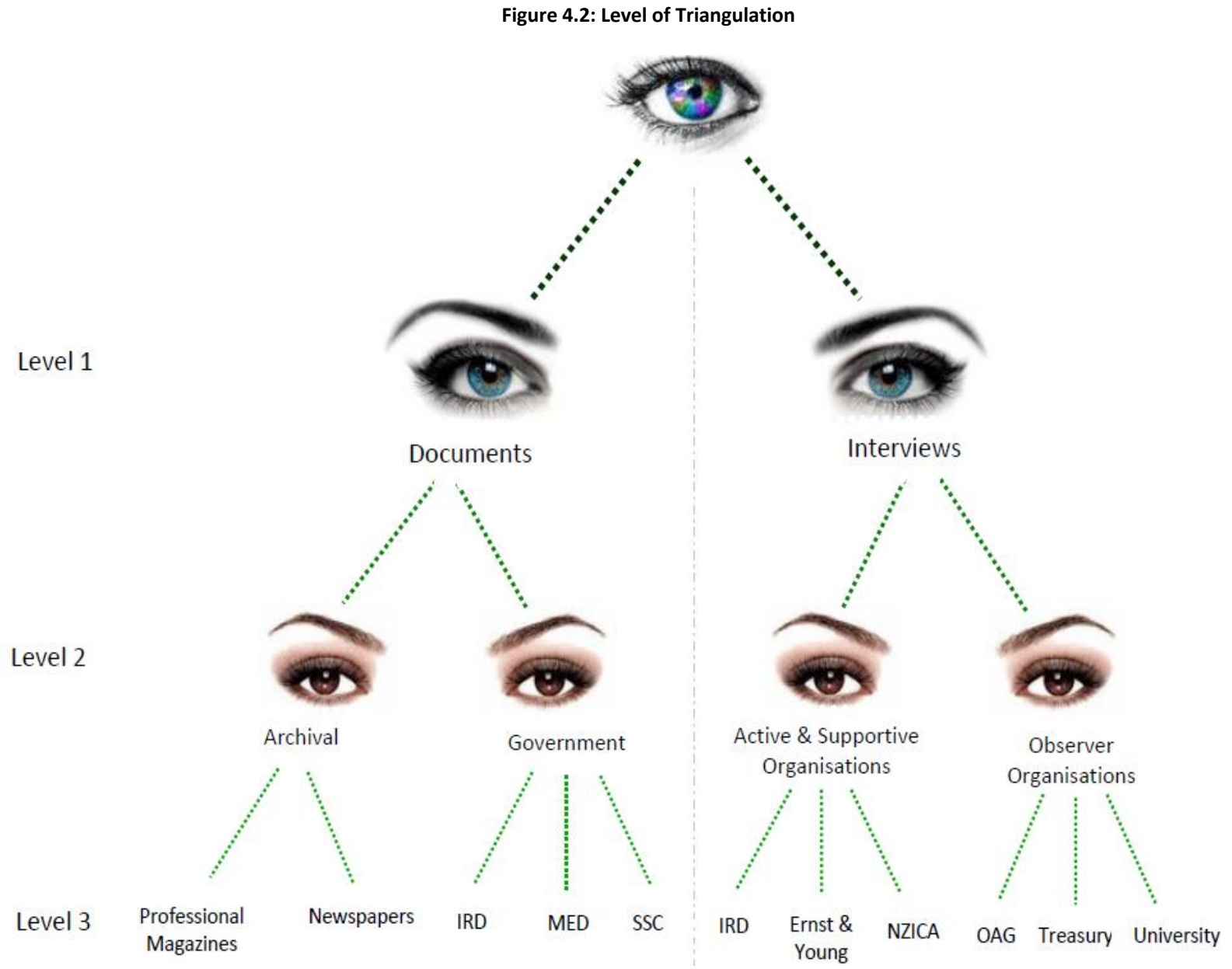

The primary sources of data are collected from interviews, and from archival and electronic documents from the New Zealand government agencies, and private and associated relevant organisations. Interviews are conducted with government officers, chartered accountants, directors, consultants, and academics. These interviewees are from active and supportive as well as observer stakeholders involved in the XBRL initiatives (the classification of stakeholder involvements are explained in Section 4.6.2.1. The insights from the XBRL stakeholder interviews are then compared and contrasted for cross-validation purposes. Documents produced by the XBRL stakeholder organisations are also collected. The documents include newspapers and media releases, and annual reports and research reports, which are publicly available. Minutes of meetings and XBRL project documents from relevant government agencies or ministries are also obtained. These documentary 
data sets are compared to identify similarities and differences that assist in the verification of the revised research framework (Miller, Dingwall and Murphy, 2004).

The documents, as given in Table 4.5 below (sources used for this study for documentation) are used to triangulate the information from the interviews. Government websites of, for example, the IRD, the Statistics Department and the MED, are used to download government reports and opinion articles, which are relevant and relate to XBRL. The documents also include organisational records such as minutes of meetings, consultation papers, and presentations, which are provided by potential interviewees. The rationale for using multiple sources of data is to triangulate the evidence for the reasons detailed above.

The documentary and interview data are then triangulated against each other. Documents can confirm and disprove interview results (Yin, 2003). Therefore, convergence or divergence of the results between different data sources enables an assessment of the research framework's validity and increases the confidence in the results (Hopper and Hoque, 2006). The following section describes the data sources and methods of data collection used in this study.

\subsection{Research Design}

In this section, the case study's data collection and data analysis methods will be introduced and explained.

\subsubsection{Data Collection}

As discussed above, an important principle of data collection in case study research is triangulation. The use and combination of interview and document analysis to study the same phenomena will provide strong evidence that will make the findings and conclusion of this study more reliable and consistent (Yin, 2003).

Table 4.5 provides the three major sources of evidence generally used in a case study. The table lists the strengths and weaknesses as identified by Yin (2003), and the last column provides examples of the utilization of these sources in this study. As seen in Table 4.5, each source has its strengths and weaknesses, thus through a combination of sources, this study can provide reliable findings. 
Table 4.5: Data Collection Method: Strengths, Weaknesses and Sources Used

\begin{tabular}{|c|c|c|c|}
\hline $\begin{array}{l}\text { Source of } \\
\text { evidence }\end{array}$ & Strengths & Weaknesses & $\begin{array}{l}\text { Sources used for this } \\
\text { study (2000-2010) }\end{array}$ \\
\hline Archival records & $\begin{array}{l}\text { - Stable- can review } \\
\text { repeatedly. } \\
\text { - Unobtrusive- not } \\
\text { created as a result of } \\
\text { the case study. } \\
\text { - Exact- contains exact } \\
\text { names, references and } \\
\text { details of events. } \\
\text { - Broad coverage - long } \\
\text { span of time, many } \\
\text { events, and many } \\
\text { settings. } \\
\text { - Precise and } \\
\text { quantitative. }\end{array}$ & $\begin{array}{l}\text { - Restrictive- difficult to get } \\
\text { the relevant documents. } \\
\text { - Selection biased if data } \\
\text { collection is incomplete. } \\
\text { - Reporting bias- affects the } \\
\text { unknown bias of } \\
\text { researcher. } \\
\text { - Access may be } \\
\text { deliberately blocked. } \\
\text { - Accessibility could be } \\
\text { limited for privacy } \\
\text { reasons. }\end{array}$ & $\begin{array}{l}\text { - National Business } \\
\text { Review (April 2001- } \\
\text { December 2011). } \\
\text { - Chartered Accountants } \\
\text { Journal (April 2000- } \\
\text { March 2007). } \\
\text { - New Zealand } \\
\text { newspapers (April 1999- } \\
\text { September 2011). } \\
\text { - Other professional } \\
\text { magazines (March } \\
\text { 1998-July 2010). } \\
\text { - Government documents. }\end{array}$ \\
\hline Documentation & $\begin{array}{l}\text { - Same as archival } \\
\text { records. }\end{array}$ & - Same as archival records. & $\begin{array}{l}\text { - Government documents. } \\
\text { - Organisational records } \\
\text { such as material } \\
\text { provided by participants } \\
\text { (minutes of meetings, } \\
\text { consultation papers, and } \\
\text { presentations). } \\
\text { - Reference material } \\
\text { downloaded from } \\
\text { organisational websites. } \\
\text { - Opinion articles (the } \\
\text { organisation's } \\
\text { publications either } \\
\text { hardcopy or through the } \\
\text { website). }\end{array}$ \\
\hline Interviews & $\begin{array}{l}\text { - Targeted- focuses } \\
\text { directly on case study } \\
\text { topic. } \\
\text { - Insightful-provides } \\
\text { perceived causal } \\
\text { interfaces. }\end{array}$ & $\begin{array}{l}\text { - Bias due to poorly } \\
\text { constructed questions. } \\
\text { - Response bias. } \\
\text { - Inaccuracies due to poor } \\
\text { recall. } \\
\text { - Reflexivity- interviewee } \\
\text { gives interviewer what } \\
\text { they want to hear. }\end{array}$ & $\begin{array}{l}\text { - Interviewees are from } \\
\text { various organisations } \\
\text { such as government } \\
\text { agencies, accounting } \\
\text { firms, consulting firms } \\
\text { and universities. There } \\
\text { are } 16 \text { people involved } \\
\text { as interviewees with a } \\
\text { total of thirty-five } \\
\text { interview sessions } \\
\text { consisting of } 40-60 \\
\text { minutes for each } \\
\text { session. }\end{array}$ \\
\hline
\end{tabular}

There are differing periods for the archival records. The National Business Review was not available for all the required timeframe and most issues of Chartered Accountant Journal were not relevant to XBRL. For some events, the researcher needed to examine the reporting environment pre-2000 as well as during the study period through the New 
Zealand newspapers and other professional magazines, both of which potentially influenced the XBRL development in New Zealand.

Even though the archival records and documentation have the same strengths and weaknesses, they are from different sources. While archival records are collected by the researcher from various places, the sources of documentation are usually provided or suggested by the interviewees. According to Walsham (1995) and Silverman (2000), the most common and powerful data sources for qualitative case study research are interviews and document analysis (archival records and documentation). Therefore, as indicated in Table 4.5, this study uses qualitative semi-structured interviews and documentation, as well as other accessible sources for its data collection. The next section explains each of these data collection methods in more detail.

\subsubsection{Archival Records and Documentation}

Documents play a distinct role in any data collection when conducting a qualitative case study. Therefore, it is important to search the relevant documents in a systematic way (Yin, 2003). The most significant use of documents in this study is to provide an initial understanding of the non-adoption of XBRL. Later documents are used to validate interview data.

As discussed in Section 4.5, this study collects documents from a variety of sources for the period from March 1998 to December 2011. Most of the relevant documents were available electronically and were downloaded from the websites of the IRD, the Statistics Department, the SSC, the MED and media companies. Other documents not available through electronic sources were acquired through libraries or by making a formal request to the relevant organisations and government authorities. However, some documents were not available because they had been disposed of, deleted from the website domain or misplaced. Some documents were obtained to provide an understanding of the wider social, economic, and political environments that were likely to influence the decision relating to the non-adoption of XBRL.

This study collected 382 documents. A breakdown of the type of these documents is provided in Figure 4.3. 


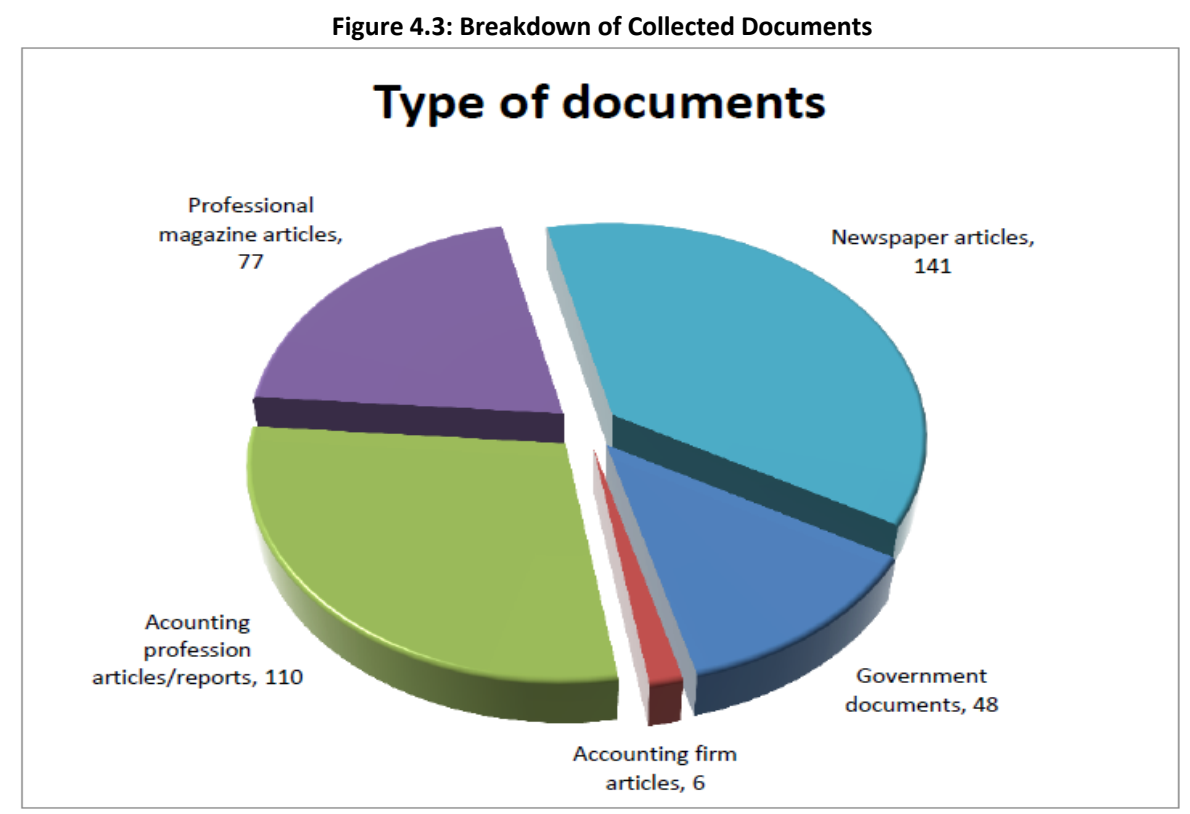

Documents from newspapers that covered XBRL technology and related stakeholder involvement were the largest number of documents at $36.9 \%$. Next, documents from the accounting profession including articles or report updates on XBRL from around the world, XBRL activities in New Zealand and XBRL related research constituted $28.8 \%$ of the documents collected. This was followed by documents from professional magazines at $20.2 \%$. Then, government documents such as the minutes of meetings, consultation papers, budget reports, minister speeches, research reports and presentations accounted for $12.6 \%$ of the documentary data set. Lastly, documents from accounting firms, which discussed and commented on XBRL initiatives, were $1.5 \%$ of those collected.

\subsubsection{Interviews and Interviewee Selections}

This study utilises interviews as a data collection tool. Interviews can take one of the several forms: structured, semi-structured or unstructured (Yin, 2003). A structured interview uses a formal questionnaire, but the interview is conducted face-to-face with the respondent. It is often related to a survey that requires collecting a large volume of data from a broad range of respondents (Gillham, 2000). In semi-structured interviews, questions are specified, but the interviewee is free to move beyond these questions to elaborate on his or her opinion, knowledge, experience and perceptions regarding a particular issue or past event relevant to the questions (Schram and Steen, 2001). Unstructured interviews mainly focus on the interviewee's thoughts, experiences, and feelings. This type of interview allows 
the researcher to prepare only a few key questions before the interview (Denscombe, 1998).

In this study, a semi-structured interview technique has been used. The semi-structured interview has been selected for three reasons. First, the technique is widely recognized as a powerful tool for generating rich data in investigating under-researched phenomenon like the non-adoption of XBRL (Fountain, 2001). Second, the technique assists in exploring participants' experiences and views of XBRL non-adoption; yet at the same time, it allows the interviewer to explore participants' responses further or to clarify issues emerging from the interview (Gillham, 2000; Sekaran, 2000), regarding XBRL adoption. Finally, a semistructured interview is a suitable data collection technique if it is used within the context of a multiple-case study (Jankowicz, 2005). That is because it allows the researcher to dictate both the topic and issue to be investigated while minimizing or preventing data bias through the careful pre-design of the interview questions.

Potential interviewees were identified by reviewing the prior literature and then performing a preliminary analysis of publicly available documents related to XBRL projects in New Zealand, technology adoption, XBRL stakeholders' perceptions, and the government's policy regarding technology adoption. Relevant groups identified included government agencies and ministries, accounting firms, the accounting professional body, business organisations and other stakeholders such as academics. About half of the identified interviewees were approached using personal connections and the snow-balling technique (Flick, 2009). Personal contacts are used to ensure that the person contacted will be willing to talk to the researcher (Arksey and Knight, 2002). Meanwhile, the snowballing technique is where the previous interviewee will suggest further contacts; personally introducing the researcher to them or just allowing their names to be mentioned in invitation letters that are sent to these contacts (Flick, 2009; Bui, 2011). The rest of the interviewees were contacted via email, which includes an invitation letter and an Information Sheet (as in Appendix C). The letter is customised so that it appeals to the person contacted.

The interviews were conducted in a semi-structured but informal manner. Interviewees were given opportunities to focus on the issues that interested them the most, instead of being pressured to comment on every single question (Warren, 2002). There were common questions that were presented to all groups and some customised questions that were only 
intended for a particular group. Customised questions were designed to suit the specific role, background and experience of interviewees in relation to the XBRL initiatives. Initially, the questions were formulated based on the prior literature, documents, and archival records, with the aim to explore and understand the factors that influenced the decision regarding XBRL adoption (Research question 1). Additionally, questions were constructed to discover and investigate the implications of the government's decision regarding XBRL for XBRL stakeholders (Research question 2). Then, following the reflection method, as described in Section 4.4, the interview questions were continuously reviewed to reflect new understanding and insights gained from the analysis of prior interviews. A list of sample semi-structured interview questions is provided in Appendix D.

The interviewees have been selected based on their job and involvement in XBRL projects. Some of the interviewees have double or triple roles in the different XBRL initiatives. For example, Interviewee A had been working in a government agency. Later, he moved to a university. Further, the interviewees' professional background varies depending on the role they play in the XBRL projects. The interviewees' backgrounds cover strategic, advisory, policy-making and technical areas. This diversification in the professional backgrounds of XBRL project members or observers provides sufficient data about different aspects of the XBRL initiatives, particularly regarding factors influencing XBRL adoption decisions. It should be noted that the data collected from the interviews has been validated through the usage of document analysis as explained in Section 4.6.1.1.

Table 4.6 provides the list of the 16 interviewees with some basic information relating to them. The details are listed in chronological order based on the interview date. The first column provides a unique and anonymous identifier for each interviewee. This identifier is used throughout the remainder of this chapter only. Some of the interviewees are well known at the domestic and/or the international level. Thus, by providing their organisation's name, people (especially those within the XBRL and accounting communities) will easily identify this person. The second column provides the number of sessions for each interviewee. The detail contained in the third column is their occupation area. The fourth column is used to categorise the interviewee's stakeholder group. 
Table 4.6: Summary of Interviewees' Details

\begin{tabular}{|c|c|c|c|}
\hline Interviewee & $\begin{array}{c}\text { Number of } \\
\text { Sessions }\end{array}$ & Area of occupation & Stakeholder group \\
\hline \multirow{2}{*}{$A$} & \multirow{2}{*}{2} & Government officer & Government agency \\
\hline & & Academic & Other stakeholder \\
\hline \multirow{2}{*}{$B$} & \multirow{2}{*}{2} & Government officer & Government agency \\
\hline & & Consultant & Business organisation \\
\hline \multirow{3}{*}{ C } & \multirow{3}{*}{2} & Government officer & Government agency \\
\hline & & Steering Committee Member & Professional body \\
\hline & & Auditor & Accounting firm \\
\hline $\mathrm{D}$ & 1 & Government officer & Government agency \\
\hline \multirow{3}{*}{$\mathrm{E}$} & \multirow{3}{*}{6} & Auditor & Accounting firm \\
\hline & & Steering Committee Member & Professional body \\
\hline & & Auditor & Accounting firm \\
\hline \multirow{2}{*}{$F$} & \multirow{2}{*}{2} & Academic & Other stakeholder \\
\hline & & Steering Committee Member & Professional body \\
\hline G & 1 & Government officer & Government agency \\
\hline \multirow{3}{*}{$\mathrm{H}$} & \multirow{3}{*}{2} & Auditor & Accounting firm \\
\hline & & Steering Committee Member & Professional body \\
\hline & & Government officer & Government agency \\
\hline \multirow{3}{*}{1} & \multirow{3}{*}{3} & Steering Committee Member & Professional body \\
\hline & & Tax Advisor & Accounting firm \\
\hline & & Consultant & Business organisation \\
\hline \multirow{2}{*}{$\mathrm{J}$} & \multirow{2}{*}{4} & Steering Committee Member & Government agency \\
\hline & & Government officer & Government agency \\
\hline $\mathrm{K}$ & 1 & Academic & Other stakeholder \\
\hline \multirow{2}{*}{$\mathrm{L}$} & \multirow{2}{*}{3} & Academic & Other stakeholder \\
\hline & & Institute Director & Professional body \\
\hline M & 2 & Government officer & Government agency \\
\hline $\mathrm{N}$ & 2 & Government officer & Government agency \\
\hline $\mathrm{O}$ & 1 & Government officer & Government agency \\
\hline $\mathrm{P}$ & 1 & Academic & Other stakeholder \\
\hline
\end{tabular}

Note: Area of occupation refers to the interviewee's occupation during their involvement in a specific XBRL initiative.

Figure 4.4 shows the interviewees' involvement from 1998 until 2012 in accounting and XBRL related activities either in or outside New Zealand. Based on the researcher's investigation, most of the interviewees were involved in more than one XBRL project. Interviewees like Auditor E, Academic F, Tax Advisor I and Academic L were involved in the LEAP+ project. At least seven interviewees; Steering Committee Member C, Steering Committee Member E, Steering Committee Member F, Steering Committee Member $\mathrm{H}$, Steering Committee Member I, Steering Committee Member J and Institute Director L were involved with Project First Step. While in the e-GIF project, Government Officer $H$, Government Officer J, Institute Director L, Government Officer M, Government Officer N, 
Government Officer O, Steering Committee E, and Consultant I were involved. Finally in the SBR programme, stakeholders like Government Officer A, Consultant B, Auditor C, Government Officer D, Auditor E, Government Officer G, Government Officer H, Consultant I, Government Officer J, Academic K, Government Officer N, and Academic P were involved. Their observations, opinions, experience, and knowledge enrich the data and assist in validating the results.

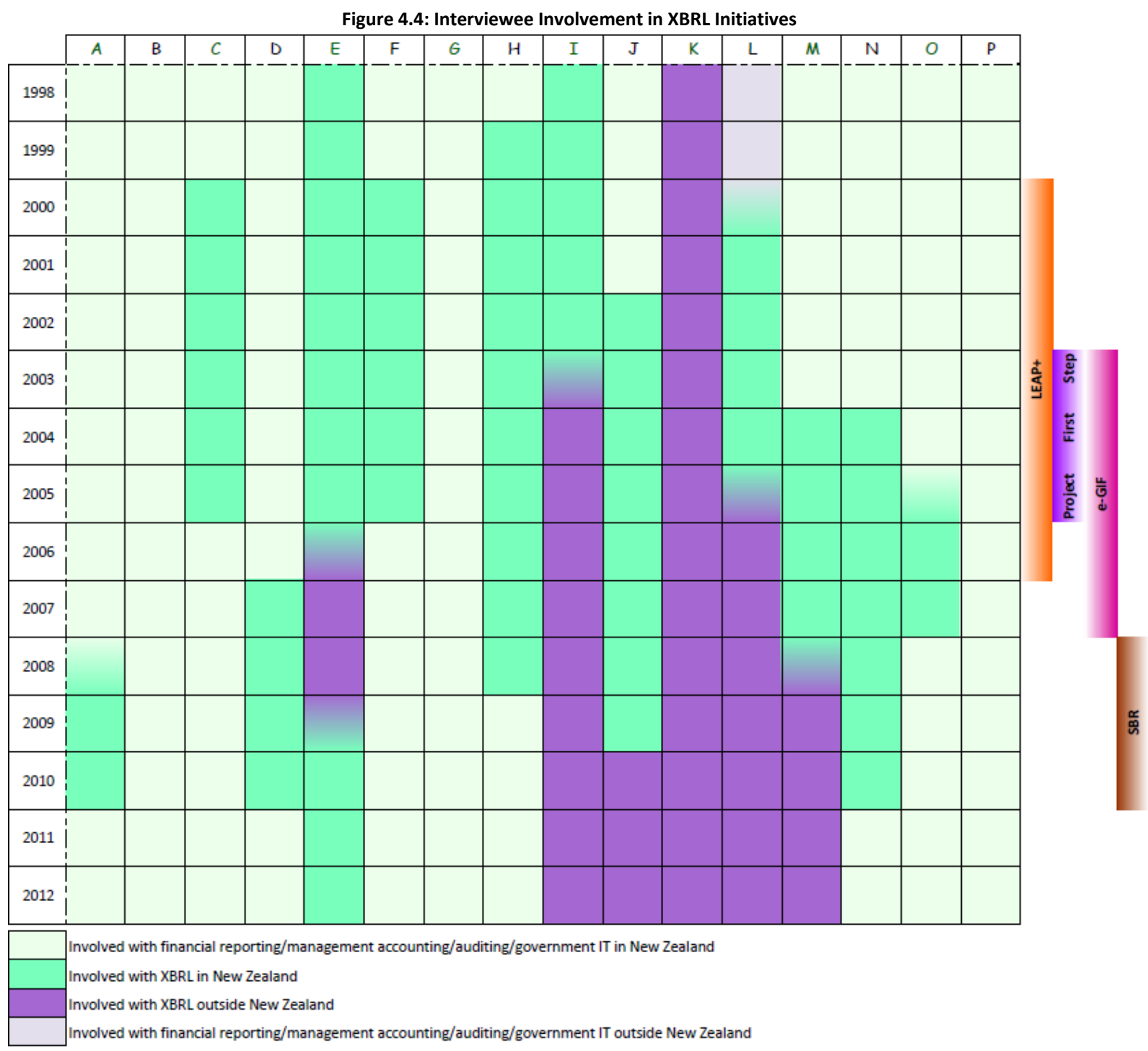

All interviewees were employed in senior roles within their respective organisations. The interviews were conducted during the period October 2013 to February 2014. The information sheet (as in Appendix B) for project initiation and consent forms (as in Appendix E) were provided to the interviewees before the commencement of the interviews. The information sheet included a brief description and the purpose of the study, guidelines for gathering information, and the protecting of interviewees' confidentiality. 
Each interview sessions lasted between 40 to 60 minutes, and the interviewee determined the time and location. Most of the interviews were conducted on a one-to-one and face-toface basis; others were carried out via a telephone call or Skype. All interviews were recorded with permission from the interviewees and transcribed shortly afterwards. Silverman (2000) indicates this is advisable as interview issues and topics are still fresh in the researcher's mind, and it allows a discussion of different findings before the next scheduled interview. As mentioned, in some circumstances, the discussion guide, which had been designed using key issues highlighted in the literature, was extended to incorporate new ideas or areas raised in previous interviews. This ensured that future interviews continued to add to the researcher's knowledge. This action is consistent with the reflection method (Section 4.4).

\subsubsection{Data Analysis}

In data analysis, the researcher examines, categorizes, tabulates, and recombines the evidence collected to address the propositions. Data analysis is one of the most difficult parts of the case study approach as there are many strategies or techniques but not all suits for each study particularly on non-adoption scenario (Yin, 1994).

Miles and Huberman's (1994) book is among one of few sources to guide researchers in qualitative data analysis process. They state that data analysis consists of three concurrent flows of activity: data reduction, data display and conclusion drawing or verification. Data reduction refers to a process of selecting, focusing, simplifying, abstracting, and transforming the collected data (Miles and Huberman, 1994). Data display is a process of organizing, compressing assembly of information that permits conclusion drawing and action (Miles and Huberman, 1994). Meanwhile, in conclusion drawing, the data is giving meanings by noting regularities, patterns, explanations, possible configuration causal flows and propositions. In this stage, researcher verify the data by re-checking with previous notes, searching for opinions of other interviewees or looking for replicate findings in other data set.

\subsubsection{Data Coding and Identifying Research Themes}

As mentioned above, all the interviews were digitally recorded and transcribed. The interviewees' identities were removed from the transcripts, and a code has been assigned 
as a means of identification (e.g., Government Officer A, Consultant B). A separate list of actual interviewees and the codes assigned to them is kept confidential.

Coding is a process that is used to generate research themes that contain pointers to the real data (Richards, 2014). The coding built to help the researcher to code the transcripts is based on events, stakeholders, factors and the implications of the non-adoption of XBRL (as in Appendix F). Instead of using a computerised coding system such as Nvivo, the researcher chose to apply a manual coding system, which uses colour as its main coding technique. For example, orange was used for the technological factors, pink for the organizational factors and green for the environmental context factors. The manual coding employed ensures consistency in coding and provided the ability to build strong understanding throughout the different sources of data.

Prior to coding, all the transcripts were reviewed first. During the reviews, the researcher coded the transcripts based on interviewees' involvement in the XBRL projects including information such as year, stakeholder group and stakeholder involvement (as shown in Appendix F). This thesis refers to stakeholder involvement as the level of stakeholder participation in any of the XBRL projects. Their involvement can be classified into active, supportive and observer. Active means the stakeholder participates and is involved throughout the project. Normally, active stakeholders fund the project or contribute other resources like equipment and expertise. A supportive stakeholder participates in the project by supporting the active stakeholder with information, skills, idea development, and anything else related to XBRL, but for a certain period of time. Meanwhile, an observer stakeholder is one that observes what is happening in the project. To some degree, observer stakeholders report their observations related to XBRL to the public. Different stakeholders have different types of involvement, thus building different perspectives or interpretations towards XBRL technology. By presenting different points of view in relation to the research objective, it contributes to the reliability of this study's findings. Later each transcript was coded one by one to identify the predicted and unpredicted factors and finally, the potential implications.

The process of coding in this study was started by using descriptive coding (Miles and Huberman, 1994), where phrases, words, and sentences from the interview transcripts or documents have been labelled using relevant words related to the stakeholder groups, 
stakeholder involvement, factors, and implications. Each recorded transcript is stored in a Word Document. After completing all the interviews, the transcripts were coded. At this point, the following options were available:

i) Coding the data at the word level;

ii) Coding the data at the line level;

iii) Coding the data at the sentence level; and

iv) Coding the data at the paragraph level.

The data in this thesis was coded at the sentence and paragraph levels. When coding is done at the sentence level that results in a loss of meaning then the researcher will use coding at the paragraph level. This is done to ensure the completeness and meaningfulness of the data. Each sentence or paragraph was either (a) coded into one of the categories that were pre-determined based on the factors in the research framework; (b) coded into a new category that was not pre-determined but had emerged during the interviews; (c) coded into multiple categories; or (d) not coded if it was found to be unrelated to the factors that affect the non-adoption of XBRL.

Axial coding has thus been used to develop the research themes (Jones and McEwen, 2000) systematically. Axial coding is achieved by developing relationships and core categories according to a prior research model (Creswell, 2003). This step assists in reducing the data required to be analysed. Throughout this coding process, the transcripts, in particular, have been revisited to ensure the axial codes and meanings have been interpreted in context and according to the research framework. Further, answers have been mapped to a particular interview question and compared to other interviewees' transcripts.

\subsubsection{Reliability and Validity}

There are no pre-established standards in qualitative research to ensure the quality of the data analysis and the accuracy of the findings. However, there are several actions that can be taken to achieve the quality. A brief discussion of these methods can be found in method-related literature such as Guba and Lincoln (1994); Miles and Huberman (1994) and Patton (2002). The methods employed in this study were purposely chosen to increase the validity and reliability of the findings of the case study. 
Firstly, the researcher has to have an analytical strategy so as to treat evidence fairly, produce compelling conclusions and rule out alternative interpretations (Yin, 1984). The researcher relied on theoretical propositions that lead to the case study and then developed a descriptive framework for organizing the case study. This approach helped the researcher successfully analyse the case study evidence.

Secondly, the researcher applied an iterative two-step data analysis process. That means, the researcher conducted data collection and pre-data analysis hand-in-hand, which aided reflection and the revision of the data collection and analysis process. The second step of data analysis, which was the main case study analysis, took place after the data collection was completed.

Thirdly, as suggested by Miles and Huberman (1994), validity and reliability depend on the skills of the researcher. In order to enhance the reliability and validity of this research, the researcher made herself familiar with the study's phenomenon and setting, developed a strong conceptual interest and used a multi-method approach.

Fourthly, as discussed by Yin (1984), validity and reliability of the study findings can be established by using multiple sources of evidence, creating a case study database, and maintaining a chain of evidence. In this study, the researcher use triangulation to address an extensive range of historical, attitudinal, or behavioural issues. In creating a case study database, the researcher organized and documented the data into individual tables. In each table, the major findings for each research question were summarized. Maintaining a chain of evidence requires a researcher to have clear cross referencing to methodological procedures and to the resulting evidence (Yin, 1984). For this step, the researcher provided direct quotations from the interviews to support the study conclusions and to ensure that original evidence was not lost. At the same time, the study conclusions could be traced back to the original data.

Finally, before the actual coding took place, the researcher performed an inter-coder exercise with someone who has a strong background in interpretive research. The researcher coded the first two transcripts and the person checked for accuracy and consistency of coding in the transcripts. The person also suggested ways to improve the coding that were implemented. The exercise increased the reliability and validity of the coding guide and the coding process. 


\subsection{Ethical Considerations}

Before conducting the interviews, the research design had to be approved by the Victoria Business School's Human Ethics Committee. The application was prepared and submitted to the Human Ethics Committee. The approval was granted in December 2012. As the interviewees should be protected from harm, loss of privacy and deception; a consent form was prepared and signed by interviewees before commencing the course of interviews. All the data collected during the study has been kept in secure storage. The researcher and her supervisors are the only people that have access to the data collected.

\subsection{Chapter Summary}

The aim of this chapter is to present an appropriate research methodology for the study. Since research on the non-adoption of XBRL is considered an under-researched area, attention is given to the methods employed to justify the claim that the potential research outcome will contribute to the body of knowledge. Thus, this study needs to explain clearly the methods and methodologies, so the results are convincing and credible.

The objective of this study is to investigate the factors that influenced the decision not to adopt XBRL for use in business reporting and the implications of the decision for XBRL stakeholders. This study will take a post-positivist epistemological stance, utilizing qualitative research methods. A qualitative research method is a suitable method to use to investigate a contemporary phenomenon like the non-adoption of XBRL. Besides, this method allows the in-depth examination of each of the four XBRL projects in New Zealand through studying this phenomenon in its natural setting.

The research strategy is to conduct four case studies to investigate the influential factors relating to the non-adoption of XBRL and the implications of this. Through a case study approach, the researcher has an opportunity to investigate in-depth, the four key XBRL projects through a series of semi-structured interviews and documentation analysis. Moreover, multiple-case studies are used to explore and understand the relevant events and factors that are related to the non-adoption of XBRL. The use of multiple-case studies assists in providing insightful conclusions and supports the validity of the revised research framework. 
Interview and documentation analysis are the main data collection method utilised in this study. The data collection stage and data analysis methods have been explained. The interview and data management processes have been described. In the data analysis section, the coding technique used to identify themes has been presented and explained. The next chapter, Chapter 5 is the first of the results chapters and presents a historical chronology of significant events related to XBRL technology in New Zealand from 2000 to 2010. 


\section{Chapter 5: XBRL Initiatives in New Zealand - A Historical Overview}

\subsection{Introduction}

This chapter provides an overview of the XBRL initiatives in New Zealand based on the research findings. The XBRL journey started in New Zealand at the end of the 1990s. It is important to consider all XBRL initiatives because it provides an understanding of how each initiative happened, the people involved and the sequence of related events. The views represented do not represent the official views of an organisation but rather the views of the individuals who took part in the projects.

Through research, four XBRL initiatives or projects (case studies) were identified. The projects started with the LEAP+ project, followed by Project First Step and the e-GIF project and finally, the SBR programme. The first two projects were controlled by a group of professional individuals in private organisations or a professional body. Government agencies controlled the last two projects.

The shifting of XBRL initiatives from a professional body or private organisation to government agencies is an interesting event to explore. Many factors influenced the move. Through this XBRL history, the chapter provides the connections between the events and factors, and gives a basic background of what happened with XBRL initiatives in New Zealand from 2000 to 2010. It also provides the background for the case studies (XBRL initiatives) investigated in this thesis. In the final section, the chapter summarises this history and presents a timeline of XBRL development in New Zealand.

\subsection{An Overview: XBRL Initiatives in New Zealand}

A few people in New Zealand became interested in using XML for financial reporting as early as 1998 . These individuals also kept an eye on international developments related to $X M L$ and financial reporting. This is consistent with the nature of New Zealanders who like to be up-to-date with things related to technology (Maharey, June 18, 2010). Among the earliest New Zealanders interested in XBRL, were several key individuals including Mark 
Hucklesby, Graeme Sinclair, Grant Boyd, Josef Macdonald, Alan Teixeira and David Hay ${ }^{26}$ (Hucklesby and Macdonald, 2001e). They learned from Hoffman's experience and obtained funding from the local accounting professional body, the Institute of Chartered Accountants of New Zealand (ICANZ).

"It became very clear to Grant Boyd, myself and a few others, that effectively, we needed a sponsor to get ... XBRL into New Zealand." (Auditor E)

Since they did not have enough knowledge about XBRL, these individuals used the funds to attend seminars and conferences related to XBRL. As they started to develop the confidence to engage in XBRL-related initiatives, they established a collaborative project or group.

"...NZICA had a SIG. They had their budget. Those budgets could be used to support the interest of the group... Those funds were used to hold various events like sending delegates to some XBRL conferences. At least, we could be aware [of] and contribute to the activities of XBRL internationally." (Auditor E)

There were four key XBRL initiatives in New Zealand between 2000 and 2010:

1) The Leading Edge Accounting Product (LEAP) + project;

2) Project First Step;

3) The e-Government Interoperability Framework (e-GIF) project; and

4) The Standard Business Reporting (SBR) programme.

Figure 5.1: XBRL Initiatives in New Zealand

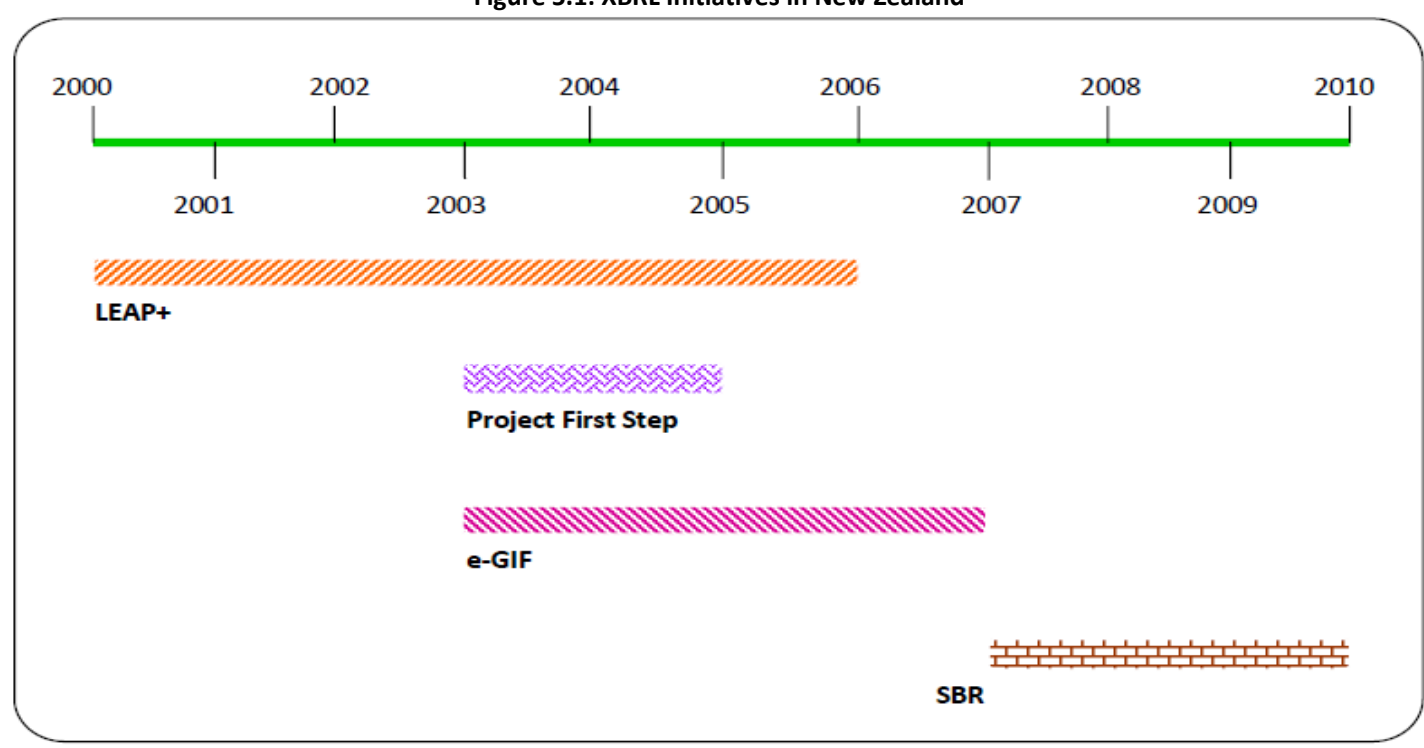

\footnotetext{
${ }^{26}$ Where names are known from publically available documents, the New Zealand Chartered Accountants Journal and the media, then, they are used in the results chapters 5 to 8 .
} 
Figure 5.1 depicts the XBRL initiatives in New Zealand. Additionally, the figure also shows the period for each of the XBRL projects. There were overlapping projects from 2003 to 2005 for LEAP+, Project First Step, and e-GIF. Each of the four initiatives will be outlined below and then expanded on and analysed in Chapters 6 and 7.

\subsection{The LEAP+ Project (2000-2005)}

The LEAP+ project was a collaboration between Ernst \& Young, an accounting firm and the Auckland University Business School. The project was designed to provide an understanding of XBRL.

"What did we do in LEAP +? We did that project when nobody in the world had heard of or had the visualization of an XBRL file. We used the style sheet to render XBRL." (Tax Advisor I)

The group built a prototype taxonomy based on International Accounting Standards (IAS) and New Zealand GAAP. With the help of EURECA Software, a website for LEAP+ was successfully built.

"Throughout 2000, there was the creation of the functional specification of what the LEAP+ website would look like. It was then developed by the software company called EURECA Software with a Project Manager." (Auditor E)

This website was used by Ernst \& Young and the Auckland University Business School from 2001 as a platform for training, learning and introducing XBRL to accounting staff and university students. Both organisations stopped using the website in 2006.

\subsection{XBRL Steering Committee under the Auspices of ICANZ (2001-2006)}

At the same time as producing this LEAP+ website, almost the same individuals supported another group formed under the auspices of ICANZ. In October 2001, a Steering Committee was formed. The original members of this XBRL-focused Steering Committee were Graeme Sinclair (Chair), Grant Boyd, Mark Hucklesby, David Hay, Alistair Boult and Raymond McNickle (Hucklesby and Macdonald, 2001e). The ICANZ General Manager for Corporate Services managed to obtain funding from the Institute for this committee to run their activities.

The goals of this committee were to (Hucklesby and Macdonald, 2001e): 
i) Provide a liaison and facilitation function for XBRL within New Zealand;

ii) Maintain contact with and keep updated on international developments;

iii) Educate members, government and businesses about XBRL as an enabler to business;

iv) Produce an education programme for members and business entities; and

v) Sponsor the development of a universal taxonomy for New Zealand in the most efficient and effective way possible.

In order to achieve the goals, the first task of the committee was to consider the types of infrastructure that were needed to support the deployment of XBRL in New Zealand. This included the development of an XBRL taxonomy based on IAS and New Zealand GAAP. At the same time, the committee also attended the $3^{\text {rd }}$ XBRL International Conference in Sydney, Australia at the end of October 2001 (Hucklesby and Macdonald, 2001e). By participating in this conference, the committee intended to invite people from government departments, industry representatives, regulators, banks, software developers and other users of financial reporting information, to be members of the Steering Committee.

As a result, people like Karen Piercy from the IRD, Andrew Garrett from the NZX, Vince Galvin from Statistics New Zealand and Stuart Judge from the Companies Office joined the committee in March 2002 (Hucklesby and Macdonald, 2002c).

The prototype of the New Zealand taxonomy built for LEAP+ was used as a reference to build the new IFRS taxonomy at the international level.

"Before that, we had done some work where we had built a prototype of the New Zealand taxonomy, the New Zealand GAAP taxonomy. That was used by some people that came to Singapore in 2002, which helped build the IFRS taxonomy." (Tax Advisor l)

The draft of New Zealand Taxonomy, which was based on IAS and New Zealand GAAP, was completed by the Steering Committee in 2002 (Boyd, 2004a). As the Steering Committee had targeted being an XBRL jurisdiction of XBRL International, they needed to have a country taxonomy and show their commitment to XBRL (XBRL, 2009). Further, in order to get more involvement and support from public organisations, additional members were approached to join the Steering Committee. Due to the efforts of the Steering Committee, XBRL International accepted their membership application officially on August 2, 2002 
(Hucklesby, 2002). With that acceptance, the Steering Committee had established a local XBRL jurisdiction in New Zealand.

\subsubsection{Project First Step (2003-2005)}

In early 2003, IFRS was introduced to the international arena. There is a possibility that the introduction of IFRS and their potential impact on financial reporting requirements in New Zealand delayed the release of New Zealand Taxonomy because the $2002 \mathrm{draft}$ would need further revisions to make sure it was compatible with the IFRS taxonomy (Boyd, 2004a; Davidson et al., 2006). At ICANZ, the appointment of a new Chief Executive Officer (CEO) with a different view and mission for the Institute more or less ceased the Institute's support. However, these two developments did not stop the Steering Committee from starting Project First Step. This pilot project, which tested the New Zealand Taxonomy on ten listed companies ${ }^{27}$ was carried out over five months from November 2003 until March 2004 (Hucklesby and Macdonald, 2003c). The NZX agreed to fund this pilot project. The outcome of this pilot was presented at the $20049^{\text {th }}$ XBRL International Conference in Auckland, New Zealand (Boyd, 2004b).

The contribution, achievement, and involvement of New Zealanders in XBRL development, either at the national or international level were followed by XBRL International communities, especially the XBRL consortium. As a result, New Zealand's XBRL key players were appointed to important positions such as Chair of XBRL International Marketing and Communications Working Group, Vice-Chair of XBRL International Domain Working Group (DWG), a member of the XBRL International Steering Committee, and core builders of the IAS taxonomy at the international level (Hucklesby, Macdonald and Teixeira, 2003b; Hucklesby and Macdonald, 2004a). It was believed such appointments had both pros and cons for the progress of XBRL in New Zealand in that it raised New Zealand's XBRL profile internationally, but it removed XBRL experts and knowledge from New Zealand.

Further, realizing that New Zealand probably only had one opportunity to host the international conference, the Steering Committee started to lobby XBRL International.

\footnotetext{
27 The ten companies were: Auckland International Airport, Carter Holt Harvey, Dairy Brands, Fisher \& Paykel Healthcare, Fletcher Building, Northland Port, Sky City, Telecom, The Warehouse and the New Zealand Stock Exchange (NZX)
} 
"In order to host the international conference, effectively we had to give notice nine months before the conference. Towards the end of 2003, we said 'Right, we want to host an XBRL International Conference in New Zealand,' which we did." (Steering Committee Member E)

\subsubsection{New Zealand's Hosting of the $9^{\text {th }}$ XBRL International Conference (2004)}

Early 2004 saw slow progress (Rondel, 2004) regarding XBRL development from the Steering Committee as possibly most of its members were busy preparing for the $9^{\text {th }} \mathrm{XBRL}$ International Conference in New Zealand and others were working overseas at the international level. The conference was held at the Hyatt Regency Hotel, Auckland from 10 until 14 May 2004, with the theme 'XBRL: Exchanging Business Information' (Boyd and Teixeira, 2004a). During this conference, the Steering Committee managed to get full support from its members. There were 190 delegates from all over the world including local delegates (XBRL, 2011). David Cunliffe (MP) was the keynote speaker at the conference (Boyd, 2004b). Cunliffe, at that time, held the ICT portfolio and was Associate Minister of Finance, Revenue, and Communication (Rondel, 2004).

News related to XBRL progress in New Zealand, which was shared during the conference, included the presentation by the NZX on Project First Step, the release of the New Zealand Taxonomy as an acknowledged taxonomy and the release of Microsoft Office XBRL tools (Boyd, 2004b). The appointment of New Zealanders at the international level also continued in 2004.

\subsubsection{Increasing Awareness in the New Zealand Business Community (2003-2004)}

As awareness about XBRL in New Zealand started to increase in 2004, more seminars and workshops were arranged. However, the Steering Committee had a specific target audience and did not put much effort into all the potential adopters (Rondel, 2004). They probably made this choice because they knew XBRL was complex, and that it would be difficult to convince people to use it. Instead of focusing on fully educating potential adopters about XBRL technology, especially on its uses and benefits, the Steering Committee chose only to look at increasing awareness among potential adopters. 
"Really, what we were trying to do was, at least, to create awareness and an early education programme; perhaps, more on awareness of the capability of XBRL and deployment in business data." (Steering Committee Member E)

Between 2003 and 2004, the Steering Committee did achieve their target of increasing awareness within interested potential adopters such as big accounting firms, government agencies, regulators, banks, business organisations, and universities. However, they did not successfully educate the chartered accountants at large (Davidson et al., 2006).

\subsubsection{The Struggle to Progress (2005)}

In early 2005, almost all interested stakeholders were busy with the voluntary adoption of IFRS. While NZICA was playing an important role in preparing its members to use the new international reporting standards, people in one of the key government agencies were busy forming the e-GIF XBRL Standard Working Group. Furthermore, the Steering Committee struggled to make progress with Project First Step because NZICA had cut their funding for the Steering Committee activities. Among the possible reasons for this cut were the different interests and lack of support from NZICA top management, the emphasis on voluntary adoption of IFRS from 2005 and the perceived limited benefit of adopting XBRL. The mandatory adoption of IFRS was to start on 1 January 2007. Throughout 2005, the Steering Committee probably survived because the committee still received fees from XBRL New Zealand members. However, this could not last forever. Dramatically reduced support from business organisations (Cordery et al., 2011), followed by the disintegration of Project First Step by the NZX;-, placed the Steering Committee in a difficult situation. Within the Steering Committee, the chair resigned his chairmanship and was replaced by the deputy chair (Steering Committee Member E). Additionally, more members went overseas for better opportunities, and others lost interest in XBRL. The Steering Committee simply ran out of team members.

\subsection{Shifting the Initiative from the Professional to Government Auspices (2006)}

With these challenges, 2006 became a critical point for the surviving Steering Committee members. The remaining members had to decide where they should go from there after the disintegration of Project First Step, the loss of funding and the lack of support from business organisations (Steering Committee Member E). 
Nonetheless, the remaining members still tried to keep it going. In 2006, they negotiated with XBRL International, in an attempt to maintain their membership without paying any fees. However, the consortium was not ready to accept that proposal.

"...we could not afford to pay the affiliation fees and XBRL International was not really prepared to allow us to come in and participate on a no fees basis." (Steering Committee Member E)

As a result, New Zealand became the first jurisdiction to stop their XBRL International affiliation (Steering Committee Member E). The second best option available to the Steering Committee was to amalgamate with the XBRL Australia jurisdiction. After some discussion and a meeting between members and XBRL Australia, the Steering Committee decided to withdraw their membership from XBRL jurisdiction. The informal process of amalgamation with XBRL Australia started and with that, the Steering Committee, under the auspices of the accounting professional body, was dissolved.

"XBRL New Zealand blended itself, almost unified itself under the jurisdiction of Australia, which was almost completed by the end of 2006. XBRL in New Zealand collapsed after a write-off." (Steering Committee Member E)

With that dissolution, the XBRL initiatives shifted from being under the auspices of private or professional organisations to being controlled by the public sector. The remaining members still provided their expertise wherever possible to support the continuation of the XBRL initiatives in New Zealand that were now in the government space.

\subsection{The e-GIF Project (2003-2007)}

The need for the development of e-GIF was first identified in February 2002 (SSC, 2008). Under its business services layer, XBRL was proposed as a standard for business reporting purposes. This e-GIF project for business reporting was led by the IRD with other members from the SSC, the MED, the Ministry of Social Development (MSD), Statistics New Zealand, The Treasury, the Accident Compensation Corporation (ACC), XBRL New Zealand, the OAG, and the NZICA. The IRD had only started to learn about XBRL in 2003 when individuals from the agency were empowered by top management to look at anything related to $\mathrm{XBRL}$ in New Zealand.

"I had a meeting with a National Advisor. He said, "I need somebody to do the watching brief for XBRL." He asked me whether or not I was interested in taking it on 
because I dealt closely with tax agents. It was something that seemed to be in line with accounting and tax agents. He asked me to look at it, and so I did. I did some research on it... I asked him if I could attend an XBRL International Conference to get a better understanding of the "nuts and bolts." I went to that conference, which was held in Auckland." (Government Officer J)

During that time, there were two XBRL projects underway in New Zealand: the LEAP+ project and the Project First Step. The IRD had direct involvement in Project First Step as a member of the Steering Committee.

What happened next? Individuals from the IRD investigated XBRL, especially from a compliance cost reduction perspective (Government Officer J). As part of their effort, IRD staff took turns attending the XBRL International Conferences. Further, they were involved and actively learnt from Project First Step and consulted with other countries such as Australia and the Netherlands (Government Officer J). In addition, the IRD mentioned they worked together with the Australians and Dutch at the local and international levels.

"...there were three main players at that stage. They were the Netherlands, Australia, and New Zealand. We did much work both internationally and locally through the e-GIF committee, around how we would put these in place." (Government Officer J)

As a result, they also formed an e-GIF XBRL Standard Working Group in 2005.

\subsubsection{The Quality Regulation Review (QRR) and Financial Reporting Amendment Act 2006}

Under the Ministry of Commerce, the Quality Regulation Review (hereafter known as QRR) commenced in May 2006 for 15 months. This review investigated ways of eliminating duplication, inconsistencies, and uncertainty where multiple regulatory frameworks intersected and looked at improving the government's process for accessing and monitoring the impact of regulations ${ }^{28}$. Through the QRR, the government considered examining the feasibility of introducing SBR as had been introduced in the Netherlands and Australia. With serious attention from government, especially the Ministry of Commerce and the Prime Minister, XBRL technology appeared to have a bright future in New Zealand. Six months after the QRR started, the MED introduced the Financial Reporting Amendment Act 2006

\footnotetext{
${ }^{28}$ http://www.med.govt.nz/templates/MultipageDocumentTOC 30135.aspx
} 
that was aimed at reducing the financial reporting obligations of a range of reporting entities. While XBRL, through the SBR proposal was going to be used to reduce the compliance cost of reporting to multiple regulators, the introduction of Financial Reporting Amendment Act 2006 had the same impact, making the use of XBRL for this purpose seemingly redundant.

\subsubsection{The e-GIF Progress (2006-2007)}

In the meantime, the IRD was actively progressing with the e-GIF project. The first phase of the e-GIF was to conduct an XBRL feasibility study in 2006 by using IR10 forms. This exercise involved two government agencies and was successfully completed. With a positive result from the phase 1, they proceeded to the next step, which was to prepare the business case for implementing XBRL within several government agencies.

The e-GIF XBRL Standard Working Group kept working on phase 2. In May 2007, there was a change of Chief Executive and Commissioner in the IRD. Not long after that, the QRR was completed, and the Cabinet Economic Growth \& Infrastructure Committee considered the QRR final report. The report itself stated that "the officials were now looking for a solution" (Dalziel, 2007). The solution was meant to be SBR, which used XBRL as a medium to achieve their goal. The QRR final report did not convince the Cabinet Economic Growth \& Infrastructure Committee that SBR was the solution, thus, the committee requested a further detailed analysis of the SBR initiative. This led to a change in the lead government agency.

\subsection{Changing the In-Charge Government Agency (2007)}

The Minister of Commerce mentioned that her ministry would like to be in charge of the initiative. However, an interviewee from one of the government agencies noted:

"Unfortunately, the IRD's executive decided that it should shift from IRD being the champion of the project to the MED taking it over. The reason for that was because MED had a business-friendly hub focus, whereas the IRD was the tax authority." (Government Officer J)

Soon after that, there were a series of meetings and the final decision was to shift the XBRL initiatives, particularly the e-GIF project, under the IRD, to MED. Again, the same government official mentioned: 
"Unfortunately, nobody wanted it; nobody wanted to pick it up in MED." (Government Officer J)

Meanwhile, people from the IRD felt reluctant to shift the e-GIF initiative, but they did not have the power to retain the initiative in their agency (Government Officer J). The initiative officially moved to MED towards the end of 2007. While the IRD had to hand over the e-GIF project to MED, people in the MED were reluctant to accept the project. However, because the Minister of Commerce had given the instruction to take over the project, the MED had no option but to accept it. They experienced difficulty in finding an appropriate chairperson for the project. Again, using the Minister's power, they managed to appoint a chairperson within the Ministry to lead the project. However, as mentioned by an interviewee from the government agency, the chairperson was not that interested in the XBRL initiative. He noted:

"They were not particularly interested and the guy that was eventually given it was due to retire (I think) not so long after. He wanted to kill it. He did not think it was particularly good; he thought it caused too much trouble; he thought it would cost too much." (Government Officer J)

Once the e-GIF project shifted to MED, the project name changed to SBR. However, MED was happy to retain the members of the e-GIF team, but brought new members from the MED into the SBR programme. Again, as happened with Project First Step, some of the original members of the e-GIF project team lost interest in XBRL and others moved overseas for better opportunities.

\subsection{Standard Business Reporting (2007-2010)}

In order to get a broad perspective when producing the business case, the MED asked people from various backgrounds, including a representative from NZICA and an accounting firm to be involved. This was probably because they wanted expert knowledge, experience, and feedback to be embedded in the business case. The group finally managed to complete the business case in April 2008 and then submitted it for review by the Cabinet Economic Growth \& Infrastructure Committee.

Among the key features of SBR is the Cluster Model of Reporting. Under this model, all government agencies would be grouped into clusters, based on having an interest in 
receiving the same or similar information from businesses (Hodgson, Dalziel and Cosgrove, 2008). Figure 5.1 illustrates the situation before the introduction of SBR. It shows that a business has to report directly to many different government agencies due to their regulatory responsibilities. Reporting requirements are influenced by factors like industry, viability, structure or whether a firm is an exporting or importing one (Hodgson et al., 2008).

Figure 5.2: Current Reporting Channels

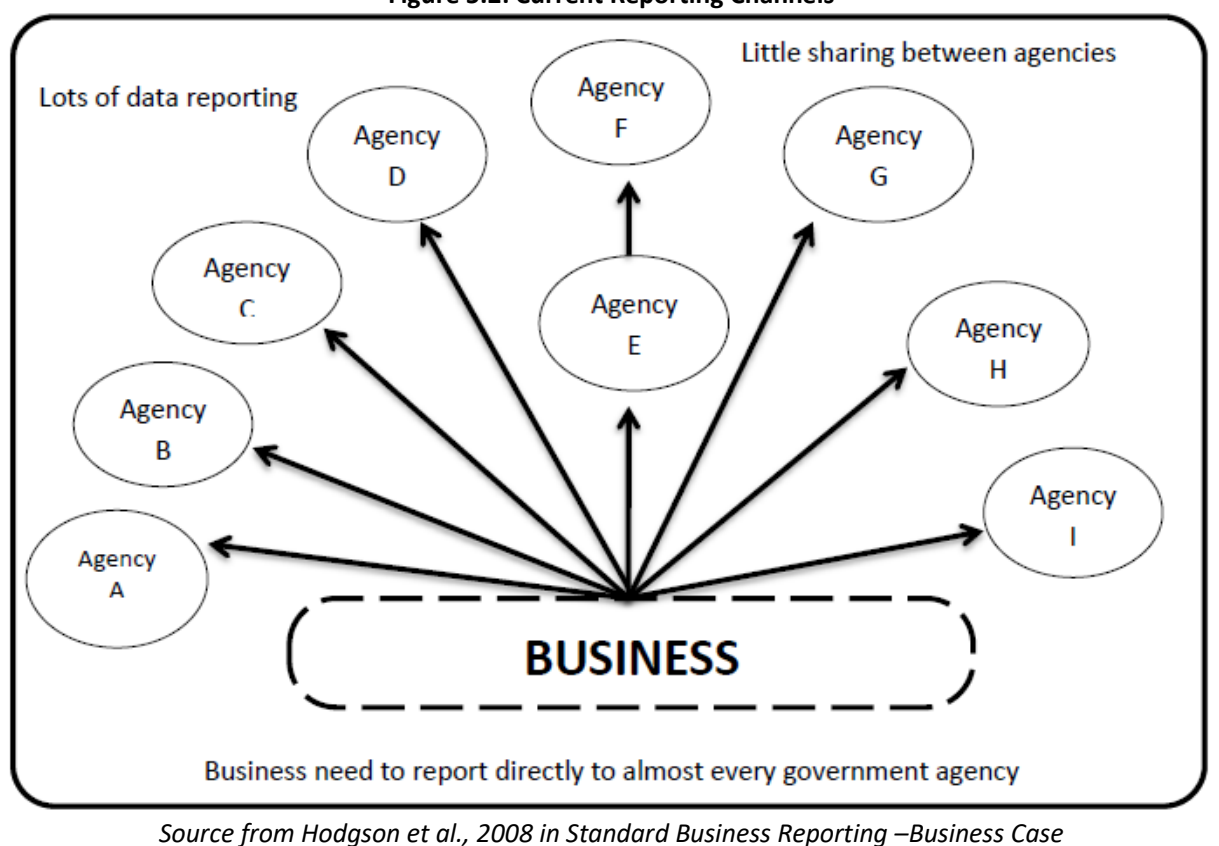

The concept of grouping government agencies into clusters would serve several purposes (Hodgson et al., 2008). First, it would ensure that government agencies with the highest degree of common interest in data definition, data sharing, and reporting arrangements were aware of each other and shared prime responsibility for achieving meaningful reductions in the reporting burden. Second, it would reduce the degree of complexity and coordination. Third, it would allow a level of customization of approach to be applied to diverse reporting realities. Lastly, the cluster model would also reduce the risks and facilitate earlier delivery of essential elements.

Figure 5.2 illustrates how a cluster of government agencies would receive the same data from businesses (Hodgson et al., 2008). There is scope for businesses to report to the group as a whole via a single or, at least, simplified channel. With streamlined reporting to a cluster, government agencies would need to develop new data sharing arrangements in some form to ensure they still had the business information they required to carry out their functions. In addition, for the purpose of data confidentiality, not all government agencies 
within a cluster would have access to all the information reported to the cluster. Each government agency would have access to the same information that they currently received from businesses. Meanwhile, businesses would not have to report the same information multiple times to various government agencies within the same cluster.

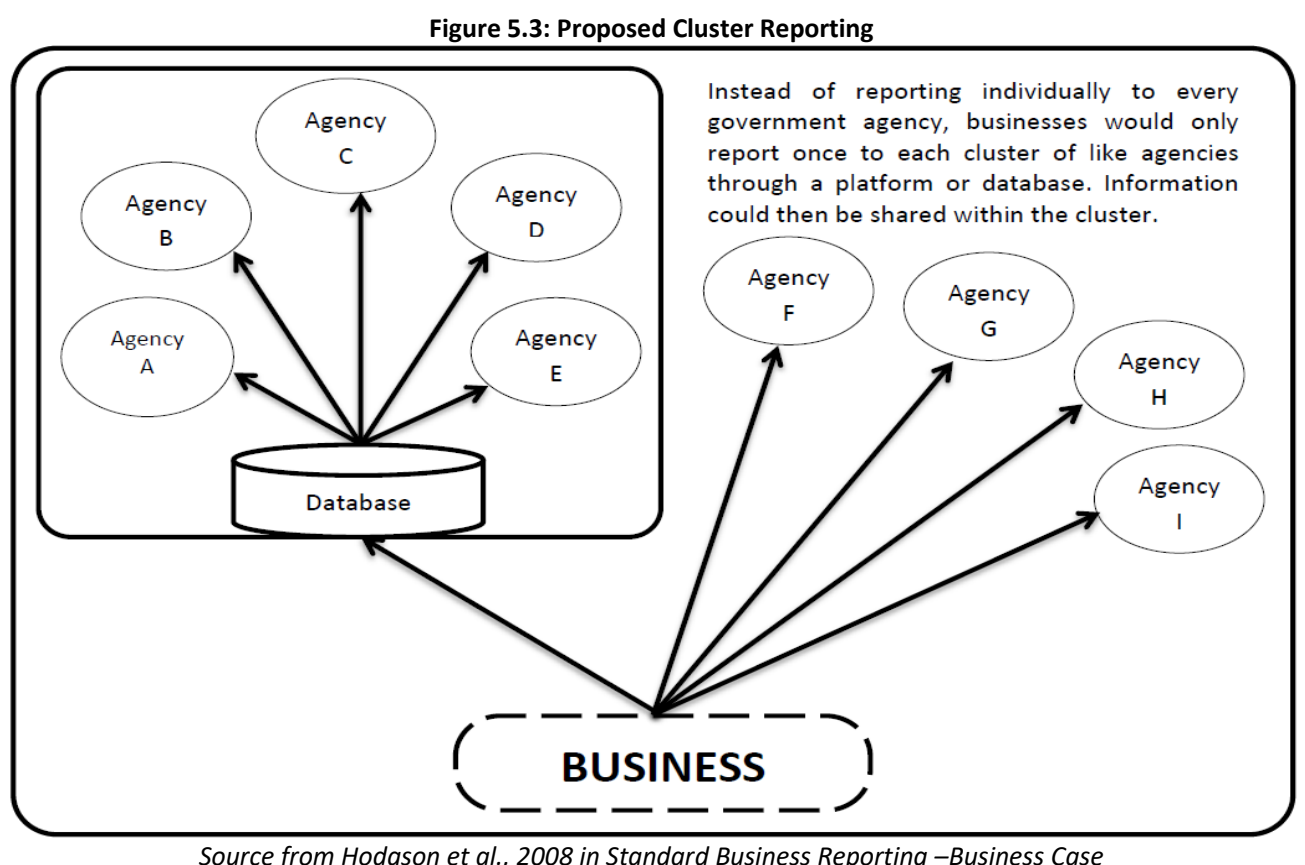

Based on research performed in Australia, Figure 5.3 shows the impact of different clusters on the total business-reporting burden (Hodgson et al., 2008). The figure details possible clusters of agencies according to their size in terms of reporting burden and number of business impacted by government agency requirements.

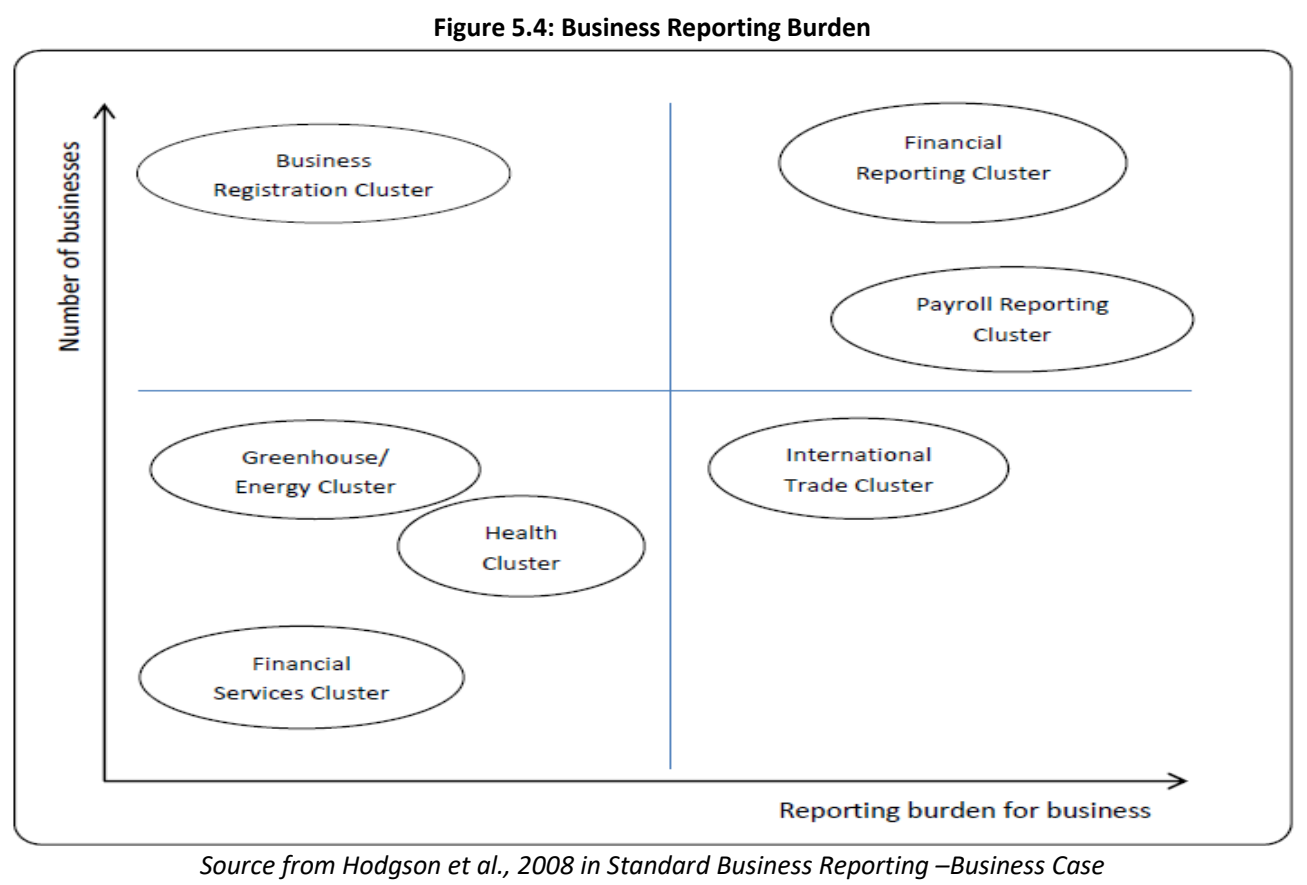


At this stage, the cabinet committee approved the technical solutions (particularly the use of XBRL technology) and the economics of the implementation of an SBR initiative. As a result, within the MED, the official SBR development team was established. Among the first things to be done was to test the taxonomy that had been completed (while in the e-GIF project) and validate it against XBRL Specification 2.1 and XML standards. From there, the team created and designed the New Zealand Taxonomy for the public sector. The team also completed the documentation of the XBRL standard and determined future governance and monitoring arrangements. At this point, the future of XBRL in New Zealand looked bright. However, two crucial events in 2008 changed the whole landscape.

\subsubsection{The 2008 General Election and the Global Financial Crisis}

Two important events happened in 2008: the $49^{\text {th }}$ New Zealand General Election and the global financial crisis. In the $49^{\text {th }}$ general election, the National Government won, which meant there was a change of government from Labour to National. Consequently, there were changes in the ministerial portfolios as well as new members of the SBR team. Very soon after the general election, the peak of the global financial crisis hit New Zealand along with other countries around the globe. This world financial crisis made the available resources, especially money, very limited. The new government had to rearrange their plans and strategies to get through these critical economic conditions. Although some XBRL stakeholders saw these two events as potential barriers to SBR, it did not impact the SBR programme immediately. However, slowly over time, the SBR group started to feel the effects of these events.

\subsubsection{Resultant Funding and Budget Cuts (2009-2010)}

During 2009, the commitment to the SBR programme continued.

"We continued to push for it, in the IRD and Statistics New Zealand in particular. In the end, it was excellent." (Government Officer J)

The SBR Working Group analysed the data from the feasibility study (done in 2006) and the IR10 pilot taxonomy (completed in 2008). Based on the analysis, the SBR Working Group concluded that the XBRL standard should be changed from 'Under Development' to 'Recommended,' under the e-GIF framework. However, this was subject to ongoing consultation with interested parties (ICT, 2011). During the Advisory Committee on 
Economic Statistics meeting in March 2009, the chair mentioned that although the government liked the concept and the SBR 'brand,' it was too expensive to be funded $(\$ 150$ million), considering the current fiscal environment. Despite directly rejecting the SBR programme, the team was encouraged to look for lower-cost alternatives (Hughes, 2009). Additionally, the SBR Working Group was asked to report back to the committee with their new plan and budget for the programme. Although that suggestion was not preferable, at least, the team had an opportunity to get funding from the government. After several meetings, the SBR Working Group came up with suggestions to enable SBR implementation. At the same time, the working group decided to invite the champion of the Netherlands SBR Programme to be the director of the New Zealand SBR programme. They hoped that with his experience; he would be able to gain support and implement SBR in New Zealand. The SBR Working Group managed to convince the government to approve funding of $\$ 3$ million for SBR Phase 1. Based on that government decision, the SBR implementation was to be done in two phases (Power, 2009):

1) Phase 1-Form harmonization and GST taxonomy pilot (\$3 million, Budget 2009/10).

2) Phase 2-Full production system implementation with core agencies (\$5 million, Budget 2010/11).

In 2010, New Zealand was still trying to recover from the global financial crisis and the government decided they should give more money to basic needs like health and education. As a result, the government decided to freeze the above funding for the continuation of the SBR programme (Hucklesby, 2010b). The SBR programme was to be revisited once the New Zealand economy had improved, providing there was a demand from stakeholder groups for completion of the SBR programme. Nonetheless, some stakeholders were not happy with that decision, but they did not have the power to push the government to continue the SBR programme (Hucklesby, 2010a). Since then, XBRL stakeholders, particularly the government agencies, accounting firms, accounting professional body and business organisations, have been quiet or have not enquired about XBRL and its related activities. Therefore, the government, as a decision maker has assumed that the 'silence' of these XBRL stakeholders means they have a reduced interest in or do not support XBRL technology adoption (Auditor E and Government Officer J). 


\subsection{XBRL Development Summary (2000-2010)}

Table 5.1 summarises the relevant events of XBRL development from 2000 to 2010 in the form of a timeline. This summary is based on the events that have been outlined in the preceding sections. Throughout the development of XBRL in New Zealand, there were four XBRL projects which were led by different Steering Committees. However, all these projects involved almost the same people from government agencies, accounting firms, professional bodies and business organisations. Other stakeholders also kept following the XBRL developments from one project to another. That means that each XBRL project in New Zealand was inter-related and potentially influence each other.

Table 5.1: The Development of XBRL in New Zealand from 2000 - 2010

\begin{tabular}{|c|c|}
\hline Year & Description \\
\hline 2000 & $\begin{array}{l}\text { Individuals from the accounting firm, Ernst \& Young establish a collaboration with the Auckland } \\
\text { University Business School (the LEAP+ project) }\end{array}$ \\
\hline 2001 & $\begin{array}{l}\text { The LEAP+ website was produced and used by Ernst \& Young and the Auckland University } \\
\text { Business School } \\
\text { The formation of a Steering Committee under ICANZ (later NZICA) } \\
\text { Funding obtained from ICANZ to develop an XBRL Taxonomy based on IAS and New Zealand GAAP } \\
\text { The Steering Committee built a prototype of the New Zealand Taxonomy based on IAS and New } \\
\text { Zealand GAAP }\end{array}$ \\
\hline 2002 & $\begin{array}{l}\text { The Steering Committee completed the draft of the New Zealand XBRL taxonomy for the private } \\
\text { sector } \\
\text { The formation of a local XBRL jurisdiction: NZ was the } 6^{\text {th }} \text { XBRL Jurisdiction } \\
\text { NZX joined XBRL-NZ Steering Committee }\end{array}$ \\
\hline 2003 & $\begin{array}{l}\text { Introduction of IFRS into the international arena } \\
\text { Revision of the New Zealand taxonomy due to IFRS introduction } \\
\text { A collaborative group established to develop a local pilot for XBRL- Project First Step } \\
\text { Funding obtained from NZX for Project First Step } \\
\text { Started the pilot with } 10 \text { listed companies (Project First Step) } \\
\text { New Zealanders appointed at the international level due to their XBRL experience } \\
\text { New CEO at ICANZ }\end{array}$ \\
\hline 2004 & $\begin{array}{l}\text { IRD serious about the e-GIF project } \\
\text { Hosted the } 9^{\text {th }} \text { XBRL Conference in Auckland } \\
\text { New Zealand Taxonomy was released as an acknowledged taxonomy by XBRL International } \\
\text { Continued appointment of New Zealanders in the XBRL International arena }\end{array}$ \\
\hline 2005 & $\begin{array}{l}\text { Voluntary adoption of IFRS in New Zealand } \\
\text { The disintegration of Project First Step by NZX } \\
\text { Reduction in support from private organisations, specifically from the accounting professional } \\
\text { body and the NZX } \\
\text { The formation of the e-GIF XBRL Standards Working Group }\end{array}$ \\
\hline 2006 & $\begin{array}{l}\text { End of New Zealand affiliation as an XBRL jurisdiction } \\
\text { Steering Committee under NZICA was disbanded } \\
\text { Informal amalgamation with XBRL Australia } \\
\text { QRR commenced with the objective to improve government processes through minimising the } \\
\text { potential impacts of regulations on businesses } \\
\text { Introduction of the Financial Reporting Amendment Act } 2006 \\
\text { The development process of XBRL shifted entirely to the government sector with the e-GIF } \\
\text { project headed by the IRD } \\
\text { XBRL feasibility study between the IRD and Statistics New Zealand completed }\end{array}$ \\
\hline
\end{tabular}




\begin{tabular}{|c|c|}
\hline & $>$ The group involved in e-GIF prepared a Business Case for the next phase of the XBRL project \\
\hline 2007 & $\begin{array}{l}\text { Mandatory adoption of IFRS } \\
\text { New Chief Executive and Commissioner at the IRD } \\
\text { Cabinet Economic Growth \& Infrastructure Committee considered the QRR Final Report } \\
\text { e-GIF project shifted from the IRD to the MED; the project name changed to SBR }\end{array}$ \\
\hline 2008 & $\begin{array}{l}\text { Completion of the Business Case for XBRL } \\
\text { Cabinet Economic Growth \& Infrastructure Committee approved further detailed analysis of the } \\
\text { technical solutions and economics of the implementation of an SBR initiative } \\
\text { Establishment of SBR Programme and Development Team } \\
\text { The IR10 pilot taxonomy completed and validated against XBRL Specification } 2.1 \text { and XML } \\
\text { standards } \\
\text { New Zealand Taxonomy for public sector designed } \\
\text { Documentation of the XBRL standard, future governance and monitoring arrangements } \\
\text { completed } \\
\text { The } 49^{\text {th }} \text { New Zealand General Election: change of government from a Labour to National } \\
\text { Government } \\
\text { Global financial crisis }\end{array}$ \\
\hline 2009 & $\begin{array}{l}\text { The SBR Working Group analysed the data from the } 2006 \text { feasibility study and the } 2005 \text { IR10 pilot } \\
\text { taxonomy } \\
\text { XBRL standard moved from 'Under development' to 'Recommended' } \\
\text { Appointment of Harm Jan van Burg as Director of SBR Programme } \\
\text { The government decided not to fund the entire SBR programme ( } \$ 150 \text { million). The team was } \\
\text { encouraged to look into lower-cost alternatives } \\
\text { The government agreed to approve } \$ 3 \text { million operating funding for SBR }\end{array}$ \\
\hline 2010 & $\begin{array}{l}\text { Government did not endorse the continuation of the SBR programme } \\
\text { The government cut funding for SBR programme in } 2010 \text { budget }\end{array}$ \\
\hline
\end{tabular}

Based on the timeline above, this chapter has identified three key findings. First, the overlapping and inter-related nature of the events means that it is potentially a combination of factors that will influence the organisational decision not to adopt XBRL for use in business reporting. In each project, the group involved had its challenges. Thus, the use of the research framework (in Section 3.4) will assist in determining the influential factors related to each XBRL project, and the results will be presented in Chapters 6 and 7 .

Secondly, as mentioned, there were three XBRL projects: LEAP+, Project First Step, and eGIF during the 2003 to 2005 period. Almost the same people were involved in these projects, but there is limited evidence that indicates the sharing or exchange of experiences outside these groups. A good example of this lack of sharing information with outside stakeholders is as follows:

"[At] the New Zealand Financial Reporting Standard Board; I did not discuss the electronic tagging...I do not think we discussed XBRL."(Institute Director L)

Limited examples where information was shared include the LEAP+ group sharing their experiences with the XBRL community at the $2^{\text {nd }}$ XBRL International Conference in New Orleans, US (Rodwell, 2001). The presentation or sharing of Project First Step was done 
during the $9^{\text {th }}$ XBRL International Conference in Auckland, New Zealand (Boyd, 2004b). The e-GIF project was only shared among the government officers attending an ICT conference in New Zealand.

Finally, the available resources were divided between three different XBRL projects. Each XBRL project had similar members and objectives, but the available resources from the Institute, accounting firms, and government organisations ended up being split between three different projects. By failing to pool all the resources into one XBRL project, the XBRL initiative stakeholders potentially contributed to the failure to get XBRL adopted in New Zealand.

\subsection{Chapter Summary}

In this chapter, the relevant events related to XBRL development in New Zealand have been reviewed and presented. Based on the data analysis, this chapter has identified four XBRL projects from 2000 to 2010. Among stakeholders, the growing interest in XBRL technology happened slowly with a mixture of positive and negative experiences during the journey.

The use of historical data provides a guide for the researcher when building an argument, and providing explanations and answering the research questions in the later chapters. Through the historical overview, this chapter provides valuable insights that act as preunderstanding for Chapters 6 and 7. These insights include that the non-adoption of XBRL in New Zealand potentially happened because of various inter-related factors; that the XBRL stakeholders may have achieved their objective if they had pooled their resources into one XBRL project and more actively shared experiences with outside stakeholders. In the next chapter, this thesis will present a detailed analysis and the results of LEAP+ project and Project First Step. 


\section{Chapter 6: XBRL Initiatives Under the Auspices of Professional Organisations}

\subsection{Introduction}

Chapter 5 presented the history of XBRL in New Zealand from 2000 to 2010. Throughout that period, many events related to XBRL happened in New Zealand. Early on, individuals from one accounting firm, Ernst and Young, and from the University of Auckland became interested in XBRL and set-up the LEAP+ project. Later on, other individuals from another accounting firm (KPMG), the New Zealand accounting professional accounting body (NZICA) and government agencies (the OAG and the IRD) joined them to establish Project First Step.

This chapter presents the findings related to the LEAP+ project and Project First Step. The views represented do not represent the official views of an organisation but rather the views of the individuals who took part in the projects. These projects were controlled by the accounting professional body or private organisations. Each project had a different background and objectives; however, both shared the same goal, that is, to bring XBRL to New Zealand. To provide insight into the first research question: what factors influenced the organisations' decisions not to adopt XBRL for use in business reporting; the researcher identified for these earlier projects, the TOE-related critical factors, which potentially influenced the non-adoption of XBRL. For the LEAP+ project, technological was the critical context with the trialability of XBRL applications and the copyright issue being the most critical factors. While for Project First Step, factors like not being perceived as a problem solver, ineffective promotion and communication of XBRL, over-enthusiastic experts and a lack of stakeholder involvement are the most critical factors, most of which are from the organisational context. The following sections provide the evidence that supports the identification of these critical factors.

\subsection{Overview of the LEAP+ Project (2000-2006)}

In New Zealand, individuals from an accounting background were monitoring XBRL developments as early as 1998. This resulted in individuals from two organisations, namely the accounting firm, Ernst \& Young, and the University of Auckland collaborating on XBRLrelated work. They used XBRL for formatting accounting documents to create a web-based 
system for teaching accounting professionals and students (users of LEAP+). In this collaboration, one party, Ernst \& Young provided funding while the other, the University of Auckland provided expertise and equipment. Based on this collaboration, they successfully produced a system and website called Leading Edge Accounting Product or LEAP+. During that time, LEAP+ was considered a 'world first' web-based product that could revolutionize global financial reporting (Hucklesby, 2001d).

LEAP+ was an online financial reporting tool that illustrated how annual reports could be prepared by a New Zealand business organisation (Hucklesby, 2003a). It was considered to be a powerful business tool because financial information could be condensed using XBRL. In addition, the user would be able automatically to exchange and reliably summarize the financial information into any (computer) language and GAAP (Hucklesby, 2001c).

\subsubsection{Objectives of LEAP+}

There were several objectives in developing the LEAP+. First, to develop a tool that could assist Ernst \& Young to promote a quality service. Within Ernst \& Young, LEAP+ served as a training tool for its staff. Second, to develop a financial statement platform model. Through LEAP+, the users could determine what and how certain things could be disclosed such as company modernisation plans, changes in policy and so on. Third, as an alternative to the traditional mode of presenting financial statements. That meant LEAP+ aimed to make financial statements available in an online mode. Fourth, identify the equipment required such as the tools and the software. As this was the first web-based product for presenting online financial statements, there was a need to identify suitable equipment. This included identifying related costs and the technical staff required. Lastly, within the University of Auckland Business School, LEAP+ was developed as a learning module for business and information management degree students. In addition, LEAP+ proved the concept of XBRL as a medium and tool for financial reporting.

Using the LEAP+ website, the user needed to select the information, export or print it and use it to undertake financial analysis or develop a report. In the university, LEAP+ was used to supply financial statement information to students and assisted the lecturer by making it easier to provide students with annual reports (Hucklesby, 2001c). Meanwhile at Ernst \& Young, LEAP+ was used internally to demonstrate the latest accounting standards (Watson, 2001). Instead of depending on the print version of the annual report or latest accounting 
standards, users could simply use LEAP+. Ernst \& Young and the University of Auckland Business School were both happy with the system as from their perspective; LEAP+ addressed their needs.

\subsubsection{Classification of Stakeholder Involvement}

In the LEAP+ project, there were three types of stakeholder involvements. The active stakeholders were Ernst \& Young and the University of Auckland. They were interested in adopting $X B R L$ because they believed $X B R L$ to be the future of financial reporting. There was one observer stakeholder, consisting of the Professional Magazines grouping. The observer stakeholders were interested in XBRL because it was the latest technology in the accounting area at that time. They wanted to explore and know about the uses, benefits, and capabilities of XBRL. The knowledge was then shared with the business community.

In the next section, the factors associated with the active stakeholder followed by the observer stakeholder cluster are presented. The discussion is based on the TOE Framework (as presented in Chapter 3, Section 3.4).

\subsection{Factors Associated with Active Stakeholder}

During the LEAP+ project, there were two active stakeholders as mentioned above. Both stakeholders were informed or influenced by various factors in the technological, organisational, and environmental contexts.

\subsubsection{Ernst \& Young}

This was the first involvement from Ernst \& Young in XBRL initiatives. As an active stakeholder during the LEAP+ project, representatives from Ernst \& Young gave their opinion about the technological and organisational contexts.

Within the technological context, there were two key factors mentioned by the interviewees; trialability of the XBRL application and a copyright ${ }^{29}$ issue. One interviewee mentioned that XBRL did work on the website designed for that purpose, indicating a degree of trialability:

\footnotetext{
${ }^{29}$ Copyright refers as an exclusive legal right either to reproduce, publish, sell or distribute something. In XBRL's case it is the right to reproduce the XBRL-based financial and business information for the public. More details are provided in Chapter 9, page 247.
} 
"I supposed it is the approving of the concept that said, "Yes, this technology does work." This is how it would appear on [the] website and how it could be used." (Auditor E)

Some issues regarding copyright appeared when the team tried to make the website available to the public. The challenge faced was in licensing the website used. The person that championed LEAP+ in Ernst \& Young felt disappointed, particularly when discussion failed to settle the copyright issue.

"Well, there was a stage where I started to feel disappointed. Then, I never took the copy of that file so I can recall the website details." (Auditor E)

Users, specifically the degree students and accounting firm staff, were able to try the LEAP+ website. However, making the LEAP+ website available to the public faced a challenge in regards to copyright.

Within the organisational context, there were three factors stated by interviewees; sufficient human capability, effective promotion and communication ${ }^{30}$ of $X B R L$, and overenthusiasm ${ }^{31}$ among XBRL experts that appears to have been significant at Ernst and Young. Ernst \& Young mentioned that the collaboration work between and the resulting increase in capability of people within the two organisations who are developed the LEAP+ website was key:

"The way this worked was Ernst \& Young was effectively financing the cost of the software developer to help build the website. But, the university was helping in terms of providing design and the IT architecture of the website for that to operate on." (Auditor E)

From the Ernst \& Young perspective, the aim of the LEAP+ project was to create awareness of XBRL through promotion and communication. An interviewee felt the team managed to show that XBRL would be a useful technology for business reporting.

“...LEAP+ was part of bringing awareness. I suppose I was trying to promote it in terms of XBRL being a useful piece technology that could assist business reporting." (Auditor E)

\footnotetext{
${ }^{30}$ Promotion and communication are the platform used to share and create XBRL related information for its stakeholders. More details are provided in Chapter 9, page 249.

${ }^{31}$ Enthusiasm refers to a strong interest in doing XBRL-related activities among its supporters. More details are provided in Chapter 9, page 249.
} 
In the XBRL context, the experts involved had enthusiasm and were excited when completing XBRL initiatives or related activities. One of the interviewees mentioned the enthusiasm among the experts during the LEAP+ project.

"In early 2000, there was a huge amount of interest, but [the projects] are run by interested people that are trying and pushing it. In New Zealand, it was not somewhere else leading some of the developments in XBRL." (Tax Advisor I)

The experts' excitement potentially separated them from the reality of the New Zealand business environment. Possibly, the experts had knowledge and skills that kept them going without realizing that other people were not interested in XBRL.

\subsubsection{University of Auckland}

The University of Auckland was the other active stakeholder. Representatives from this organisation gave their opinion on the technological, organisational, and environmental contexts associated with their involvement in the LEAP+ project.

There were four technological factors mentioned by interviewees: the struggle to understand the relative advantage of XBRL (cost versus benefits), the trialability of the XBRL application, XBRL not being seen as a problem solver ${ }^{32}$ and the need for copyright. Although the LEAP+ project was the first XBRL initiative in New Zealand, in general, the majority of the XBRL stakeholders could not see the relative advantage or value of the product in terms of financial reporting. One interviewee involved noted:

"I guess it was a matter of cost and benefit. It is a matter of perceived versus actual benefits that were really new. Thus, it was really hard for us to know the real benefits." (Academic F)

A representative from the University of Auckland mentioned they trialed the principles of $\mathrm{XML}$ and $\mathrm{XBRL}$ when building the LEAP+ website.

"We needed a tool to manage a task. We used XML because the XML tagging on anything could bring all things together...we use the principles of XBRL as well. We used the X-Link. We used the calculation linkbase and stuff like that... It was the proving of [the] concept that this tool actually works." (Academic L)

\footnotetext{
32 Problem solver refers to whether potential adopters perceive XBRL as a solution to their problems related to business reporting matters. More details are provided in Chapter 9, page 246.
} 
The result was that it was proven that $X M L$ and $X B R L$ could be used for business reporting purposes. Another academic interviewee stated that the LEAP+ website was not ideal for their degree students to use to solve financial reporting problems.

"...it was also meant to be a reference resource for our students. Students wanted to know... about the particular financial reporting standard (FRS) and with regard to $\angle E A P+$, it is how it gets there... it was not really ideal for the student either... They really wanted to be able to go back [to] the FRS to do it properly." (Academic F)

Additionally, Academic $L$ also revealed the same things happened in Ernst \& Young. The University of Auckland (and Ernst \& Young) had invested money and time to build the website and maintain it. As mentioned, they faced difficulty in making the website available to the public because they did not own the XBRL copyright. Eventually, the University of Auckland decided to stop making it available to students.

“...back in 2005, we decided to stop it. It was quite costly for we were putting quite a lot of money into it. So, it [was] better to give up on that and [give it] back to Ernst \& Young..." (Academic F)

Within the organisational context, representatives from the University of Auckland identified three factors: the development of human capability, the loss of its champion and ineffective promotion and communication. While an expert is a person, a group of experts is considered a dynamic team. In the LEAP+ project, the team managed to establish a good combination of experts (human capability) and the availability of equipment as mentioned:

"...you need the mix of $X M L, X B R L$, and accounting and have a programmer that knows about the program. It was probably just fortunate [that it] came together three different people with different expertise." (Academic L)

In addition to the above, the interviewee also noted that:

"We had Auditor E (who) was the champion inside Ernst \& Young. He had the real push. I had the XBRL and accounting expertise. We were...the push behind the Russian student, who had the most amazing programming. He made it all happened. I think if you took out any one of the elements, it would have failed." (Academic L)

In the LEAP+ scenario, the champion within the university influenced and pushed the students and accounting professionals to use LEAP+. In the early stages of LEAP+, the 
project had champions in both organisations. However, it did not last. The statement below indicates that towards the end of the LEAP+ project, it lost its champions:

"...you need a champion. But, I left to go to ICANZ. Auditor E left Ernst \& Young as well. So, we did not have the champion to keep it going." (Academic L)

Although effective promotion and communication might overcome the loss of a champion, in the LEAP+ project, the group failed to provide or get sufficient information to others through promotion and communication. For example, the team did not manage to conduct any surveys to get feedback from the students (Academic F).

Academic $L$ also mentioned they had the same reaction to one-way communication from the accounting staff and students about the XBRL application. Either in Ernst \& Young or in the University of Auckland, the initiative group did not conduct any surveys to obtain stakeholders feedback about the XBRL application.

"We thought they are ok unless they tell us; we would have upgraded the tool so that it was more interactive and evolved over time." (Academic $L$ )

Within the environmental context, the interviewees mentioned two factors; a lack of stakeholder involvement and a knowledge gap ${ }^{33}$. When the LEAP+ website was ready for its target users (the stakeholders), particularly in Ernst \& Young and at the University of Auckland, the team hoped they would get support for the continuous use of the website by staff, students and potentially other stakeholders. Academic L noted:

"The fact is it did not continue because of [a lost of] its attractions. It is a bit sad..." (Academic L)

Additionally, the interviewee also mentioned a lack of support from other stakeholders.

"But it failed. I think it was because we did not have strong backing internally in Ernst \& Young. It would not [have been a] failure if they had been very supportive and kept it going." (Academic L)

Further, in the LEAP+ project, there was a knowledge gap between the students and the project team. They had different sets of knowledge about the usefulness of the website:

\footnotetext{
${ }^{33}$ Knowledge gap refers to a difference in the level of knowledge and skills about XBRL technology between those involved in XBRL initiatives and other stakeholders. More details are provided in Chapter 9, page 252.
} 
"...they did not say it was hard, but they just found it not as useful as we thought it would be. They just do not want to use it to look for a particular piece of information." (Academic F)

\subsection{Factors Associated with Observer Stakeholder}

A review of the Professional Magazines group, such as the Chartered Accountants Journal, Computer World, and Management, indicates that they acted as an observer stakeholder cluster in relation to the LEAP+ project. This cluster review revealed important factors from the technological context.

\subsubsection{Professional Magazines}

The nature of a professional magazine is to discover and communicate new things in their area of expertise. Thus during the LEAP+, the professional magazines for the accounting profession and the business community wrote articles relating to the technical aspects of XBRL.

The two technological factors found were trialability of the XBRL applications and the copyright issue. The Professional Magazine cluster mentions the trialability of LEAP+ between the two active organisations:

"Ernst \& Young is a Navision reseller in New Zealand, and the company is trialing the $X B R L$ approach. They are working in conjunction with the University of Auckland Business School in developing the ground for XBRL. Under this joint development, Ernst \& Young are currently using XBRL as an educational device for the benefit of its clients. The university is testing it at the student level." (Isaac, 2001, p.89)

In XBRL context, particularly in relation to the LEAP+ website, owning the copyright was a way to make the website available to outside parties. The Professional Magazine ${ }^{34}$ cluster noted this:

"There are plans to make LEAP+ available to outside parties by way of licensing though that will not happen until Ernst \& Young; the university and the Institute [NZICA] settle a copyright issue relating to notes in the margin of the print version." (Watson, 2001)

\footnotetext{
${ }^{34}$ Computer World New Zealand - online version at http://www.computerworld.co.nz/article/512461/copyright blocks online leap/
} 
Users within Ernst \& Young and the university were thus, able to try the LEAP+ product. On the other hand, the team was unable to settle the issue relating to copyright. Therefore, outside parties could not use it.

\subsection{Analysis: The LEAP+ Project}

The analysis process, as discussed in Chapter 4, Section 4.6.2, has been followed while analyzing the data. The analyzing process was the most interesting part of this study. Even though it took a lot of time to understand and digest the information, the researcher learned to consider each piece of data. As such, the researcher found XBRL-related factors that were not in the research framework (as in Figure 3.4) or identified by prior research as presented in Chapter 2. In the technological context, there were two additional or unpredicted factors found: not being perceived as a problem solver, and the copyright issue. Under the organisational context, the additional factors were the ineffective promotion and communication of XBRL and over-enthusiastic experts. Within the environmental context, the additional factor was a knowledge gap between those involved in the project and other stakeholders.

As presented in Table 6.1, Ernst \& Young was an active stakeholder during the LEAP+ project. This accounting firm believed that factors relating to trialability, increasing human capability, and the promotion and communication of XBRL would have facilitated the XBRL adoption decision. Nevertheless, this accounting firm faced challenges in regards to the copyright issues associated with making the LEAP+ project publically available. Ernst \& Young believed that during the LEAP+ project, they had enough skills and resources to build the website. Later, the team used the website as a medium to introduce XBRL technology to others. Through that action, they managed to spread awareness among the business community. From here, the team, especially the experts, started to feel that XBRL was an interesting technology. However, in the end, it turns out that the experts were overenthusiastic because their interest motivated them to keep on trying to promote it without being connected to or matched by stakeholders' interest. 
Table 6.1: Overall Summary of TOE Context Factors in the LEAP+ Project

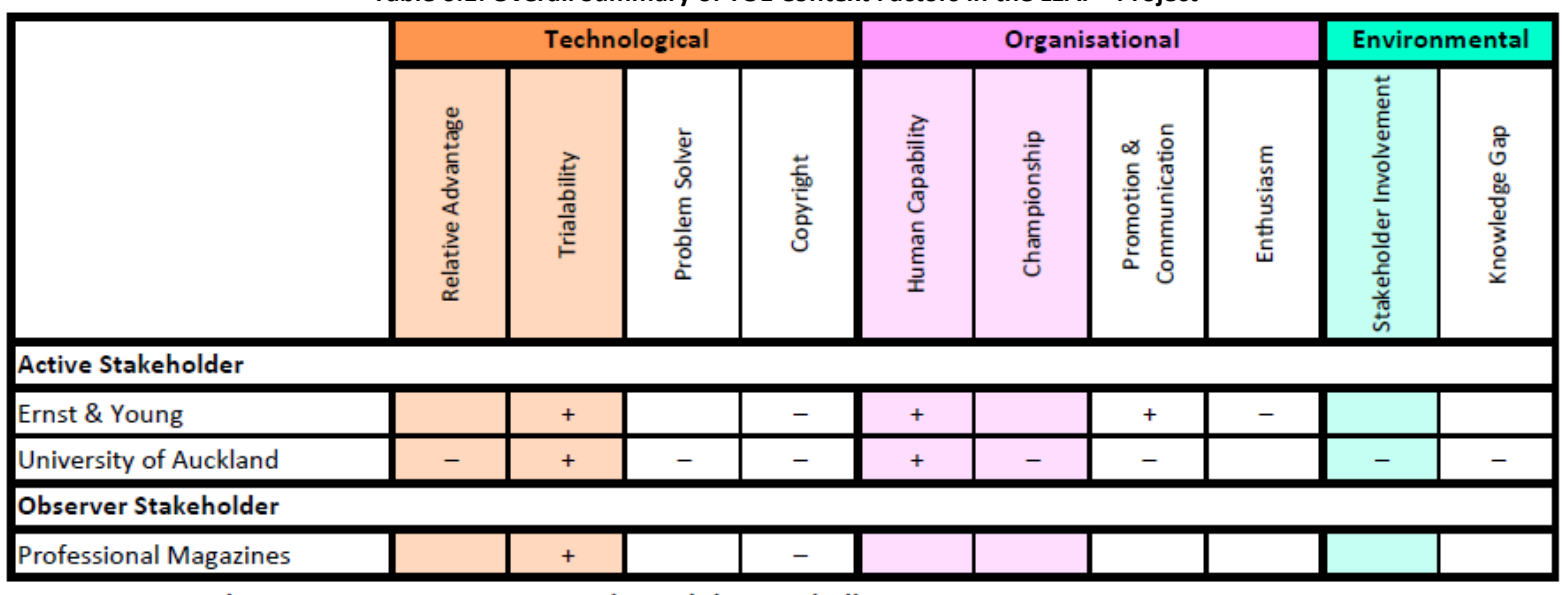

+: Driver, Facilitating, Encourage; -: Hinder, Inhibitor, Challenge

Table 6.1 also presents all the factors mentioned by interviewees from University of Auckland. Based on the findings, only two factors; trialability (technological) and human capability building (organisational) facilitated stakeholder involvement with XBRL and the use of it for teaching purposes. The interviewees agreed that the LEAP+ website was useful in proving the concept of XBRL for business reporting and they developed a team of experts that provided the human capability as well as the equipment to build the website. There were many barriers to the adoption of XBRL for educational purposes in the LEAP+ project. The absence of perceived benefits (relative advantage), that it was not seen as a problem solver, the inability to gain copyright, that there was no long-term champion, ineffective promotion and communication, a lack of stakeholder involvement, and a knowledge gap between the team and students and other staff, influenced the decision by the University of Auckland to stop using the LEAP+ website in 2005. It had been difficult for those involved in the LEAP+ project to convince students and other staff of the real benefit of using XBRL for business reporting. That was because the students and accounting staff did not perceive it as a solution to a particular problem. Furthermore, a copyright issue prohibited the University of Auckland from making the website available to outside parties. Their momentum did not last as the champion moved to another organisation, and the usefulness of XBRL was not well communicated to the stakeholders. The LEAP+ project also lacked stakeholder involvement and at the same time, there was a knowledge gap between the group involved in the initiative and the stakeholders that used or may have used the website.

As an observer stakeholder, as indicated in Table 6.1, the Professional Magazines cluster suggested that LEAP+ project proved the XBRL concept worked for business reporting. 
However, the LEAP+ group was unable to get the copyright it needed to make the product publically available.

In summary, Table 6.1 indicates that the ability to trial the product or trialability (technological) and the ability to build human capability (organisational) were facilitating factors that potentially influences an organisation to adopt XBRL. Yet, during that time, the project failed to convince others in New Zealand to adopt XBRL because of the inability of the active stakeholders to solve the copyright issue (technological). This suggests that during early XBRL initiatives in New Zealand, the technological context was the most critical factor. In the next section, another early XBRL initiative under the auspices of a professional organisation is examined.

\subsection{Background of Project First Step (2003-2005)}

Another XBRL initiative in New Zealand was Project First Step. The project ran from 2003 to 2005. The growing interest among individuals within the accounting firms and the professional accounting body, at this stage provided enough impetus to start another XBRL initiative that involved private and public sector organisations. The resultant collaboration effort was supported by the Big 4 accounting firms and twelve listed companies (Kennedy, 2004). The New Zealand Stock Exchange (NZX) was to act as the receiver or user of XBRLtagged financial information while the Big 4 and twelve listed companies were to serve as the sender of the financial information (Kennedy, 2004). Originally the six members of the Steering Committee were representatives from Ernst \& Young, KMPG, NZICA, the University of Auckland, the OAG and Carter Holt Harvey. This Steering Committee was formed somewhere in October 2001. Six months later, additional members joined. Mostly the new members were from government agencies and regulators including the IRD, the MED, Statistics New Zealand and the NZX.

\subsubsection{Objectives of Project First Step}

The basic goal of Project First Step was to deliver a platform that allows NZX listed companies to file an electronic version of the NZX Preliminary Announcements (known as Appendix 1) on a biannual basis (Boyd, 2004a). The preliminary announcement was the focus of the collaborative effort in Project First Step. 
From NXZ side, Project First Step was a platform for them to create a more efficient announcement process. Through the used of XBRL, Project First Step aimed to improve the quality and richness of information available on the market. This effort was consistent with the Market Announcement Platform (MAP) (Hucklesby and Macdonald, 2003c), which facilitated the electronic submission and dissemination of many required announcements.

\subsubsection{Classification of Stakeholder Involvement}

During the Project First Step, there were nine organisations involved either as active or observer stakeholders. The active stakeholders consisted of the OAG, the IRD, Ernst \& Young, KMPG, NZICA, and the University of Auckland. As active stakeholders, they worked together and supported each other through the formation of the Project First Step's Steering Committee. Their goal was to bring XBRL alive in New Zealand. In order to achieve their objective, they came up with a number of plans and strategies, which will be illustrated below. Meanwhile, the observer stakeholders were the Treasury, the University of Otago and the newspaper cluster.

Different stakeholders have different interests in XBRL technology. The active stakeholders are more likely to adopt XBRL for use in their organisation. For the OAG, adopting XBRL would improve the quality of financial reporting by public sector as well as private organisations. Indirectly, this would also promote transparency in financial reporting. The IRD were interested in adopting XBRL because XBRL technology would reduce the cost and errors for those preparing financial reports. During early 2000, operating costs, especially those relating to preparing financial reports, was considered too high, and their clients, who were mostly from business organisations asked for a simple yet powerful software application to act as a medium for submitting their financial reports. At the same time, the IRD needed to replace their old computer system. The introduction of XBRL as a mechanism for business reporting would have suited their needs. Those in the accounting profession; Ernst \& Young, KMPG, and NZICA, wanted to adopt XBRL because they could see significant benefits in using it for online reporting (as discussed in Chapter 1). Another active stakeholder, the University of Auckland wanted to adopt XBRL so they could educate the young accountant or auditor about the latest technology in accounting. Furthermore, they needed to be updated about XBRL because in the international arena people were discussing it. The observer stakeholders just wanted to observe the public reaction to the 
possible introduction and development of XBRL. However, the newspaper cluster shared their observations with the public, to promote $\mathrm{XBRL}$, and encourage people to learn more about XBRL.

The next subsection presents the factors associated with the active and observer stakeholders during Project First Step. The discussion will be based on the TOE Framework.

\subsection{Factors Associated with Active Stakeholder}

In Project First Step, the active stakeholders consisted of two government agencies, two accounting firms, one professional accounting body, and another stakeholder - a tertiary education institution. Their responses contributed to the identification of the various factors that can further be classified into their technological, organisational, and environmental contexts. Each active stakeholder had different factors that influenced their decision regarding $\mathrm{XBRL}$ adoption.

\subsubsection{The Office of the Auditor-General (OAG)}

Project First Step was the first involvement of OAG in the XBRL initiatives. As an active stakeholder in Project First Step, representatives from OAG revealed various factors related to the technological, organisational, and environmental contexts.

Under the technological context, there are three factors mentioned by interviewees; technological complexity, a concern for security, and stability ${ }^{35}$ issues related to the taxonomy. One interviewee mentioned the complexity of building a taxonomy.

"While in Singapore, we ended up with so many elements and jargon words. Luckily it is within the context that [the] Steering Committee can handle...it was pretty comprehensive." (Government Officer $C$ )

In addition, the interviewee also discussed complexity in relation to updating the taxonomy.

"...basically with a new standard...you needed to revise [the] taxonomy... That will

always be an issue to someone if you have an XBRL taxonomy for New Zealand, someone needs to take ownership prior to updating the taxonomy." (Government Officer C)

\footnotetext{
${ }^{35}$ Stability refers to the ability of an XBRL element such as the XBRL specification and taxonomy to remain unchanged under reasonable expected conditions and use. More details are provided in Chapter 9, page 247.
} 
In Project First Step, the security of the computer or information system was not a major concern for stakeholders. The interviewee explained the idea of XBRL was that somebody could send it to someone else and be confident in the security. This is consistent with the practice in the US, where stakeholders upload their data to make it publicly available.

"I would not have thought there is any issue with security at all, as far as I know." (Government Officer C)

However, the Interviewee mentioned about the stability of XBRL, especially as it related to the specification and taxonomy during Project First Step. Somewhere around 2003, the stakeholders started to raise issues related to stability:

"The reality is the taxonomy keeps changing across time as [each] standard comes out." (Government Officer C)

Within the organisational context, there were three factors highlighted by the interviewees; the loss of human capability, effective promotion and communication of XBRL, and enthusiasm for the project. The OAG interviewee explained the reason for a lack of experts (human capability) during Project First Step.

"Around 2004 and 2005, they (the experts) seem to have lost enthusiasm... [During] the same period, New Zealand players got involved in the international community because the fact that the thing (XBRL) is not going quickly in New Zealand." (Government Officer A)

Another interviewee from this organisation agreed and further elaborated that around 2005 or 2006, the Steering Committee lost most of their team and could not keep progressing XBRL initiatives in New Zealand.

However, the OAG thought that the Steering Committee had managed to promote XBRL during Project First Step.

"...while XBRL was in New Zealand, people were working together and [they] ran a few training sessions, seminars, and it was nice." (Government Officer A)

In addition, the interviewee also described the experts' interest in XBRL.

"To be fair many [of the] people involved that I knew well they genuinely believe XBRL was important and there would be a value in its development... They tend to do it because [of their] belief." (Government Officer A) 
He further explained that the experts used their skills and knowledge to push the technology, but in the end,

"Basically, it was all driven by enthusiastic and technical people to do with technology related things. There was not any drive from the users; there was not even a lot of energy and enthusiasm from the providers of information." (Government Officer A)

In the environmental context, the OAG interviewees identified three factors; limited stakeholder involvement, a change of laws, rules and regulations ${ }^{36}$, and a knowledge gap. Here, the interviewee mentioned the level of commitment among stakeholders that were involved in Project First Step. Most of the stakeholders could not dedicate enough time and effort to the XBRL initiatives.

"The problem with it [was that it was] pretty much voluntary time; you just try to fit it in with your work and inside or outside work. That makes it difficult as well." (Government Officer C)

One interviewee believed that changes in laws, rules, or regulations did impact the XBRL initiatives. During Project First Step, the introduction and mandatory adoption of IFRS changed the reporting environment:

"...the changes in the reporting requirements had an impact on the story of XBRL." (Government Officer A)

Further, the interviewee explained how the change affected Project First Step.

"Coming back to the adoption of IFRS, there must be an impact because people had invested time, strategizing about something...almost overnight the effort is changed, and what you had done requires significant rework." (Government Officer A)

Another OAG interviewee supported the above claim and elaborated that they needed to rework the new taxonomy. This activity involved a significant amount of work because they had to start from zero.

"During that time, we try to do a bit of a New Zealand one but then... when I worked with the IFRS, IAS taxonomy...it was quite a lot of... work to do." (Government Officer C)

\footnotetext{
${ }^{36}$ A change of laws is the modifying of laws, rules and regulations including any change either in rules or regulations related to XBRL matters. More details are provided in Chapter 9, page 253
} 
Another factor mentioned by interviewees from OAG was the absence of knowledge about XBRL:

"Even today, we lack information about how XBRL works. What does it mean for the preparer of information? Tag: how do you use it and could you use that to access information and tag technical knowledge? It would be more helpful if [there was] more access on that. I think it would [have] increased the possibility of [the] project progressing in the late 2000s." (Government Officer A)

\subsubsection{The Inland Revenue Department (IRD)}

The IRD was firstly involved with XBRL initiatives in Project First Step. As an active stakeholder, the IRD interviewee gave his view on the organisational and environmental contexts.

Within the organisational context, the interviewee mentioned the over-enthusiastic XBRL experts. During Project First Step, he had noticed an obsessive feeling towards XBRL among these experts. The interviewee believed the experts had the power, skills, and knowledge to influence stakeholders and get them to join or be interested in XBRL technology. The experts could encourage or kill the initiatives depending on how they managed their enthusiasm.

"But at that stage, there were people that loved XBRL, just wanted it for the rest of their life; or [they could be a] person who could kill it in just one moment, they are the expert." (Government Officer J)

In the environmental context, the interviewee from the IRD identified two factors; a lack of stakeholder involvement and a knowledge gap. As a member of the project, the interviewee realised there was less support and participation from the accountants.

"The accountant did not care, for them, it was a program. Let's the IT people worry about that. They could not get any support, movement, no wave of enthusiasm from their members because it did not mean anything to them." (Government Officer J)

He also noticed that the accountants, in general, were not concerned about XBRL. He explained that when the Steering Committee tried to communicate with chartered accountants, the initiative group failed to get any positive feedback. It seemed like accountants had no interest in XBRL. 
Another issue that arose was the absence of knowledge among the accountants. The interviewee had a chance to ask the accountants about their basic understanding of XBRL. The reply from the accountants was consistent with their involvement and interest in XBRL; the majority did not know anything about XBRL and did not want to know.

\subsubsection{Ernst \& Young}

Ernst \& Young maintained their involvement in XBRL initiatives as an active stakeholder. A participant from this organisation shared their perspective on the factors within the technological, organisational, and environmental contexts associated with their involvement in Project First Step.

Within the technological context, there were two factors mentioned by interviewees: limited relative advantage and it was not seen as a problem solver. The interviewee from Ernst \& Young perceived that the costs of becoming an XBRL jurisdiction and setting up the project were greater than the benefits it would bring to stakeholders.

"What you have to remember is that an XBRL jurisdiction and the project were set up through NZICA. It costs a lot of money to have an XBRL jurisdiction. I think it was about US\$25,000 a year that you have to pay across to XBRL International. Obviously, in those days, the NZS exchange to US\$ was almost two to one. That was a very expensive exercise, but eventually, [XBRL in] New Zealand... was not generating any money, [and could not] even get the government interested in being able to sustain it." (Tax Advisor I)

In addition, the interviewee added that being one of the earliest XBRL jurisdictions did not give it any advantages.

"[It was] not worth paying money across to an international body for what it gets back from it... It was not economically viable to sustain that." (Tax Advisor I)

Another interviewee from Ernst \& Young also believed there was little benefit from becoming an XBRL jurisdiction.

"Again, there was really nothing happening in the New Zealand space that came from membership of XBRL New Zealand...People were paying their money, but what will they get in return. The answer was very little." (Auditor E) 
The interviewee explained that the benefits, like XBRL has the ability to share information between people was not needed, indicating the costs of XBRL were greater than the benefits it would bring for stakeholders in New Zealand.

"Obviously, the key benefit of XBRL is being able to exchange information - a vast amount of information with different people at different times. There really was no kind of demand for that in the New Zealand context." (Auditor E)

In the organisational context, Ernst \& Young commented on the financial support that was available. During Project First Step, the Steering Committee managed to get funding from NZICA. They used the funding to educate their members by getting them to attend XBRL International Conferences. The funds were also used to organize seminars and workshops around the country. However, one of most critical events relating to Project First Step was the withdrawal of funding by NZICA.

"What we had in New Zealand around 2004? We had an organisation that was stable. However, one of the things that happened during that time was the NZICA made a decision to cut the budget, which I think significantly reduced its financial support for XBRL initiatives in New Zealand." (Auditor E)

The interviewee also mentioned the consequences of this budget cut.

"When the Institute cut back its financial support, it was incredibly significant...the issue that the New Zealand Steering Committee faced during that time (when I was chair until 2006) was how and where are we going to get the funding to remain a member of XBRL International?" (Auditor E)

Under the environmental context, the interviewee mentioned one factor, stakeholder involvement. The involvement of the NZX in Project First Step was really helpful in terms of building the momentum of XBRL in New Zealand.

"In New Zealand, we had Mark Weldon being appointed as Chairman at the NZX. He had a guy called Carl Daucher, who helped drive and promote the deployment of XBRL into stock exchange electronic filings." (Auditor E)

The interviewee also mentioned the lack of involvement of a software developer. During Project First Step, the Steering Committee had not invited any software developer to join the project. 
"That was because the software developer could not build a business case around the advantages of [embedding] XBRL into their software." (Auditor E)

Nor did they get any attention from software developers.

"We could not get the attention of the software developer...basically, almost all the software developers were from overseas...there was no software company that was really interested in developing accounting software for New Zealand." (Auditor E)

\subsubsection{KPMG}

Project First Step was KPMG's first involvement in the XBRL initiatives. KMPG gave their view on the factors that were important in the technological and organisational contexts.

Within the technological context, the interviewee from the KMPG mentioned two factors; that there was no relative advantage and that it was not perceived as a problem solver. According to Auditor $\mathrm{H}$, it was difficult to convince people that there was a relative advantage in using XBRL. This situation created a dilemma.

"The more we spoke to both (users and preparers), the more difficult it appeared. It was all about the cost benefit issue. They are asking if we put additional efforts into doing it, what benefits are we getting in return? It was a reasonably difficult conversation saying "it would not save you anytime in doing it plus you are going to spend more time in setting it up." (Auditor $\mathrm{H}$ )

Then, the interviewee mentioned the capability of XBRL as a problem solver in the stakeholders' organisation. However, the stakeholders just could not see how they could convert the potential. Thus, the stakeholders saw it as a perceived benefit instead of a real benefit.

"There was no attraction; no result, it was just potential. That potential was never converted." (Auditor $\mathrm{H})$

Under the organisational context, the interviewee only mentioned the promotion and communication of XBRL. This organisation looked at promotion and communication from a different perspective. The interviewee explained that during Project First Step, the Steering Committee tried to get business organisations (senders) to send their financial statement using XBRL to the relevant government agencies and regulators (receivers). Unfortunately, there was no receiver that was capable of processing XBRL-formatted reports at that time. 
That meant the communication was not complete, and the potential of XBRL could not be proven.

"The other issue is...like a telephone conversation, you can get a sender to set themselves up, but if you have not got the receiver, then there is no benefit to the sender. That is the whole communication equation." (Auditor $\mathrm{H}$ )

\subsubsection{NZICA: XBRL Steering Committee}

Interviewees from NZICA that were involved in the XBRL Steering Committee consisted of directors and members. Documents from the Chartered Accountants Journal and the annual report of NZICA are also referred to below. They mentioned factors from the technological, organisational, and environmental contexts.

In the technological context, there were four factors stated; the complexity of $\mathrm{XBRL}$, trialability, the instability of the taxonomy and the availability of tools and software ${ }^{37}$. The level of complexity for each type of technology is different. It depends on factors such as the availability of software tools, knowledge, and technical support. In Project First Step, interviewees' viewed the complexity of XBRL from different perspectives. From the point of view of XBRL as an element, it was noted that:

"...using the feature of calculation linkbase, it has so much complexity towards the end. I think people feel isolated when you start to talk about XBRL." (Institute Director L)

He added that having a big vision among the Steering Committee also contributed to the complexity.

"...all the complexity in XBRL was because they have this big vision in mind. People find it hard to get their head around this XLink and things like that." (Institute Director L)

From the documents, Hucklesby, Macdonald, and Teixeira (2003a) suggested that XBRL technology and IFRS created confusion for some accountants.

"...the adoption of XBRL in New Zealand needed to be accelerated. The Steering Committee should make an immediate start to tackling the adaptation of the IFRS $X B R L$ electronic standard to New Zealand GAAP...for those few accountants who presently track both XBRL and IFRS 'a very complex, some would say confused

\footnotetext{
${ }^{37}$ Availability of tools and software are defined as the accessibility of equipment that enables potential adopters to try a new technology like XBRL. More details are provided in Chapter 9, page 248.
} 
situation has developed' given the number of accounting standards that are currently under revision." (Chartered Accountants Journal, Hucklesby et al., 2003a, p.52)

As Project First Step was a pilot project using an XBRL format in financial reporting, by exposing the XBRL technology to its stakeholders, it should have reduced the uncertainty or fear of using the technology in the future. Moreover, as part of the preparation to host the $9^{\text {th }}$ XBRL International Conference, XBRL New Zealand needed to generate and increase interest in XBRL:

“...XBRL New Zealand is considering [a] XBRL pilot project to generate even more interest in its local jurisdiction among the government and regulators in the lead up to the conference." (Chartered Accountants Journal, Hucklesby, Macdonald and Teixeira, 2003b, p.56)

Concerns, however, were expressed about the stability of the taxonomy, due to the early stage of XBRL development.

"...it could be too early because the taxonomy had not matured, XBRL had not stabilized." (Institute Director L)

There was also a further concern about the maturity of the XBRL Specification. In order to have a better understanding of the issue, Hucklesby and Macdonald (2004b) interviewed Tim Bray, who was involved in the creation of XML and reported on this in the Chartered Accountants Journal. Mr. Bray emphasized XBRL needed to be stable before it could go to the next step, adoption by organisations:

"...the success of XML is attributed in part to the fact that there had only ever been one release of its specification to date. Stability is the essential ingredient for adopting any new standard." (Chartered Accountants Journal, Hucklesby and Macdonald, 2004b, p.47)

Further, Mr. Bray suggested some ways to reach stability. The group needed to implement XBRL in organisations and observe what happens:

"The only way to find out what the business issues are...is to implement and observe. Focus instead on adoption. Failure to do this will turn XBRL into nothing more than 'an interesting science project'." (Chartered Accountants Journal, Hucklesby and Macdonald, 2004b, p.47)

There was also limited tools and software available during Project First Step. 
"...the most significant issue is perhaps the lack of tools to easily create XBRL instance documents. This difficulty means that the business case for data preparers can be difficult to establish." (Chartered Accountants Journal, Boyd, 2004b, p.1)

The lack of suitable tools and software was also an issue at the international level. The President of XBRL International during that time, Louis Matherne mentioned:

"Our survey indicates that accounting software vendors with software for large companies are setting the pace for the push to the XBRL-enabled accounting applications." (Chartered Accountant Journal, Hucklesby, 2003c, p.50)

Within the organisational context, NZICA interviewees mentioned five factors; the presence of enthusiasm among the XBRL experts, the absence of mandatory adoption strategy ${ }^{38}$, and a lack of championship, human capability, and promotion and communication. A champion is an important person as they drive technology adoption from the start until it is successfully adopted. Stakeholders need to believe that this person, who has an important position and power in his or her organisation, can push the technology through. One interviewee stated that none of the politicians were interested and thus did not get involved with the XBRL initiatives.

"...none that I am aware of. We did not come up with any politician or become political. At that stages [there was] no involvement other than small bureaucratic people and some from the industries, but not a politician." (Steering Committee Member F)

As the Steering Committee that ran Project First Step was under the auspices of NZICA, a champion for XBRL within NZICA could have been the CEO because they had the power to support or not support the project. In 2004, NZICA appointed a new CEO, who changed the Institute's strategic position (Annual Report of ICANZ, Schofield, 2004, p.6). He introduced a new Five-Year Strategic Plan that was based on stakeholder input, which did not include a vision for XBRL (Annual Report of ICANZ, Muriwai, 2004, p.8; Annual Report of NZICA, Muriwai, 2005, p.8). Therefore, the championship of XBRL by NZICA disappeared during Project First Step.

\footnotetext{
${ }^{38}$ Adoption strategy refers to an approach or method employed to get stakeholders to start using a new technology like XBRL. In this thesis, there are two strategies: voluntary and mandatory adoption. More details are provided in Chapter 9, page 250 .
} 
Most interviewees considered the experts to be the key players in relation to XBRL technical expertise. Even though they might be not as important as a champion, they could contribute towards a successful XBRL adoption as they are the people that drive and introduce a new technology to stakeholders. In addition, one interviewee mentioned that driving XBRL initiatives as a group is more effective than as a single person.

"I guess having that group, and a number of people made it easier for each of us rather than just a single person trying to sell the message. Of course, it gave each other or everyone confidence." (Steering Committee Member H)

In early stages of Project First Step, the group had enough team members so that they could support and work together to achieve their goals. However, when most of the XBRL technical experts went overseas, the group started to lose momentum.

"I left the Institute in April 2005. Grant Boyd left at about the same...I think towards the end of 2004, something like that. [Steering Committee Member I] had left to go to the UK by then. [Steering Committee Member E] was not too far after that. Thus, many of the people involved just disappeared out of New Zealand. I think that is where momentum started to be lost. The most important thing that you need is the people that move the thing and are quite interested in it." (Institute Director L)

XBRL as a new technology needs promotion and to be well communicated to all its possible stakeholders. The information channel must be clear. Otherwise, people will get confuse and thus, reject the technology. The group used many approaches to promote and communicate XBRL.

"I supposed one of the things we were trying to do is to draw attention to XBRL. I said, "Right, I will write a whole lot of articles to fit in the Chartered Accountants Journal," which I did." (Steering Committee Member E)

Other than these articles, the Steering Committee also promoted XBRL via 'cocktail' conversations, networking, and Yahoo groups. Even though the promotion was carried out as planned, the methods used were not effective in capturing the attention of stakeholders. Moreover, during Project First Step the group did not target their audience effectively. Interviewees explained why promotion and communication of XBRL during Project First Step was not effective: 
"Our campaign was not really to implement it. It was more just to create a campaign of awareness." (Steering Committee Member E)

"It is a matter of talking to the right level. We were largely talking to the accountant within the government sector. We were not talking to the CFO of the government [agencies] and all of the ministers." (Steering Committee Member H)

The Chartered Accountants Journal also mentioned the ineffective promotion and communication of XBRL during Project First Step. The potential adopters simply asked:

"Why should I produce XBRL information when I have no one to send it to? To solve this problem, XBRL New Zealand began raising the awareness of XBRL through a number of targeted seminars and regular articles in the journal." (Chartered Accountants Journal, Boyd, 2004a, p.9)

While New Zealand was an XBRL jurisdiction, the Steering Committee used their website to communicate with its members as well as other stakeholders. However, this channel was not fully utilized to disseminate information related to XBRL.

"John Palmer has recently been appointed to help XBRL New Zealand with its administration and communication...Mr. Palmer sees this rebranded website as critical to sharing knowledge and experience and welcomes comments from members of the Institute on ways it can be further developed to help support the development and deployment of this technology around the country."(Chartered Accountants Journal, Hucklesby, 2006, p.46)

In Project First Step, the interviewees had two different views on the enthusiasm of those involved. The first view was that enthusiasm was a driver to keep them going.

"...what we had was...within NZICA, people who thought that XBRL has great potential." (Steering Committee Member E)

In the second view, the interviewee explained that the experts were so enthusiastic about the technology, that it motivated them to keep on exploring XBRL for business reporting, until at one stage, they reached a point far from their original goals.

"But, for those of us involved in it...[it was] just the excitement, the newness, the potential that carried us along. Obviously, to a point where we did have some influence, we did get the IRD thinking about it." (Steering Committee Member H) 
The stakeholders in Project First Step had different views on how XBRL technology could be adopted. There were two options either a pull strategy (mandatory) or a push strategy (voluntary). Most of the early XBRL adoptions at the international level used a pull strategy. Thus, some stakeholders believed that mandatory adoption was the best option. Hucklesby and Macdonald (June 2002, p.23) explained the options:

"The XBRL landscape is being shaped by the 'pull' of the needs of regulators. By this, we mean that regulatory authorities are seeking to obtain information from their constituents more quickly using XBRL (a 'pull strategy'), rather than market forces 'pushing' the adoption of this technology from the constituents up to the regulatory agencies." (Chartered Accountants Journal)

Even though the interviewees suggested and supported a mandatory adoption strategy, they had no power to implement the pull strategy. Thus, the Steering Committee needed a key government agency (and minister) to help them realize their goal.

Under the environmental context, those interviewees gave their views on five factors; a lack of a successful adoption story, limited stakeholder involvement, insufficient critical mass, changes in laws, rules and regulations as well as a knowledge gap. The previous XBRL initiative, the LEAP+ project, was not successful in bringing XBRL into New Zealand organisations. Therefore, there was no successful adoption story in the New Zealand context. In order to expose potential users to successful XBRL adoption stories, the Steering Committee developed a website.

"[The] website will provide a suite of XBRL demonstrations, pilots, proof of concept and implementations where you can click on a point in the supply chain to access prototypes and demonstrations. Interactive narrative components offer descriptionsof-use cases, explanations of the technical aspects of the implementation and insights into the impact of the new XBRL process." (Chartered Accountants Journal, Hucklesby and Macdonald, Aug 2004, p.40)

In the early years of the Steering Committee, the interviewee viewed that the group had successfully attracted attention from government agencies, and they wished to be involved with the XBRL project.

"In the SIG, there were people from various government departments. I remember

[Steering Committee Member C] from Audit New Zealand; [Steering Committee 
Member H] from KPMG. We also approached others through email but there was just no reply or they rejected it. Probably we did not need involvement with other organisations anyway." (Steering Committee Member F)

After Project First Step was finished, the results were presented at the $9^{\text {th }}$ XBRL International Conference by Carl Daucher. He mentioned the support from NZICA and the Steering Committee:

"The Institute was a critical component of this project- it brought the knowledge of IFRS and helped us create something bigger than just our relationship with an issuer. We were very lucky to have the support of the Institute and the XBRL Working Group in this effort."(Chartered Accountant Journal, Rondel, June 2004, p.39)

However, after the XBRL International Conference and perceiving a lot of challenges to adopting XBRL in New Zealand, the Steering Committee decided to 'wait and see' what was happening to XBRL at the international level.

"We reached the conclusion that we really have to wait...to see what was being achieved internationally. Then, use that [overseas XBRL experience] as a case study to bring back to New Zealand and say 'this is what is being done in the US and in the UK'." (Steering Committee Member H)

There was also limited support and interest from chartered accountants as reported by Davidson et al. (2006) in their study on XBRL awareness among the chartered accountants in New Zealand.

The third factor in the environmental context is not achieving a critical mass among potential adopters. One interviewee stated:

"So, when we did it at NZX, the pilot only had a few hundred (whatever it is) of large companies in New Zealand. It was not prevalent, if XBRL was not a tax mandate because it will not effect to all company." (Steering Committee Member I)

Another interviewee had the same view on critical mass.

"You imagine if New Zealand introduces XBRL and XML filing for financial statements. How many companies are on the stock exchange? A hundred or a thousand something? There would not be a huge incentive to create consumption software for only hundreds of New Zealand companies." (Institute Director L) 
It is possible that the introduction of IFRS in New Zealand somewhere around 2003, did affect XBRL development. First, the Institute's focus was diverted to IFRS instead of to XBRL adoption. One interviewee indicated that the introduction of mandatory IFRS adoption had an impact on the process of adopting XBRL. Government Officer A explained that the Steering Committee had been planning for XBRL adoption. However, the Institute decided to adopt IFRS on a mandatory basis. Here, XBRL and IFRS were competing, in order to get attention from the Institute for funding purposes. During that time, the Steering Committee tried to grab the Institute's attention so they will get continuous funding for XBRL-related activities. However, the new CEO's vision for the Institute was more about supporting IFRS adoption than adopting XBRL.

Even though, Project First Step was the second XBRL initiative in New Zealand; most of the stakeholders did not have accurate knowledge about XBRL. Institute Director L mentioned that while he was working at the Institute, he noticed that a lot of people were still wondering how to use the technology in business reporting. In fact, he mentioned the ignorance of XBRL technology was not only in New Zealand, it also happened in other countries like the UK and the US.

"I think XBRL was quite a bit more developed in the UK because they used XBRL for income tax and quite a few filings. However, if you speak to most people, only a few people knew about it. Even when we observed [what was happening] in the US, there is one company called Web Filing. They have to file using the XBRL format for filing the financial statements around the SEC's requirement. Something like $60 \%$ of them used this company." (Institute Director L)

\subsubsection{University of Auckland}

The University of Auckland had been an active stakeholder since the LEAP+ project. During Project First Step, this organisation revealed some factors in the technological, organisational and environmental contexts.

Within the technological context, the interviewee from the University of Auckland mentioned three factors: not recognizing the relative advantage of $\mathrm{XBRL}$, complexity in understanding the XBRL process, and not being seen as a problem solver. While in other countries, XBRL was starting to develop and stakeholders were learning to use XBRL, many 
New Zealand's stakeholders were struggling to understand the benefits of XBRL for business reporting purposes. Academic $\mathrm{F}$ from the University of Auckland shared this observation:

"I guess it should be developed...but in New Zealand, they just did not see it is beneficial to them." (Academic F)

This interviewee also believed there was complexity within the process of introducing and implementing of XBRL. Through his involvement in Project First Step, he recalled that XBRL was something that was too complex to understand and to implement

During Project First Step, it became apparent that various stakeholders did not want the introduction of XBRL. Whether or not they had sufficient information about XBRL, they decided that the technology was not for them. Academic F mentioned that XBRL was not the solution to any problem the stakeholders had. He explained it could be one of the reasons why the stakeholders never demanded the technology.

In the organisational context, the interviewee commented on the human capability and enthusiasm aspects. Like other interviewees from active organisations, Academic $F$ perceived a lack of XBRL experts affected the development of XBRL during Project First Step.

"...the lack of experts in New Zealand was one of the factors that influenced the nonadoption of XBRL." (Academic F)

In addition, this interviewee explained the reasons for limited experts during that time. It happened in 2005; as most of the experts were looking for other opportunities, especially from overseas. They wanted involvement in XBRL initiatives, but they anticipated that initiatives in New Zealand would likely fail. The rest of Steering Committee also lost their enthusiasm in continuing the project, including the interviewee.

"...other people went overseas while others lost interest and the whole thing started to lose momentum...there could have been some other things that happened, but I was not involved in it since then." (Academic F)

The interviewee (Academic F) viewed that during Project First Step, many XBRL supporters, especially the experts were over enthusiastic. They had a tendency to overstate the benefits of XBRL. 
Under the environmental context, Academic $\mathrm{F}$ commented on a lack of stakeholder involvement. As the Steering Committee was trying hard to bring XBRL alive in New Zealand, the stakeholders, particularly from the business organisations, were not putting the same effort into making XBRL happen. This condition contributed to the failure of XBRL initiatives.

"...there was no enthusiasm even when organisations are going to get the benefit from it by having better information; cost saving...I mean it would be worthwhile for the private sector to put funds into this initiative. However, it [stakeholders] did not seem to be delighted that the Steering Committee wanted to develop it while others seem to be trying to get a free ride." (Academic F)

\subsection{Factors Associated with Observer Stakeholder}

There were three observer stakeholders, which consisted of one government agency and two others from the stakeholder' organisations group. These organisations contribute to the identification of various factors from the technological, organisational, and environmental contexts.

\subsubsection{The Treasury}

The Treasury's first involvement in an XBRL initiative was through Project First Step. As an observer organisation, The Treasury interviewee gave their view on factors that were from the technological and organisational contexts.

In the technological context, the interviewee commented on XBRL not being considered a problem solver. The interviewee suggested that financial analysts could not see the benefit of XBRL.

"That was the problem with XBRL. If the analyst really can get the most benefit out of it, they will be surely willing to pay for it. However, they are not (I am sorry). This is really a problem." (Government Officer $G$ )

Under the organisational context, the representative from Treasury mentioned the effective promotion and communication of XBRL. The efforts of the Steering Committee in introducing XBRL through seminars, workshops, or conferences created interest among potential users. The interviewee shared his experience as he had attended some of the conferences related to financial reporting. 
"It was a topic that came up at some of the conferences. As a standard setter, we got some education sessions on it. I was a little bit interested in it because I could see it being a way of formalizing a reporting process that was going to be... as I understood, it was going to be in accounting software packages." (Government Officer G)

\subsubsection{University of Otago}

Project First Step was the first involvement of the University of Otago in an XBRL initiative. As an observer stakeholder, this interviewee gave his opinion on the factors within the technological, organisational, and environmental contexts.

Under the technological context, Academic $\mathrm{P}$ mentioned about XBRL not being seen as a problem solver. As an academic, the interviewee had close relationships with financial analysts in New Zealand. Based on his previous research, financial analysts were not interested in XBRL technology. They were happy with their existing system.

"The analysts - when I talked to them, they were not particularly interested in it. Because they said, "We have our structures or ways of doing things. We are perfectly happy with what we have." (Academic P)

He further disclosed that financial analysts were not convinced about or did not need XBRL to deliver their work.

"If you ask the analysts, it was almost a non-issue to them...For them; it was not a big problem because they actually said: "We have our system, our data; we do not need this." (Academic P)

Within the organisational context, the interviewee commented on three factors. There was a lack of championship, poor promotion, and communication and over enthusiasm by those promoting XBRL. The interviewee believed that every new technology needs a champion. Without a champion, it would be difficult for a technology like XBRL to reach the adoption stage. However, in Project First Step, the interviewee perceived they did not have a champion.

"I was not saying it was not there, but nobody was championing it [XBRL initiative] particularly well, as to what the benefits were."(Academic $P$ )

In term of promotion, the interviewee explained that the promotion needed to be targeted towards educating people especially the XBRL stakeholders. Through his observation, the 
interviewee noticed that the XBRL initiative group focused on an awareness campaign instead of educating the stakeholders (Academic P).

This interviewee mentioned another factor; the over enthusiasm among the interested people or experts. Based on his observations, the interviewee recalled that the experts tried to influence stakeholders to accept XBRL. However, he believed that the experts were making many promises that would be difficult to keep or only telling good things about XBRL.

"I think a part of the problems is there had been many promises and very few deliverables. Even now, it is not clear what XBRL is giving us." (Academic $P$ )

Within the environmental context, this interviewee commented on two factors; a lack of stakeholder involvement and critical mass. Academic $\mathrm{P}$ considered that it was really difficult to get the stakeholders involved with XBRL. During that time, the majority of stakeholders did their best to avoid an XBRL compliance program and related activities.

Then, the interviewee shared his view on the critical mass of the NZX using XBRL. The financial analysts were only interested in NZX listed companies. However, they were not interested enough to use XBRL as there were only 150 companies. For them, the number was too small. Moreover, adopting XBRL for limited use was considered a waste. Without huge numbers of stakeholders wanting or demanding this technology, then it would not reach critical mass.

"So, who is going to use this information? If you only have one or two analysts tracking a company in New Zealand, it would be probably a waste of what time you have. I think that it is definitely part of the problem. There were not a huge number of people out there saying, "We need this information." (Academic P)

\subsubsection{Newspapers}

A function of newspapers is to alert stakeholders to any interesting developments in the business arena. As an observer stakeholder, the New Zealand local newspapers (as a cluster) commented on factors within the technological and organisational contexts.

In the technological context, there were two factors: security and trialability that were mentioned by the local newspapers. Some business organisations were considering using 
XBRL in their computer systems. However, they had concerns related to information security and integrity when using XBRL as reported below:

"There is the issue of what management wants to be released and how they want it to be interpreted. So there are important security and integrity issues." (New Zealand Herald, Richard Wood, 2003a)

Other local newspapers highlighted that the initiative group needed to address the securityrelated issues first before stakeholders would adopt XBRL.

"XBRL could even be used by Statistics to suck automatically relevant data out of businesses' computer systems if corporates agree and the appropriate security arrangements are put in place first." (Dominion Post, Richard Wood, 2004)

The local Wellington newspaper also reported on the trialability of XBRL by stakeholders. During Project First Step, a few NZX listed company trialed XBRL technology. At the same time, the XBRL Steering Committee explored XBRL's ability to reduce compliance costs.

"...efforts have gone into working out how to avoid additional compliance costs for businesses and exploring how XBRL could be used to help generate reports for other organisations." (The Dominion Post, Richard Wood, 2003b)

Within the organisational context, this stakeholder cluster commented on two factors; enthusiasm and the choice of a voluntary adoption strategy. From Scoop Independent News, Carl Daucher (from the NZX) mentioned their excitement about the XBRL initiative:

"We are very excited about the XBRL initiative because it will help eliminate duplication and reduce the risk of errors, making it easier and more efficient for companies to share information with the market." (The Dominion Post, Richard Wood, 2003b)

In regards to the adoption strategy, the Steering Committee had two suggestions on how organisations could adopt XBRL; either mandatory or voluntary adoption. Through the Dominion Post, Carl Daucher mentioned why the NZX had chosen voluntary adoption.

“...filing documents using XBRL would not be made compulsory in New Zealand in the near future. We'd like to see the tools become more widely available and for companies to see the benefits on their terms." (The Dominion Post, Richard Wood, 2003b) 


\subsection{Analysis: Project First Step}

The analysis below has assisted the researcher in exploring the relevant factors that influenced the adoption or non-adoption decision. Through the process, the researcher identified factors that were not in the research framework as presented in Chapter 3, Section 3.4 or in the prior literature as in Chapter 2. In the technological context, the additional (unpredicted) factors were the stability of specification and taxonomy and the availability of tools and software to support XBRL adoption. Under the organisational context, the additional factor was the choice of adoption strategies. Lastly, within the environmental context, the additional factor was a change in laws, rules, or regulations that altered the focus of stakeholders.

Based on the above findings, the OAG viewed information security and the promotion and communication of XBRL as factors that would facilitate organisations to adopt XBRL. However, other factors like the complexity of XBRL, an unstable XBRL specification and taxonomy, a lack of XBRL experts, the over-enthusiastic experts, a lack of stakeholder involvement (or demand for XBRL), a knowledge gap and a change of laws, rules or regulations hindered and influenced their decision not to push for adoption of XBRL in relation to $\mathrm{XBRL}$ for business reporting purposes. $\mathrm{XBRL}$, as demonstrated in Project First Step, was complex in terms of building and updating the taxonomy. It happened that in the early 2000s, the specification as well as taxonomy (at the international level) was not stable and thus, every revision of the specification impacted on the taxonomy. In New Zealand, the Steering Committee also had an issue with who was responsible for updating the taxonomy. Was the responsibility the Steering Committee's or the Financial Reporting Standard Board's? Either way, New Zealand during that time had a limited number of experts as experienced New Zealander experts were involved at the international level, and further their involvement was on a voluntary basis. Even though the experts had a genuine interest in XBRL technology, towards the end of Project First Step, they became overenthusiastic as they tried to get XBRL adopted. This was mainly because there was no demand for XBRL from stakeholders as a whole. In addition, there was a need to have more information on XBRL such as how the tags function in the XBRL format. By narrowing this information gap, it would have assisted the stakeholders to understand XBRL better and showed how it could be used for business reporting. The impact of the introduction of IFRS in 2003 and subsequently mandatory adoption in 2007 had an impact on the XBRL story as 
the Steering Committee needed to update the taxonomy. Unfortunately, this updating exercise required an extended period of time as understanding and building a taxonomy based on IFRS was complex and by this time, the focus of the experts had changed.

As an active stakeholder, the IRD perceived that the experts were over-enthusiastic, that there was a lack of stakeholder involvement and a knowledge gap, which all acted as barriers to adopting XBRL for business reporting. During Project First Step, they believed that the experts had enough influence to bring XBRL to New Zealand. However, what happened was that in New Zealand, the experts deviated from their original plan and failed to influence the accountants enough to get them to accept the idea of XBRL, possibly because the accountants had no idea about XBRL.

Ernst \& Young maintained its involvement as an active stakeholder. The interviewees considered that XBRL had no relative advantage, was not a problem solver, and that there was a lack of financial support and stakeholder involvement. During the early years, the Steering Committee had funding from NZICA and used that to fund XBRL related activities including paying their membership as an XBRL jurisdiction. Ernst \& Young viewed that paying the membership fees was a waste because New Zealand did not implement XBRL for use in business reporting. At the same time, the stakeholders could not see the benefits of XBRL. Thus, it was perceived that XBRL was not the solution to any problem that the stakeholders were looking to solve. Towards the end of Project First Step, the Institute cut the funding for the Steering Committees' activities, which affected their ability to continue as an XBRL jurisdiction and progress XBRL activities within New Zealand. Even though the Steering Committee had support from the NZX, it was not enough as they did not have any involvement from software developers or demand for XBRL from other stakeholders.

As an active stakeholder, KPMG believed that XBRL did not provide a relative advantage, was not a problem solver and that there had been ineffective promotion and communication. These factors were barriers to adopting XBRL. The Steering Committee had difficulties in developing an effective communication channel for the XBRL-based documents. During that time, business organisations were prepared to act as senders in the project, but government agencies did not have the ability or desire to act as receivers. Because of this situation, both groups of stakeholders could not see the benefits of using XBRL for business reporting. People from KPMG tried to convince the stakeholders of the 
benefits of using XBRL in business reporting. The stakeholders, instead, asked what they would get in return. This situation put KMPG staff in a difficult position because, in the early years of XBRL in New Zealand, the Steering Committee and the stakeholders invested in the technology. The benefits would have come later after successful implementation. However, stakeholders wanted to see the benefits at that time, which was impossible. Thus, from KPMG's viewpoint, XBRL was not a solution for New Zealand's stakeholders because they could not see the benefits.

As an active stakeholder, the professional accounting body (NZICA) and the Steering Committee identified two facilitating factors; trialability and enthusiasm. They believed that the XBRL pilot project reduced uncertainty among XBRL stakeholders. Thus, trialability positively influenced XBRL adoption. Further, enthusiasm towards XBRL technology was perceived to be a key driver and provided the momentum to keep them going. However, there were more barriers than facilitators relating to the decision to adopt XBRL. The barriers to adopting XBRL were factors like complexity, an unstable XBRL specification, limited tools and software, a lack of human capability, no championship, ineffective promotion and communication, not having mandatory adoption, no prior successful adoption story, lack of stakeholder involvement, a knowledge gap, no critical mass as well as a change in regulations relating to financial reporting. The technology was complex and difficult to understand because of the calculation-linkages it was based on. Further, there was too wide a vision between the Steering Committee and confusion about the relationship between XBRL technology and IFRS. As the XBRL specification changed, the taxonomy also had to change. Thus, an unstable taxonomy became a problem for stakeholders. The limited availability of tools and software to create XBRL instance documents added another challenge to the adoption of XBRL. Working as a team was more effective than working as individuals. Thus, when the team members began to leave, the momentum regarding getting XBRL adopted in New Zealand disappeared. There were also difficulties in obtaining the support of a champion for Project First Step either from the Institute or from one with a political background. The Steering Committee had promoted XBRL through many platforms. However, internal communication within NZICA about XBRL needed to be improved. Moreover, the group failed to utilize fully their website to effectively disseminate information to stakeholders. Although, it was believed that mandatory XBRL adoption was the best option, neither the Steering Committee or the 
Institute had the power to enforce its adoption. The absence of successful adoption stories in New Zealand hindered stakeholder's engagement. In addition, there was a large knowledge gap between the interested parties; the same situation that also had happened in other countries. Critical mass in using XBRL technology by stakeholders in New Zealand was hard to achieve since there were only around 150 companies on the NZX. Furthermore, the introduction of IFRS was believed to affect XBRL initiatives as it diverted the Institute's (as well as stakeholders) attention to mandatory IFRS adoption.

The University of Auckland was an active stakeholder during Project First Step. They believed that XBRL technology provided no relative advantage, was complex and was not seen as a problem solver by potential stakeholders in New Zealand. These interviewees could not see the benefits of using XBRL for business reporting; instead all they saw was the complexity of the XBRL technology. Thus, the stakeholders decided that XBRL was not a solution to their business problems. In the organisational context, they believed that the lack of experts towards the end of Project First Step hindered the initiative. These experts, earlier on had a tendency to overstate the real benefits of XBRL. Additionally, this organisation perceived there was no stakeholder involvement from business organisations.

As an observer stakeholder, the Treasury believed that the promotion and communication were sufficient to facilitate the adoption of XBRL in New Zealand organisations. However, not being considered as a problem solver by stakeholders hindered XBRL development, in particular, XBRL was not seen as a solution by key financial analysts.

The University of Otago was an observer stakeholder during Project First Step. Factors like not being perceived as a problem solver, no championship, ineffective promotion and communication, over-enthusiastic experts, a lack of stakeholder involvement and no critical mass were viewed as inhibitors to XBRL adoption. XBRL technology was not seen as a problem solver by financial analysts as their analysis tools for evaluating listed companies' financial statements were considered sufficient. Project First Step also had difficulty in finding an influential champion and promotion focused on creating awareness instead of educating stakeholders. Enthusiasm among experts led them to over-sell the benefits to stakeholders, but they had no deliverables that stakeholders could see. Thus, it was difficult to get stakeholders engaged with the project. 
The local New Zealand newspapers were also an observer stakeholder cluster during Project First Step. Trialability and enthusiasm were seen as facilitating factors. Business organisations had a chance to test the XBRL application, through being involved in Project First Step. The local newspapers also reported how enthusiastic the NZX was about XBRL initiatives. However, the NZX decided not to adopt XBRL on mandatory basis until the right tools and software became available and business organisations demanded it. At the same time, business organisations wanted the initiative group to address issues regarding security and integrity before they would agree to use XBRL. Thus, an analysis of newspaper articles revealed that security and a voluntary adoption strategy were barriers to adopting XBRL.

Table 6.2 presents the overall findings relating to the context factors that were relevant in Project First Step. There are more inhibitors than facilitating factors to making the decision to adopt XBRL as an outcome of this initiative. In fact, trialability is the only common facilitating factor, across the active and observer stakeholders.

Table 6.2: Overall Summary of TOE Context Factors in Project First Step

\begin{tabular}{|c|c|c|c|c|c|c|c|c|c|c|c|c|c|c|c|c|c|c|}
\hline & \multicolumn{7}{|c|}{ Technological } & \multicolumn{6}{|c|}{ Organisational } & \multicolumn{5}{|c|}{ Environmental } \\
\hline & 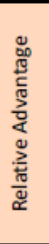 & $\frac{\overrightarrow{\mathrm{J}}}{\frac{\mathrm{U}}{\mathrm{a}}}$ & $\begin{array}{l}\text { 壳 } \\
\text { 心 }\end{array}$ & 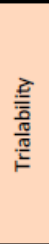 & 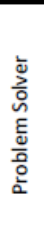 & $\begin{array}{l}\text { 壳 } \\
\text { 言 } \\
\text { 心 }\end{array}$ & 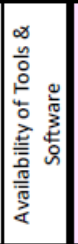 & 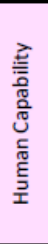 & 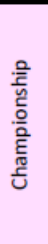 & 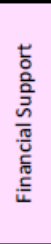 & 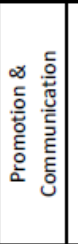 & 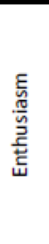 & 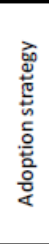 & 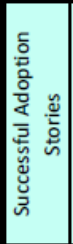 & 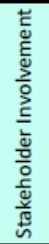 & 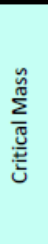 & 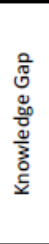 & 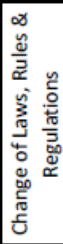 \\
\hline \multicolumn{19}{|l|}{ Active Stakeholder } \\
\hline OAG & & - & + & & & - & & - & & & + & - & & & - & & - & - \\
\hline IRD & & & & & & & & & & & & - & & & - & & - & \\
\hline Ernst \& Young & - & & & & - & & & & & - & + & & & & - & & & \\
\hline KPMG & - & & & & - & & & & & & - & & & & & & & \\
\hline NZICA (Steering Committee) & & - & & + & & - & - & - & - & & - & + & - & - & - & - & - & - \\
\hline University of Auckland & - & - & & & - & & & - & & & & - & & & - & & & \\
\hline \multicolumn{19}{|l|}{ Observer Stakeholder } \\
\hline Treasury & & & & & - & & & & & & + & & & & & & & \\
\hline University of Otago & & & & & - & & & & - & & - & - & & & - & - & & \\
\hline Newspapers & & & - & + & & & & & & & & + & - & & & & & \\
\hline
\end{tabular}

+: Driver, Facilitating, Encourage; - : Hinder, Inhibitor, Challenge

Under the technological context, the majority of the interviewees, either from active or observer stakeholders, agreed that XBRL was not seen as a solution to stakeholders' problems relating to business reporting. Additionally, there appears to be no relative advantage, and the complexity of XBRL also contributed to its non-adoption. Within the organisational context, most of the interviewees highlighted promotion and communication of $\mathrm{XBRL}$ as well as enthusiasm among the experts regarding XBRL. The majority of 
interviewees agreed that XBRL was not well promoted and communicated to stakeholders. Furthermore, the majority believed that the experts were over-enthusiastic in relation to XBRL's benefits. In addition, a lack of experts, later on, to enable XBRL to be implemented, influenced the stakeholders' decision not to adopt XBRL. Finally, in the environmental context, most of the interviewees suggested that a lack of stakeholder involvement (or demand) and a knowledge gap between those promoting XBRL and other stakeholders, lead to the decision by stakeholders not to demand the adoption of XBRL.

\subsection{Chapter Summary}

The aim of this chapter is to present and determine the factors that influenced the nonadoption decision for the two XBRL initiatives under professional auspices, the LEAP+ project and Project First Step. Before presenting the findings, this chapter provides a brief overview of each project including its objectives and the classification of the stakeholders that were involved. The factors identified within the technological, organisational, and environmental contexts are presented based on whether the organisation involved was an active or observer organisation.

Based on the data analysis, trialability and sufficient human capability (as experts) encouraged two stakeholders to investigate adopting XBRL during the LEAP+ project. However, the LEAP+ project team faced a copyright issue, which meant the project website could not be made available to other stakeholders.

Meanwhile, during Project First Step, trialability was the key facilitating factor that potentially allowed the project to proceed. However, there were many barriers and challenges in getting stakeholders to adopt XBRL. During the Project First Step, factors like not being perceived as a problem solver, ineffective promotion and communication, overenthusiastic promotion by supporters and a lack of stakeholder involvement in the process hindered the possibility of XBRL adoption for business reporting.

Therefore, both the XBRL initiatives carried out under the auspices of professional organisations or groups failed to get XBRL adopted by organisations for business reporting purposes in New Zealand. In the next chapter, this thesis will present the findings of XBRL initiatives that were undertaken under the auspices of government agencies. 


\section{Chapter 7: XBRL Initiatives Under the Auspices of Government Organisations}

\subsection{Introduction}

Chapter 6 presented the findings of the LEAP+ Project and Project First Step. People from the private organisations controlled both of these projects. This chapter presents the results of the other two projects, the e-GIF project, and SBR programme. The views represented do not represent the official views of an organisation but rather the views of the individuals who took part in the projects. The e-GIF project and SBR programme were government initiatives. These projects need to be investigated because its will allow the understanding of why the government decided not to adopt XBRL for business reporting in New Zealand. Furthermore, it will allow the identification of the factors that influenced the government's decision.

The presentation of the findings related to the two initiatives starts by giving a brief overview of each project, which includes the objectives and the classification of stakeholder involvements. Based on this classification the factors that influence the decision are presented. The analysis of each project summarises, examines, and identifies the critical factors. The final section of the chapter summarises the overall findings for the e-GIF and SBR initiatives.

\subsection{Overview of the e-GIF Project (2003-2007)}

The e-Government Interoperability Framework or e-GIF was a set of policies, technical information and guidelines (SSC, 2008). The framework covered the interoperability of public sector data and information resources, ICT and electronic business processes. Additionally, any government agency was invited to add its information, ICT, or processes to the framework as it was based on 'open' international standards (SSC, 2008).

Under the e-GIF, e-government was defined as government agencies working together to provide better service and information to individuals and businesses by using technology such as XBRL. It was mostly about establishing common standards across government, delivering services more effectively and providing a way for government agencies to work 
together using technology. In New Zealand, e-government presented opportunities such as developing higher quality, cost-effective, government services and a better relationship between people and their government agencies (SSC, 2008).

Further, In terms of interoperability, it refers to the ability of government agencies to share information, and integrate information and business processes by using common standards. For example, the XBRL standard could be utilized as a medium to enable the sharing and integration of information about business processes gained from business reports.

\subsubsection{Objectives of the e-GIF Project}

Through the e-GIF project, the government agencies aimed to (SSC, 2008):

i) Have systems that work easily together electronically;

ii) Make systems, knowledge and experience reusable from one agency to another;

iii) Reduce the effort needed to deal with the government online by encouraging consistency of approach; and

iv) Minimise the reliance on tapes and disks to exchange data, as these have their security issues and are not scaleable for the level of interoperability many services will need in the future.

Additionally, the aim of the e-GIF was to improve the practical application of ICT between the public and government, within and between agencies or within a global contact. The development of an e-GIF can be seen as improving the public face of government by making it easier for people to deal with multiple agencies. If the ICT systems and the processes have the ability to support interoperability, then people would find it easier to do business with the government as a whole. E-GIF would improve government agencies use of ICT by adopting common ICT technical standards. For example, if government organisations such as the IRD, Statistics New Zealand, the Companies Office, and ACC were using the XBRL standard, this would enable them to share and integrate financial statement information and related business reporting processes. By using the same technical standards under eGIF, for example, government agencies would have in-depth knowledge about that standard. Further, by using a standard such as XBRL, particular agencies would have the infrastructure to deliver the required governmental services and to share information. 
The IRD agreed to lead the e-GIF project in New Zealand. This was for two reasons. First, their current IT system needed to be upgraded as it was last done in the 1980s. In searching for suitable technology to replace their system, they discovered the potential of XBRL to collect structured data for information sharing and business reporting (mainly through Project First Step). Second, IRD was the primary user of the business data provided by businesses. On average, every month each New Zealand business needs to submit returns to the IRD, which will be inputted into their IT system. The same data is also supplied to other government agencies throughout the year. They believed that by leading the project, they could influence the architecture and design of any whole-of-government ICT system. The IRD established a Working Group as discussed in Chapter 5 (Section 5.6), who agreed to work together towards the development of the e-GIF, along with XBRL New Zealand and NZICA.

\subsubsection{Classification of Stakeholder Involvement}

There were six organisations involved in the e-GIF project. They can be classified into active, supportive and observer organisations. All government agencies involved such as the IRD, the MED, and the SSC were active organisations. These active organisations were involved closely with the e-GIF project as they had a representative on the Steering Committee as well as the Working Group. Their commitment included attending meetings, seminars, and conferences; providing funds and sharing skills and technical resources. There were two supportive organisations; NZICA and a Tax Management Consulting Firm. Both organisations provided advice and guided the active organisations. Additionally, they also attended meetings wherever required. The only one observer organisation was the OAG. Even though an observer organisation, their representative attended the meetings. However, their participation was limited to being informed as to what the e-GIF project intended to do and how it could affect their operations.

Each organisation involved had a different interest in the XBRL technology. For example, the IRD was interested because they needed to replace their old computer system. They also wanted to use XBRL as a medium to reduce the cost of operations and as an effective way of sharing information. The MED had similar intentions in their desire to adopt XBRL. However, their perspective was from the business organisation viewpoint. The use of XBRL would save costs and time for business organisations when preparing and submitting their 
financial reports to government agencies. Meanwhile, the SSC was interested because they believed in the ability of XBRL to act as a medium to share information between government agencies. Through the standardisation of information, XBRL could be used to prepare and share information between and within related organisations. As supportive organisations, NZICA, and the Tax Management Consulting Firm encouraged the other organisations to adopt XBRL because they could see the benefits of using it and believed that XBRL was the future in financial reporting. In contrast, the OAG was interested in XBRL but only from the viewpoint of how the technology might impact their current operations.

The next subsection presents the factors associated with the non-adoption of the e-GIF project (and thus, XBRL) from the active, supportive and observer organisational point of view.

\subsection{Factors Associated with Active Stakeholders}

In e-GIF, there were three active stakeholders as discussed above. Each organisation provided reasons and related factors that could explain the organisation's intention to adopt or not adopt XBRL technology, within the e-GIF framework.

\subsubsection{The Inland Revenue Department (IRD)}

The IRD had been an active stakeholder since Project First Step. The representatives from IRD mentioned various factors under the technological, organisational, as well as environmental contexts.

Under the technological context, the interviewees identified seven factors; providing a relative advantage, compatibility, complexity, security, trialability, being a problem solver and a lack of availability of tools and software. During the e-GIF project, the IRD could see the benefits of using XBRL for tax purposes.

"We could utilize XBRL. We could do the extension of the taxonomy to the IFRS to utilize it for taxation purposes." (Government Officer M)

Government Officer J explained the taxonomy acts like a bridge from the existing computer system to XBRL. Thus, any computer system was considered to be compatible with XBRL.

"That is why you have the taxonomy. It provides a translation from one system to another. You do not need to change your computer programme. All you do is you hook 
up to connect to the taxonomy and just run your programme the way it is." (Government Officer J)

According to that interviewee's explanation, relevant government agencies had been considering the security issues of using XBRL for business reporting since Project First Step. So far, they had identified no security issues in adopting XBRL.

"[There are] no security issues. You have to put the information. You need to make sure that whatever the information is, it is correct at the end of the day." (Government Officer J)

After series of discussions with software developers, the IRD concluded that security was not an issue.

"We talked to the software developers like QuickBooks, Oracle, and SAP. They were all fine with that [security level] and all you need is to push a button. There will be a checking process, and it would come up on the screen for you to validate. When you are happy with it, or somebody is happy with it, you just press the button and all the information will be sent." (Government Officer J)

Through the e-GIF, the IRD had a chance to build and try the XBRL application in their organisation. The IRD discovered two significant findings. First, the technology was suitable as a mechanism to share financial data within government agencies.

"As the result of the pilot project that we undertook with the Statistics New Zealand, we could show it was an appropriate standard to use for sharing financial data." (Government Officer M)

Second, XBRL has the ability to detect a certain level of previously unknown errors in financial reports. Therefore, the IRD viewed XBRL as a problem solver for their current problems.

"That level of errors was not known until we used XBRL, which enables us to detect a large scale of analytics ${ }^{39}$." (Government Officer M)

Additionally, the IRD perceived that XBRL was a complex technology and that the level of complexity was increased because the XBRL International consortium kept upgrading the taxonomy without considering the readiness of the XBRL community as a whole.

\footnotetext{
${ }^{39}$ Analytics is defined as the scientific process of transforming data into insights for making better decisions (https://www.informs.org/About-INFORMS/What-is-Analytics)
} 
"I think...that one of the mistakes that the XBRL community made was becoming too complex... I believe that it really went too far into areas that were too complex, which made it more difficult for someone to understand. Specifically, I think of the work they did on a dimensional taxonomy. I think that was probably unnecessary for the level of maturity [in the international community] and the people were not ready for that. I think most of the work that they are doing around the XBRL-GL, again probably a little bit too soon." (Government Officer $M$ )

In addition, the interviewee explained the XBRL taxonomy is the area that made $X B R L$ too complex.

"I think the data architecture, which is effectively what a taxonomy is; it is always complicated, and it does not matter what technology you used to achieve it. It is hard work." (Government Officer M)

Furthermore, at that point in time, XBRL technology had not matured in terms of the availability of tools and software. The interviewee felt users had the right to ask if they could use XBRL to assist them in reporting.

"I certainly think it is appropriate to ask, whether or not the tools had matured enough actually to make it easier for businesses to report or whether or not it is adding more work to their reporting." (Government Officer $M$ )

Within the organisational context, five factors appear to be important at the IRD; a lack of championship, limited human capability, a change of programme sponsor ${ }^{40}$, effective leadership $^{41}$, and enthusiasm. The interviewee considered that the absence of real championship from top management delayed many important and urgent decisions related to XBRL adoption. Without that championship, progress had been slow because the person in-charge could not make any decisions related to XBRL.

"Harm Jan van Burg, he was the champion in the Netherlands, was at a higher director's level. Paul Madden, who lead the Australian programme of work, he was on par with him. He was the Assistant Commissioner. He has a lot of power. Me, here being a champion in New Zealand, I was a National Advisor. I had no power. It made a huge difference because they went through and faced the same problems as I did. But,

\footnotetext{
${ }^{40}$ Programme sponsor refers to the government agency that is responsible for organizing a particular XBRL initiative in New Zealand. More details are provided in Chapter 9, page 251.

${ }^{41}$ Leadership and championship are differentiated based on the degree of influence the person has in the XBRL project. More details are provided in Chapter 9, page 251.
} 
they just said, "Make it happen" and it would happen. Whereas I could not do that, I had to rely on a number of people [who were] decision makers. They made the decision, and I had to convince them." (Government Officer J)

The absence of power became an issue when internal decisions were being made.

"The architecture and again because of my position, I did the design work. But at the end of the day, they cancelled the architecture within the IRD. They could say 'No, we are not doing the architecture.' I had no power to say 'Why?' to anyone." (Government Officer J)

However, during the e-GIF project, the IRD provided strong leadership within the group to complete the tasks that needed to be delivered.

"I guess in terms of the stuff that I was involved with; there were sufficient leadership and support to complete what we needed to complete. I do not think we were lacking the support that we needed to deliver our standard for sharing data." (Government Officer M)

Like Project First Step, the e-GIF project experienced the loss of expert knowledge from the accounting profession. This made it difficult for any progress to be made on.

"These people (the experts) within the accounting profession, they were interested in it. However, they ended up in some other places, which made it harder for us." (Government Officer J)

Another interviewee from the IRD stated that having a limited number of experts in XBRL was a big challenge and became a real problem.

"The other big challenge that I had around the skills was there were not many people that understood XBRL as well as I do. There were not many people in New Zealand who could work on it. That was problematic." (Government Officer M)

While attending an XBRL conference, the interviewee noticed that the XBRL experts showed their enthusiasm towards XBRL technology. The interviewee agreed that enthusiasm was an important factor that enabled the adoption of new technology like XBRL.

"They talked about it, felt enthusiastic, I want to change the world, get people converted to it and a certain extent, - it is true. You need people to believe in it and think that it is a good idea." (Government Officer J) 
The interviewees also mentioned the change of programme sponsor. The IRD started the eGIF project. Then in 2007, the initiative moved to the MED.

"When the project was in the IRD [sponsor of the project] it was in the e-GIF, things happened, moved along, were very positive...As soon as it went to the MED, it started to fall apart." (Government Officer J)

Within the environmental context, the IRD representatives mentioned four factors: a lack of stakeholder involvement from politicians and insufficient critical mass, a culture of working independently ${ }^{42}$ in the government agencies and the influence of trading partners. From the IRD's perspective, there was a lack of political involvement in the XBRL initiative.

"I think we really struggle to get political involvement; we really needed it." (Government Officer M)

Stakeholders responded differently during the e-GIF project. Some were interested, some were just observers, and some were actively involved.

"Well, there was no MP in the National Government, but there were a number of MPs that were interested [in XBRL] in the Labour Government. I mean Michael Cullen who was the IRD Minister, Statistics New Zealand, their minister and chief were keen...because they could see the advantages from the statistical collection point of view. The Prime Minister at that time, she was in favour a little as well." (Government Officer J)

"The OAG came occasionally, and they came under the stipulation that it will be a "watching brief" for them, and they will not participate actively in it." (Government Officer J)

"The MED had this "watching brief" on the programme just like the OAG." (Government Officer J)

The interviewee also commented on the importance of the Big 4 accounting firms and software developers in getting organisations to adopt XBRL.

"The Big 4 was very important for us because they have a lot of business customers, tax, audit work and all that stuff. They are going to be the main player in that respect.

\footnotetext{
${ }^{42}$ Culture of working independently refers to the way that government agencies operate in New Zealand, where every agency prefers to work alone or separately from other agencies. More details are provided in Chapter 9, page 254.
} 
They also have a lot of power in government, accounting, and financial circles." (Government Officer J)

"Most of the software developers...they need to develop software that could use XBRL." (Government Officer J)

If the majority of government agencies adopted XBRL for use in business reporting, then the level of critical mass would have been reached.

"I think the only way that it could really be of benefit in terms of business reporting is for a lot of agencies and organisations to adopt it together." (Government Officer M) However, during the e-GIF project, fewer than ten government agencies agreed to adopt XBRL. As a result, there was no critical mass towards adopting XBRL.

The low critical mass among the XBRL stakeholders, especially from the government agencies, was predominantly because the government agencies liked to work independently. XBRL use would enable government agencies to share data among themselves. However, in New Zealand, sharing data or working together was not part of the culture:

"It was really hard for government agencies to work together. We all wanted to make our own boat work better for our government agencies." (Government Officer J)

Further, different beliefs and motivations influenced the way people work.

"I think the key challenge was that people were reluctant to agree on a standard around sharing data. It was probably true of all type of initiatives. I think people have different motivations." (Government Officer $M$ )

Furthermore, New Zealand does a large amount of international business, especially with Australia. It was thought that when Australia adopted XBRL use for business reporting, then it would be easier for people in New Zealand to convince politicians to accept the technology.

"The IRD does a lot of business work with customs, has a lot of business with UK, Canada, US and Australia. I saw how they were doing things. I know we had to look at the work done in New Zealand. If it had been done in Australia, then it will be a lot easier to convince the politicians here in New Zealand to do it, because we trade a lot with Australia." (Government Officer J) 


\subsubsection{The Ministry of Economic Development (MED)}

The MED was an active organisation under the e-GIF project. An interviewee from this organisation shared his opinion on the technological and environmental contexts.

Within the technological context, Government Officer $\mathrm{H}$ commented on the complexity of XBRL. In the e-GIF project, the interviewee explained that the different computer settings in each organisation made XBRL adoption complex. It needed a translator and that the translator was the taxonomy.

"We had a whole lot of differences in businesses' settings and the one core system was in the government. You need a translator between these two systems."(Government Officer $H$ )

In the environmental context, the interviewee mentioned trading partners. As a neighbouring country, New Zealand has a tendency to refer to Australia. When, the Labour Government in Australia approved their SBR project (that uses XBRL), the Labour Government in New Zealand started to get interested in XBRL technology.

"[Under the e-GIF project) the Labour Government was looking for ways to reduce the compliance cost on business using XBRL technology. That was on the back of what was happening in Australia. The Labour Government in Australia had approved a project, an implementation project." (Government Officer $\mathrm{H}$ )

\subsubsection{The State Services Commission (SSC)}

The SSC became firstly involved with XBRL initiatives during the e-GIF project. As an active organisation, the SSC commented on the organisational and environmental contexts.

Under the organisational context, the interviewee mentioned two factors; the change of programme sponsor and ineffective promotion and communication. While the e-GIF project was under the control of the IRD, they were committed to XBRL initiatives, particularly the e-GIF project. However, once the programme sponsor moved to the MED, the new organisation created delays, and wasted money. Instead of continuing with the e-GIF project, the MED decided to re-evaluate its investment in XBRL.

"...under the IRD, XBRL was at a high level of business decision making. It was in principle -'Yes, we need this to be done so we could get these things out of it,' whereas in the MED, it was more pragmatic. We have to focus on building a business 
case by [the end of April for] the investment that we were going to put into it." (Government Officer N)

There was also disagreement about the effectiveness of the promotion and communication of e-GIF. Government Officer N believed the initiative group should have worked harder to reach the stakeholders.

"How do you move that group in order to justify the business case? That is the big challenge. That is not the key person problem. That is the marketing, influencing, and facilitating-get out there and get involved with small business consultations. That is why something was wrong with the Working Group." (Government Officer N)

Within the environmental context, the interviewee mentioned two factors; stakeholder involvement from ministries and the culture of working independently in government agencies. The e-GIF project had been agreed on and accepted among the Labour Government Ministers. The acceptance was translated by giving support through their ministry's involvement.

"It looked like the business case was working out. The ministers wanted it." (Government Officer N)

The interviewee noticed the nature of how government agencies work in New Zealand. Each agency had their own information system, which made it impossible to share data between agencies. Government Officer N provided this example:

"I mean the Treasury can find their data in their information system and they would depend on what is in their systems...There are much more independent government agencies. But that should not be an issue." (Government Officer $N$ )

\subsection{Factors Associated with Supportive Stakeholders}

Under the e-GIF project, there were two supportive organisations: NZICA and a Tax Management Consulting Firm. Both organisations mentioned various factors from their point of view that matched factors in the TOE Framework.

\subsubsection{New Zealand Institute of Chartered Accountant (NZICA)}

The NZICA was an active organisation in Project First Step. However, under the e-GIF project, this organisation became a supportive organisation. The opinion of interviewees 
associated with NZICA contributed to the factors for the technological, organisational, and environmental contexts.

In the technological context, Institute Director $\mathrm{L}$ commented on two factors: relative advantage and the unstable XBRL specification and taxonomy. The group was looking for the relative advantage of using XBRL from a cost reduction perspective.

"I think the way we saw it - we were trying to reduce the cost within the reporting systems in New Zealand. We saw advantages that XBRL could facilitate..." (Institute Director L)

Additionally, Institute Director L perceived there was another benefit of using XBRL in government agencies. He suggested XBRL would transform the way government could deliver its services to the public.

"I think most of the benefits are actually in reducing cost...there are some [other] benefits like better access..." (Institute Director L)

During the early stage of the e-GIF project, XBRL was still being developed, especially the XBRL specification and taxonomy. The interviewee mentioned that they could not use XBRL as it was still growing and this was very challenging.

Under the organisational context, the NZICA interviewees commented on four factors; a lack of championship, insufficient leadership, ineffective promotion and communication, and not having a mandatory adoption strategy. During the e-GIF project, someone with a passion for XBRL technology had supervised the project, but that person had no power to make 'it happen'. According to Institute Director L, the person was not a particular champion but that person was someone who was interested in XBRL technology.

The NZICA approached some of the government agencies to lead the e-GIF project. However, the agencies did not respond well. They were not ready in terms of budget.

"My impression was nobody wanted to be the first movers because it was going to hit their budget lines...Nobody wants to bear the cost of the budget or being the first mover... Therefore, the Statistics guy wants the IRD to go first; the IRD would like Statistics to go first and so on." (Institute Director $L$ ) 
During the e-GIF project, the group continued their promotion of XBRL to various stakeholders. Nevertheless, as far as NZICA were concerned, they did not communicate their plan well enough.

"I think a lot of it actually comes down to the vision that we never shared with the key decision makers." (Steering Committee Member E)

The NZICA had a clear strategy that they wanted government agencies to adopt XBRL through the e-GIF project. That was the reason why they had approached Statistics New Zealand and the IRD. The group hoped that any one of these government agencies would mandate the adoption of XBRL for business reporting.

"The reason I focused on Statistics and the IRD; it is because, in our early thoughts on $X B R L$, we thought that the best thing to do was create demand." (Institute Director L)

Within the environmental context, the interviewees commented on two factors: a lack of stakeholder involvement from software developers and a knowledge gap. The NZICA approached as many stakeholders as they could to join the XBRL initiatives. Some did not wish to be involved, other were happy to be involved and welcomed the technology as a way of assisting them in their tasks.

"...during 2004-2006, the IRD said 'We are the biggest consumer of financial statement information in New Zealand. We want a platform to help us consume the information'." (Steering Committee Member E)

In addition, Steering Committee Member E shared his views on involvement from the software developers.

"I believe that has been one of our weaknesses. To answer your question - No, software developers were not really involved in the New Zealand context." (Steering Committee Member E)

The interviewee further explained why the software developers did not get involved.

"The software developers never [got involved] because they could not build the business case around the advantage of [embedding] XBRL into their software." (Steering Committee Member E)

As an expert in XBRL technology, Institute Director $L$ believed the group faced some challenges in bringing XBRL to New Zealand. One challenge was bridging the knowledge gap. 
"It is hard to explain to somebody that they should take this on. They do not understand what it is. We cannot develop [software embedded with XBRL]. It was a bit of an understanding issue." (Institute Director L)

He further explained:

"It was hard because XBRL was not accounting and not computing. It was kind of in the tools. So, if you are speaking to a pure accountant, they do not understand it. You speak to computer people; they cannot understand the judgement that goes into accounting." (Institute Director $L$ )

\subsubsection{Tax Management Consulting Firm}

The second supportive organisation under the e-GIF project is a consultant firm. This organisation contributed to the organisational and environmental context factors.

In the organisational context, there were three factors revealed during the interviews with a consultant from this organisation. The factors were no championship but the presence of leadership, and the change of programme sponsor. While assisting the e-GIF Working Group, the interviewee noticed there was no championship.

"It needs somebody within the government with some point of influence to be championing it or owning it." (Consultant I)

Consultant I suggested that the initiative group or the experts needed to share the idea with a person that has the power to make decisions.

"...you either have to get somebody locally on the board of an organisation or inside the regulator that believes this is the right technology and to lead the technology until it succeeds." (Consultant I)

The interviewee believed the IRD was the right leader for the e-GIF project.

"In New Zealand, it started from the tax authority. That was the one, which was the right leader and [they needed to] cooperate or encourage other regulators." (Consultant I)

The change of leadership, from the IRD to the MED towards the end of the e-GIF project, did not help the XBRL initiative. 
"...However, someone in the MED, chaired and oversaw that because the e-GIF was an across government initiative. Therefore, tax was driving and starting it, but ultimately they had to hand it over to the MED (the group) that was responsible for the next step." (Consultant I)

Within the environmental context, Consultant I commented on two factors; insufficient critical mass and the influence of trading partners. Based on the interviewee's experience, implementations by tax authorities are more likely to succeed because it affects everybody in the economic system.

"One of the most successful roll out for XBRL is when the Tax Authority backs it up. They have the most to gain from it because the tax people have to do it and it will affect everybody. Anything driven by revenue is always going to be successful."(Consultant I)

Unfortunately, in New Zealand, before the IRD could get XBRL adopted, the XBRL initiative was moved to the MED, making adoption of it less likely.

Australia and New Zealand have a close business and trading relationship. This is also reflected in the way these countries do their business reporting. During meetings and discussions, the interviewee noticed tension between the representatives from the two countries. Australia wanted New Zealand to copy what they had done in Australia. However, New Zealand wanted to do the e-GIF project in its own way.

"...there was a lot of tension as well. What Australia wanted to do was tell New Zealand, that New Zealand should copy what they were doing and how the group should do the project in New Zealand. New Zealand is quite capable of doing the project on its own, so there was some tension there as well." (Consultant I)

\subsection{Factors Associated with Observer Stakeholders}

In the e-GIF project, there was one observer stakeholder, the OAG. The interviewee provided some factors related to the technological and environmental contexts.

\subsubsection{The Office of the Auditor-General (OAG)}

In Project First Step, the OAG was an active organisation. However, their involvement in the e-GIF project changed to be one of an observer stakeholder. 
Within the technological context, there were three factors; no relative advantage, compatibility with existing information systems, and the complexity of taxonomy mentioned by the interviewee. While observing the e-GIF project, the interviewee perceived there was no real benefit in using XBRL for business reporting.

"I do not see the real benefit of XBRL in helping an individual entity to report." (Government Officer O)

Even though most of the government agencies were not using XBRL, their systems were XML-based, which was considered compatible with XBRL. The interviewee suggested that the Treasury reporting system was compatible with XBRL.

"If you think about a number of existing processes already, there are things that well apply but they are not pure XBRL. You could use them as tools, techniques, or processes. For example, the Treasury consolidate on a monthly basis and then we audit on an annual basis for the financial statements of the government." (Government Officer O)

The interviewee also viewed XBRL as complex because of the use of a taxonomy.

"You have to be dealing with similar entities or you will end up with complicated things. If you have 10 entities and you want them to use XBRL, and send their stuff to the Companies Office. They just say the words - population of 10. If all 10 entities are similar, then the XBRL taxonomy is simple. But, if the 10 entities are all totally different businesses or sizes or different in everything, the taxonomy becomes complicated." (Government Officer O)

Under the environmental context, the representative of this organisation identified two factors: a lack of stakeholder involvement and a knowledge gap. As the OAG moved from being an active to being an observer stakeholder, their involvement in e-GIF became less significant.

"We're not an active member; we are just keeping an eye on what they're doing. So we can understand any audit implications from their discussion." (Government Officer O)

The lack of proper information and limited knowledge about XBRL also influenced the way the stakeholders behaved and their response towards XBRL. 
"That is probably what we are missing here, to understand how and what benefits are derived from doing it, what costs are incurred by doing it, what is the lesson they had learned from this area." (Government Officer $O$ )

\subsection{Analysis: The e-GIF Project}

Through the analysis of the findings, this study found factors other than those in the research framework (Chapter 3 ) or prior literature (Chapter 2) that influenced the adoption decision by stakeholders. In the organisational context, there were two factors found: leadership and a change of program sponsor. Meanwhile, under the environmental context, the one factor revealed was the culture of working independently in government agencies.

Based on the above findings, the IRD believed that having a relative advantage, being technologically compatible, having no security issue, being able to be trialed, being a problem solver, their enthusiasm for XBRL, effective leadership, and the influence of trading partners had the potential to facilitate their XBRL decision. During the e-GIF project, from within the IRD, they built an XBRL pilot application. They found that XBRL provided benefits such as detecting previously unknown errors in one of the return forms; that XBRL was compatible with their computer system; there were no security issues, and XBRL was a solution to their existing problems related to business reporting. In addition, the IRD had effective leadership, which encouraged those that were enthusiastic to keep progressing with the XBRL project. Moreover, their trading partners with whom they exchanged information with, especially Australia, were considering adopting XBRL. Nevertheless, the IRD saw some challenges in adopting it, such as its complexity, the limited availability of tools and software, a lack of a champion, the lack of human capability, a change of programme sponsor, a lack of stakeholder involvement, a knowledge gap, no critical mass, and a culture of working independently whitin government agencies that needed to be overcome before they could adopt XBRL. The interviewees perceived XBRL as being complex because every upgrade of the specification required a revision of the taxonomy. As a taxonomy is complex, then every revision of the taxonomy also increases the complexity in XBRL. The interviewee believed that stakeholders, particularly from business organisations had a right to ask and know about the availability of tools and software that support XBRL. By being assured of the availability, they would be more likely to apply the technology in their organisation. There were problems in finding a champion, either a 
politician or from top management of the lead agency. The in-charge person of the e-GIF project in the IRD did not have the same status (or power) as the champions in Australia and the Netherlands. The absence of knowledge about XBRL meant that stakeholders did not demand XBRL-enabled software from software developers. Only certain stakeholders, especially those from some of the government agencies were prepared to adopt XBRL in their organisations. Thus, the e-GIF XBRL initiatives had no critical mass. Further, the practice of government agencies in New Zealand to have independent information systems was opposed to the purpose of XBRL.

The interviewee from the MED suggested that alliances with international organisation (trading partners) may have facilitated the organisational decision to adopt XBRL. However, the complexity of having different information systems became a barrier for the MED.

The interviewee from the SSC (in contrast to other interviewees) perceived they had sufficient stakeholder involvement particularly from the ministries during the e-GIF project. Nonetheless, they would have to address barriers such as the change of programme sponsor from the IRD to the MED, ineffective promotion and communication of XBRL and a culture of government agencies working independently, to enable them to adopt XBRL in their organisation.

The NZICA, as a supportive stakeholder, could see the benefits of XBRL for business reporting and had a clear strategy, the mandatory adoption of XBRL. This organisation believed that both the benefits and mandatory adoption would encourage stakeholders to adopt XBRL. However, existing barriers, such as an unstable XBRL specification and taxonomy; no real championship; no leadership at the lead agency; poor communication at higher levels; no involvement from software developers; and difficulties in explaining XBRL concepts, hindered the stakeholders from adopting XBRL.

In the other supportive stakeholder, the consultant from the Tax Management Consulting Firm believed that effective leadership and influence of trading partners could facilitate the adoption decision. Nonetheless, they perceived there were challenges or barriers to adopting XBRL for business reporting. For instance, the initiative group had difficulties in finding the right champion for the e-GIF project and getting a significant number of stakeholders involved. Additionally, the change of programme sponsor affected the 
decision to adopt XBRL because the new lead agency (MED) was not interested in the XBRL initiative.

The OAG was the only observer stakeholder and viewed the compatibility of information systems in government agencies with XBRL technology as a potential facilitating factor. In contrast, the OAG interviewee perceived factors like that XBRL had no real benefits, the complexity of the taxonomy, limited stakeholder involvement, and limited knowledge among stakeholders as inhibitors to XBRL adoption.

Table 7.1 presents the overall findings of the e-GIF project. It illustrates that the e-GIF project had many challenges or barriers to getting XBRL adopted. However, there were improvements in some of the influencing factors when compared to previous XBRL initiatives. For example, there were four facilitating factors: relative advantage, compatibility, leadership and the influence of trading partners in the e-GIF project, instead of only one facilitating factor, trialability during Project First Step.

Table 7.1: Overall Summary of TOE Context Factors in the e-GIF Project

\begin{tabular}{|c|c|c|c|c|c|c|c|c|c|c|c|c|c|c|c|c|c|c|c|c|}
\hline & \multicolumn{8}{|c|}{ Technological } & \multicolumn{7}{|c|}{ Organisational } & \multicolumn{5}{|c|}{ Environmental } \\
\hline & 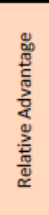 & 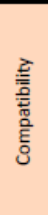 & $\frac{\frac{a}{x}}{\frac{d}{a}}$ & 壳 & 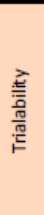 & 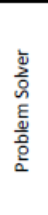 & 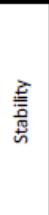 & 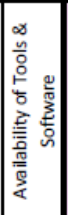 & 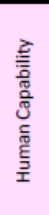 & 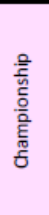 & 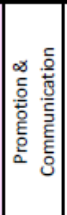 & 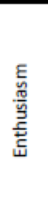 & 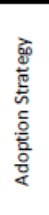 & 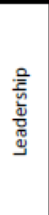 & 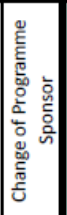 & 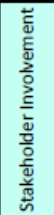 & 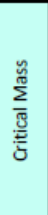 & 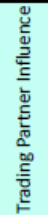 & 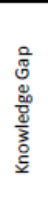 & 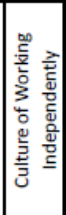 \\
\hline \multicolumn{21}{|l|}{ Active Stakeholder } \\
\hline IRD & + & + & - & + & + & + & & - & - & - & & + & & + & - & - & - & + & & - \\
\hline MED & & & - & & & & & & & & & & & & & & & + & & \\
\hline SSC & & & & & & & & & & & - & & & & - & + & & & & - \\
\hline \multicolumn{21}{|l|}{ Supportive Stakeholder } \\
\hline NZICA & + & & & & & & - & & & - & - & & + & - & & - & & & - & \\
\hline Tax Management Consulting Firm & & & & & & & & & & - & & & & + & - & & - & + & & \\
\hline \multicolumn{21}{|l|}{ Observer Stakeholder } \\
\hline OAG & - & + & - & & & & & & & & & & & & & - & & & - & \\
\hline
\end{tabular}

Additionally, the key factors during the e-GIF project were the complexity related to the XBRL taxonomy within the technological context; having no real champion and a change of programme sponsor (from the IRD to the MED) from the organisational context; and a lack of stakeholder involvement and demand and a knowledge gap from the environmental context. Those key factors are considered the main barriers in the e-GIF project (as in Table 7.1), and thus, the initiative group had to face the fact that XBRL was not going to be adopted under the e-GIF project. In the next section, this thesis will present the findings related to and the analysis of the SBR programme. 


\subsection{Overview of the SBR Programme (2007-2010)}

The first SBR programme started in the Netherlands in 2004, followed by Australia in 2006 (van Burg et al., 2010). In New Zealand, the SBR Programme was established on June 2008 using the Australian experience as a blueprint $(\mathrm{Ng}, 2009)$. Other countries like the UK, Singapore, and China also considered implementing SBR programmes (Hodgson et al., 2008).

An SBR is defined by the Standard Business Reporting Programme Netherlands \& Standard Business Reporting Australia (Highfield, 2009) as a single report standard, which harmonizes and reduces the data reported by recognized accounting standards. As defined by Hodgson et al. (2008), SBR is a programme of work that operates across the whole-of-government and aims at reducing costs to business when reporting information to the government. In addition, SBR can reduce costs to business through standardisation; either at a place of lodgement ${ }^{43}$, in data definitions or communication language. For the purpose of this study, the definition above by Hodgson et al. (2008) is used.

The $\mathrm{QRR}^{44}$ study and KPMG cost survey both indicate that significant compliance cost burden existed for businesses in New Zealand in 2007-2008 (Hodgson et al., 2008). This was because people are required to input information through a web interface several times for different government agencies. The SBR programme would provide a platform that connects business to government electronically. Willis (2009) mentioned that SBR has the ability to reduce the reporting burden by $25 \%$. This was one of the primary reasons why SBR was investigated.

\subsubsection{Objective of SBR}

An SBR programme aims to simplify business to government reporting in several ways (SBR Australia, 2011). SBR helps to remove unnecessary or duplicated information from government forms. That means, businesses are able to take action faster and more efficiently. SBR also helps to automatically pre-fill forms, which saves time in filing the documents. Through SBR, businesses are able to make financial reporting a by-product of business processes. By using SBR, the businesses and government agency indirectly would adopt a common reporting language like XBRL, which is based on international standards

\footnotetext{
${ }^{43}$ It is a reduction in the number of places where businesses are required to file information.

${ }^{44}$ Background documents, including a sector studies report, cabinet papers and a full list of the changes to regulations implemented since the start of the review were available on the Ministry of Economic Development website.
} 
and best practice in reporting. In relation to $\mathrm{XBRL}, \mathrm{SBR}$ would provide an electronic interface to government agencies directly from accounting software, which will also provide validation and confirm the receipt of reports. Through XBRL, SBR is also able to provide a single secure online sign-on for businesses to all government agencies involved (Hodgson et al., 2008).

\subsubsection{The Current Status of SBR}

The Labour Government liked the concept and the SBR 'brand'; however it could not fund the project which needed NZ\$150 million. Therefore, after presenting the SBR- Business Case to Cabinet $^{45}$ in May 2008, the cabinet requested further working including a cost and benefit analysis; conceptual design development; stakeholder consultation and the scoping of the rationalisation of forms currently in use by SBR agencies (Power, 2009). Under the National Government and due to the fiscal environment during 2009, the scale of investment still required to implement the complete SBR solution was considered not feasible (Power, 2009). As a result, the cabinet recommended a number of smaller scale initiatives focusing on the SBR goals of business compliance reduction, facilitating the increase in the productivity and capabilities of small and medium enterprises (SMEs) and

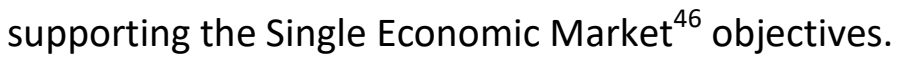

One of the initiatives designed to reduce compliance costs was the harmonisation and rationalisation of identified SBR forms. Included in this was the development and piloting of a goods and services tax (GST) return taxonomy. This initiative involved two phases (Power, 2009). The first was form harmonisation and the GST taxonomy pilot with a budget of NZ\$3 million (Budget 2009/10). The second was the implementation of a full production system within core agencies which required NZ\$5 million. XBRL was to be implemented under phase two.

\subsubsection{Classification of Stakeholder Involvement}

Under the SBR programme, there were eleven active, supportive and observer organisations involved. The active organisations were the IRD, the MED, the SSC, and NZICA.

\footnotetext{
${ }^{45}$ Cabinet Economic Growth \& Infrastructure Committee

${ }^{46}$ Single Economic Market refers to the concept of a Trans-Tasman Market, which first emerged at government-to-government level at a January 2004 meeting between the New Zealand Finance Minister, Dr Michael Cullen, and the Australian Treasurer, Mr Peter Costello. The two Ministers agreed to a number of initiatives with the long-term goal of enabling a properly constituted New Zealand company to function as a company in Australia as of right and vice versa (Hodgson et al., 2008).
} 
These organisations had representatives on the SBR group and were committed to all activities related to XBRL. The XRB and a consultancy firm were the supportive organisations. These organisations provided advice and guidance to the active organisations based on their expertise. The supportive organisational representatives attended meetings and worked with the group. Interestingly, in the SBR programme, there were five observer organisations from government agencies, an accounting firm, a business organisation and from the other stakeholder cluster. The increasing number of observer organisations indicates that more people were interested in SBR and thus, XBRL development in New Zealand.

Every stakeholder involved had a slightly different interest in XBRL (as part of SBR). As mentioned in subsection 7.1.2, the IRD was interested in XBRL because they needed to upgrade their existing computer system. Similarly, the MED was looking for a new system so they could provide a better service to business organisations. The SSC was interested in XBRL because the XBRL use promoted data sharing and better quality of data. As an accounting professional body, NZICA was interested in XBRL because it directly impacted on and had applications within the accounting profession. Supportive organisations like the XRB were interested in XBRL because they were concerned about issues related to business reporting requirements. The XRB needed to make sure any XBRL implementation met New Zealand reporting requirements. Furthermore, the Tax Management Consulting Firm was involved with XBRL because they had a genuine interest in XBRL. Moreover, by giving advice, the consultant helped to promote XBRL. The observer stakeholders involved in SBR observed the development of XBRL and considered the potential use of XBRL for business reporting in their organisations.

\subsection{Factors Associated with Active Stakeholders}

This study interviewed representatives from four active organisations: the IRD, the MED, the SSC and NZICA. Each organisation identified various factors from the technological, organisational, and environmental contexts. 


\subsubsection{The Inland Revenue Department (IRD)}

The SBR programme was the third XBRL initiative that the IRD was involved in. The IRD representative, Government Officer J gave their view on the technological, organisational, and environmental contexts.

Under the technological context, the IRD mentioned two factors; a perceived relative advantage and complexity. According to the interviewee, big companies could see the benefits of using XBRL.

"It was only of small benefit to the larger clients because they already have electronic accounting systems. This could be an add-on to them. However, they could see the benefits as well because there was much reporting done for internal financial reporting [purposes]." (Government Officer J)

However, based on the interviewee's experience, XBRL technology was complex particularly in building the enterprise architecture required within the IRD computer system.

"XBRL was too complex and did not necessarily do the thing that we wanted it to do." (Government Officer J)

Within the organisational context, the IRD interviewee commented on three factors; a lack of human capability, ineffective leadership, and the existence of a mandatory adoption strategy. During previous XBRL projects, experts had left New Zealand to continue their interest in and contribute to XBRL development in the international arena. The same thing happened again during the SBR programme. In the IRD, for example, they really struggled to get people with the skills and knowledge about XBRL. To overcome this, the IRD looked for help from New Zealanders, who had been working on SBR in Australia.

"The main shortage of knowledge and skills is actually people that know the XBRL language. That is where we struggled, we got some of New Zealanders, who had been working on or were working in the SBR programme in Australia to come over and start building the taxonomy for the SBR programme in New Zealand." (Government Officer J)

In fact, limited expertise in XBRL was the global problem.

"That is one of the problems with XBRL that has very much remained globally. There is a large skill shortage of people that actually can implement it." (Government Officer J) 
As in the e-GIF project, the SBR Steering Group also planned to make XBRL adoption mandatory. Government Officer J indicated that the government had the power to make it happen.

"...the government needs to mandate XBRL. The returns need to be filed in XBRL format. To make it work, the government [needs to say] 'It has to be done.' The software developers would be quite happy in doing it, saying "We do not have a problem in doing it." (Government Officer J)

The SBR Programme Director from the MED had no interest in leading the XBRL initiative. Thus, he did not give full commitment to the SBR programme.

"I heard behind the scenes from some of the most senior people in IRD, that they would not... [be] the programme sponsor. He was a director or something similar in the MED. That was the starting point and he was not $100 \%$ behind the project and [did not] push it." (Government Officer J)

In the environmental context, the representative from IRD gave his viewed on the negative impact of the change of government ${ }^{47}$. Early on in the SBR programme, the government showed interest and supported the XBRL initiative.

"We still had the Labour Government, who just felt enthusiastic about it. They were quite happy to throw a million dollars to get the job done. Lianne Dalziel was the original minister that we approached about the concept. She was just so enthusiastic about it. Everyone was really enthusiastic about it from the government." (Government Officer J)

After the general election, New Zealand had new government under the National Party. According to the interviewee, the change of government had a negative impact on XBRL progress in New Zealand.

"[with] the change in government, money dries up, makes more things sort of on hold and [XBRL] did not progress further." (Government Officer J)

\footnotetext{
${ }^{47}$ As explain in Chapter 5, New Zealand had the $49^{\text {th }}$ General Election in 2008. This general election resulted in a change of government from the Labour Government to the National Government. More discussion on this factor is provided in Chapter 9, page 254.
} 


\subsubsection{The Ministry of Economic Development (MED)}

This organisation was first involved as an active organisation in the e-GIF project. Under the SBR programme, the MED representative identified factors from the technological and environmental contexts.

Within the technological context, the MED interviewee revealed three factors; a lack of relative advantage, complexity and not being perceived as a problem solver. The SBR Working Group worked hard to prove and demonstrate the benefits of XBRL to stakeholders.

"We (the SBR group) were struggling with the small to medium size businesses. We were struggling to find the [dollar] cost saving, and the time cost saving in their processes to justify the size of investment [needed] to set up the system." (Government Officer H)

However, results from cost-benefit exercises showed that the cost was greater than the benefits.

"In writing a more detailed business case, we did mobilize a team to go out and talk to the SMEs across the country. The result from that exercise was that the benefits were not as great as what we had understood or anticipated." (Government Officer H)

Further, the interviewee explained the cost-benefit challenge in evaluating the relative advantage of XBRL adoption.

"The challenge was the cost-benefit. When we invest this amount of money, then we will get this amount of saving within the compliance cost regime of SMEs. That is definitely the challenge. As we went through further into the details, the cost of the system - the XBRL capabilities keep rising but the central benefits to business keep reducing. We were just going the wrong way." (Government Officer $\mathrm{H}$ )

Therefore, it was hard for them to justify the investment needed to implement XBRL.

"Coming back to the SBR, again the whole cost-benefit equation was not compelling. We could not say SMEs had sufficient savings by implementing XBRL. We had to justify the cost of setting up the SBR system." (Government Officer $H$ )

While involved in another XBRL project, the interviewee thought that XBRL was complex because of the process; elements in XBRL like the taxonomy, calculation-link and specification; and building the taxonomy. Another complexity in XBRL was the identification 
of individuals in-charge in SMEs. The purpose of identification was to secure the use of XBRL while sending the business and financial information to government agencies.

"Included in that was the identification. They had to identify the company. There was an issue around the identification related to the Single Business Number (SBN). You had to have authentication of who it is in the company that is authorized to send the electronic information. They had to have identification of that person. There were additional complexities when you look into the requirements of IRD." (Government Officer $H$ )

The Working Group tried to promote XBRL technology to stakeholders. However, their efforts did not change peoples' mind-sets about XBRL. Thus, stakeholders in New Zealand did not perceive XBRL as a problem solver.

"Really, XBRL did not get off the ground, did not even start. No matter how hard we tried, it did not start. That's really came back to not having a sufficiently compelling case, there was not any compelling reason that really attracted anyone to say "Yes, we really have to do this." (Government Officer $\mathrm{H}$ )

Under the environmental context, this organisation's interviewee mentioned five factors; positive stakeholder involvement, the negative impact of the culture of working independently, the influence of a trading partner, the change of government and the global financial crisis $^{48}$. The SBR programme received support from the Labour Government, with the relevant ministry wanting to know more about the business case.

"In SBR, it really became serious. From the April document we did, the Labour Government's cabinet gave it a tick ( $V$ ) and said 'Yes, continue. We want more details'. A business case was to be done by December 2008." (Government Officer H)

The Working Group also managed to get support from a local software developer in New Zealand, XERO. The group had discussions with Rod Drury in 2008 and he was supportive of the XBRL idea.

One of the key uses of XBRL was to enable data sharing among government agencies. However, each government agency worked independently and had developed separate

\footnotetext{
${ }^{48}$ As presented in Chapter 5, New Zealand faced the peak of global financial crisis at the end of 2008. Chapter 9 provides further discussions on this factor on page 255 .
} 
processes and supporting information systems. Thus, the Working Group had difficulty in convincing individual government agencies to use XBRL.

"That was the difficulty and (I guess) one of the big questions - if the government sector is going to do it; it would need to do it in a collaborative way... But... when we were doing the SBR, it became very clear that each of the government departments operated in their own silo." (Government Officer H)

The interviewee noticed that the policy advisors in the MED started to get interested when they knew Australia was considering using XBRL for business reporting.

"The history of the state in terms of setting up the SBR as I understand it was not the CFOs within the government sectors. It was some policy advisors within the MED that became aware of what was happening in Australia." (Government Officer H)

Under the Labour Government, the Working Group tried to get a majority vote to implement SBR from the Cabinet Economic Growth \& Infrastructure Committee. However, during the process, the government changed.

"I guess they did to some extent - support the continuation of the detailed business case, because it would not be a whole of cabinet vote; then the government changed." (Government Officer $\mathrm{H}$ )

The change of government meant the group needed to repeat the same process of getting the vote of the Cabinet Economic Growth \& Infrastructure Committee, and funding from the government. This event delayed the decision to adopt XBRL.

When the researcher asked the interviewee, would the SBR programme continue if the government had not changed? Surprisingly, the interviewee responded 'No.'

"...it might not because even with a Labour Government continuing with the global financial crisis...that changed the whole landscape. They might have cancelled this thing as well." (Government Officer $\mathrm{H}$ )

\subsubsection{The State Services Commission (SSC)}

The SSC continued its involvement as an active organisation in the SBR programme. During the SBR programme, this organisation identified factors in the technological, organisational, and environmental contexts. 
Within the technological context, Government Officer $\mathrm{N}$ mentioned that being a potential problem solver was an influencing factor when making an adoption decision. This organisation was interested in XBRL technology due to its ability to share data within and between the government agencies.

"The SSC was interested in advancement. That was why they put me in the Steering Group. Because again it was very close to their alignment with the whole-ofgovernment view on 'We need this standard' and not only between government agencies." (Government Officer $N$ )

Under the organisational context, the interviewee mentioned three factors; a lack of human capability to work together, no need for a mandatory adoption strategy and a lack of strong leadership. Government Officer $\mathrm{N}$ mentioned the capability of team members to work together to achieve their objectives.

"There were factions in the IRD. I would say - you might have some of the IRD there that really supported it but down here - they did not want to do it. Again, I suspected they had some factions in the MED. Within the MED, as you know, they are big and have a lot of sub-businesses. Some of their business might say 'Yes' and some might say 'No'." (Government Officer N)

In the SBR programme, the SSC representative believed it was not necessary to mandate the use XBRL technology.

"I do not agree that mandating is necessary unless it is a successful standard. You may signal [that] the mandate [will happen] at the later date." (Government Officer N)

Based on the interviewee's observations, he noticed that there had been ineffective leadership during the SBR programme. The MED, as the lead agency did not have a genuine interest in the initiative and that agency took advantage of the real interest of another agency, the IRD.

"The lead agency put some people on the Steering Committee so they knew what was going on and could still run it. They also acted...[in a] 'passive resistant' [manner]." (Government Officer N)

In the environmental context, there were four key factors stated by the interviewee: the presence of successful adoption stories, a lack of stakeholder involvement, the culture of government agencies working independently and the change of government that appear to 
have been important at the SSC. There was a history of successful adoption of technology in government. SEEMail was one of these.

"One of the most successful [adoption] in government was called secure mail or SEEMail. It is a simple but...secure way that you can send emails within the government agencies. It was largely driven by the Treasury, the Commission and a couple of other government agencies." (Government Officer $N$ )

During the SBR programme, not all stakeholders were genuinely committed to the XBRL initiative. Some of them just wanted to be involved but were not particularly interested in XBRL.

"Some agencies did come and really get behind it, as it was in their line of business interest but some of the agencies were just pretending that they were interested in XBRL." (Government Officer N)

Another concern was that each agency had different information systems and the systems were not connected to each other because every agency wanted to control their system. Thus, this situation encourages a culture of each government agency working independently.

“...agencies have a lot of [information] traffic. Government agencies don't like working together." (Government Officer N)

The interviewee further noticed that the Labour and National governments had different leadership styles.

"...under the Labour Government - the way that the government managed was pretty much 'Please come in and join us; please do this.' Whereas under the National Government it is 'You are going to do it unless you are conducting something [similar]." (Government Officer $N$ )

In addition, the National Government seem to be focused on planning and action. Nevertheless, the Labour Government had a different approach.

"The National Government had a clear vision to deal with. They have this cost saving government. Whereas the Labour Government, it was just come and assimilate with them. In the last few months, they were involved with it [SBR]." (Government Officer N) 
Thus, when the government changed from Labour to National, there appeared to be a huge difference in leadership style and once the National Government said 'No', they meant it.

\subsubsection{New Zealand Institute of Chartered Accounting (NZICA)}

The organisation was involved in the Project First Step and e-GIF XBRL initiatives. In the SBR programme, this accounting professional body was an active stakeholder. The representative from this organisation shared his views on factors within the technological, organisational, and environmental contexts.

In the technological context, the interviewee commented on the perceived relative advantage of XBRL. Every year government would have a fixed budget for ICT. The interviewee felt if the budget was used to build a taxonomy, which could be shared by the government agencies, then it was not a waste. In fact, adopting XBRL gave long-term benefits.

"...it is a waste of social costs when you think of the \$2.5 billion each year that the government spends on technology support to keep the New Zealand government going. Then, spending $\$ 100$ million to get a taxonomy or dictionary that will allow you to classify and analyse information - seems to be a no-brainer to me." (Steering Committee Member E)

Within the organisational context, Steering Committee Member E gave his views on a lack of championship and the adoption strategy proposed. As mentioned, championship is an important factor when adopting a new technology. Not having championship will negatively influence the chances of technology like XBRL being adopted.

"When you are introducing a new technology, you need someone who can see the vision of what you will be able to achieve. I think that has always been the problem; the person hardly can see the vision of what can be achieved." (Steering Committee Member E)

The interviewee elaborated more by giving examples of what had happened to XBRL initiatives in other countries.

“...in the US, XBRL keeps going because Christopher Cox, the Chairman of SEC said 'It is the way it should be. We are going to make this work.'...XBRL works in the UK-because the Commissioner of Tax said, 'Well, we're going to use XBRL as a platform to distil 
and analyse taxation returns.' They just made it happened. In NZ, there was just no one high enough from the political world. There was no one that had the knowledge and power to put this technology in place." (Steering Committee Member E)

The interviewee suggested somebody from the government needed to make the effort to adopt XBRL for use in business reporting.

"I mean effectively someone like John Key or Steven Joyce has to say, 'We are going to invest and put some effort behind deploying XBRL in New Zealand.' Because, unless there is a high level of political will and the drive to make it work, it just is not going to happen." (Steering Committee Member E)

The interviewee also viewed that mandatory adoption was the best option in order to get the full benefit of XBRL.

"...it is either you go for it completely or not at all. In some ways, you have to be cruel to be kind in order to get some benefits from SBR." (Steering Committee Member E)

Under the environmental context, factors such as: a knowledge gap, insufficient critical mass, the culture of government agencies working independently, and the global financial crisis were considered as important and influenced the adoption decision. Every stakeholder had a different understanding of or need regarding XBRL technology. These differences created a knowledge gap and finally, this gap became a barrier to XBRL adoption.

"I think that what XBRL means is - it really does mean different things to different people." (Steering Committee Member E)

Further, the interviewee explained why there was a knowledge gap within the stakeholder groups.

"Because people actually do not understand how the information could be used. If people understood how XBRL could be used to save costs, it would be a no-brainer." (Steering Committee Member E)

For those who had been involved with XBRL initiatives for some time, they felt disappointed when other stakeholders could not see the benefit of XBRL.

"For me, it is frustrating that people have not been able to see the bigger picture of the benefits that the standardized taxonomy could have." (Steering Committee Member E) 
As XBRL was a new technology in New Zealand, only a few people were interested and wanted to use the technology. Thus, without critical mass, XBRL adoption was potentially not possible.

"XBRL is like a fax machine or actually like the Internet. If you have only got a few people using it-it does not work. You have to get an infrastructure within organisations to make it work." (Steering Committee Member E)

Most of the government agencies had their information systems; having to introduce XBRL into them was not going to attract their interest in adopting the technology. Thus, Steering Committee Member E perceived, given that most government agencies liked to work independently, successful XBRL adoption was not feasible.

Towards the end of the SBR programme, New Zealand was facing the global financial crisis. The interviewee perceived that the global financial crisis was a good reason for some stakeholders not to adopt XBRL. As for government, they had a tight budget and needed to keep their investment in technology minimal.

"... [There were] some other issues like the global financial crisis. It was a very good and convenient excuse as to why no investment was to be made in XBRL." (Steering Committee Member E)

\subsection{Factors Associated with Supportive Stakeholders}

There were two supportive organisations involved with the SBR initiative. Both organisations identified factors in the technological, organisational, and environmental contexts.

\subsubsection{The External Reporting Board (XRB)}

The XRB was first involved with an XBRL initiative during the SBR programme. The XRB'S view confirmed some of the factors that influenced stakeholders' decision not to adopt XBRL.

Within the technological context, Government Officer A and Government Officer D shared their opinions on the lack of relative advantage in XBRL, security concerns, and that it was not perceived as a problem solver. Government Officer A agreed that XBRL had some 
benefit. However, they believed that stakeholders could not see the real benefit of adopting XBRL for business reporting.

"To be honest, I think it would be good to have the benefits [of XBRL] but, in reality, the users do not seem to see the benefits themselves, so they decided it could be a benefit but not for them." (Government Officer A)

Meanwhile, Government Officer D mentioned that Treasury has a system called Crown Financial Information Systems (CFIS), which assists them in collecting data. By replacing CFIS with XBRL, Treasury would not get any more advantages.

"The government financial statements, which is something I know about [are produced] by the Treasury on a consolidation basis; they use CFIS. They have financial information of the Crown government departments; they already have it in CFIS. So changing to XBRL would not necessarily have any particular advantages other than statistically." (Government Officer D)

Another government agency, MED was also evaluating XBRL, but they could not see the benefit of XBRL for them.

"They (MED) are looking across the group; well they are saying, "Where are we going to get the best value for money?" Obviously, there is no value for money on research into SBR." (Government Officer D)

In the early investigation into SBR, stakeholders from business organisations did not have sufficient knowledge that could help them to understand the XBRL process. One of their concerns was security while using XBRL within SBR.

"...business people like me for example, would not have the knowledge of the processthe tag things. How do I trust that, how do I know that the information coming out from my accounting package is accurate, [when it] is sent to the IRD. How do I trust the system to do that?" (Government Officer A)

Subsequently, if SBR was well accepted among XBRL stakeholders, then the security issue could be solved by building an accounting package with XBRL embedded in it.

"...unless they get to the point when SBR is wide spread and everyone has trust. Instead of building their system, they just need to buy accounting packages. I mean $X B R L$ is embedded in the accounting package." (Government Officer $A$ ) 
There was some interest in XBRL. However, none of that interest indicated the stakeholders needed XBRL. That means XBRL was not a solution that the stakeholders were looking for.

"... because as the users told us, they did not need it. I think...telling you that they did not need it, they did not want it or it had not reached the point when a consensus of users was telling you 'Yes, we need it' and that you must do it." (Government Officer A)

In early 2012, the government decided to adopt a new reporting frame called General Purpose Financial Reporting (GPFR). During the meetings, there was no discussion on XBRL.

"The decision was to adopt the new framework in early 2012 (April 2012) and 2 sets of standards. Really, XBRL was not an issue and was never ever discussed in the same meeting or in the same documents." (Government Officer A)

Using the new reporting requirements, the government aimed to reduce compliance costs. It seemed to be a replacement for SBR and thus XBRL.

"I did think that the government 'appetite' to do this at that time was very low because they had already tried to reduce compliance costs. By introducing XBRL, it will dissolve the effect and will nullify what they are doing." (Government Officer D)

In the organisational context, factors like ineffective promotion and communication of XBRL, limited enthusiasm, a lack of financial support and leadership, as well as the absence of a mandatory adoption strategy were identified. The MED assisted other stakeholders, like the XRB, by providing the information they needed.

"They were just helping us to find out what we could, to keep our board informed and decide whether there was any issue that we had to deal with." (Government Officer A)

From another perspective, it was difficult to talk to the right person in the MED.

"It was difficult to find out who was responsible within the MED; it was difficult to connect to the person that was involved in the project at that stage." (Government Officer $A)$

During the SBR programme, the majority of the stakeholders were not interested in XBRL technology. Based on Government Officer A's involvement and observation, he perceived that the initiative group drove the XBRL activities more than they should have. 
"Government was looking into the issues. It was driven more by the theoretical supply side [argument]...I am not aware that it was driven by people saying "We desperately need this." (Government Officer A)

Adopting a new technology like XBRL needs resources especially money. Without sufficient resources, XBRL initiatives will struggle to progress. During the global financial crisis, the initiative group did not manage to get the needed funding from the government.

"The budget decision was taken in 2009, [and resulted in] only a small budget. In 2010, nothing - essentially nothing. We were tracking that through in 2009 and 2010. Of course, during the latter part of 2010 effectively the decision was made on this thing [SBR]." (Government Officer A)

Government Officer A also shared the reason for no further funding. In the discussion between the SBR initiative group and the government decision makers, the government chose not to invest further in any XBRL related activities. Additionally, another interviewee believed the MED placed a low priority on funding for the SBR or XBRL initiatives.

"I suppose in a way it was through a lack of funding priority within the MED; we can use the funding we [have] got for the SBR or something else, which is more important." (Government Officer D)

In addition, the political and ministry levels had less of a commitment to any types of funding related to XBRL activities.

"It was clear that there was a lack of commitment to any funding either from the politicians or from anybody within the ministries to continue the research into XBRL." (Government Officer D)

Government Officer D stated that adopting XBRL through the SBR programme would work well if the government agreed to mandate the technology. Unfortunately, none of the government agencies, either from the IRD or the MED agreed to mandate XBRL for use in business reporting.

While attending a meeting at the MED, XRB realised that the organisation did not show any leadership in regards to the SBR programme.

"It was not chaired by someone from the MED but held somewhere in MED. They invited other people from the IRD and us to that meeting. However, I do concur with a view that the MED was not going to fund the project. However, in 2009, the MED did 
not seem...definitely showed no leadership and they would rather facilitate the meeting. They were not championing the project or anything." (Government Officer A)

In fact, the interviewee stated the MED was not interested or did not want the leadership role.

"However, because what had happened was...there was not any leadership; MED was not taking any leadership role. They do not want the leadership role." (Government $\operatorname{Officer} A)$

Under the environmental context, the interviewees from XRB mentioned four factors; a lack of stakeholder involvement, a knowledge gap, the change of government and influence from a trading partner. During the SBR programme, it was hard to see any real evidence that stakeholders wanted XBR. In reality, the government agencies, the accounting professional body or the stock exchange who were dealing with financial and business reporting were pushing the technology and encouraging the stakeholders to accept XBRL. Again, this absence of demand from outside stakeholders translated into very little interest in XBRL technology and limited stakeholder involvement.

"Again, I am sure the heart of the problem is the absence of demand. If there were [demand], the whole business communities would be saying 'The government needs to build a platform' [so they could] interact with them using this technology. Then the government would have to look at it much more seriously but there was no real evidence of anyone demanding [XBRL]." (Government Officer A)

For the MED itself, the XRB interviewee mentioned they placed a low priority on adopting XBRL technology.

"The problem that we had while doing it, there was really a lack of interest in the MED overall. There were constant changes in personnel. So, we were finding it quite difficult to get to talk to people." (Government Officer D)

Further, the interviewee stated that the MED had never employed any person that was responsible for XBRL initiatives.

"It was not their priority. It was not a person's sole job to do it. I did not see any people that had been employed by the ministry that were totally dedicated to XBRL." (Government Officer D) 
In the last conversation between the interviewee and people in the MED, it was suggested that the XRB observe the XBRL developments in Australia.

"The MED suggested we just watched what was happening in Australia. See what happen and collaborate with them as much as we can, provided it does not cost us any money and then we will pick it up once they make a decision. And we will pick it up; see what we can do with what they have got." (Government Officer D)

Based on that conversation the XRB decided to 'wait and see'. Instead of supporting the initiative in New Zealand, they would observe XBRL developments in Australia.

"We made a conscious and deliberate decision, we were just stepping back now and watching. We called it a 'watching brief'." (Government Officer A)

Consequently, the way the MED behaved in relation to the SBR programme influenced the XRB's decision not actively support the adoption of XBRL for use in business reporting.

The absence of knowledge on XBRL also influenced the way the stakeholders reacted towards the SBR initiative.

"From the user's perspective, they did not understand the technology. Then how could they build or rely on the information, while they cannot see it, audit it or put their opinion on the account? They need to comply with a series of standards that they understand like IFRS." (Government Officer A)

Information about XBRL was not delivered equally to all levels. As an evaluator or supportive organisation, the XRB was not given any information related to XBRL including what was in the review documents.

"To be honest during that time, we did not know what the different levels that were used to describe [XBRL] in the review documents. Knowing that, we were just interested in - how XBRL, the way we understood it, could affect financial reporting, because that is our responsibility." (Government Officer A)

Further, Government Officer A explained that in New Zealand, the business communities had a different belief about information characteristics.

"We had a very different conception of information - how it is captured, how the top can use it and all those sorts of things. However, it will be a slow and steady evolution that I would expect to happen in New Zealand." (Government Officer A) 
The XRB were more concerned with having the same business and financial reporting environment as Australia. From July 2010, the SBR programme employing XBRL technology was implemented as a voluntary adoption in Australia, while at the same time in New Zealand a decision whether to adopt or not adopt SBR had not been made. As many New Zealand companies trade with and are in Australia, by not having the same or compatible technology this could hinder the reporting process and trading between these two countries.

"We need to be talking to Australia about what New Zealand needs to do. Because there is a risk here - Australia had gone ahead and we were trying to create a business environment that was eventually one environment between Australia and New Zealand. Therefore, that is why we have to talk with businesses that have the same accounting standards especially now. However, if we have very different technology that could be a major problem." (Government Officer A)

Further, Government Officer A added that they had not received any feedback from business organisations. In their opinion, there could be two reasons that explain this condition. First, none of the business organisations realised they had a problem in their information system. Second, business organisations chose to 'wait and see' what happen with SBR development in Australia.

The change of government affected the SBR programme by the new government withdrawing its budget or funding. There were different funding priorities between the Labour and National Government. Under the National Government, the SBR programme was not one of their priorities.

"There could be political reasons for a change in approach, but they had a significant change in budget circumstances in 2008 and 2009. Then, you have this new government coming in. Thus, the stream of work has not been given much prominence. So, when the new government came in, they would not be learning about the thing [XBRL and SBR] as [if they were involved when it] first came in. They would not be so committed to the initiative, it was optional and easier (I think) for them to say 'No, we are not going to fund that'." (Government Officer A)

In addition, the new government was in a tough situation during the global financial crisis. The government needed to provide a smaller budget in 2009. 
"The National Government tend to be more favourably disposed to an initiative like this, which would allow potential savings to business through the more efficient transformation of government agencies, and better use of information. So it would be counter to what you would naturally expect, except for the fact that they were new in the government and faced incredible challenges. They could not afford spending on many things." (Government Officer $A$ )

Eventually, the slow progress with the SBR programme encouraged the MED minister to remove the SBR budget line.

"Well, that was happening in New Zealand from the political side. They were going to say, "Well, let us hang on" and that would be Simon Power I think, the Minister of Commerce at that stage when the MED was controlling it." (Government Officer D)

\subsubsection{Tax Management Consulting Firm}

The consultant was also involved with the e-GIF XBRL initiative. He and his organisation maintained their involvement as a supportive stakeholder during the SBR programme. The representative shared his views on each context in the TOE Framework.

Under the technological context, Consultant I mentioned that not being perceived as a problem solver appeared to influence the stakeholder decision about adopting XBRL. The SBR programme was under MED control. However, the MED did not need XBRL technology in their existing information systems or even recognise XBRL as a problem solver.

"...they proposed to build the XBRL application in the MED to be a centre of that particular project [SBR]. However, they (the MED) were not necessarily the people that were championing it. Because obviously they (the MED) did not need XBRL as much as the tax authority and other agencies that created the XBRL application." (Consultant I)

Within the organisational context, the interviewee from this organisation shared his opinion related to ineffective leadership in the lead agency. Even though the SBR programme was under the control of the MED, people from the IRD did all the hard work relating to XBRL. The IRD paid the consultant's fees.

"When I came to New Zealand as an advisor, it was the MED kind of running it. However, it was all prepared by and the people that were really pushing it were from 
the IRD. Therefore, I did everything through the IRD; I was even paid by the IRD." (Consultant I)

In the environmental context, Consultant I mentioned one factor, the change of government that he considered as a key influencing factor in the adoption decision. Under the Labour Government, the Working Group gathered information and prepared a business case. Then, the business case was presented to the relevant ministers. During the evaluation process, there was a change of government. He believed that the new government did not have sufficient time to evaluate the potential and benefits of XBRL for business reporting. Thus, the new government made their decision based on their knowledge and understanding of XBRL capacities for business reporting.

\subsection{Factors Associated with Observer Stakeholders}

There were five observer stakeholders during the SBR programme: The Treasury, Grant Thornton, a Management Consulting Firm, the University of Otago, and University of Hawai'i. The researcher classified the interviewee's views into their technological, organisational, and environmental context.

\subsubsection{The Treasury}

The Treasury's first involvement with an XBRL initiative was during Project First Step when it was an observer stakeholder. During the SBR programme, the Treasury remained an observer stakeholder. Government Officer $\mathrm{G}$ shared his opinions regarding XBRL and SBR, which have been classified into the respective technological, organisational, and environmental contexts.

Under the technological context, the Treasury interviewee mentioned the compatibility of systems and that XBRL was not perceived as a problem solver. XBRL is an XML-based application. Both of these languages are compatible with the Treasury CFIS system, which uses XML.

"In Treasury, we need to collect financial statement information from all the government agencies. It is about 40 government departments, 100 entities and 10 state-owned enterprises that we need to pull the information from. It was a bit of a question in my mind, [what was] XBRL's future for doing that. We currently have a CFIS system, which uses XML rather than XBRL." (Government Officer G) 
The Treasury built CFIS to collect financial data and do the analysis. The system is sufficient for Treasury activities. Thus, the Treasury believed that they did not need XBRL.

"Our system was developed for us so that we can efficiently prepare the consolidated set of accounts - that is the objective we have. Why was XBRL not picked up? It was not efficient as a consolidation tool." (Government Officer $G$ )

In the organisational context, the interviewee stated one influencing factor for XBRL adoption; a lack of a championship. The SBR programme had difficulties in finding a champion within the public sector organisations.

"Maybe XBRL suffered because [there was a] lack of a champion within the public sector. It might not have been the right call." (Government Officer G)

Within the environmental context, the interviewee shared his views on factors such as limited stakeholder involvement, a knowledge gap, and the change of government. As Treasury had their own reporting system, they did not have any reason to investment in XBRL.

"We can use our existing system. We do not need to invest in it. We have our databases and we can just rely on our system." (Government Officer G)

Government Officer $\mathrm{G}$ believed the majority of stakeholders did not see the benefit of adopting XBRL. The absence of proper knowledge about XBRL, especially the use of the taxonomy, affected stakeholder perceptions towards XBRL.

"I think XBRL suffered from not being a powerful business case to corporates because they [the corporates] could not see that they were going to get benefits from using the tagging in their current ledger." (Government Officer G)

The National Government wanted to transform government operations so they become more efficient and effective. Since the XBRL benefits were not clear, the government decided that SBR and the XBRL initiative was not a priority.

"It was certainly clear when the National Government came into power that their focus was more on the public sector being more efficient, more effective, getting activities away from the back office systems to more on the front office systems, providing a better amount of services. When the benefit was not clear, then the project was not getting any priority." (Government Officer $G$ ) 


\subsubsection{Grant Thornton}

As an accounting firm, Grant Thornton only became involved with an XBRL initiative during the SBR programme and as an observer stakeholder. Auditor C shared his views on the technological and environmental contexts.

In the technological context, the interviewee mentioned the compatibility of XBRL with stakeholders' existing information systems. Having an XML-based computer system means it is compatible with XBRL technology.

"The interesting thing is the Treasury's government financial statements are produced using an XML tag approach as far as I understand, a bit like XBRL tags the data." (Auditor C)

Thus, by adding the taxonomy to the CFIS, it would transform the system into XBRL.

"So it is not a big leap to go from CFIS to XBRL potentially. All you need is to create some simple tags, some layers of taxonomy or the IFRS taxonomy and then you addon." (Auditor C)

Within the environmental context, this organisation viewed the global financial crisis as one of the key non-adoption influencing factors. During the global financial crisis, every stakeholder had limited money to spend. The government, for example, had a tight budget. Thus, the SBR programme could not be fitted into the government's budget.

"The only thing I can think of is the global financial crisis. Everyone was short of money and we could not get money to invest in XBRL." (Auditor C)

The government had to organize their revenue, prioritise their spending, and do more with less.

"...that could be an impact on the government's revenue. Basically, you have to give good services to the public by trying to do more for less, like trying to prioritize where you are spending the money." (Auditor $C$ )

\subsubsection{Management Consultancy Firm}

The SBR programme was the first involvement by this Management Consultancy firm in XBRL initiatives. As a representative from an observer stakeholder, the Management Consultant mentioned his views on the technological and environmental contexts. 
Under the technological context, Consultant B shared his views on whether XBRL was a problem solver. XBRL had been introduced as a problem solver; however, the way it should work is that problems need to be looking for solutions, not the other way around.

"The technology would solve the problem. However, very often the case is that technology is in search of a problem, rather than [there being] a problem in search of appropriate technology. XBRL is one of the examples. [It was] a technology in search of problem, where it was not sure what is the problem, particularly in the public sector." (Consultant B)

As XBRL, technology was looking for a problem to solve, then it would be difficult for it to address the specific problems in each agency. The interviewee agreed that XBRL had the ability to improve business reporting as promoted by the initiative group as well as XBRL International. However, the interviewee was not sure of the ability of XBRL to address the specific problem in each government agency.

Within the environmental context, there were three factors mentioned by interviewee; a lack of stakeholder involvement, insufficient critical mass, and a culture of working independently within government agencies that he considered as influencing factors in the adoption decision. Most of the stakeholders had never demanded XBRL technology. In Treasury, for example, they had CFIS as their information system. This system was independent of other agencies. Therefore, the agency was not actively involved with any of the XBRL initiatives in New Zealand.

In order to adopt XBRL technology, it has to reach a certain percentage of demand (critical mass). Otherwise, adoptions tend not to succeed.

"So you cannot develop or implement the technology in organisations unless you have met the demand of those active people within the organisations." (Consultant B)

Working together was not part of culture in the New Zealand government agencies. Each agency had their own information system. While the SBR programme promoted data sharing between the agencies, the existing culture was not consistent with the SBR idea.

"Here, what we have - everybody is doing their own things. For instance, the CFIS system only provided information to the agency [Treasury]." (Consultant B) 


\subsubsection{University of Otago}

This organisation had been involved with XBRL initiatives since Project First Step. As an observer organisation, the interviewee from the University of Otago shared their observations of the factors under the technological and environmental contexts.

Under the technological context, the interviewee mentioned not being a problem solver as one of the influencing factors in XBRL adoption. One of the government agencies would have to transform its operation for it to work. Their existing information system was considered old fashioned and could be updated by using XBRL. Unfortunately, this agency could not see how XBRL would assist them.

"It was the MED. They collected financial and business data in a particularly poor way. They just pulled in PDF annual reports and had not embraced digital technology at all. XBRL would have been one way for them to do that. However, they did not do it."(Academic P)

Within the environmental context, three factors; a knowledge gap, the change of government and the global financial crisis were considered important factors in influencing the stakeholder decision. The XBRL stakeholders in New Zealand did not seem to understand how to use the information from XBRL. Their ignorance about XBRL hindered XBRL progress.

"...again it comes down in part, to the leadership - a lack of foresight about how to use this information. That is because New Zealand is such a small country where most people are not hunting that level of complexity of knowledge. From their perspective, they just say, 'Hey' they are going to produce a file from their annual reports and they are just going to throw them on the website and job done. They do not really think about how this information could be used to enhance the productivity of the New Zealand economy." (Academic P)

The National Government had different views on cost cutting to the previous Labour Government. The XBRL technology was seen as an expensive application and there was limited demand from stakeholders. Thus, they gave a low priority to funding the project, which leads to a cut in the budget for any related activities.

"...they had a more cost-cutting culture. I would not be surprised if they saw this as a marginal proposition and cut costs on that basis." (Academic $P$ ) 
The global financial crisis did not affect the SBR programme immediately but slowly killed the initiative. From the government decision makers' perspective, XBRL adoption only had average benefits.

"Well to the extent where the money is tight after the GFC, anything which is considered to have only marginal cost-benefit is going to be chopped." (Academic P)

\subsubsection{University of Hawai'i}

As a new observer organisation during the SBR programme, the interviewee from the University of Hawai'i shared his views on the technological, organisational, and environmental contexts.

Under the technological context, Academic $\mathrm{K}$ commented on the fact that it was not a problem solver. In general, some technologies are not successful because the stakeholders are not using them or do not see them as their solution. In XBRL's case, most of the stakeholders did not see it as a solution.

"...There are many examples of adoptions that do not proceed, even though their IT is miserable. Because the collective need does not outweight the individual needs." (Academic K)

Within the organisational context, the interviewee shared his views on a championship as a key influencing adoption factor. In order to influence stakeholders to accept and use XBRL technology, the initiative group needed a champion. In the US, the champion really pushed the use of XBRL technology in the SEC.

"We would not have had XBRL in the US if it was not pushed by the Chairman of the SEC, who championed it...If there was no Christopher Cox, [there would be] no XBRL in the US SEC setting." (Academic K)

In New Zealand, none of the top management from government agencies or politicians pushed for XBRL adoption.

In the environmental context, the interviewee viewed limited stakeholder involvement as an important factor in the XBRL adoption decision. In New Zealand, most business organisations are SMEs. In order to get support from them, software developers need to build a system suitable for SMEs. During the SBR programme, the initiative group did not 
manage to get any involvement from software developers. That means it would be hard for the SMEs to be part of the SBR programme.

"...because you are dealing with small enterprises - these systems need to be built into other major systems that the smaller company is using for accounting. The accounting software developers, they are the essential party in the value chain." (Academic K)

\subsection{Analysis: The SBR Programme}

The SBR programme had the greater number of organisations interested in it than the previous three XBRL initiatives. Four active stakeholders, two supportive stakeholders, and five observer stakeholders followed its progress. While analysing the findings, the researcher discovered some additional unpredicted factors that were not identified in the previous literature (Chapter 2) or research framework (Chapter 3), which the researcher believes have influenced the stakeholder decision not to adopt XBRL. These factors were the change of government and the global financial crisis, which existed in the environmental context.

The IRD maintained its involvement as an active stakeholder. The interviewee from this organisation identified positive relative advantage and mandatory adoption strategy as drivers to adopting XBRL. Nonetheless, Government Officer J perceived other factors such as the complexity of XBRL, a lack of human capability, ineffective leadership, and the change of government as barriers to adopting XBRL through the SBR programme. The interviewee stated that XBRL technology was complex in terms of building the enterprise architecture required within the IRD information system. This organisation also lacked the human capability as most of their experts had moved overseas; a condition that forced the IRD to search for other experts to help them progress this XBRL initiative. At the same time, the IRD believed that they had ineffective leadership from the MED. To make things worse, the change of government reduced the financial support the initiative group required to progress their activities.

Like the IRD, the MED also maintained its involvement as an active stakeholder. There were two factors; stakeholder involvement and the influence of trading partner that would have facilitated this organisation to adopt XBRL. On the other hand, Government Officer $\mathrm{H}$ mentioned many barriers to XBRL adoption, such as there was no relative advantage, the complexity in determining the Single Business Number (SBN), that XBRL was not a problem 
solver, the culture of government agencies working independently, the change of government and the global financial crisis. The SBR initiative group was struggling to convince stakeholders, particularly those from SMEs of the benefits of using XBRL in their organisations. Furthermore, the interviewee found it was difficult to use XBRL to determine the SBN for every business organisation. This would have created additional complexities if they had adopted XBRL. The MED believed the majority of the stakeholders were not attracted to using XBRL technology, as they could not see that XBRL would improve their business reporting. The interviewee perceived that most of the government agencies preferred to work independently and did not share data between agencies. These stakeholders tend to build their own information system so as to have control over their data. The change of government interrupted the development of XBRL (as part of the SBR programme) with the government having the final say in any technology adoption decision. Finally, the global financial crisis limited the ability of government to spend money on an XBRL initiative that they did not consider important.

As an active stakeholder, the SSC perceived factors such as being a potential problem solver and having successful adoption stories as drivers to adopting XBRL. However, there were many factors that they considered barriers to XBRL adoption. The factors were ineffective leadership, lack of human capability, missing a mandatory adoption strategy, lack of stakeholder involvement, the culture of government agencies working independently and the change of government. Based on the interviewee observations, the appointed leader from the MED showed little interest in XBRL and had limited involvement with XBRL initiatives. Among the members of the SBR group, there were factions among the government agencies. About half of the members supported the use of XBRL technology and the other half showed little interest. The same situation occurred with other stakeholders. Some were genuinely interested in XBRL technology, whereas the others were pretending and not serious about their involvement. The interviewee believed it was not necessary to mandate XBRL adoption. Instead, stakeholders needed to learn about and understand how XBRL could be used in business reporting. Further, each government agency had its own information system that supported the agency's operations. However, these information systems did not link to each other. Although this limited the ability to share data among the government agencies, they had no issue with this. Instead, they felt comfortable in working independently. The change of government influenced the adoption 
decision because the Labour and National Government's had different leadership styles. The National Government was more authoritative in their decision-making especially when it related to the budget, whereas the Labour Government was less imposing, probably because during their term in office there was less stress on the budget.

The NZICA, as an active stakeholder in the SBR programme, viewed the potential relative advantage of XBRL and a mandatory adoption strategy as facilitating an organisation's decision to adopt XBRL. Nevertheless, the interviewee from this organisation perceived that other factors such as a lack of championship, a knowledge gap, no critical mass, the government agencies culture of working independently and the global financial crisis hindered the adoption of XBRL for business reporting. The interviewee explained that without a champion the XBRL initiative faced difficulty in progressing forward as nobody was pushing for the initiative. Additionally, each of the stakeholders had different levels of understanding, information, and skills related to XBRL. These conditions created a knowledge gap and this gap became a barrier as the initiative group needed to think about and address each level of understanding differently. It takes time to do that and eventually, it slows down the progress towards adopting XBRL. During the SBR programme, the accounting professional body believed that only a small number of stakeholders were interested in using the technology in their organisation. Thus, the benefits of using XBRL could not be realised by the stakeholders. Moreover, almost all government agencies had their own information system and felt comfortable in working independently. They could not see any benefit of adopting XBRL since they had sufficient information to carry out the required tasks. Additionally, during the global financial crisis, the NZICA interviewee thought the majority of stakeholders had limited resources, especially money, to invest in XBRL matters. This constrained resource situation influenced their involvement in and decision to not adopt XBRL.

The XRB was a supportive stakeholder in the SBR programme. Based on the findings, the interviewees perceived that the influence of trading partners could have facilitated a stakeholders' decision to adopt XBRL. On the other hand, there were more inhibitors that influenced the stakeholders' decision not to adopt XBRL for use in business reporting. From the technological context, the interviewees thought that the government agencies did not see the benefits of using XBRL in their organisation. The business organisations were concerned about security when sending their financial reports to the government agencies 
via an XBRL-embedded application. The stakeholders also decided that XBRL was not for them as it was not a solution for any of their business reporting problems. Within the organisational context, the lead agency failed to promote XBRL and the SBR programme and communicate relevant information to its stakeholders. The situation led to a low level of enthusiasm for XBRL related activities among stakeholders. One of the big challenges in the SBR programme was insufficient financial support from the lead agency. XRB viewed this as an indication of the low funding priority within the lead agency (MED) to progress the XBRL initiative. Additional to that, Government Officer A perceived that the SBR programme had ineffective leadership because the person in-charge was not genuinely interested and did not exercise his responsibility as a leader. Eventually, this led to an absence of mandatory adoption strategy. In the environmental context, the XRB perceived that there was a lack of stakeholder involvement from business organisations, government agencies, and ministries. The business organisations did not understand the technology, as they did not have information and basic knowledge about XBRL. Meanwhile, the MED, for example, responded based on the business organisations indifference to XBRL. The ministry did not employ any employees to handle the XBRL technology. The existence of a knowledge gap among the stakeholders potentially explains their reaction towards XBRL initiatives. The XRB believed that the change of government after the general election in 2008, affected the SBR programme with the reduction of the budget in 2009 and the cutting of the budget in 2010 .

As a consultant involved in the SBR programme, Consultant I perceived three factors as barriers to XBRL adoption. The interviewee noticed that the MED did not want to implement XBRL in their own information systems as they did not see it as a problem solver and they provided no leadership for the SBR programme. Further, the change of government affected the SBR programme as it was not a priority for the new government.

The Treasury had been an observer stakeholder since Project First Step. During the SBR programme, Treasury viewed compatibility with their information system as a driver to XBRL adoption. However, there were other factors that were seen as inhibitors such as not being perceived as a problem solver, a lack of a champion, limited stakeholder involvement, a knowledge gap and a change of government. From the Treasury perspective, XBRL has not seen as a problem solver for them as they had their own CFIS system, which was sufficient to support their operations. Because of that, Treasury refused to get actively involved with 
any of the XBRL initiatives. Government Officer $G$ believed the SBR programme suffered because the initiative group failed to get the right person to champion the programme. Moreover, the majority of stakeholders did not see the benefit of adopting XBRL in their respective organisations because they did not have knowledge and information about it. Additionally, the Treasury thought the change of government did impact the SBR programme because the National Government had a different focus when compared to the Labour Government. Since the National Government did not clearly see the benefits of XBRL for government operations, the SBR programme was not given a high priority.

Grant Thornton was also an observer stakeholder during the SBR programme. This accounting firm viewed the compatibility of the CFIS Treasury information system with XBRL as a facilitator for the XBRL adoption decision. However, they believed that the global financial crisis hindered the adoption decision as stakeholders had limited resources to spend on or invest in the SBR programme.

As an observer stakeholder, the Management Consultancy Firm interviewee believed factors like not being perceived as a problem solver, a lack of stakeholder involvement, insufficient critical mass, and the culture of government agencies working independently as barriers to adopting XBRL. In the SBR programme, Consultant B thought that XBRL technology could not address all the government agencies' different problems. XBRL might be suitable for the IRD and Statistics New Zealand but had yet to prove its suitability in the SSC. He had observed little demand from the stakeholders for XBRL technology. The Treasury, for example, depended on its CFIS system to run its operations so had no need for XBRL or SBR. The interviewee believed there was an insufficient critical mass, mainly because very few government agencies had agreed to adopt the technology in their organisations. The culture of government agencies working independently also impacted the XBRL adoption decision, because that culture did not match with the XBRL idea, particularly in relation to data sharing.

The University of Otago interviewee shared his views on the factors that would influence $\mathrm{XBRL}$ adoption. Academic $\mathrm{P}$ perceived that $\mathrm{XBRL}$ was not a problem solver, there was a knowledge gap among XBRL stakeholders and the change of government and global financial crisis were barriers in adopting XBRL. Some government agencies, for example, the MED could not see how XBRL would assist them to improve the agency's operations. 
Instead of exploring the capability of XBRL for their agency, they decided that XBRL was not for them. The interviewee also believed that XBRL stakeholders had little interest in information that could be generated using an XBRL format. That was because the stakeholders did not know that the XBRL-generated data could have others uses especially to improve productivity. Due to the change of government, the National Government decided to cut the SBR budget based on a cost-benefit equation that showed little benefit to adopting XBRL. Furthermore, the government had to decide where to invest to achieve the best return. During the global financial crisis, the government had to set their priorities and XBRL technology was not a technology being demanded by stakeholders. Thus, the budget for the SBR programme was frozen.

The University of Hawai'i was another observer stakeholder. This interviewee viewed factors, like not being a problem solver, missing championship and a lack stakeholder involvement, as barriers to XBRL adoption. Academic $\mathrm{K}$ perceived XBRL was not a solution to stakeholder problems because the stakeholders never demanded the technology. The XBRL initiative in New Zealand did not have any champion from the top management level of the government agencies or from politicians, which was a serious problem because nobody was pushing for the SBR programme to be successfully implemented. There was no involvement from the software developers during the SBR programme. This influenced the involvement from business organisations especially the SMEs because there was no tools and software with XBRL-embedded applications that could be used.

Table 7.2 summarizes the overall findings of the SBR programme. Based on this table, the majority of the influencing factors are challenges or barriers to adopting XBRL for business reporting purposes. In this initiative, the stakeholders perceived that the compatibility of information systems with XBRL (technological) and influence of trading partner (environmental) as drivers in XBRL adoption. 
Table 7.2: Overall Summary of TOE Context Factors in the SBR Programme

\begin{tabular}{|c|c|c|c|c|c|c|c|c|c|c|c|c|c|c|c|c|c|c|c|c|}
\hline & \multicolumn{5}{|c|}{ Technological } & \multicolumn{7}{|c|}{ Organisational } & \multicolumn{8}{|c|}{ Environmental } \\
\hline & 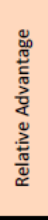 & 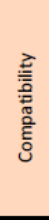 & $\begin{array}{l}\frac{\vec{z}}{x} \\
\frac{\mathrm{u}}{0} \\
\bar{\Xi} \\
\end{array}$ & 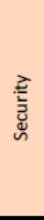 & 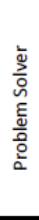 & 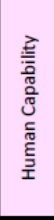 & 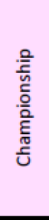 & 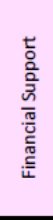 & 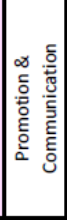 & 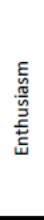 & 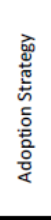 & 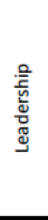 & 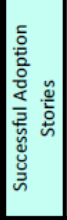 & 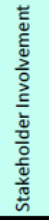 & 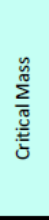 & 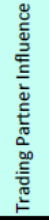 & 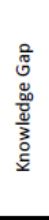 & 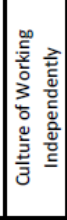 & 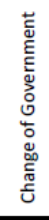 & 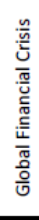 \\
\hline \multicolumn{21}{|l|}{ Active Stakeholder } \\
\hline IRD & + & & - & & & - & & & & & + & - & & 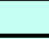 & & & & & - & \\
\hline MED & - & & - & & - & & & & & & & . & & + & & + & & - & - & - \\
\hline SSC & & & & & + & - & & & & & - & - & + & - & & & & - & - & \\
\hline NZICA & + & & & & & & - & & & & + & & & & - & & - & - & & - \\
\hline \multicolumn{21}{|l|}{ Supportive Stakeholder } \\
\hline XRB & - & & & - & - & & & - & - & - & - & - & & - & & + & - & & - & \\
\hline Tax Management Consulting & & & & & - & & & & & & & - & & & & & & & - & \\
\hline \multicolumn{21}{|l|}{ Observer Stakeholder } \\
\hline Treasury & & + & & & - & & - & & & & & & & - & & & - & & - & \\
\hline Grant Thornton & & + & & & & & & & & & & & & 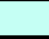 & & & & & & - \\
\hline Management Consultancy Firm & & & & & - & & & & & & & & & - & - & & & - & & \\
\hline University of Otago & & & & & - & & & & & & & & & - & & & - & & - & - \\
\hline University of Hawai'i & & & & & - & & - & & & & & & & - & & & & & & \\
\hline
\end{tabular}

However, as presented in Table 7.2, the SBR programme had more inhibiting or hindering factors. For example, under the technological context, most stakeholders believed that XBRL was not a problem solver. Furthermore, they agreed that ineffective leadership from the MED was the critical factor in the organisational context. In addition, key barriers in the environmental context included a lack of stakeholder involvement or demand for XBRL, a knowledge gap about XBRL, the culture of working independently in government agencies, the change of government, and global financial crisis. It could be argued that given the number of barriers, environmental was the most critical context for the SBR programme. Nonetheless, all the above challenges contributed to the non-adoption of XBRL for use in business reporting in New Zealand.

\subsection{Chapter Summary}

In this chapter, the TOE framework as discussed in Chapter 3 is used to make an in-depth analysis of the findings. The chapter identified and presented all the influencing factors related to non-adoption of XBRL under the government auspices, within the three contexts.

In the e-GIF project, the analysis indicates that perceived relative advantage, technology compatibility, effective leadership from the IRD and the need to do business with a key trading partner (Australia) had the potential to facilitate XBRL and e-GIF adoption. Nonetheless, factors such as complexity related to the XBRL taxonomy, no real championship at higher governmental levels, the change of programme sponsor (from the 
IRD to the MED), a lack of stakeholder involvement and demand for $X B R L$, and a knowledge gap about XBRL were among the key factors that lead to the non-adoption of XBRL and eGIF. In terms of context, the organisational and environmental were the most critical contexts.

During the SBR programme, compatibility with existing information systems, and the influence of trading partners encouraged the investigation of XBRL adoption. However, this initiative had several critical factors like not being perceived as a problem solver, ineffective leadership by the lead agency (the MED), a lack of stakeholder involvement among stakeholders, a knowledge gap about XBRL, the culture of working independently in government agencies, the change of government (from the Labour to the National Government), and the global financial crisis in 2008 that hindered the adoption of XBRL. In terms of context, for the SBR programme, environmental was the critical context.

All the challenges and barriers identified above worked together to influence the stakeholders (especially the government's) decision not to adopt XBRL for use in business reporting. Eventually, the two XBRL initiatives under the government auspices (e-GIF and SBR) failed to get XBRL implemented in New Zealand for use in business reporting purposes. In Chapter 8, this thesis will present the second research question findings relating to the implications of the government decision not to adopt XBRL for stakeholders. 


\section{Chapter 8: Implications of the Government Decision Regarding XBRL}

\subsection{Introduction}

Chapter 7 presented the findings of the e-GIF project and SBR programme, which were under government control. It also answered the first research question by identifying the factors that influenced the government and other organisations' decisions not to adopt XBRL use for business reporting. The purpose of Chapter 8 is to answer and present the second research question by identifying the implications of a government decision not to adopt XBRL for XBRL stakeholders. The views represented do not represent the official views of an organisation but rather the views of the individuals who took part in the projects.

The analysis below suggests that each stakeholder group is affected differently based on their involvement and intention in relation to XBRL use. There are both short-term and long-term implications of not adopting XBRL for the stakeholder groups impacted by the government decision. These groups include the government agencies, accounting firms, accounting professional bodies and business organisations.

The next two sections of this chapter identify and analyse the short-term and long-term implications of the government decision for the stakeholder groups. Following this, an alternative view; that there are no stakeholder implications is presented. The chapter is concluded with a summary.

\subsection{Implications of the Non-Adoption of XBRL for Stakeholders}

Over half of the interviewees believed there were implications resulting from the nonadoption decision. Their arguments were based on their personal experience, knowledge, and observations of what transpired in other countries. For example, one interviewee suggested the implications would emerge over time.

"...[There will be no impact in the] immediate future...we are going to have enough difficulties in getting people used to the new Financial Reporting Act for the next 4-5 years...and the Institute of Chartered Accountants is producing a format for special 
purpose financial statements which will be applicable to, or a guideline, for members of the Institute." (Government Office D)

The views of the interviewees suggest that the XBRL stakeholders at that time would be busy adjusting themselves to the new financial reporting requirements. However, as they got used to these new requirements, they would have another look at XBRL, because their major trading partners were using an XBRL application for business reporting. By not adopting XBRL, the New Zealand stakeholders might be left behind unless they adopted technology that was more advanced than XBRL. This situation creates the possibility that stakeholders would face implications by not adopting XBRL for business reporting in the 2010s.

The implications are categorized based on the stakeholder groups and discussed below. Five stakeholder groups were identified in Chapter 3. However, the interviewees only mentioned the implications for four stakeholder groups, namely: government agencies, accounting firms, accounting professional bodies and business organisations. None of the interviewees mentioned any impact on the other stakeholder groups as discussed in Chapter 3: the universities, software developers, and the XBRL International consortium. This is consistent with the limited involvement of these groups in the XBRL initiatives as detailed in Chapters 6 and 7.

Based on suggestions from interviewees it became apparent that the implications could be divided into short-term and long-term. Short-term implications are those where the stakeholders will feel the impact immediately once the government decided not to adopt XBRL for business reporting. Meanwhile, the long-term implications potentially affect stakeholders five to ten years after the decision took place.

\subsubsection{Implications for Government Agencies}

There are three short-term implications of non-adoption of XBRL use for business reporting related to the government agencies. First, government agencies, such as Inland Revenue and Statistics New Zealand will be unable to perform specific types of data analysis on similar data because there is an absence of data in an XBRL format that can be used for data analysis purposes by multiples agencies residing in a single database. As part of the eGIF project or SBR programme, the groups involved proposed one database sitting in one 
government agency, preferably the IRD or the MED. The database would collect, analyze and keep all financial and non-financial data in an XBRL format. Without this database, the agencies do not have sufficient data, of this type, particularly from business organisations to perform this type of analysis.

At least two interviewees gave the example of the reporting environment in the US. Since 2005 , the SEC has collected data from companies listed on the stock exchange ${ }^{49}$. Then, the data is analyzed as required for particular purposes. One of these interviewees, Auditor $C$, compared the US and New Zealand's reporting environment, especially from a stock exchange perspective. He viewed that New Zealand had a lost opportunity to do comprehensive data analytics.

Another interviewee, Institute Director L, mentioned how the SEC used their existing database to gain benefits such as using it as an interrogating or monitoring tool for data mining, as well as the basis for establishing enforcement procedures. Believing that XBRL has abilities to interrogate and mine data effectively and efficiently, this interviewee recommended that the government should implement XBRL in their business reporting information system.

"That would be really helpful, I mean if they [government] began to get the data, go through it, analyze it and use it for interrogation and so on." (Institute Director L)

Similarly, based on Government Officer M's experience in evaluating company financial conditions, XBRL would assist him to undertake that financial analysis:

"From a practical perspective, if I am doing due diligent to acquire a company, then I would want to be able to undertake financial analysis in the simplest way possible. It is very time consuming to do that. If the company is using the same standard, the same way of structuring the financial data as the company that I am currently working for, it is much easier to undertake due diligence." (Government Officer M)

As a result of the government decision not to adopt $\mathrm{XBRL}$, the government missed the opportunity to establish a database of business financial and non-financial information that would lend itself to data mining and analysis by the government agencies.

\footnotetext{
${ }^{49} \mathrm{http} / / /$ www.eaton.com/Eaton/OurCompany/InvestorRelations/FinancialReports/SECXBRLFilings/index.htm
} 
The second implications relate to there being no data sharing among government agencies. During the e-GIF project, the SSC promoted XBRL as an enabler for sharing data within government agencies. The idea was to encourage all agencies to work together by using the same standard, that of XBRL. An interviewee from an observer stakeholder believed that XBRL has the ability to produce standardized data, a common language, and common presentation. Users of data would find it easier if the data were shared in an XBRL format. Moreover, it provides better understanding, and interpreting the data becomes easier since every piece of data or information has been structured in the same way. Further, the users know where to find the data in the report (Government Officer O).

Because of these capabilities, XBRL was selected in both e-GIF and SBR as the solution to existing problems in government operations with reporting financial information. Another interviewee from an active stakeholder believed that standardized data would benefit XBRL stakeholders. This is especially true when the data is shared online.

"I think there were some potential or definite benefits in standardizing the way data was shared between organisations. It is the case for any transmission of data, whether financial or not, it is always better to have it standardized. That is the fundamental requirement for the internet to operate." (Government Officer $M$ )

Another concern among stakeholders was security issues with the shared data. This was considered as a major challenge among government agencies. In response, one of the interviewees, Auditor C, claimed that the security of data is guaranteed as it is covered in standard government privacy requirements, and it was safe to share their information. In the SBR proposal, the Working Group emphasized security when sharing data among government agencies. Through the proposed cluster reporting methods, the Working Group tried to build confidence regarding data security in government agencies as well as business organisations; to encourage them to use XBRL.

However, by the government failing to fund the adoption of XBRL for use in business reporting, government agencies missed the opportunity to gain the benefits of shared data:

"I think it was a lost opportunity, in terms of not having a common platform to share information between government departments." (Auditor E)

The final short-term implication was that the government agencies lost the chance to remove inefficient processes in their operation. A part of the e-GIF project and SBR 
programmes' objectives was to eliminate unnecessary processes such as collecting physical forms, entering data manually, analyzing it, and generating general reports; in each government agency. XBRL technology can transform the government information systems particularly those related to business reporting, to become more interactive and efficient. More than one-quarter of interviewees argued that had the government adopted XBRL, it would have improved business reporting processes.

"It would save government dollars because you would not need people processing the same information in different government agencies." (Government Officer J)

Each government agency, for example, the IRD, the MED, and Statistics New Zealand, receive and process the same data or information from business organisations at least once a year. It takes time to process, save, and maintain the information in their databases.

"There is an opportunity cost for not doing it [adopting XBRL]. Here is the cost - we missed [the chance to improve] the efficiency of our system." (Government Officer $N$ )

Further, this interviewee explained that the absence of XBRL in government agencies meant some stakeholders spent more money to send and get similar data from different government agencies. Additionally, under certain conditions, the users could get poor data quality. That is because the data needs to be corrected or adjusted before it is analyzed (Government Officer N).

For government agencies, there are also three long-term implications. Firstly, government agencies will have limited ability to detect and eliminate mistakes and errors in financial reports. Most of the government agencies in New Zealand still collect data by using physical forms. As the number of businesses increases, the number of transactions and processes needed to be increases within government agencies. Because the government agencies will still be using traditional methods to process an increasing amount of data, there will be a tendency for more mistakes, leading to errors in processing the data.

Secondly, government agencies could face difficulties in getting data and information for policymaking. The absence of a central database using XBRL in any government setting results in less accessible data and information. Some government agencies may have problems getting enough data and accurate information to assist them to carry out their budgeting and planning tasks and functions efficiently. Alternatively, the respective 
agencies could conduct surveys or other research to get such information. However, this would take time and involve costs.

Finally, without this centralized data, government agencies are working in an unintegrated or unconnected manner. Each government agency has their own information systems, which are not linked to other organisations information systems and are being maintained independently by each agency. Because the different systems, have different functions and protocols they probably will be incompatible. Thus, the ability of government agencies to work together and share information is limited.

For example, during the e-GIF project, the IRD built a pilot XBRL application. In this pilot application, the IRD successfully computerized over 220,000 IR10 records into an XBRL format and later on transferred these records to Statistics New Zealand ${ }^{50}$. When using this data, two of the interviewees, Government Officer J and Government Officer M, explained that they had found errors and mistakes in the IR10 manual forms. In their view, it was an interesting finding because they never thought that XBRL had the ability to detect errors. At Statistics New Zealand, the received data was then used to evaluate tax compliance risk and assist with policy and strategic research ${ }^{51}$. Additionally, the XBRL information could be useful in creating an annual enterprise survey. The output from this survey would be stored in a national business database and used to support whole-of-government economic, fiscal, and monetary decision-making. Therefore, if XBRL technology had been implemented, the ability to detect errors in the financial reports, assist in generating data and information for government policymaking, and build an integrated platform that connected government agencies would have be achieved.

\subsubsection{Implications for Accounting Firms and the Accounting Professional Bodies}

There are short-term related implications of the government decision for accounting firms and the accounting professional bodies. Both of these stakeholder groups share the same short-term, as well as, long-term implications as below because most accountants who work in accounting firms are also a member of one or more accounting professional bodies. The implications are the accountants will lack the opportunity to retain their XBRL skill levels. Further, by using XBRL they would have been able to free up time for other purposes.

\footnotetext{
${ }^{50} \mathrm{http} / / / \mathrm{www} . e . g o v t . n z /$ standards/eXtensible-business-reporting-language/current-projects

51 http://www.ird.govt.nz/resources/0/c/0c69ec804ee4ec74aa05eab6c72de7d5/ir10g-2014.pdf
} 
As mentioned previously in Chapter 5, Charles Hoffman introduced XBRL as an alternative to the traditional method of preparing financial statements, distributing financial information, analyzing financial data and other activities relevant to accounting. One interviewee from an observer stakeholder suggested that XBRL makes accounting work easier (Academic K). This view is consistent with the ability of XBRL to produce financial statements or any other type of report by just pushing a button.

"XBRL is accounting software that makes work easier than to have manual standard for various accounts and so on." (Academic K)

In other words, by using XBRL technology, accountants can produce fast and quality financial statements and other related business reports. Thus, this interviewee argued that by having XBRL embedded in accounting software, accountants would have more time to update their skills and knowledge in their field, as well as learn how to use or produce XBRL data.

As the accountants studied the potential of XBRL, they discovered its benefits by using the technology. Most of the professional accounting bodies around the globe promote XBRL through annual conferences, seminars, workshops, articles and social media sites like Facebook and Twitter. The accounting bodies in countries like the UK, US, Europe, China, and India regularly update their members with new information about XBRL. Their active involvement, as members of XBRL International, means they stayed connected and support and encourage each other. Moreover, XBRL International has created a conducive environment that stimulates XBRL developments internationally.

In contrast, the New Zealand-based accounting professional body had a different view. In the past, members of ICANZ, who were also auditors or accountants in accounting firms, used to write articles related to XBRL. They were also working as a team under the auspices of ICANZ, and organized monthly seminars and workshops. Some of them attended XBRL International conferences and became members of XBRL International. Some of them also became experts in the XBRL area. XBRL International recognized their expertise by appointing them to important positions at the international level as mentioned in Chapter 5 (Section 5.4.1). Over time, many of these New Zealand experts moved overseas, in order to contribute further to XBRL International activities and develop the XBRL skill levels of others. 
Even as government agencies pursued XBRL initiatives like the e-GIF project and SBR programme, accountants, particularly from accounting firms and the accounting professional bodies became less involved in XBRL in New Zealand. As stated in the 2004 Annual Report of ICANZ, the professional body's strategic direction shifted because the Institute had a new CEO. This event influenced the way the accountants behaved. The CEO cut funding for XBRL activities and diverted it to other initiatives. With limited funds, the Steering Committee had difficulties in organizing seminars or workshops related to XBRL matters. Even worse, the Steering Committee had insufficient funds to pay it membership fees to XBRL International, which eventually forced the committee to stop being an XBRL Jurisdiction. Thus, most of the chartered accountants in New Zealand decided to 'wait and see' or have a 'watching brief' for any new developments in XBRL. Further, the NZX decision to only have voluntary adoption of XBRL influenced the accounting firms' direction and involvement in XBRL activities, especially at the national level. Another event that influenced the accounting firms and professional accounting body's involvement was the introduction of IFRS in 2003, which diverted their focus to the resulting changes in business reporting.

Eventually, interest in XBRL among the two accountant stakeholder groups waned to the point where initiatives by them to explore XBRL dried up. Consequently, in general, the New Zealand accountants' skills and knowledge about XBRL grew increasingly out of date, when compared to accountants in the international arena.

Accounting firms and accounting professional bodies have to also face two long-term implications. Firstly, XBRL was a waste of an unused application in business reporting that consumed many resources. From 2000 until 2010, the particular initiative groups developed and invested in XBRL related applications such as XBRL prototype software, taxonomies, and equipment. In the LEAP+ project, the stakeholders from an accounting firm and a university produced a web-based accounting system. It was believed that this product had the ability to assist accountants as well as university students in applying relevant accounting standards and checking the standard details. Later in 2001, stakeholders from accounting firms, government agencies, business organisations, the accounting professional body and universities established a steering committee. Through this committee, they built and trialed an XBRL application in their respective organisations. The XBRL pilot application had the ability to capture, analyze and keep the data electronically. By having these 
capabilities, it was predicted that XBRL would improve the relevant organisation's operations especially those related to business reporting. Again, in 2006, the initiative groups through the e-GIF project built another XBRL application that had the ability to transform the government operations to become more effective via the use of electronic medium. Additionally, this application aimed to reduce compliance costs for business organisations.

All these three attempts to use XBRL for business reporting failed to be implemented or selected as a solution to perceived stakeholders' problems in business reporting or related areas. That means initiative groups built and invested in XBRL related applications, but the stakeholders chose not to apply these applications. This is seen as a wasted investment. Further, the interviewees viewed this scenario as application abandonment.

"...there is a risk that the concept behind the XBRL could be abandoned because of implementation issues..." (Government Officer M)

Secondly, as professional accountants or members of accounting professional bodies and accounting firms now have no reason to update their skills and knowledge of $X B R L$, there will be limited development of XBRL-related activities, including education, innovation, and skills. One interviewee from an active stakeholders suggests that XBRL should be part of the professional exams.

"I had been talking about XBRL being part of the accounting professional exam. Presumably, XBRL was also being covered in university syllabuses. I mean I had spoken with some universities...Obviously, some academics are monitoring XBRL development." (Auditor E)

It is hard to determine how interested accountants in New Zealand are in XBRL. There has been no news about XBRL in the newspapers, professional magazines or any media in recent years. No seminars about XBRL have been conducted, and research on XBRL has been limited. However, people do still talk about XBRL occasionally. For example, in some the university syllabuses, XBRL is taught to students. Further, about half of the interviewees suggested that young accountants needed to be exposed, trained, and instilled with XBRL knowledge. 


\subsubsection{Implications for Business Organisations}

The findings revealed two short-term implications of the non-adoption of XBRL for business organisations. First, it meant that the barriers making it difficult for business organisations to access and connect with either government agencies or other businesses were retained. The existing practices of reporting require business organisations to submit their reports to each government agency such as the IRD, the MED, and Statistics New Zealand separately. The business organisations are required to file their financial reports with some government agencies more than once a year. This exercise is time-consuming and costly. For SMEs, these routines become a barrier to compliance since they do not have enough resources. Moreover, preparing the reports can become a significant overhead for them. Thus, government agencies, like the IRD and the MED tried to get XBRL adopted for business reporting purposes through the e-GIF project and SBR programme. These agencies wanted to build a platform for businesses to submit and retrieve their financial reports. If businesses had any issues or problems with their reports, they could go directly to the responsible agency or financial reporting cluster. One of the interviewees, Auditor $\mathrm{C}$, argued that this platform would provide easy interaction between businesses and government agencies. Even though building this platform would cost the government, the benefits it would bring was a worthwhile investment to consider, especially when using XBRL could reduce the barriers for businesses to access and connect with government agencies.

Another interviewee agreed that XBRL provided easy access to financial information.

"From the company perspective, XBRL makes it easier to provide financial information to potential investors." (Institute Director L)

The easy access for potential investors allows for more investment to come into domestic markets. This is what has happened in the stock exchanges of countries like US, China, and South Korea (Wang and Goa, 2012). By mandating the use of XBRL in submitting business and financial reports, it has enabled potential investors to have easy access to financial and business information for companies listed on the respective stock exchanges.

The second implication was the government did not take an opportunity to reduce the compliance costs to business. Compliance costs are another barrier for business organisations. Every business organisation in New Zealand is required to submit their financial information to specific government agencies. For example, business organisations 
need to submit data on company registration, their annual return and to update shareholder details to the Companies Office. Data such as their income tax return, GST registration and returns, employer registration, PAYE returns, FBT returns and IR10 (Financial Statements Summary) are submitted to the IRD. Business organisations are also required to submit annual and other related surveys to Statistics New Zealand. Some of the data are repeated to these and other government agencies. From the business organisation perspective, the government failed to reduce the compliance costs burdens for them particularly in relation to the cost and time to prepare and complete the returns (as will be explained next).

One interviewee from an active stakeholder, Government Officer N, claimed that some business organisations especially SMEs were complaining about too much compliance with many reports and returns having to be submitted to at least several government agencies every year. Each government agency needs almost the same data from the SMEs. However, they have to use different forms, and fill them in manually and attach them with related financial statements. These requirements are tedious and require time to complete. As a result, business organisations have to divide their time between fulfilling the requirements and their own business operations. In some circumstances, business organisations have to prioritize their resources. For example, the business organisation could outsource their business reporting and associated accounting matters to accounting firms. Although this action would allow them to focus on their business operations, the outsourcing would come at a cost. Furthermore, they are still responsible for making sure they have fulfilled all the related requirements. Whatever the conditions, business organisations need to balance doing business with the need to fulfill business reporting requirements as required by the related government agencies.

$X B R L$ can remove the repetition of data and its provision and thus reduce compliance costs.

"The idea of XBRL in the SBR context is to reduce the cost of compliance. If you do not adopt, it means you do not reduce the cost of compliance." (Academic K)

The interviewee, Academic $\mathrm{K}$ firmly argued that without adopting XBRL the compliance costs to business organisations would remain unchanged. A supporting view from an interviewee, who was involved with the e-GIF project and SBR programme, claimed that 
XBRL offers more benefits to stakeholders than just compliance cost reduction, especially for small business organisations.

"From a point of view of compliance cost reduction, accuracy and speed of the datathat would be the benefits for them. Being accurate for small businesses, compliance cost reduction and being able to spend time doing their business, rather than doing the government's returns." (Government Officer J)

Again, this interviewee linked the benefits of $X B R L$, the failure in adopting $X B R L$ and compliance costs.

"We did not manage to remove any compliance costs from businesses. We did not manage to reduce the cost to government of receiving data from businesses." (Government Officer J)

The non-adoption of XBRL means that business organisations missed opportunities to obtain associated benefits and to reduce their compliance costs.

In the long run, the non-adoption of XBRL would affect business organisations especially SMEs, by potentially reducing their ability to continue their operations as compliance and other costs increase. Failure to address the barriers (as identified above) eventually could lead to business organisations suffering in long run. Most of the SMEs have limited resources in terms of time and money. With increasing reporting burdens and other financial requirements, they may not be able to evaluate a new investment or have enough resources to consider a potential investment. Thus, they will miss out on growth opportunities.

Moreover, the absence of a shared database in the government setting could affect the decision-making process in business organisations as they currently need to go to an individual government agency to get the information they require, possibly resulting in less accurate and too much information. This will hinder them when making decisions. Through an XBRL application, data or information could be retrieved faster and be of better quality; thus, it will facilitate business organisations in making better decisions.

"I think the flexibility and the ability to link to better quality data that is coming in faster, the ability to assist in better decision making. Possibly the private sector used this link for their value added services. They all are missing out on the big opportunity cost out there." (Government Officer N) 
Again, this interviewee from an active stakeholder mentioned that business organisations missed the chance to use XBRL to assist them in their decision making. Thus, there is the tendency to make ineffective decisions. In the next section, this chapter presents the analysis of the short-term and long-term implications of the non-adoption of XBRL.

\subsection{Analysis: The Implications of the Non-Adoption of XBRL}

Table 8.1 summarizes the short-term and long-term implications of the government decision for XBRL stakeholders as identified and discussed in Section 8.1. Based on the table, several stakeholder groups have been affected differently by the government decision. It appears the most affected have been the government agencies, followed by business organisations, and lastly accounting firms and accounting professional bodies.

Table 8.1 Summary of Short-term and Long-term Implications of the Government's Decision

\begin{tabular}{|c|c|c|}
\hline $\begin{array}{l}\text { Stakeholder } \\
\text { Group }\end{array}$ & Short-term & Long-term \\
\hline \multirow{3}{*}{$\begin{array}{l}\text { Government } \\
\text { Agencies }\end{array}$} & Unable to perform specific data analysis & $\begin{array}{l}\text { Difficulty in detecting errors and mistakes } \\
\text { in financial statements submitted to } \\
\text { government }\end{array}$ \\
\hline & $\begin{array}{l}\text { No data sharing among government } \\
\text { agencies }\end{array}$ & $\begin{array}{l}\text { Difficulty in getting data and information } \\
\text { for policy making within government }\end{array}$ \\
\hline & $\begin{array}{l}\text { Lost opportunity to remove inefficient } \\
\text { processes }\end{array}$ & $\begin{array}{l}\text { Work in an unintegrated or unconnected } \\
\text { manner }\end{array}$ \\
\hline \multirow{2}{*}{$\begin{array}{l}\text { Accounting Firms } \\
\text { and Accounting } \\
\text { Professional } \\
\text { Bodies }\end{array}$} & Lack of XBRL skills development & Waste of costly unused application \\
\hline & $\begin{array}{l}\text { Missed opportunity to free up time for } \\
\text { other purposes }\end{array}$ & $\begin{array}{l}\text { Limited development in accounting } \\
\text { related areas: education, innovation, and } \\
\text { skills }\end{array}$ \\
\hline \multirow[t]{2}{*}{$\begin{array}{l}\text { Business } \\
\text { organisations }\end{array}$} & $\begin{array}{l}\text { Difficulty in accessing and connecting with } \\
\text { government agencies or other businesses }\end{array}$ & \multirow[t]{2}{*}{ Ineffective business operations } \\
\hline & Compliance costs are not reduced & \\
\hline
\end{tabular}

Some members of the active and supporting stakeholders such as the IRD, the SSC, Ernst \& Young and NZICA; and especially those who were involved with previous XBRL initiatives, consider there are implications to the government decision. However, it has been difficult for them to prove these. For these stakeholders, they were involved in building XBRL applications, they trialed these applications, and they experienced the benefits and capabilities of XBRL. In contrast, other stakeholders mostly from the observer groups did not gain this experience and this influenced their view on XBRL for business reporting. Further analysis based on the classification of stakeholder involvement and the TOE contexts highlights other interesting findings regarding the trend of stakeholders' views. This is discussed in detail in Chapter 9, Section 9.1.4. 
In the next section, this chapter will present the opinions of those who perceived that there were no implications as a result of the government decision to not adopt XBRL.

\subsection{Alternative View: No Implications for Stakeholders}

About 30 percent of the interviewees stated there were no implications of the government decision for stakeholders. For example, Consultant B provided three reasons for the lack of significant implications. First, he felt the government agencies did not require an XBRL solution. Almost all government agencies did not see XBRL as a solution or even realize they had problems in their information systems. Second, government agencies preferred to be independent in their operations or when delivering their tasks.

"Every government agency is doing their own things." (Consultant B)

This interviewee mentioned that the Treasury, a government agency, had their own reporting system named CFIS. This system is used to collect and analyze financial data for the Crown entities. Further, in the e-GIF project, only two government agencies (the IRD and Statistics New Zealand) shared data using XBRL technology. Other agencies only observed the project. Third, Consultant B believed that in future, the government could revisit the technology if they had the need for standardized data.

"That may change a little bit later; there is more scope for that to be revisited. For

example, if there were any standardizing expectations, it would come out of that." (Consultant B)

Consultant B suggested that as the National Government had to face the global financial crisis in 2008 , it did not have the funds to choose XBRL as an enabling technology to reduce the compliance costs for business organisations. However, this scenario could change as factors in organisations and the environment change.

Another interesting view was the suggestion that there are no implications from $a$ costbenefit perspective. An interviewee from an active stakeholder gave this opinion.

"I do not think there were any implications, given that the cost-benefit equation really was not working. The answer has to be no, and the status quo is fine until something better comes along. I do not think there are any downside implications to the nonadoption of XBRL. Why complicate things when it is not going to drive any additional benefits? Just keep it simple, keep doing what you are doing." (Government Officer H) 
This interviewee's view is based on his experience in conducting a survey of business organisations early on during the SBR programme. The survey's result showed that SMEs and accountants were having difficulty in understanding the XBRL concept. Most of SMEs and accountants could not see the benefits of XBRL for their organisations and the SMEs responded that they did not think that XBRL would save them time when doing business.

Further, Government Officer $\mathrm{H}$ added that the government needs to invest money in improving the legacy systems within the government. He believed that adopting XBRL would just advantage certain stakeholder groups. Improving the existing legacy systems would benefit all stakeholders.

"It is better not to spend money on the converter [taxonomy]. Spend it on the underlying legacy system to improve those and to understand the bigger requirement picture-more connected government. You have not only the advantages for the SMES but also the advantages for public citizens and [for] having a more connected government." (Government Officer $H$ )

It was also suggested that most business organisations in New Zealand did not see any need for change.

"They have been paying this compliance cost for a long time. As long as they are willing to pay the company tax..." (Academic K)

The above arguments provide a contra view and suggest there are links between adoption factors and the view that there are no implications of not adopting XBRL. Among the influencing factors were that it was not seen as a problem solver, there was no relative advantage, it was missing a mandatory adoption strategy, there was a culture of working independently within government agencies and a knowledge gap. In other words, when the government chose not to adopt XBRL use for business reporting, there were no major changes in the business environment. Therefore, some interviewees believe there are no implications relating to the government decisions.

\subsection{Chapter Summary}

In this chapter, the findings of the short-term and long-term implications of not adopting XBRL have been presented. Four main stakeholder groups: government agencies, accounting firms, accounting professional bodies and business organisations are potentially 
affected by the government decision. Interestingly, each of these stakeholder groups faces a different short-term impact relating to the government decision not to adopt XBRL for business reporting. For example, government agencies are unable to perform specific types of data analysis, there is no data sharing between agencies, and it means that their processes are less efficient. For the accounting firms and accounting professional bodies, the accountants' skill with respect to and knowledge of XBRL has stagnated. In addition to concerns relating to accessing and connecting with government agencies and other businesses, the business organisations continue to bear compliance costs that would have been reduced with $X B R L$ use.

In addition, the government decision came with long-term implications. The government agencies will continue to miss errors and mistakes in financial statements, face difficulty in getting data and information for policymaking and will continue to deliver their services in an unintegrated manner. Accounting firms and accounting professional bodies have wasted time and resources on a failed and abandoned application and have slowed down development in accounting skills and knowledge of XBRL. Finally, the business organisations have lost the opportunity to improve their business operations including making more effective decisions.

In Chapter 9, this thesis will further examine and discuss the evidence and analysis for each research question, the proposed research framework, and the propositions (as given in Chapter 3). This provides an understanding of the theoretical and practical contributions of this research to the literature. The final chapter also outlines the limitations of this thesis as well as presenting opportunities for future research. 


\section{Chapter 9: Discussion and Conclusion}

\subsection{Introduction}

In New Zealand, XBRL initiatives ran from early 2000 until 2010. Over this time, four key projects were conducted by the professional (accounting firms and accounting professional bodies) and government agencies. The aim of these projects was to introduce XBRL to New Zealand. Unfortunately, none of the projects was successfully implemented on a sustainable basis. This thesis investigated in detail the factors that influenced organisations' (including government) decisions not to adopt XBRL for business reporting. In addition, the research explored the short-term and long-term implications for the XBRL stakeholders of the government decision not to adopt XBRL.

In order to answer the research questions, this thesis developed a research framework based on the TOE Framework and prior literature. Chapter 3 presented twelve associated propositions, which are restated in this chapter. Chapter 4 explained and described the relevance of the research methodologies used to conduct the case studies of the four XBRL projects. Chapter 5 presented the historical chronology of XBRL development and projects in New Zealand from 2000 to 2010. The three subsequent chapters presented the analysis of the findings. Chapter 6 identified the factors that influenced the professional and business organisations' decision towards the non-adoption of XBRL. Chapter 7 identified the factors that influenced the government agencies' decisions. Further, Chapters 6 and 7 provide reasons as to why stakeholders decided not to adopt XBRL for business reporting. Chapter 8 examined the implications of the government decision for XBRL stakeholders.

This final chapter concludes the thesis by firstly, discussing the influencing XBRL adoption factors and then using the findings to validate the research framework and propositions, and to provide an overall evaluation of the main outcomes. The contributions of these results to the academic knowledge and practice are outlined, followed by the limitations of the research and the remaining issues to be solved in future research. Lastly, concluding statements are presented. 


\subsection{Factors Influenced Organisations Decision on Non-Adoption of XBRL}

The research framework (Figure 3.4 of Chapter 3) has three parts: the TOE Framework, the Organisation Decision, and Implications. The first and second parts of the research framework are discussed in this section, which is organised into four sub-sections: predicted factors, unpredicted factors, and further analysis of the TOE contexts, stakeholder involvements, and stakeholder groups. Additionally, as suggested by Figure 3.4, the TOE context factors are influenced by stakeholders, including their decisions not to adopt XBRL for business reporting.

\subsubsection{Predicted Factors}

The first research question was motivated by the lack of studies investigating the factors that influenced the organisational decision on whether to adopt XBRL or not. The existing literature is largely limited to studies concentrating on a company's adoption, investor benefits, user's preferences of reporting format, taxonomy development, countries experience, voluntary adoption, mandatory adoption, and disclosure (as discussed in Chapters 2 and 3). Thus, the literature provides a limited understanding of non-adoption of XBRL, especially from the governmental point of view. In order to address this limited understanding, the first research question was:

What factors influenced the organisations' decisions not to adopt XBRL for use in business reporting?

In answering this research question, the thesis identified predicted and unpredicted factors. The predicted factors are included in the twelve propositions (Table 3.4), while the unpredicted factors were found while analysing the results. The twelve predicted factors are discussed first.

P1: If the adoption costs are perceived to exceed the benefits, then the organisation is less likely to adopt XBRL for use in business reporting.

The interviewees' views on the relative advantage of adopting XBRL were generally mixed. During the LEAP+ project, Ernst \& Young and the University of Auckland struggled to convince accounting staff and university students of the real benefit of XBRL. The same situation happened in the Project First Step. Stakeholders saw the adoption costs but could not see the benefits. The stakeholders' acceptance of XBRL benefits, especially in the IRD and NZICA, improved in the e-GIF project and SBR programme. Nevertheless, overall 
stakeholders were not convinced of the benefits of using XBRL for business reporting. Thus, the results support Proposition 1, the government and private organisations did not seek to adopt XBRL because the costs were perceived to exceed the benefits. This finding is consistent with Doolin and Troshani (2007), Troshani and Rao (2007), Cordery et al. (2011), and Troshani et al. (2011). In a recent study, Rosa and Caserio (2013) perceived that relative advantage is a key factor in XBRL adoption.

P2: If the XBRL technology is perceived to be inconsistent with an organisations existing information systems, tasks, the current needs and objectives, then the organisation is less likely to adopt XBRL for use in business reporting.

None of the interviewees from the LEAP+ project or Project First Step mentioned this compatibility factor, but it did exist in the e-GIF project and SBR programme. The first stakeholders were only introduced to the technology and had not yet explored the technology requirements. It was only a few years after XBRL introduction that many stakeholders learned about and understood the technology's requirements. Moreover, government agencies more seriously considered XBRL as part of a possible information system for business reporting. Most government agencies' information system was already XML-based, making many key government agencies' information systems compatible with XBRL. The results, therefore, do not support Proposition 2, as although XBRL is compatible with the existing information system in most government agencies, XBRL was not adopted. The finding is partially supported by Mousa (2011), where the existing information system in the HMRC and Companies House were compatible with adopted XBRL technology.

P3: If the XBRL technology is perceived to be relatively difficult to understand and use, then the organisation is less likely to adopt XBRL for use in business reporting.

The initiative group of the LEAP+ project did not mention complexity. XBRL complexity became a concern during Project First Step. The majority of interviewees from Project First Step, the e-GIF project, and SBR programme agreed that XBRL is complex. Project First Step mentioned the complexity of XBRL elements such as it being calculation-link-based and XLink, building and revising the taxonomy, and the process of implementing XBRL in organisations. In the e-GIF project, however, the interviewees highlighted the complexity of different information systems among the stakeholders' organisations, continuous upgrading of the taxonomy, and understanding the taxonomy for various industries. During the SBR programme, the interviewees shared their views on the complexity of building the 
architecture for XBRL applications, and assigning the identification of the organisations' Single Business Number (SBN). These complexity issues in XBRL influenced the governmental as well as private organisations' decision not to adopt XBRL for business reporting. Thus, the results support Proposition 3 . This finding is similar to Doolin and Troshani (2007), Troshani and Rao (2007), Cordery et al. (2011) and Mousa (2011). The stakeholders from business organisations as well as government agencies felt that XBRL was a complex technology to understand and implement.

P4: If there is perceived to be a lack of safeguarding mechanisms for the movement and storage of data and information through $X B R L$, then the organisation is less likely to adopt XBRL for use in business reporting.

The interviewees had mixed views on the security issue. None of the interviewees from the LEAP+ project was concerned about security when using XBRL. In Project First Step, the OAG was not concerned about security, but the media was. In the e-GIF project, the IRD had no issue at all in using XBRL. However, during the SBR programme, the lack of knowledge about XBRL led to a feeling of insecurity in using XBRL for business reporting by the XRB. The interviewee from the XRB mentioned that business organisations wanted to ensure their data would not be accessed by an inappropriate entity or manipulated by an irresponsible person. Further analysis found that ambiguity in regards to security influenced particularly the government's decision not to adopt XBRL for business reporting. Therefore, the result supports Proposition 4. This finding is similar to that of Mousa (2011).

P5: If there is perceived to be limited opportunity to test the XBRL technology, then the organisation is less likely to adopt XBRL for use in business reporting.

Trialability is believed to reduce the uncertainty around XBRL adoption. In the LEAP+ project, university students and accounting staff experienced XBRL by using the LEAP+ website. The NZX and some listed companies trialed XBRL during Project First Step. In the eGIF project, at least two government agencies, the IRD and Statistics Department trialed XBRL. All these pilot projects successfully proved that XBRL could work for business reporting. Additionally, during the e-GIF project, the IRD discovered that XBRL had the ability to detect errors and mistakes in business returns. From there, the stakeholders involved could see the benefits and potential of using XBRL in their information system. Through trialling these XBRL applications, stakeholders exposed themselves to new knowledge and information; thus, they gained more confidence and should have been 
more comfortable in adopting the technology. Thus, the results do not support Proposition 5 , as XBRL was not adopted. Other studies of XBRL that found similar results are Doolin and Troshani (2007) and Cordery et al. (2011).

P6: If it is perceived that staff has a low level of knowledge and expertise in XBRL, then the organisation is less likely to adopt XBRL for use in business reporting.

The analysis of XBRL initiatives indicates that there was a lack of human capability. The LEAP+ project was the exception because in this project the initiative group had sufficient experts. A lack of ongoing human capability emerged during the Project First Step. Almost all the New Zealand experts moved overseas for better opportunities and to work on the XBRL technology being adopted in other countries. Furthermore, during the e-GIF project and the SBR programme, the Steering Committee had a limited number of experts, but they managed to overcome this obstacle by inviting experts (or consultants) from overseas. For example, they invited Paul Madden during the e-GIF project and Harm Jan van Burg for the SBR programme. Nonetheless, this was considered a short-term solution because the experts/consultants could only commit and contribute for a certain period. Moreover, this solution increased the adoption cost for the lead organisations. Thus, organisations in New Zealand need to train people on XBRL especially if they want to resurrect XBRL in the future. Overall, a lack of local experts influenced the governmental and private organisations' decisions on the non-adoption of XBRL. Thus, the result supports Proposition 6 . This finding is consistent with Troshani and Rao (2007), Mousa (2011) and Troshani et al. (2011). As discussed in Section 3.2.2.1, Srivastava and Teo (2010) suggests human capability is only important in e-government, however this thesis's result indicates human capability is important in both e-business and e-government.

P7: If there is perceived to be an absence of an XBRL champion at the decision making level in the project, then the organisation is less likely to adopt XBRL for use in business reporting.

The XBRL initiatives suffered because no champion lasted throughout the project. Whenever the group started a XBRL project, they had a champion. However, the champion did not last until the point where adoption was feasible or agreed. For example, in LEAP+, the champion from Ernst \& Young did not continue his support as champion as he was disappointed at the limited cooperation from ICANZ and eventually he left to go overseas. In other XBRL initiatives, the lead organisation changed their top management. Normally, 
when top management is changed, there is a tendency towards changing the organisation's vision, strategic planning, budgets, and priorities. There was a change of CEO in ICANZ during the Project First Step. During the e-GIF project, there was a change of Chief Executive and Commissioner in the IRD. In addition, there was another issue during the eGIF project. The initiative group had a champion from top management; however, because of a change in top management, the group lost their champion. Another person took charge of the e-GIF initiative, but he was not considered a champion. That is because he did not have the power to make a decision, to influence people to work together for XBRL adoption or to convince people to accept XBRL use for business reporting. In the SBR programme, the project lacked a champion, as the Chair of the Steering Committee was not interested in XBRL. The result supports Proposition 7 and influenced the government and the private organisations decisions not to adopt XBRL for use in business reporting. Doolin and Troshani (2007) and Cordery et al. (2011) also found that not having a champion inhibits the adoption of XBRL.

P8: If it is perceived that funds for investing or building the organisational IT related to $X B R L$ are unavailable, then the organisation is less likely to adopt XBRL for use in business reporting.

Financial support is needed to fund XBRL activities and develop the XBRL infrastructure. During Project First Step, ICANZ changed their top management, which affected the financial support for XBRL development in New Zealand as the new CEO had a different vision and strategy for the Institute. Additionally, ICANZ needed to prepare for mandatory IFRS adoption in 2007. Consequently, Project First Step's Steering Committee did not obtain financial support from the Institute's top management, thus, forcing them to look for other funding. Some interviewees believed the Steering Committee should have competed more strongly to be a top priority in ICANZ. In the e-GIF project, the change of programme sponsor from the IRD to the MED affected the financial support. During this time, the IRD was committed and gave a high priority to the project, however, the MED especially one of its departments, did not see the potential of using XBRL in business reporting. Thus, when the MED was placed in-charge of the SBR programme, they did not give it full support, instead placing a low priority on the programme. Some SBR Steering Committee members tried to lobby the National Government for support, but the MED did not push hard enough to get a supplementary budget for continuing the SBR programme. These situations 
indicate a lack of priority from funding providers in financing the XBRL initiatives as the initiative groups struggled to compete with other institute or government priorities. This result supports Proposition 8. Financial support influences the government's and private organisations' decision to adopt XBRL. Studies like Troshani and Rao (2007), Cordery et al. (2011) and Troshani et al. (2011) had similar findings.

P9: If it is perceived that there are limited successful adoption stories of XBRL technology by stakeholders, then the organisation is less likely to adopt XBRL for use in business reporting.

There were no successful adoption stories of XBRL in New Zealand, as none of the XBRL projects led to successful adoption. During Project First Step, the Steering Committee attempted to tell successful adoption stories of XBRL from other countries and placed them on the XBRL New Zealand website. The website provided simple guides and demonstrations related to XBRL. Unfortunately, when XBRL New Zealand disbanded in 2006, the website was closed, removing a source where potential users would be able to learn from successful adoption stories. In the SBR programme, an interviewee mentioned a successful adoption of technology by government, SEEMail. Even though it was not an XBRL successful adoption story; at least, from the governmental perspective, government agencies had successfully adopted a technology within agencies. Overall, interviewees believed that without successful XBRL adoption stories, it was difficult to convince the decision makers in private organisations or government to accept and adopt XBRL for business reporting. Therefore, the results support Proposition 9. There were limited successful adoption stories, which influenced the governmental and private organisations' decision not to adopt XBRL. Troshani and Rao (2007) mentioned that limited local XBRL success stories influenced the stakeholders' decisions not to adopt XBRL technology in their organisation. They argued that when potential adopters could not observe local XBRL benefits live, non-standard forms of adoption were likely to emerge and the XBRL development and adoption effort would be likely to lose its focus. Troshani et al. (2011) found limited successful stories as a barrier to adopting a new technology.

P10: If there is perceived to be a lack of effectiveness in stakeholder participation, then the organisation is less likely to adopt XBRL for use in business reporting.

Throughout the XBRL initiatives, the groups faced difficulties in getting the XBRL stakeholders involved. In the LEAP+ project, the initiative group did not obtain continuous 
support from accountants and auditors in Ernst \& Young and degree students and academic staff in the University of Auckland. During Project First Step, the Steering Committee members' involvement and commitment was on a volunteer basis. Most chartered accountants were not aware of XBRL and software developers were not involved in Project First Step. Private organisations appeared to avoid being involved in XBRL activities. The same scenario happened in the e-GIF project and the SBR programme. The initiative groups managed to obtain some support and commitment from the Ministers but only on an occasional basis. Furthermore, a change of government and the global financial crisis influenced ministries' involvement in XBRL initiatives. Furthermore, although various stakeholders were involved, it was not continuous. These conditions led to a lack of stakeholder involvement in the XBRL projects. Therefore, the result supports Proposition 10. A lack of stakeholder participation indirectly influenced the government's and private organisations' decision in adopting XBRL. This finding is similar to Troshani and Rao (2007) and Cordery et al. (2011).

P11: If there is perceived to be an insufficient number of organisations adopting XBRL, then the organisation is less likely to adopt XBRL for use in business reporting.

The XBRL history, as presented in Chapter 5, shows New Zealand did not reach a critical mass of XBRL adoption. In Project First Step, for example, the Steering Committee proposed mandatory adoption of XBRL by the NZX. This action would result in the approximately 150 companies listed on the NZX having to use XBRL for business reporting, creating a critical mass. However, this did not happen. During the e-GIF and SBR, only a small number of government agencies were interested in adopting XBRL. Again, there was no critical mass that encouraged XBRL adoption under government auspices. Therefore, the result supports Proposition 11 that having no critical mass is a barrier to adopting XBRL, and influences the private and government organisations' decision. Doolin and Troshani (2007) and Mousa (2011) also found critical mass was an influencing factor in technology adoption.

P12: If there is perceived to be a lack of trading partner influence, then the organisation is less likely to adopt XBRL for use in business reporting.

Trading partners could influence the organisational decision in several ways. For instance, many business organisations in Australia and New Zealand have a close business relationship. It is probable that when Australia adopted XBRL for business reporting, New Zealand businesses that report in Australia would need to fulfil the reporting requirements 
of that country. Another way is through political influence. When the Labour Party in Australia decided to adopt XBRL, the Labour Party in New Zealand also showed interest in XBRL as a way of reducing costs for New Zealand businesses and government agencies. Thus, the findings do not support Proposition 12 because trading partner influence had the potential to facilitate the private organisations' or the government's decisions to adopt XBRL. This finding is consistent with previous studies of Doolin and Troshani (2007) and Cordery et al. (2011).

Table 9.1 Summary of Predicted TOE Context Factors for XBRL Initiatives

\begin{tabular}{|c|c|c|c|c|c|c|c|c|c|c|c|c|}
\hline & \multicolumn{5}{|c|}{ Technological } & \multicolumn{3}{|c|}{ Organisational } & \multicolumn{4}{|c|}{ Environmental } \\
\hline & 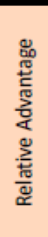 & 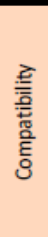 & 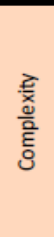 & 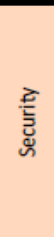 & 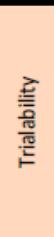 & 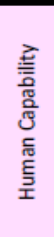 & 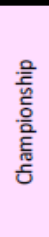 & 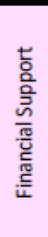 & 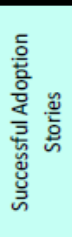 & 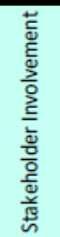 & 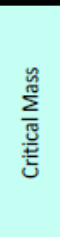 & 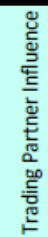 \\
\hline PROPOSITION & $\mathrm{P} 1$ & $\mathrm{P} 2$ & $\mathrm{P3}$ & $\mathrm{P} 4$ & $\mathrm{P5}$ & P6 & P7 & P8 & $\mathrm{pg}$ & $\mathrm{P} 10$ & $\mathrm{P} 11$ & $\mathrm{P} 12$ \\
\hline \multicolumn{13}{|c|}{ LEAP+ } \\
\hline Ernst \& Young (A) & & & & & + & + & & & & & & \\
\hline University of Auckland (A) & - & & & & + & + & - & & & - & & \\
\hline Professional Magazines (O) & & & & & + & & & & & & & \\
\hline \multicolumn{13}{|c|}{ Project First Step } \\
\hline $\mathrm{OAG}(\mathrm{A})$ & & & - & + & & - & & & & - & & \\
\hline $\operatorname{IRD}(\mathrm{A})$ & & & & & & & & & & - & & \\
\hline Ernst \& Young (A) & - & & & & & 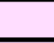 & & - & & - & & \\
\hline KPMG (A) & - & & & & & . & & & & & & \\
\hline NZICA (Steering Committee) (A) & & & - & & + & - & - & & - & - & - & \\
\hline University of Auckland (A) & - & & - & & & - & & & & - & & \\
\hline Treasury $(\mathrm{O})$ & & & & & & & & & & 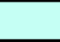 & & \\
\hline University of Otago $(\mathrm{O})$ & & & & & & & - & & & - & - & \\
\hline Newspapers (O) & & & & - & + & & & & & & & \\
\hline \multicolumn{13}{|c|}{ e-GIF } \\
\hline $\operatorname{IRD}(\mathrm{A})$ & + & + & - & + & + & - & - & & & - & - & + \\
\hline $\operatorname{MED}(\mathrm{A})$ & & & - & & & & - & & & . & 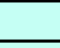 & + \\
\hline $\operatorname{SSC}(A)$ & & & & & & & & & & + & & \\
\hline NZICA (S) & + & & & & & & - & & & - & & \\
\hline Tax Management Consulting Firm (S) & & & & & & & - & & & - & - & + \\
\hline $\mathrm{OAG}(\mathrm{O})$ & - & + & - & & & & & & & - & & \\
\hline \multicolumn{13}{|c|}{ SBR } \\
\hline $\operatorname{IRD}(A)$ & + & & - & & & - & & & & 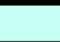 & & \\
\hline $\operatorname{MED}(\mathrm{A})$ & - & & - & & & & & & & + & & + \\
\hline $\operatorname{SSC}(A)$ & & & & & & - & - & & + & - & & \\
\hline $\operatorname{NZICA}(\mathrm{A})$ & + & & & & & & - & & & . & - & \\
\hline XRB (S) & - & & & - & & & & - & & - & & + \\
\hline \multicolumn{13}{|l|}{ Tax Management Consulting (S) } \\
\hline Treasury $(\mathrm{O})$ & & + & & & & & - & & & - & & \\
\hline Grant Thornton $(\mathrm{O})$ & & + & & & & & & & & & & \\
\hline Management Consultancy Firm (O) & & & & & & & & & & - & - & \\
\hline \multicolumn{13}{|l|}{ University of Otago $(\mathrm{O})$} \\
\hline University of Hawai'i $(\mathrm{O})$ & & & & & & & - & & & - & & \\
\hline Proposition results & $\sqrt{ }$ & $\mathrm{X}$ & $\sqrt{ }$ & $\sqrt{ }$ & $\mathrm{X}$ & $\sqrt{ }$ & $\sqrt{ }$ & $\sqrt{ }$ & $\sqrt{ }$ & $\sqrt{ }$ & $\sqrt{ }$ & $x$ \\
\hline
\end{tabular}

(A): Active ; (S): Supportive ; (O): Observer

+: Driver, Facilitating, Encourage; - : Hinder, Inhibitor, Challenge

$\mathrm{V}$ : Supporting the proposition; X: Not supporting the proposition 
Table 9.1 summarises the results relating to the predicted factors and shows that the results support almost all propositions except for P2, P5 and P12. Based on these results, factors like having no relative advantage, complexity, ambiguity in security, a lack of human capability, having no championship, insufficient financial support, limited successful adoption stories, a lack of stakeholder involvement and insufficient critical mass inhibited and influenced the government's and private organisations' decisions not to adopt XBRL technology. Meanwhile, compatibility, trialability, and trading partner influence can encourage organisations' decisions to adopt XBRL. However, in the case of New Zealand, the other factors (above) appear to have dominated and thus, XBRL has not been adopted. Other factors, which contributed and influenced the government and private organisations' decisions on the non-adoption of XBRL, were also discovered. The next subsection identifies and explains these other unpredicted factors.

\subsubsection{Unpredicted Factors}

The findings suggest that additional fourteen factors influence government and the private organisations' decision regarding the adoption of XBRL for business reporting purposes. This thesis arranged the factors according to the TOE framework. The operational definition of these factors as given in Appendix B and where possible the supplies literature is identified.

\section{Technological Context}

There are an additional four factors in the technological context. During the LEAP+ project, two influencing factors were discovered: being a problem solver, and copyright. In Project First Step, another two influencing factors, stability, and the availability of tools and software were found. The discovery of four unpredicted factors during the LEAP+ and Project First Step increased the total factors under the technological context to nine. No additional factors were found during analysis of the e-GIF project and SBR programme. However, some of the additional factors were applicable to these later projects.

Problem solver refers to how potential adopters perceive XBRL as a solution to problems related to business reporting matters. Two government agencies could understand and see XBRL as their solution. The IRD saw XBRL as part of their solution when replacing their old computer system. Further, the SSC agreed with the IRD that XBRL would enable data sharing within government agencies. However, most other interviewees perceived that 
XBRL was not a problem solver for their current problems (see Table 9.2). Many of these stakeholders had no opportunity to try XBRL in their organisation or to learn from other successful adoption stories. With their limited knowledge of XBRL, they concluded that XBRL was good, but it was not for them. Overall, the results suggest this factor inhibited the XBRL adoption and influenced the private and government organisations' decision not to adopt XBRL. Based on this finding, being perceived as a problem solver is a possible influencing factor in technology adoption. This is similar to previous studies, for example, Dunne et al. (2009) found most of their respondents do not perceive the lauded benefits of $\mathrm{XBRL}$ to be relevant to them, even though they are presumably for the most part interested in financial information.

Copyright appeared as an inhibitor in the LEAP+ project. Copyright is defined as an exclusive legal right to reproduce, publish, sell, or distribute the matter and form of something ${ }^{52}$ related to financial and business information. The initiative group wanted to obtain a licence to 'use the notes in the margin of the printed version'. These notes pointed to written material to which the Institute owned the copyright, the actual text of which was not in the print version but could be accessible on the web. However, during that time, the group did not manage to settle the copyright issue with the Institute. Therefore, the team was unable make the website or application available to the public. Thus, the results suggest copyright issues could be a barrier to adopting new technology such as XBRL. In this case, it influenced the private organisations' decision on XBRL adoption.

During Project First Step, stakeholders were looking for stability or the maturity of the XBRL taxonomy, because the XBRL taxonomy had kept changing. Stability refers to the ability of an XBRL element, such as the XBRL specification and taxonomy, to remain unchanged under reasonably expected conditions and $u \mathrm{~s}^{53}$. Whenever XBRL International upgraded the specification, the taxonomy also changed. That meant users needed to update their current taxonomy and it took time for them to understand new items in the specification and determine the content of a new taxonomy. When XBRL International introduced XBRL in 2000, they used Specification 1.0 (Richards and Tibbits, 2002). A few months later, the nonprofit consortium enhanced the XML schema to Specification 2.0 (XBRL, 2009). XBRL International further upgraded the specification in 2003 to Specification 2.1, which remains

\footnotetext{
52 http://www.merriam-webster.com/dictionary/copyright

53 http://www.businessdictionary.com/definition/stability.html
} 
the current specification (XBRL, 2009). During the process of reaching stability in the XBRL Specification (2000-2003), users felt it was difficult to understand the taxonomy. In the end, the users perceived that XBRL is complex, due to the use of the changing taxonomies. Further, in New Zealand, the first taxonomy was built based on IAS and New Zealand GAAP. Later on, the introduction of IFRS forced the Steering Committee to revise the existing taxonomy so that it would be consistent with IFRS. During the early part of the e-GIF project, the stakeholders also observed that the XBRL specification and taxonomy had not reached maturity in the international arena. That result suggests that perceived instability of the XBRL specification and taxonomy is a barrier for XBRL adoption. This factor influenced the adoption decision by private and government organisations. Additionally, this finding confirms an early exploratory study by Doolin and Troshani (2007) that instability of XBRL is inhibitor to XBRL adoption.

Availability of tools and software is defined as the accessibility of equipment that enables potential adopters to try a new technology like XBRL. According to Rogers (1995), availability is important as these tools and software enable potential adopters to access the characteristics of technology like XBRL easily, and determine its suitability for their needs. Early on, as XBRL was immature, local software developers were reluctant to develop XBRL tools and software, delaying potential users' ability to try XBRL. Thus, limited availability of XBRL tools and software was considered to be an obstacle and influenced the private and government organisations' decision not to adopt XBRL. That means instability of XBRL (as discussed above) influenced software vendors' decision to develop their XBRL software because small changes in the newer versions of the specification created serious compatibility problems between the tools and software that rely on previous versions and those that rely on newer ones. Again, this finding confirms a study by Doolin and Troshani (2007) that limited tools and software is inhibitor to XBRL adoption.

\section{Organisational Context}

The findings suggest five additional factors in the organisational context. During the LEAP+ project, two factors were revealed: promotion and communication, and enthusiasm for XBRL. Later, in Project First Step, the adoption strategy was believed to influence private organisations' decision in adopting XBRL for business reporting. During the e-GIF, two other factors namely, leadership and change of programme sponsor were discovered to influence 
$X B R L$ adoption among the stakeholders. The total number of XBRL adoption influencing factors is now eight under the organisational context.

Promotion and communication refers to the platform through which stakeholders create and share information about $X B R L$, in an attempt to influence others to accept the idea of XBRL. The interviewees had mixed views on this factor during LEAP+ and Project First Step. About half believed they had promoted XBRL and had succeeded in influencing potential users to accept the technology. However, the other half argued they did not see any effective communication between XBRL initiative groups and potential users. The same situation occurred during the e-GIF project and SBR programme. In the SBR programme, the Steering Committee was perceived not to have shared information with either their members or other stakeholders. The findings suggest the initiative groups undertook promotion well but communicated poorly. Most of the initiative groups promoted their XBRL projects, but they did not really push the stakeholders to accept the idea of adopting XBRL. Their intentions were just to create awareness, not to educate stakeholders. This is possibly why, when interested stakeholders had some comments and needed more information, the initiative groups did not respond effectively. Another potential reason is that the initiative groups did not have the information. Even within the committees, members of each project had different knowledge and limited levels of understanding and skills related to XBRL. The lack of experts in each XBRL initiative, except in the LEAP+ project, restricted the ability of the initiative groups to supply or share related information with the interested stakeholders. The results suggest that ineffective promotion and communication is a barrier and influenced the XBRL adoption decision. Grgeta (2006) and McFarland (2007) also have suggested that groups like the accounting profession should be more actively involved in communicating XBRL knowledge through journals, courses, continuous development programmes and tertiary education at universities to encourage XBRL adoption.

Enthusiasm refers to a strong interest in the XBRL initiatives and activities among XBRL supporters. The XBRL supporters were attracted to the newness of XBRL technology as a tool for digital business reporting. They were exploring 'what is there for me?' Most of the XBRL supporters in New Zealand were members of the initiative groups and wanted to implement XBRL in their organisations. In early 2000, these people initiated three XBRL projects; LEAP+, Project First Step and e-GIF, almost at the same time. Their excitement in 
undertaking XBRL activities led them to attract more people to join the initiatives. They obtained financial and non-financial support from inside and outside of their organisations. Their enthusiasm encouraged them to develop a big vision; the mandatory adoption of XBRL. However, at some point, their excitement began to shift from this original intention. Early on, XBRL supporters wanted to explore XBRL use for business reporting and create awareness among stakeholders. While progressing with the XBRL projects, the supporters started to push vigorously for the adoption of XBRL in New Zealand. As their momentum and enthusiasm increased, they began to be perceived as over-enthusiastic. Consequently, stakeholders started to reduce their XBRL involvement and slowly removed their support. This factor had a similar impact to that noticed earlier due to the instability of XBRL specification and taxonomy, when the international experts were progressing too fast in upgrading the XBRL elements (Troshani and Doolin, 2005). Hence, it is suggested that being over-enthusiastic inhibited and influenced the government's and private organisations' decision to adopt $\mathrm{XBRL}$, and thus, is a potential influencing factor in adopting new technology.

Adoption strategy refers to an approach or method employed to get stakeholders to start using new technology like XBRL. Adopters could choose not to adopt it, to adopt XBRL voluntarily, or for it to be mandatory. In voluntary adoption, the adopters use XBRL on an optional basis and without regulatory enforcement. Under mandatory adoption, the adopters are forced to adopt XBRL due to rules or regulations. The analysis showed that almost all interviewees perceived mandatory adoption would benefit stakeholders and would be more likely to succeed, like XBRL adoption in the UK and the US. Both of these countries (along with others) have mandated XBRL adoption through government agencies and regulators. In the UK, the HMRC mandated XBRL use, requiring organisations to submit their financial reports in an XBRL format. In the US, the SEC has also mandated that listed companies should submit their financial statements in XBRL format. However, in New Zealand because there was no continuous championship during Project First Step; no real championship in the e-GIF project and no championship during the SBR programme, mandatory adoption did not happen. Moreover, ineffective leadership led to an absence of mandatory adoption, particularly during the SBR programme. Thus, not having a mandatory adoption strategy inhibits XBRL adoption, and it influenced the governmental and private organisations' adoption decision. This finding provides empirical evidence that supports 
Steenkamp and Nel (2012) conjecture that if XBRL is mandatory, companies have little or no choice but to implement it.

This thesis differentiates between championship and leadership factors. With championship (as discussed above), the person takes an extraordinary interest in the adoption, implementation, and success of XBRL projects. The champion tries to force the idea through entrenched internal resistance to achieve change ${ }^{54}$. The person also commits themselves to their organisation, strives to achieve their goal, and serves the community as a whole. That means the person considers not only their organisation but goes beyond the organisational boundaries (Thompson, 2009). Meanwhile, in leadership, the person leads the XBRL project at an agency or organisational level. As an effective leader, the person creates an inspiring vision of the future; motivates people to engage with the vision; manages the delivery of the vision; and coaches and builds a team to achieve the vision ${ }^{55}$. Leaders are also responsible for providing information, knowledge, and methods to realize the vision ${ }^{56}$. That means that in this thesis, leadership and championship are differentiated based on the degree of influence the person has in the XBRL project. The leadership factor existed in the e-GIF project and the SBR programme. XBRL initiatives under the IRD had competent leadership, where the leader could influence the staff inside his organisation. However, the leader did not have enough power to influence the stakeholders to require a mandatory adoption strategy. The situation became worse when a change of programme sponsor from the IRD to the MED happened during the SBR programme, resulting in ineffective leadership. Therefore, this finding suggests ineffective leadership is a barrier to adopting $X B R L$ and influenced the government organisation decision on XBRL adoption. The findings are consistent with Pudjianto et al. (2011) and Troshani et al. (2011).

A programme sponsor refers to the government agency that is responsible for organizing and is committed to developing ${ }^{57}$ a particular XBRL project in New Zealand. The programme sponsor is also known as the lead agency. Two government agencies, the IRD and the MED were involved as programme sponsors for specific XBRL initiatives. The IRD provided sufficient commitment, support, leadership, and priority in funding during the e-GIF project. However, the decision to shift the initiative from the IRD to the MED changed the whole

\footnotetext{
${ }^{54}$ http://www.businessdictionary.com/definition/champion.html

55 https://www.mindtools.com/pages/article/newLDR 41.htm

${ }^{56}$ http://www.businessdictionary.com/definition/leadership.htm

57 http://www.businessdictionary.com/definition/sponsor.html
} 
picture related to adopting XBRL in New Zealand because the MED did not give the same attention to the XBRL initiative as the IRD had. Even though this factor only appeared in the e-GIF project, it did influence the government decision and became one of the key elements in the organisational context. Thus, it is suggested that a change of programme sponsor inhibits XBRL adoption and is a possible influencing factor in technology adoption, especially by government organisations.

\section{Environmental Context}

There are five additional factors in the environmental context. Knowledge gap was found to be an influencing factor in adopting the LEAP+ project. Then in Project First Step, a change of laws, rules, and regulations was believed to have influenced stakeholders' adoption decisions. During the e-GIF project, another factor was found: the culture of government agencies working independently. The SBR programme added another two factors: a change in government and the global financial crisis. With the addition of these five factors, the total number of influencing adoption factors is now nine under the environmental context.

Tichenor, Donohue, and Olien (1970) discuss the knowledge gap from the mass communication perspective and argued that populations with higher socioeconomic status tend to acquire information at a faster rate than those with lower status, so the gap in knowledge between these segments tends to increase rather than decrease. In this thesis, knowledge gap refers to the difference in the level of knowledge and skills about XBRL technology between those actively involved in XBRL initiatives and the stakeholders who are just observers. In addition, the interested parties in each of the XBRL projects had a different set of understandings of, expectations about, and needs from, XBRL technology. Additionally, as discussed in Section 9.1.1, ineffective promotion, and communication can lead to a knowledge gap. From the LEAP+ project to the SBR programme, the initiative groups slightly improved their promotion activities but maintained communication channels about XBRL to stakeholders at a low level. In some situations, stakeholders demanded information related to XBRL. However, the initiative groups did not deliver the required information to stakeholders. As a result, the knowledge gap increased between these groups and stakeholders. This factor becomes a barrier and influences the government's and the private organisations' decision to adopt XBRL. Furthermore, with the existence of a knowledge gap, the stakeholders have difficulty in evaluating the relative advantage of 
using XBRL or seeing XBRL as a solution to their problem in business reporting. Moreover, they might think that XBRL is complex. The absence of knowledge and information also leads to a lack of a champion, a lack of stakeholder involvement and no critical mass. Troshani and Doolin (2005) noted that the lack of education among employees in organisations could potentially affect the low adoption of XBRL in Australia. Pinsker and Li (2008) also suggest that a relative paucity of XBRL adoptions worldwide might be due to the lack of insight and guidance regarding various adoption issues. From that, it is suggested that a knowledge gap is a potential influencing factor in technology adoption.

A change of law is the modification of the law to improve $i^{58}$. In addition to statutes, it includes any change in rules and regulations related to XBRL matters. Pinsker and Li (2008) suggest that regulation significantly stimulates adoption. The SEC's XBRL filing programme stimulated corporate interest in XBRL. In New Zealand, there were some change of laws, rules, or regulations that potentially impacted on XBRL adoption, such as the introduction of IFRS in 2003, the introduction of the Financial Reporting Amendment Act (FRA) in 2006 and IFRS mandatory adoption in 2007. The introduction of IFRS shifted ICANZ's focus from potentially adopting XBRL to preparing for adopting IFRS. The FRA could have been positioned as a substitute or complement to XBRL technology, as both the FRA and XBRL have the ability to reduce the compliance cost of reporting by business organisations. However, in New Zealand, the government did not choose to complement the FRA with XBRL. Instead, it chose to use the FRA alone, as it was the cheaper option. Further, with the mandatory adoption of IFRS, most of the stakeholders' attention was diverted to IFRS matters. That means for every change of laws, rules or regulations; the XBRL initiative groups needed to compete for stakeholders' attention. However, they did not succeed. A lack of championship, ineffective promotion and communication and the missing mandatory adoption strategy meant it did not happen. Based on these findings, it is suggested that a change of laws, rules, and regulations inhibit XBRL adoption. This factor in particular influenced the private organisations' adopting decision. This finding provides empirical evidence and support the conjecture by Steenkamp and Nel (2012) that legislation appears to have influenced the adoption of XBRL in South Africa.

${ }^{58}$ http://thelawdictionary.org/change/ 
The culture of working independently refers to the way government agencies operate ${ }^{59}$ in New Zealand, where each agency prefers to work alone or separately without influence from or control by other agencies ${ }^{60}$. The analysis revealed that most of the government agencies preferred and were comfortable with working independently. Each agency wanted autonomy in its decision-making and to have full control of its operations. That culture and the idea of XBRL contradicted one another. While XBRL promotes data sharing among the government agencies, the culture rejects the idea, as the agencies would need to depend on another agency for some data. In certain conditions, they believed that this would delay the decision-making process or result in inefficient operations. Further, the agencies argued that every agency has different needs and motivations. Moreover, each agency wanted to protect their data. In contrast, XBRL supporters argued that XBRL could transform the way government operated and delivered its services to the public, reducing the cost and time to process the same data. Thus, it would support the decision-making process and improve government operations. Additionally, XBRL had security standards that would protect all data in the system. However, not all government agencies were able to see or accept these benefits. Some were comfortable with their current information system. Other agencies could see no reason to change their culture. Thus, the XBRL initiative groups faced difficulties in convincing each of the government agencies to use XBRL for business reporting. This factor existed in the e-GIF and SBR programme, which suggests the culture of working independently, influenced the government organisations decision on adopting $\mathrm{XBRL}$ technology. Therefore, this factor is a barrier and contributes to the non-adoption of XBRL. This finding is supported by Pudjianto et al. (2011). Slightly differently in an Italian study, Rosa and Caserio (2013) found adopting XBRL could lead to new IT skills and competence, which could affect the accounting and reporting activities and thus, a resistance to change is likely to happen.

A change of government is a shift of political power from one political party to another through a general election ${ }^{61}$. In New Zealand, the $49^{\text {th }}$ General Election in 2008 resulted in a new National-led government. The Labour Party had initiated the XBRL projects in 2003. However, after the general election in 2008, the National Party had to decide whether to adopt XBRL or not. The observations from stakeholders like the government agencies,

\footnotetext{
${ }^{59}$ http://www.merriam-webster.com/dictionary/culture

${ }^{60} \mathrm{http}: / /$ dictionary.reference.com/browse/independently

${ }^{61}$ https://en.wikipedia.org/wiki/Regime change
} 
business organisations, and universities, were that the Labour Government had applied a 'light and soft' approach to their leadership. They had invited the public to join and work with them. In contrast, the National Government had applied a 'strong and hard' approach to their management. They forced and commanded the public to follow their instructions. That explains why the Labour Government did not mandate XBRL technology during the eGIF project. They wanted the stakeholders to learn about and be ready for XBRL adoption. On the other hand, the National Government 'liked' the XBRL idea but the economic conditions during that time made it infeasible to adopt XBRL. Therefore, they decided to cut funding in 2009 and eventually, froze the budget in 2010 for any XBRL-related activities. This suggests a change of government inhibited XBRL adoption.

The global financial crisis affected all economic activity. Even though the impact was not immediate, slowly it killed the XBRL initiatives. During the crisis, money dried up, and almost all resources became limited ${ }^{62}$. The government, for example, had to restructure their budget and prioritize areas. The government decided to prioritize education and health. That meant that during and after the global financial crisis, government focused its budget on the basic needs of the public and reducing its own operating costs. As adopting technology requires a large investment and adopting XBRL was not considered a basic need, XBRL initiatives were not a priority in the government budget and funding was cut. Based on that finding, the global financial crisis is a potential influencing factor and inhibited the government decision to adopt XBRL. This finding is in contrast to prior studies like Melvin and Tylor (2009) and Steenkamp and Nel (2012) who suggest that the world-wide economic turmoil did not affect business organisations' decision to implement XBRL. Furthermore, less than quarter of Melvin and Tylor's (2009) respondents thought the process to implement XBRL was delayed or postponed due to the economic conditions.

Based on the above discussions, Table 9.2 summarises the unpredicted factors that were found during the analysis phase. Some factors affect organisations with different intensity. For example, the copyright issue and a change of laws, rules and regulations did not directly influence the government decision. Factors like the instability of the XBRL specification and taxonomy, and a limited range of tools and software influenced the private organisations' decision. Meanwhile, factors such as not being perceived as a problem solver, ineffective

\footnotetext{
${ }^{62}$ http://www.businessdictionary.com/definition/global-financial-crisis.html
} 
leadership, a knowledge gap, and a change of government highly influenced the organisations, especially the government decision not to adopt XBRL.

Table 9.2 Summary of Unpredicted TOE Context Factors for XBRL Initiatives

\begin{tabular}{|c|c|c|c|c|c|c|c|c|c|c|c|c|c|c|}
\hline & \multicolumn{4}{|c|}{ Technological } & \multicolumn{5}{|c|}{ Organisational } & \multicolumn{5}{|c|}{ Environmental } \\
\hline & 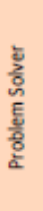 & $\frac{\overline{5}}{\frac{5}{8}}$ & $\begin{array}{l}\text { z } \\
\text { 㖕 } \\
\text { 心 }\end{array}$ & 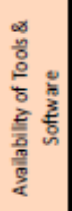 & 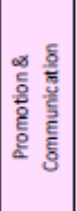 & $\begin{array}{l}\text { E్ } \\
\text { 酸 } \\
\text { है }\end{array}$ & 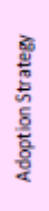 & 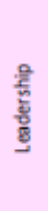 & 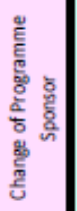 & 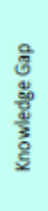 & 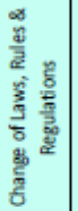 & 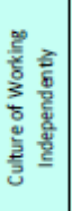 & 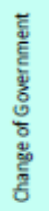 & $\begin{array}{l}\frac{5}{5} \\
\frac{5}{0} \\
\frac{\pi}{c} \\
\frac{\pi}{4} \\
\frac{\pi}{\pi} \\
\frac{8}{6}\end{array}$ \\
\hline \multicolumn{15}{|c|}{ LEAP+ } \\
\hline Ernst \& Young (A) & & - & & & + & - & & & & & & & & \\
\hline University of Auckland (A) & - & - & & & - & & & & & - & & & & \\
\hline Professional Magazines $(\mathrm{O})$ & & - & & & & & & & & & & & & \\
\hline \multicolumn{15}{|c|}{ Project First Step } \\
\hline OAG (A) & & & - & & + & - & & & & - & - & & & \\
\hline IRD (A) & & & & & & - & & & & - & & & & \\
\hline Ernst \& Young (A) & - & & & & & & & & & & & & & \\
\hline KPMG (A) & - & & & & - & & & & & & & & & \\
\hline NZICA (Steering Committee) (A) & & & - & - & - & + & - & & & - & - & & & \\
\hline University of Auckland (A) & - & & & & & - & & & & & & & & \\
\hline Treasury (O) & - & & & & + & & & & & & & & & \\
\hline University of Otago $(O)$ & - & & & & - & - & & & & & & & & \\
\hline Newspapers (O) & & & & & & + & - & & & & & & & \\
\hline \multicolumn{15}{|c|}{ e-GIF } \\
\hline $\operatorname{IRD}(\mathrm{A})$ & + & & & - & & + & & + & - & & & - & & \\
\hline \multicolumn{15}{|l|}{ MED (A) } \\
\hline $\operatorname{SSC}(\mathrm{A})$ & & & & & - & & & & - & & & - & & \\
\hline NZICA (S) & & & - & & - & & + & - & & - & & & & \\
\hline Tax Management Consulting Firm (S) & & & & & & & & + & - & & & & & \\
\hline OAG (O) & & & & & & & & & & - & & & & \\
\hline \multicolumn{15}{|c|}{ SBR } \\
\hline IRD (A) & & & & & & & + & - & & & & & - & \\
\hline MED (A) & - & & & & & & & & & & & - & - & - \\
\hline $\operatorname{SSC}(\mathrm{A})$ & + & & & & & & - & - & & & & - & - & \\
\hline NZICA (A) & & & & & & & + & & & - & & - & 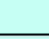 & - \\
\hline XRB (S) & - & & & & - & - & - & - & & - & & & - & \\
\hline Tax Management Consulting (S) & - & & & & & & & - & & & & & - & \\
\hline Treasury (O) & - & & & & & & & & & - & & & - & \\
\hline Grant Thornton (O) & & & & & & & & & & & & & & - \\
\hline Management Consultancy Firm (O) & - & & & & & & & & & & & - & & \\
\hline University of Otago $(\mathrm{O})$ & - & & & & & & & & & - & & & - & - \\
\hline University of Hawai'i (O) & - & & & & & & & & & & & & & \\
\hline Results & $\mathrm{x}$ & $\mathrm{x}$ & $\mathrm{x}$ & $\mathrm{x}$ & $\mathrm{x}$ & $\mathrm{x}$ & $\mathrm{x}$ & $\mathrm{x}$ & $\mathrm{x}$ & $\mathrm{x}$ & $\mathrm{x}$ & $\mathrm{x}$ & $\mathrm{x}$ & $\mathrm{x}$ \\
\hline
\end{tabular}

(A): Active ; (S): Supportive ; (O): Observer

+: Driver, Facilitating, Encourage; - : Hinder, Inhibitor, Challenge

v: Facilitating adoption; $\mathrm{X}$ : Inhibiting adoption

The findings of the unpredicted factors were considered as new findings in the context of non-adoption of XBRL. However, the factors need to be further validated with other literature outside accounting and IS areas. This is especially important when the unpredicted factors are similar to the predicted one. For example, under the technological context, there are two factors, relative advantage (predicted factor) and problem solver (unpredicted factor), which have some similarity. Since the researcher had a different definition for relative advantage (based on the literature) to the one given by the 
interviewees which is referred to as problem solver (as shown in Appendix B), this thesis presents the factors as two different items under the technological context. Literature outside accounting and IS areas may in time confirm that these are the same factor. In addition, the unpredicted factors could be validated by other researchers in the future.

\subsubsection{Further Analysis: The TOE Contexts}

Pinsker and Li (2008) suggest there may not a single right way to make the adoption decision. It may be a combination of top management or companies IT managers' efforts and depend on corporate culture, being technologically savvy and other factors. As such, through the historical overview in Chapter 5, this thesis suggests the non-adoption of XBRL in New Zealand happened because of a combination of influencing factors. In Chapters 6 and 7 , the factors were discovered by examining the XBRL initiative under the professional organisational as well as government auspices. Additional analysis of the TOE context provides more understandings on the phenomenon of non-adoption of XBRL as summarised in Table 9.3. This table shows that adoption-influencing factors are a combination from technological, organisational, and environmental contexts.

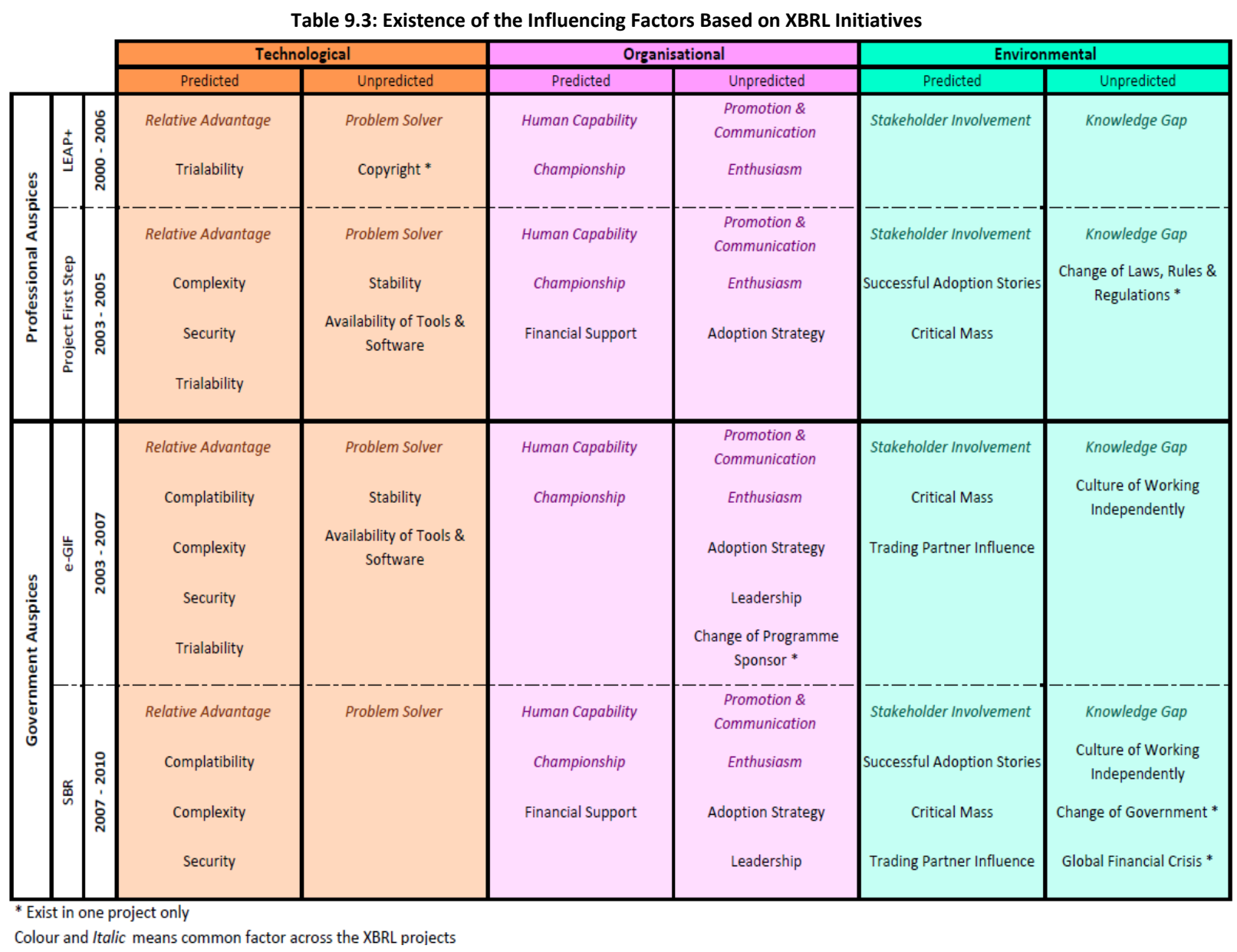


Within the technological context, no relative advantage and not being perceived as a problem solver were the common factors throughout the XBRL projects. Factors like trialability, instability of XBRL specification and taxonomy, and a limited range of tools and software are time-based factors. After 2007, XBRL International resolved the related issues of the maturity and stability of the XBRL specification and taxonomy. Additionally, more tools were made available, and software embedded with XBRL functionality was developed. However, other factors such as compatibility, complexity, and security of XBRL remained until 2010. Additionally, copyright only appeared once during the LEAP+ project, as XBRL International addressed this issue early at an international level.

Under the organisational context, more factors were found to be common across the projects: a lack of human capability, no championship, ineffective promotion and communication, and over-enthusiasm among experts. Insufficient financial support appeared during Project First Step and the SBR programme as these projects would have changed the way organisations operated and interacted, suggesting a need for significant investment, which was not forthcoming. In 2003 to 2010, the Working Groups of respective projects decided against a mandatory adoption strategy. Furthermore, XBRL initiatives under the government auspices had inefficient leadership. The change of programme sponsor as a factor only existed in the e-GIF project, and could be related to a lack of championship and leadership.

In the environmental context, there were only two common factors, a lack of stakeholder involvement and a knowledge gap. Limited successful adoption stories was a factor during Project First Step and the SBR programme because there were no successful adoptions of XBRL in the previous initiatives that could encourage a wide range of stakeholders to adopt XBRL. From 2003 to 2010, the Working Group of Project First Step, e-GIF and SBR faced insufficient critical mass. This is potentially related to the failure to make XBRL adoption mandatory. Meanwhile, factors like trading partner influence and a culture of working independently only appeared when the projects were under the government auspices, possibly, as New Zealand's trading partners were adopting XBRL for business reporting purposes and government agencies were comfortable with their existing information systems and ways of operating. Change of laws, rules, and regulations appeared once in Project First Step during the voluntary adoption of IFRS in 2005. Likewise, change of government and global financial crisis only existed in the SBR programme. 
In terms of contextual influence, the number of technological context factors increased from the LEAP+ until the e-GIF projects, which suggests the technological context created the most concerns, needing more attention and significantly influenced XBRL initiatives from 2000 until 2007. However, the number of technological factors decreased in the SBR programme. The technological context thus became less critical as more research was conducted and many issues associated with XBRL technology had been addressed. The number of organisational context factors steadily increased during the first three XBRL initiatives. However, as in Figure 9.1, the organisational context became stable (under the government projects) as organisations realised they need to prepare their organisations for XBRL. In other words, the organisational context remained significant under the professional and governmental XBRL initiatives. The environmental context is slightly different because the numbers of influencing factors continue to increase. Nonetheless, there were factors like a change of laws, rules, and regulations, a change of government and the global financial crisis that appeared once as unpredicted factors but influenced the organisational decision on XBRL adoption. Thus, potential adopters of XBRL should focus more on the environmental context as it appears to become more significant, particularly under governmental projects.

Figure 9.1: Influence of TOE Context on XBRL Initiatives

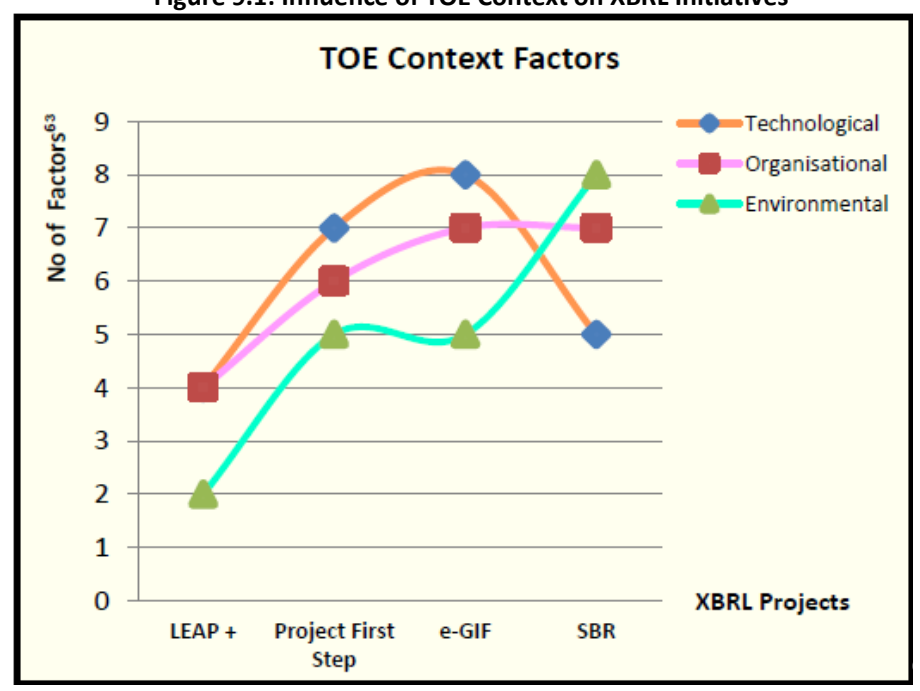

\subsubsection{Further Analysis: The Stakeholder Involvements}

This section analyses the TOE contexts in relation to the stakeholder views and XBRL initiatives. As discussed in Chapter 6 (Section 6.1 .2 and Section 6.5.2) and Chapter 7

\footnotetext{
${ }^{63}$ No of factors refers to the existing number of factors in every context.
} 
(Section 7.1.2 and 7.6.3), stakeholder involvement can be classified into active, supportive and observer groupings. Analysing the involvement of each stakeholder grouping contributes to the understanding of XBRL development in New Zealand.

The majority of active and supportive stakeholders stated the non-adoption of XBRL has implications for stakeholders. Moreover, as would be expected, active and supportive stakeholders revealed most of the findings related to the unpredicted factors (see Table 9.2). In contrast, in Chapter 8 (Section 8.3), the observer stakeholders believed that the government's decision has no implication for XBRL stakeholders. Thus, they have different views of how non-adoption of XBRL influenced the stakeholders. Further analysis between the TOE contexts and the classification of stakeholder involvement reveals a difference in emphasis on the TOE contexts in the four XBRL projects. Below the results of the analysis are summarized.

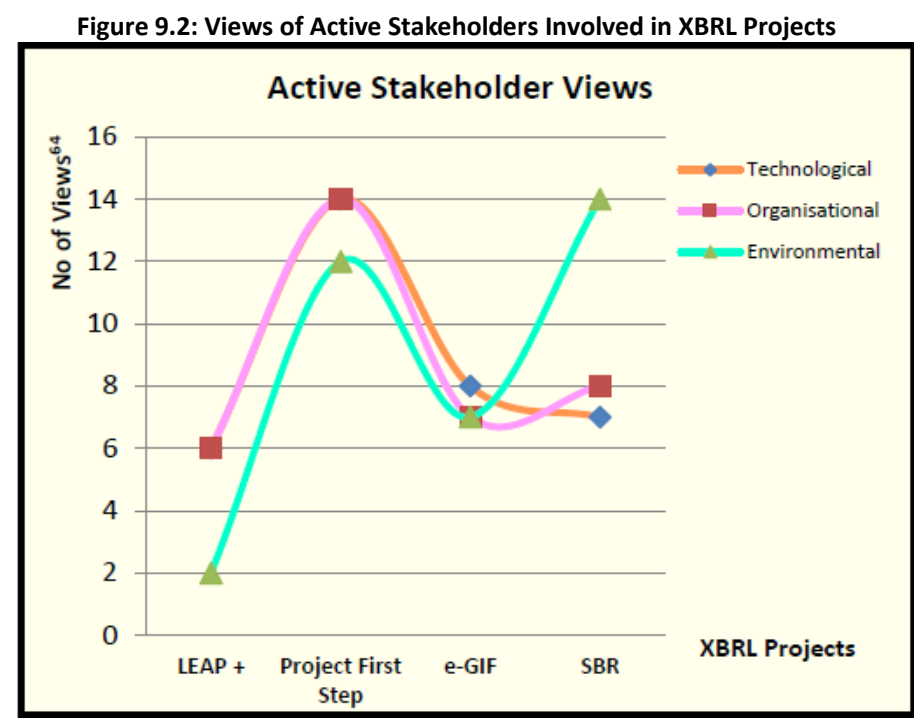

Figure 9.2 shows that active stakeholders prioritized the technological and organisational contexts, when the projects were under the auspices of professional organisations. During that time (2000-2006), XBRL was considered new. Only a few people knew about XBRL. Thus, active stakeholders thought technological and organisational factors needed more attention. Meanwhile for projects under government auspices, the active stakeholders viewed environmental and organisational contexts as the most critical context that resulted in non-adoption of XBRL. Further, as more became known about XBRL, and its capabilities in aiding business reporting, and as it was implemented internationally, the environmental

\footnotetext{
${ }^{64}$ No of views refers to number of stakeholder views on each context.
} 
context became important, which happened during 2007-2010. However in New Zealand, other factors under the environmental context affected non-adoption of XBRL including two one-off unpredicted factors; the global financial crisis and change of government, along with a culture of working independently in government agencies.

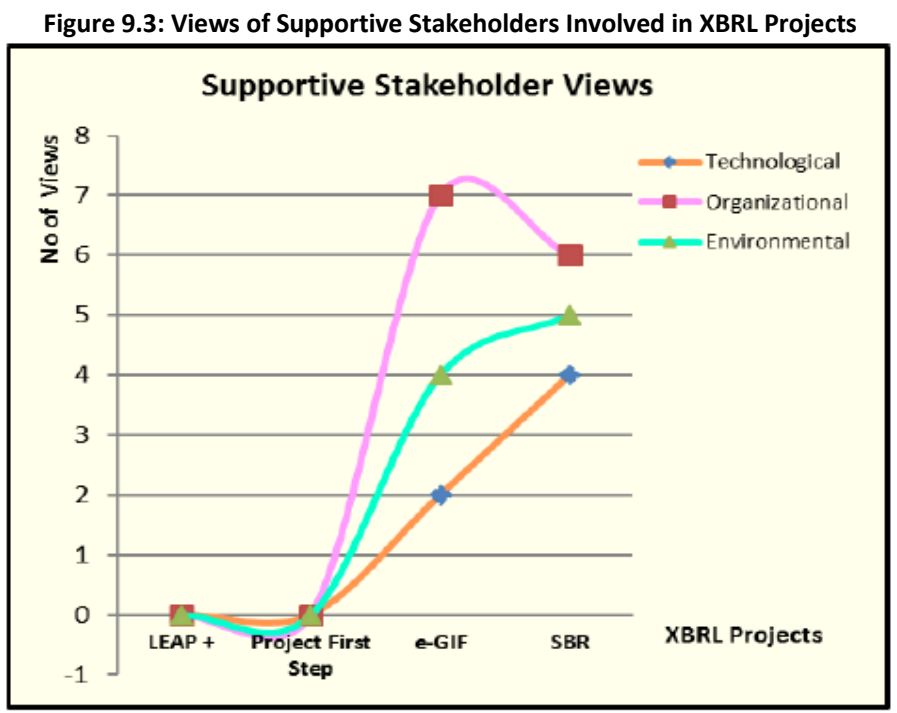

Supportive stakeholders also emphasised organisational and environmental contexts but placed different degrees of importance on these. As in Figure 9.3, no supportive stakeholders were involved in the two XBRL projects under the auspices of professional organisations. However, under the government projects, supportive stakeholders' views emphasised the organisational context. They placed priority on addressing organisational issues such as no championship, a lack of human capability and ineffective promotion and communication.

Figure 9.4: Views of Observer Stakeholders Involved in XBRL Projects

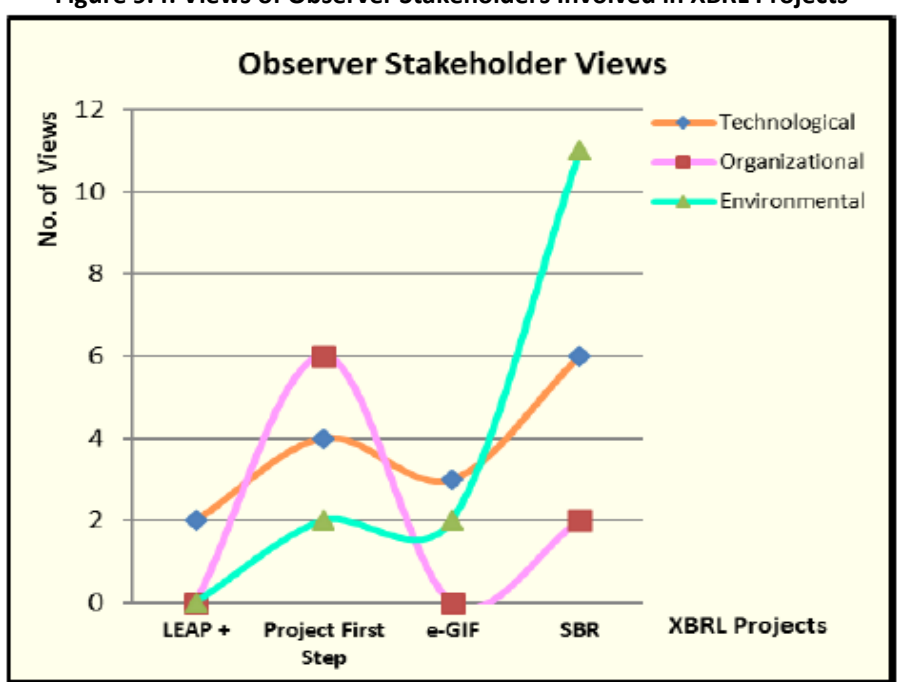


Figure 9.4 shows that like the active stakeholders, observer stakeholders' focused more on the organisational and technological contexts, for the professional projects. However, the observer stakeholder views shifted to the technological and environmental context factors when the XBRL initiatives were under the auspices of government organisations. That potentially happened because observer stakeholders were not directly involved with the government projects and limited information was made available to them.

Based on the above discussion, two important points emerge. First, stakeholder views depend on their knowledge, experience, and interest in XBRL, and the availability of information. For instance, active stakeholders were involved closely with XBRL initiatives and they contributed ideas, attended meetings, and devoted their time and energy to XBRL projects. Thus, they had more information regarding XBRL initiatives in New Zealand. Even though supportive stakeholders contributed ideas and attended meetings, they were not involved as active stakeholders because they did not have a vested interest in the projects and they could not 'vote' for any decision. Additionally, their involvement could be limited to certain periods, particularly if they were paid consultants. Meanwhile, observer stakeholders' views were limited because they had only a passing interest in the XBRL initiative, and information about these XBRL projects was not widely available. Thus, because of their different backgrounds, each stakeholder constructed their own view.

Second, there seems to be a learning curve for each stakeholder. The active stakeholders had little knowledge about XBRL during their first involvement in the project under professional auspices. Active stakeholders gained experience while running the LEAP+ project. Then, they continued to learn, develop, and increase their understandings of XBRL in Project First Step. For example, in the LEAP+ project, the collaboration group developed a website based on XBRL technology. They identified XBRL requirements such as tools and software, and the need for human capability. Based on their experience in the LEAP+ project, the active stakeholders built a suitable XBRL application during Project First Step. This exercise was easier because of their prior experience. As XBRL initiatives shifted to governmental auspices in 2006, active stakeholders again had to learn about XBRL in a government context. Thus, in the e-GIF project, they had little knowledge on XBRL use for business reporting from the government perspective. The need for learning was reduced in the SBR programme as they understood and became familiar with the idea of using XBRL for e-government purposes. For instance, in the e-GIF project, active stakeholders developed 
and trialled XBRL applications in their agencies. During the SBR programme, they did not have to build any XBRL applications because during the e-GIF project, they had proved that $\mathrm{XBRL}$ technology is compatible with the government information systems.

The learning curve was different for supportive stakeholders, as it only started during the eGIF project. Moreover, their involvement was based on their technical knowledge and experience of global adoption of XBRL. They just needed to understand the New Zealand adoption scenario from the government context. Therefore, their learning curve was not as significant.

\subsubsection{Further Analysis: The Stakeholder Groups}

This section analyses the TOE context in relation to the views of stakeholder groups and XBRL projects. As discussed in Chapter 3 (Section 3.3), stakeholder groups are divided into government agencies, accounting firms, professional bodies, business organisations and other stakeholders. Analysing the groups' views contribute to the understanding of which context factor is the most important and how interest among the stakeholder groups changes over time.

In every project, the government agencies steadily increased their understanding on XBRL, as depicted in Figure 9.5. Moving from the LEAP+ project to the SBR programme, this group identified more issues relating to the environmental and organizational context, which needed to be addressed. In contrast, though the technological context was important during the e-GIF, government agencies viewed it as less important in the SBR programme.

Figure 9.5: Views of Government Agencies in XBRL Projects

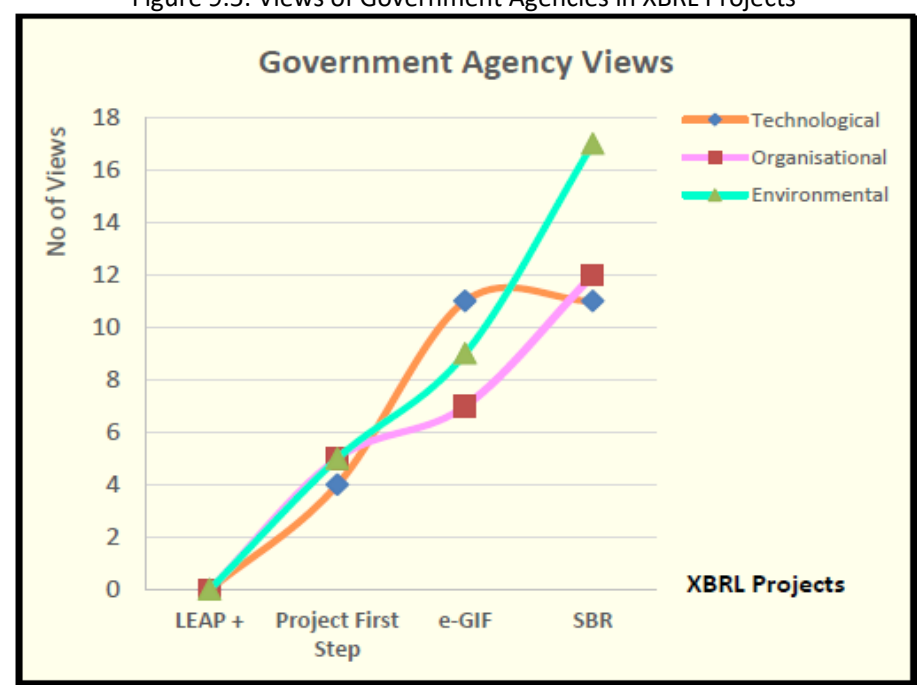


The accounting firms group had slightly different views from the government agencies. In the beginning, the organisational context was considered important but toward the end, this context became less significant. Instead, the technological and environmental contexts were more important from this group's perspective as shown in Figure 9.6.

Figure 9.6: Views of Accounting Firms in XBRL Projects

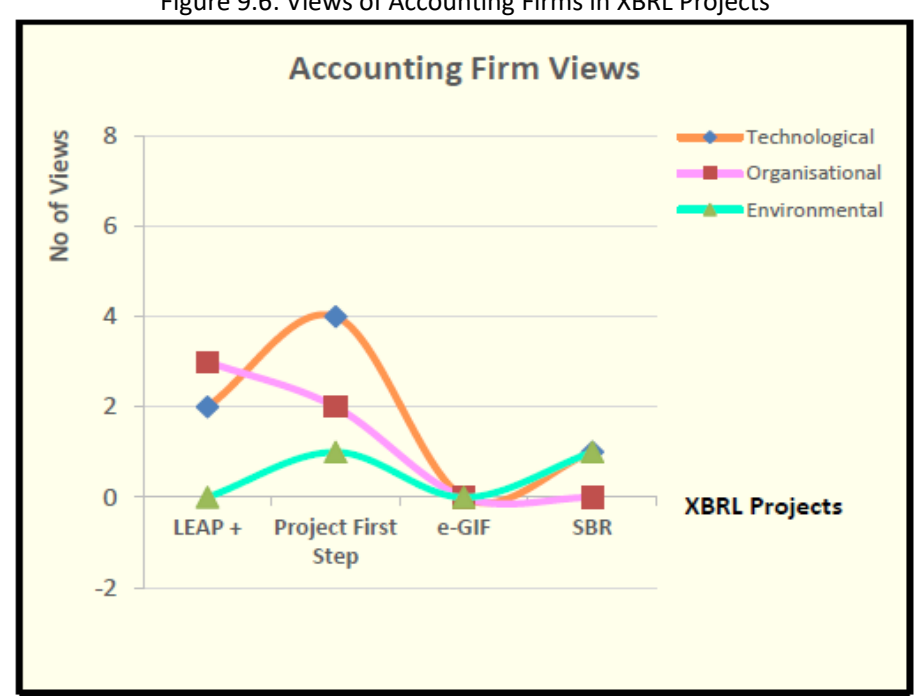

In Figure 9.7, the professional bodies viewed factors relating to the technological context as important in the early XBRL initiatives. At the same time, this group perceived there were no important issues related to environmental and organizational contexts. However, this view changed over time, and more issues related to the environmental context were addressed toward the end of XBRL initiatives in New Zealand.

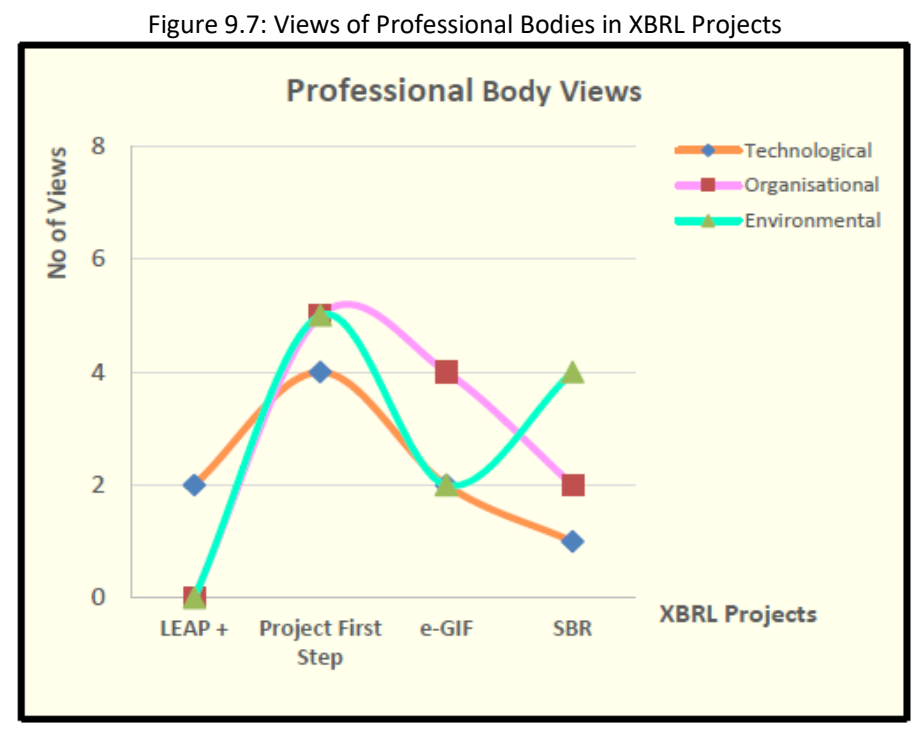

The business organisations group viewed the technological and organizational factors as important contexts in Project First Step. Then, slowly they realised that there were more 
influencing factors related to the environmental context that needed to be addressed as illustrated in Figure 9.8.

Figure 9.8: Views of Business Organisations in XBRL Projects

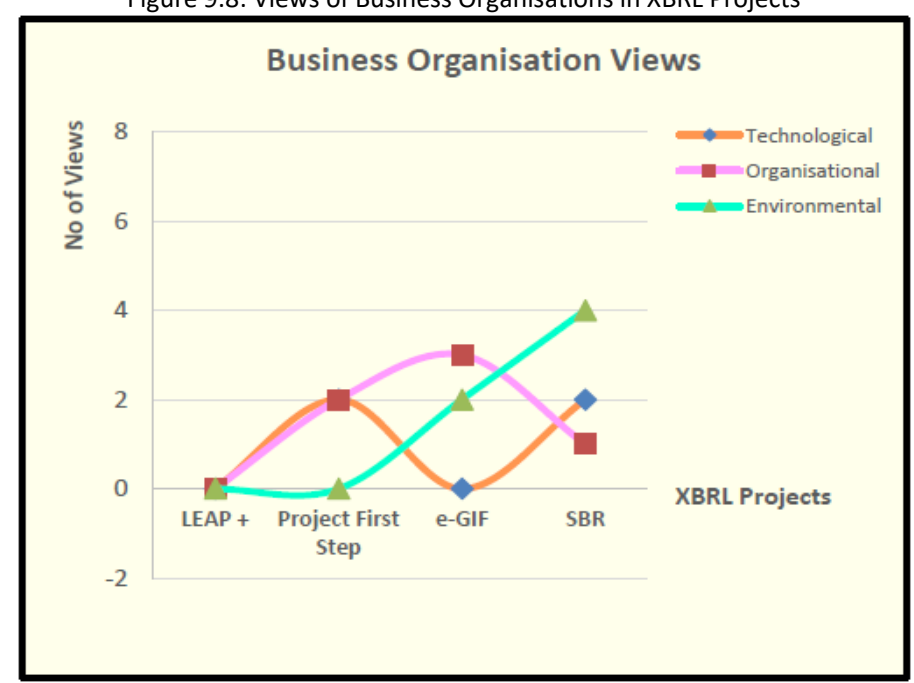

In Figure 9.9, the other stakeholders group viewed the technological and organisational contexts as more important during the early XBRL initiatives. Over time, this group changed their views and the environmental context became more important.

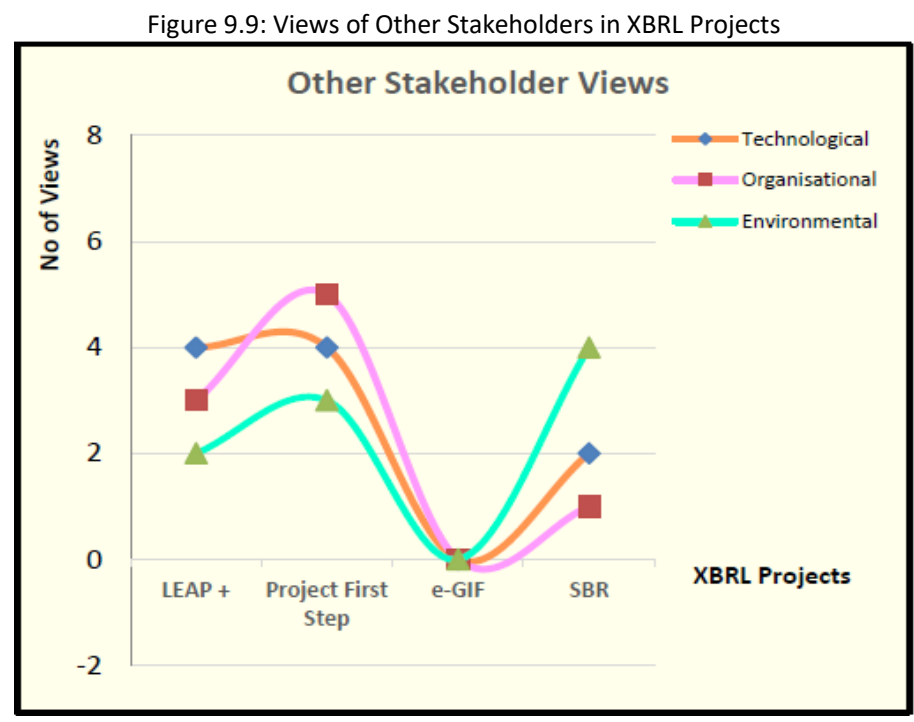

Based on the above discussion, it can be seen that first, each of the stakeholder groups views change over time. The changes of views as discussed earlier (in Section 9.1.4) were based on the stakeholder's knowledge, experience or exposure, and interest in XBRL. Second, government agencies and professional bodies stakeholder groups perceived that the importance of an influencing context could be prioritised. Both of these groups were the lead organisation for the XBRL projects. The professional body (NZICA) was the lead organisation for Project First Step, IRD led the e-GIF project, and MED led the SBR 
programme. Finally, by combining the stakeholder group views it can be seen that all the stakeholders groups agreed that environmental was the most significant influential context, followed by technological and organisational, in the non-adoption of XBRL in New Zealand (as represented by the SBR project), and depicted in Figure 9.10.

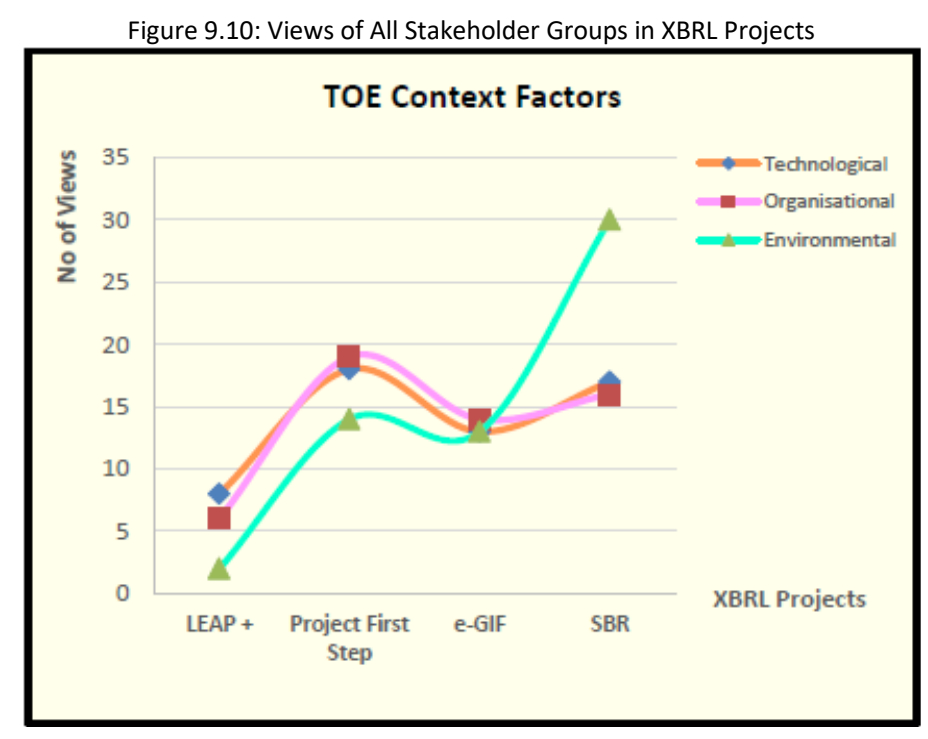

Further, based on the analysis above, this thesis suggests that more issues related to the technological context arose during the early proposals to introduce XBRL technology. As stakeholders started to develop their understanding of XBRL, and gain knowledge and experience on XBRL related matters, the environmental context started to become an important context and needed further attention. Meanwhile, the organisational context remained important throughout the XBRL development in New Zealand. These results are consistent with previous studies including Barua, Konana, Whinston and Yin (2004), Zhu et al. (2006), Al-Qirim (2007) and Oliveira and Martins (2010).

\subsection{Implications of the Non-Adoption of XBRL}

This thesis has addressed the second research question:

What are the implications of the government decision regarding XBRL use in business reporting for $X B R L$ stakeholders?

Any government decision is believed to affect, stakeholders in someway economically. For example, if the government decides to mandate XBRL adoption, economically-orientated advantages and disadvantages will ensure. The advantages could include reducing compliance costs, providing quality financial information, and having shared databases that 
support decision-making. Potentially, negative impacts for stakeholders include staff becoming redundant, the adoption of a new set of rules, and adjusting the culture to new tasks or operations (Doolin and Troshani, 2007).

In the case of New Zealand, the government decided not to adopt XBRL. Interviewees had two different views regarding the government's decision. One set of interviewees, particularly from the active and supporting stakeholders, believed the government's decision had implications for stakeholders. In contrast, the interviewees from the observer stakeholders believed there were no implications for stakeholders.

The active and supportive stakeholders considered that the government decision affected the stakeholders in both the short-term and long-term. In the short-term, three implications for government agencies were identified: being unable to perform specific data analysis, limiting the ability to share data among government agencies and losing the opportunity to remove inefficient processes in the governmental system. Accounting firms and accounting professional bodies face a lack of XBRL skill development and missed opportunities to free up time for other purposes. There are also two implications for business organisations: difficulties in accessing and connecting with government agencies or other businesses and not benefitting from reduced compliance costs.

Similarly, there are long-term implications of the non-adoption of XBRL for stakeholders. In the long-term, government agencies like the IRD and the MED have reduced their ability to detect errors and mistakes in the financial statements that are submitted to them. Without quality financial data and information, the agencies potentially have future difficulties when making policies related to business reporting and economic development (Chen, 2012). Moreover, the government will continue to work in an unintegrated or unconnected manner because government agencies maintain their culture of working independently.

In the long-term, accountants in accounting firms and accounting professional bodies have had to accept the cost of abandoning applications that were developed during the LEAP+, Project First Step and e-GIF projects. Although, XBRL supporters from accounting firms and accounting professional bodies invested much effort, time, or money, in the end, the XBRL applications developed were redundant. Many supporters felt disappointed and thought it was a waste. Additionally, there is a possibility that accountants in New Zealand will be left behind regarding XBRL technology because of limited knowledge development in 
accounting-related areas such as in education, innovation, and skills. Eventually, this may limit New Zealand trained accountants' ability to compete with overseas accountants and to work overseas.

Most business organisations aim to make a profit. One way to do this is to increase their productivity. The introduction of XBRL to business organisations could help them to achieve this by assisting them in their operations (Bharosa et al., 2013). As financial statements could be prepared, submitted, and analysed with XBRL based applications, it would enable organisations to focus on their core business. Given that, most New Zealand businesses are SMEs; these business organisations do not have the same resources and capabilities as large companies. Thus, if reporting burdens and other financial requirements increase in the future, the SMEs may face an increase in compliance costs, which impacts their ability to operate effectively.

Table 9.4: Comparisons of Findings with Existing Literature on Implications for Stakeholders

\begin{tabular}{|c|c|c|c|}
\hline Study & Context & Stakeholder & Implication of XBRL Adoption \\
\hline $\begin{array}{l}\text { Yoon et al. } \\
(2011)\end{array}$ & Korea & $\begin{array}{l}\text { - Business } \\
\text { Organisations }\end{array}$ & - Reduce information asymmetry \\
\hline Chen (2012) & $\begin{array}{l}\text { US, The } \\
\text { Netherlands, } \\
\text { Australia and } \\
\text { Singapore }\end{array}$ & - Government & $\begin{array}{l}\text { - Increase accountability and transparency } \\
\text { - Improve the ease of public dissemination and analysis }\end{array}$ \\
\hline $\begin{array}{l}\text { Bharosa et al. } \\
\text { (2013) }\end{array}$ & $\begin{array}{l}\text { The } \\
\text { Netherlands }\end{array}$ & $\begin{array}{l}\text { - Government } \\
\text { Agencies } \\
\text { - Business } \\
\text { Organisations }\end{array}$ & $\begin{array}{l}\text { - More efficiency } \\
\text { - Higher information quality } \\
\text { - Reduce redundant controls }\end{array}$ \\
\hline $\begin{array}{l}\text { Shan and } \\
\text { Troshani } \\
(2014)\end{array}$ & US & $\begin{array}{l}\text { - Accountants } \\
\text { - Auditors }\end{array}$ & $\begin{array}{l}\text { - Reduce audit costs } \\
\text { - Enhance the credibility and reliability of financial } \\
\text { statements }\end{array}$ \\
\hline $\begin{array}{l}\text { Umoren and } \\
\text { Jeremiah } \\
\text { (2015) }\end{array}$ & Nigeria & - Accountants & $\begin{array}{l}\text { - Enhance financial reporting comparability across } \\
\text { companies } \\
\text { - Increase understandability and relevant of XBRL-based } \\
\text { financial reports }\end{array}$ \\
\hline Study & Context & Stakeholder & Implication of XBRL Non-Adoption \\
\hline \multirow[b]{2}{*}{$\begin{array}{l}\text { David (2016) } \\
\text { (This thesis) }\end{array}$} & \multirow[b]{2}{*}{ New Zealand } & $\begin{array}{l}\text { - Government } \\
\text { agencies }\end{array}$ & $\begin{array}{l}\text { Short-term } \\
\text { - Unable to perform specific data analysis } \\
\text { - No data sharing among government agencies } \\
\text { - Lost opportunity to remove inefficient processes } \\
\text { Long-term } \\
\text { - Difficulty in detecting errors and mistakes } \\
\text { - Difficulty in getting data and information } \\
\text { - Continue to work in an unintegrated or unconnected } \\
\text { manner }\end{array}$ \\
\hline & & $\begin{array}{l}\text { - Accounting } \\
\text { firms } \\
\text { - Accounting } \\
\text { Professional } \\
\text { Bodies }\end{array}$ & $\begin{array}{l}\text { Short-term } \\
\text { - Lack of XBRL skill development } \\
\text { - Missed opportunity to free up time } \\
\text { Long-term } \\
\text { - Waste of costly unused applications } \\
\text { - Limits overseas employment opportunities }\end{array}$ \\
\hline
\end{tabular}




\begin{tabular}{|c|c|c|c|}
\hline & & $\begin{array}{l}\text {-Business } \\
\text { Organisations }\end{array}$ & $\begin{array}{l}\text { Short-term } \\
\text { - Difficulty in accessing and connecting with government } \\
\text { agencies or other businesses } \\
\text { - Compliance costs not reduced } \\
\text { Long-term } \\
\text { - Ineffective business operations }\end{array}$ \\
\hline
\end{tabular}

Table 9.4 presents the comparison of prior literature with this thesis's findings regarding potential implications for stakeholders. There are three differences between this thesis and the prior literature. First, this thesis identifies the implications of non-adoption of XBRL, while prior literature identified the implications of adopting XBRL. Second, the implications were categorized into short-term and long-term for each relevant stakeholder group. Finally, the findings are not specific to one group of stakeholders. As in Chapter 3 (Section 3.3), five stakeholder groups were identified. However, only four stakeholder groups were potentially affected by the government decision as in Table 9.4. The previous studies only considered one or two stakeholders when examining the implications of adopting XBRL.

\subsection{Key Results and the Revised Research Framework}

This thesis identified four XBRL initiatives in New Zealand during 2000 to 2010: the LEAP+ project, Project First Step, e-GIF project and SBR programme. These initiatives were either under the auspices of professional or governmental organisations. While Chapter 6 presented the findings of the two professional-organized projects (LEAP+ and Project First Step), Chapter 7 presented the two initiatives under the auspices of government organisations (e-GIF and SBR).

The first research question asked what factors influenced the organisations' decisions not to adopt XBRL use in business reporting. The factors that influenced the organisations' decision are a combination of technological, organisational, and environmental context factors. There were twelve predicted factors. Nine of these factors were inhibitors of XBRL adoption and supported the respective propositions. Another three factors were facilitators in adopting XBRL and did not support the respective propositions. Additional unpredicted factors were identified and they inhibited the XBRL adoption decision by organisations.

The factors that inhibited or facilitated XBRL adoption influenced each of the XBRL initiatives differently. The copyright issue only existed in the LEAP+ project, a change of laws, rules and regulations appeared once during Project First Step, a change of programme 
sponsor appeared during the e-GIF project, and a change of government and the global financial crisis appeared during the SBR programme. Most of the one-off factors were predominantly environmental in nature. Under the professional projects, LEAP+ and Project First Step, the technological and organisational context significantly influenced the professional organisations' decisions. Meanwhile, under the governmental initiatives, e-GIF and SBR, the important contexts shifted to environmental and organisational contexts. The organisational context, thus, remained important for the four XBRL initiatives. Additionally, it appears that the environmental context will be a significant context in the future.

Stakeholder involvement was further classified into active, supportive and observer groupings. Each stakeholder grouping had different views and beliefs regarding the nonadoption of XBRL particularly with respect to the implications of the government's decision for stakeholders in New Zealand. While, active and supportive stakeholders perceived that the government's decision had implications for stakeholders, observer stakeholders viewed that non-adoption of XBRL had no implication for stakeholders. The difference potentially exists because each stakeholder had different knowledge, experience and interest in XBRL technology. Additionally, the limited publically available information related to XBRL technology and the projects probably discouraged stakeholder interest.

In answering the second research question, this thesis found that the non-adoption of XBRL had implications for stakeholders including government agencies, accounting firms, accounting professional bodies and business organisations. The implications were classified into short-term and long-term for respective stakeholders. Each stakeholder faced different potential impacts from the government decision.

The results from the analysis of the longitudinal multiple-case study data are summarised in Figure 9.5. As discussed in Chapter 3, the research framework had three main parts: the TOE framework, the organisational decision, and the implications of the government's decision for stakeholders. The additional factors identified are included in the first part in the relevant context. The implications of government decision are presented in the third part. All the additional factors as well as the implications are identified by italics and a green colour. 


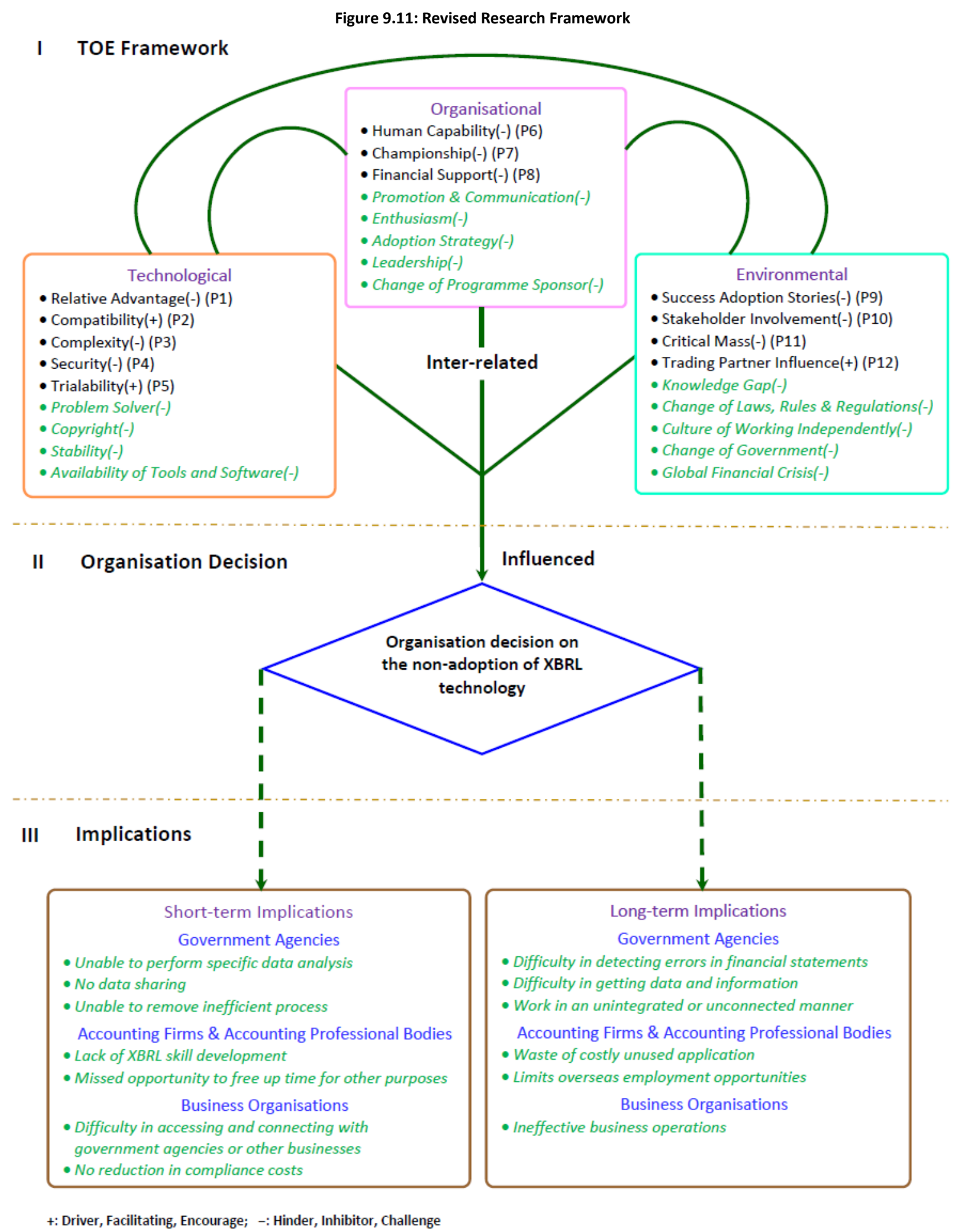

\subsection{Contributions}

The results of this thesis contribute to academic knowledge and have implications for practice. Contributions to knowledge and the academic literature are discussed, followed by the contribution to practice. 


\subsubsection{Contributions to Knowledge}

This thesis contributes to the academic knowledge in several ways. First, this thesis provides a history of XBRL in New Zealand. XBRL initiatives in New Zealand started as early as 2000, but there is limited available complete documentation relating to these early initiatives. Moreover, most of the government documents related to XBRL are not available to public. This thesis presents the important events related to XBRL activities in New Zealand from 2000 until 2010, where these events are arranged in chronological order, in the form of a timeline as given in Chapter 5. The history reveals that four XBRL projects: LEAP+, Project First Step, e-GIF, and SBR, attempted to get XBRL implemented in New Zealand. This history extends our knowledge of past and current XBRL activities. It provides a better understanding of XBRL development in New Zealand, preserves the knowledge and experience of the XBRL attempts in a written form, and gives a public voice to those involved. Thus, it enables accountants and others to learn from history.

Second, this thesis finds fourteen unpredicted factors, which are associated with the nonadoption of XBRL. The employment of a combination of research methods; that is, a longitudinal multiple case (Section 4.3), the reflection method (Section 4.4) and the triangulation method (Section 4.5), provide a holistic view about the XBRL non-adoption phenomenon in New Zealand. In addition, a post-positivism philosophy enables the researcher to explore the phenomenon in more depth, which enabled fourteen unpredicted factors to be identified.

Third, this thesis adapts the TOE framework. The TOE framework's original use was to analyse a technology adoption scenario at the organisational level. Thus, the results are limited to factors that influence adoption in an organisation. However, this thesis employs the framework to investigate a non-adoption scenario at the project level. Therefore the thesis findings presented are from a non-adoption perspective. This suggests that the TOE framework can be used for analysis at both the project and organisational level and for nonadoption as well as the traditional adoption scenarios.

Fourth, this thesis provides a contrasting view of technology adoption. Prior studies on XBRL adoption are mostly from the business organisation perspective. Some previous literature does argue that the governmental sector strongly influences XBRL adoption, but little evidence is provided. This thesis incorporates the government perspective as well as 
business and professional perspectives to provide a holistic investigation of the factors behind the non-adoption of XBRL in New Zealand.

Fifth, it provides a way to classify stakeholders involved in technology adoption decisions by their type of involvement. In the initial stage, the stakeholders are grouped into five classifications: government agencies, accounting firms, professional bodies, business organisations and other stakeholders. However, during the data collection stage, interviewees mentioned that their involvement took many different forms. They could be involved as an active participant, play a supportive role, or be an observer. Based on this evidence, the decision was made to analyse the data in more detail, by sub-classifying the stakeholder's involvement into active, supportive and observer classifications.

Finally, it is suggested that the stakeholder group view changes over time. The use of a longitudinal multiple case study enables the analysis of the stakeholders' views from 2000 until 2010. During the earlier private and professional initiatives, the majority of stakeholders considered the technological and organisational contexts to be more important than the environmental context. However, their views changed during the government initiatives, where the environmental and organisational contexts were more important in influencing the non-adoption of XBRL in New Zealand. Thus, these findings suggest that the stakeholders' views did not remain constant across the different XBRL nonadoption decisions.

\subsubsection{Contributions to Practice}

The first contribution to practice is the practical insights regarding why the government chose not to adopt XBRL for business reporting. In the LEAP+ project, the copyright issue was the main barrier for XBRL adoption. Then, in Project First Step, different barriers appeared including not being a problem solver, ineffective promotion, and communication, over-enthusiasm of the experts and lack of stakeholder involvement. While these two projects were still operating, e-GIF had begun as a government initiative. The government started e-GIF without addressing or removing any barriers from the existing projects. Perhaps, the e-GIF Working Group were aware of some barriers being encountered from the existing projects, but during that time, there was limited documentation and interest for reporting of XBRL activities, or the barriers had not been recognised outside the initiative. During the e-GIF, that initiative group faced obstacles relating to the complexity 
of XBRL, finding the right champion, a change of programme sponsor, getting stakeholder involvement and closing the knowledge gap. Without recognizing or overcoming these barriers, the e-GIF project was incorporated into the SBR programme. Later in SBR, the Working Group still had difficulties in convincing stakeholders about the use and benefits of XBRL. The barriers in SBR included not being a problem solver, absence of leadership, lack of stakeholder involvement, a knowledge gap, change of government and the global financial crisis.

This thesis suggests all the critical factors above are inter-related. It appears the main reason for non-adoption is an absence of demand, and limited knowledge of XBRL within the XBRL stakeholders. That shows in the factors of not being perceived as a problem solver and the knowledge gap. Each XBRL project tried to create demand by finding the right champion, proposing a mandatory adoption strategy, and increasing stakeholder involvement. A champion could use their power and resources to influence stakeholder acceptance of XBRL. A mandatory adoption strategy would force stakeholders to use XBRL for business reporting and they would have no choice but to accept and learn to use XBRL. The Labour Government chose not to mandate XBRL because they were not convinced about its relative advantage and believed there was poor demand from stakeholders, especially business organisations. The National Government could not require mandatory adoption as the country was facing the global financial crisis. However, since 2010, stakeholders are still not demanding XBRL and the government have assumed that demand and interest for XBRL has reduced. Thus, the government has introduced a new financial reporting framework, which suits New Zealand's reporting requirements, but does not include XBRL.

Based on the above discussion, the absence of demand throughout the XBRL projects, either under the professional or government initiatives, was probably the main cause of the failure in XBRL adoption in New Zealand. The absence of demand most likely appeared because of the knowledge gap. Thus, stakeholders would never demand XBRL because they did not have enough information about it. The current scenario is unlikely to change until the stakeholders know more about XBRL benefits and its use in business reporting.

The second contribution is providing an understanding of the short-term implications of the government decision not to adopt XBRL for XBRL stakeholders. XBRL stakeholders need to 
know what the implications of a government decision are, because government decisions could influence the way they operate. This thesis has identified implications to government agencies, accounting firms, accounting professional bodies and business organisations. Without XBRL, government agencies are unable to perform specific data analysis, share data among government agencies and to remove inefficient processes. Accountants in accounting firms and accounting professional bodies cannot update their skill levels and miss an opportunity to free up their time for other purposes. Business organisations retain a barrier to access and connect with government and business and continue to bear business reporting compliance costs. It is questionable whether the stakeholders recognize these implications to them. This could be for three reasons. First, their view that XBRL is not a solution to their problems, or they do not have a problem with their information system. Second, the existence of a knowledge gap among stakeholders. Third, the stakeholders are not ready to change. However, some stakeholders have recognized the implications of the government decision. For example, some members from the e-GIF Working Group moved overseas and continued to work on XBRL activities. They use their skills to implement XBRL and also update their knowledge on XBRL. A few academics continue to conduct studies on XBRL-related issues to try to explain what has happened, to increase awareness of XBRL or to identify the implications of non-adoption XBRL within New Zealand stakeholders.

The final contribution is providing a discussion on the long-term implications of the government decision for XBRL stakeholders. By ignoring the long-term implications, means stakeholders could face significant consequences. For example, a government agency may have difficulty in detecting errors in financial statements, in getting data and information to support policy-making and to access services within government agencies. Accounting firms and accounting professional bodies must accept the wasted investments in costly XBRL applications that have been abandoned. Moreover, they have to face a future without XBRL-related education, innovation, and skills. A New Zealand trained accountants will develop a slightly different set of practices and skills as compared to accountants working in countries that have implemented XBRL. This potentially limits the accountants' opportunity to work overseas or for a multinational company. Without XBRL, there is a possibility that business organisations are less effective than they could be. 


\subsection{Limitations and Future Research}

Despite the above contributions, as with any research this thesis has several key limitations. These limitations correspond to opportunities for future research.

Firstly, this thesis has limited generalizability regarding the geographical area. This thesis was conducted in New Zealand. As a result, it is uncertain whether the findings could be applied more broadly to other countries. Further research on non-adoption in other countries would be necessary.

Secondly, there is potential interviewer bias during either the data collection or analysis. The data collected for the four cases is highly contextual in nature. This made the presentation and analysis of the case studies difficult and potentially introduced a degree of bias. In order to overcome this bias, empirical evidence was sought through a variety of sources; interviews, document analysis and collection of archival records. Through this triangulation, internal validity was improved. Another way to reduce interviewer bias would be to conduct a survey. Additionally, future survey research could identify the correlation or degree of influence for each factor on organisational decisions relating to XBRL adoption. Moreover, the use of a survey-type questionnaire in future research could confirm the additional factors found in this thesis.

Thirdly, this thesis applied a single theoretical framework, the TOE Framework of DePietro et al. (1990). The TOE framework can be used to investigate a variety of technology adoption and as such, the specific factors identified within the three contexts may vary across different technologies. However, there is an argument that the TOE framework does not provide the theoretical underpinning necessary to establish a causal relationship (Mishra, Konana, and Barua, 2007). In certain circumstances, combining the TOE framework with other theories could identify specific technological, organisational, and environmental factors and establish the causal relationships that are needed for better proposition development (Mishra et al., 2007). For instance, the TOE framework could be combined with theories such as institutional theory and DOI. By combining TOE framework with another theory in future research, the new framework would provide more insight into certain phenomena.

Fourthly, this thesis did not aim to investigate the inter-relatedness or interaction among the influential non-adoption factors. The TOE framework has an ability to analyse the 
interactions among the potential factors. However, this thesis has not gone further and examined them. Thus, this limitation opens another avenue for future research to investigate the interaction among the influential non-adoption factors.

Fifth, the cases in this thesis are not mutually exclusive. The researcher assumes that each of the cases (XBRL project) is independent. However, in reality the cases are inter-related because the majority of the stakeholders are involved in more than one XBRL project. Thus, there could be potential bias in the views expressed by the interviewees.

Lastly, this thesis did not seek evidence to support the perceived impacts of the government's decision, to XBRL stakeholders. It only identified and examined the understanding of stakeholder regarding the effects of the government decision. The results therefore only provide some evidence about the possible implications of the government decision on the stakeholders' organisational operations. Further, other countries' experience provides evidence of how XBRL can be used to collect, analyze, save and retrieve the data for certain purposes as well as being used as a monitoring and enforcement tool. $A$ comparative study of New Zealand with other countries' experience could highlight in more detail the implications of the government's decision.

\subsection{Concluding Statement}

The aim of this thesis was to investigate why business and professional organisations and the New Zealand government have decided not to adopt XBRL for use in business reporting and the implications of that decision for XBRL stakeholders. In order to achieve this aim, two research questions were developed:

a) What factors influenced the organisations' decisions not to adopt XBRL for use in business reporting?

b) What are the implications of the government decision regarding XBRL in business reporting for XBRL stakeholders?

This thesis has addressed the research questions by providing empirical evidence regarding the factors that influenced the XBRL decision. Further, this thesis has highlighted the potential implications of the government decision not to adopt XBRL for XBRL stakeholders.

The government decision had some implications for stakeholders. As a result of not adopting XBRL for business reporting, the interviewees refer to it as 'lost opportunities'. The 
government agencies do not have shared databases to undertake data analytics, data interrogation, or data mining. The non-adoption has also encouraged the continuation of a culture of working independently in the government agencies. Without XBRL, business organisations would face a barrier while accessing and connecting with government (B2G) and other businesses (B2B), and have lost the opportunity to reduce reporting-related compliance costs. New Zealand trained accountants have had their opportunity to upgrade their skills and knowledge limited.

Further, stakeholders such as government agencies, accounting firms, professional bodies and business organisations have erected barriers that affect their abilities to detect errors in the financial statements, getting data and information to support organisational policymaking, and upgrading skills and knowledge of XBRL.

The key knowledge contributions of this thesis are in documenting the history of XBRL development in New Zealand from 2000 until 2010, through a longitudinal multiple-case study of the four key XBRL initiatives using a post-positivism philosophy. It also takes a contra-view of adoption and presents multi-sectorial perspectives (business, professional and government), and adds to our understanding of the TOE framework in an XBRL setting. Meanwhile, there are three significant contributions to practice. The first is the rationale behind the government decision not to adopt XBRL for business reporting. Second and third is the understanding of the short-term and long-term implications of not adopting XBRL in New Zealand.

In conclusion, the uniqueness of XBRL history in New Zealand made it interesting and relevant to review. The difficulties in the XBRL journey of professional, as well as, government initiatives, shows that stakeholders' involvement was not consistent and demand was not present for a variety of reasons (factors). The results suggest there are various factors from the TOE framework that influenced the decision of the organisations, business, professional and government. This thesis results provide valuable insights into government agencies, accounting firms, accounting professional bodies and business organisations decisions and the barriers or inhibitors that can effect technology adoption. Because of the presence of these barriers, XBRL technology was not adopted, and there is little prospect that it will be adopted in the future. 


\section{A Guide to New Zealand's \\ Central Government Agencies}

Public Service - By definition, the Public Service comprises the departments listed on the Schedule 1 of the State Sector Act 1988 including any departmental agencies listed on Schedule 1A of that same Act.

State Services - By definition, the State Services comprises the agencies that operate as instruments of the Crown in respect of the Government of New Zealand (i.e. the Executive Branch of Government). This includes the Public Service, most Crown entities, the Reserve Bank, a range of agencies listed on Schedule 4 of the Public Finance Act 1989, companies listed on Schedule 4A of the Public Finance Act, and a small number of departments that are not part of the Public Service.

State sector - By convention, the State sector comprises the agencies whose financial situation and performance is included in the Financial Statements of the Govemment of New Zealand as part of the Government reporting entity under the Public Finance Act 1989. This includes the State Services, tertiary education institutions, State-Owned Enterprises and Mixed Ownership Model companies, as well as a small number of agencies that operate as instruments of the Legislative Branch of Government.

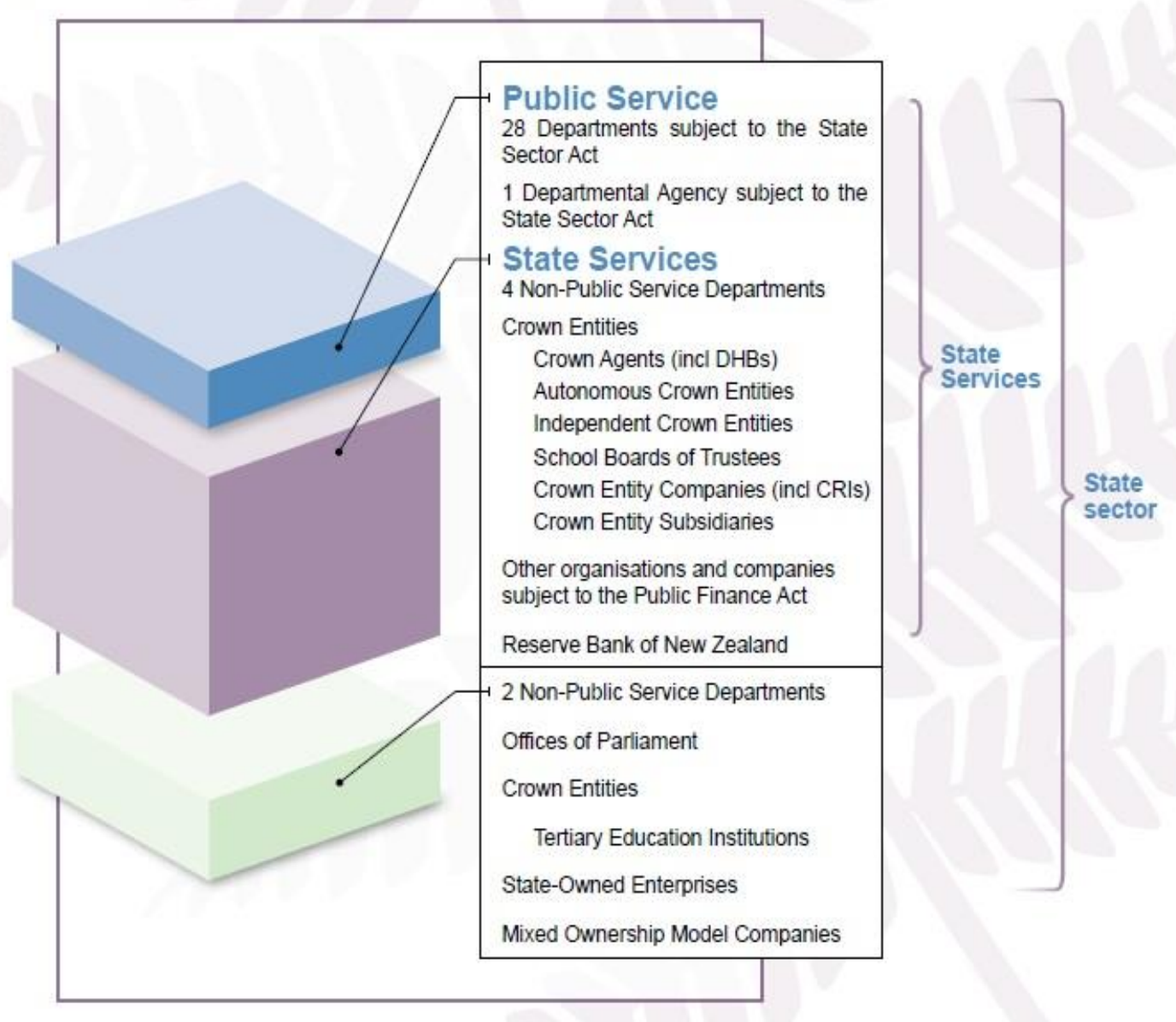


PUBLIC SERVICE

Departments

- Mritsty of Business, Inovation and Employment

Department af Conservation

Department of Corrections

Crown Law Othce

- Mristy for Cuhure and Hertage

- Minithy of Defence

Ministry of Education

Eoucation Revew Omce

Ministry for the Environment

Mristry of Forelgn Aftairs and Trace

Government Communications Securty Bureas

Mristry of Heath

Inand Revenue Department

Department of intemai. Afärs

Ministy or Justce

Land Intomation New Zealand

Minstry of Msor Develogment

New Zealand Customs Service

Ministy for Padfle Peoples

Mnistry for Primary noustries

Department of the Prime Minister and Cabinet

Serous fraud once

Ministy of Socla Development

State Senice6 Commission

Statstics New Zealand

Mristry of Transport

The Treasury

Mristy tor Women

Departmental Agencies

- Cantertury Eartoguake Recovery Authorty (hosted by the Department of the Prime Minister and Cabinet;

NON-PUBLIC SERVICE DEPARTMENTS

Once of the Clent of the House of Representabves

New Zealand Detence Force

New Zealand Police

New Zealand Securtty intelligence Senvice

Panlamentary counsel Omce

Pariamentary Counsentary Service

CROWN ENTITIES

Statutory Entities

Crown Agents

- Accident compensalon Conporation

Calaghan innovation

Careers New Zealan

CNil Aviation Authority of New Zealand

District Heath Boards (20)

- Auckiand Distret Healh Board

- Bay of Plenty District Heahn Boaro

- Canteroury Dlsrict Heam Boars

Caital and Coast District Heath Board

Countes Manukas District Heath Boar

Hawkes Bay District Heakn Board

Hutt District Heath Board

Lakes Dstrict Heath Board

- MidCentral Dissrict Health Board

Nelison Marborough Distrct Health Boart

Northland District Heath Boary

South Canterbury District Heath Board

Southem District Heath Boars

Tarawhin District Health Boars

Taranaki District Heath Boars

- Wakab Distrct Health Board

Wararapa District Heath Board

Watencha District Heath Board

West Coast District Heath Boarc

- Whanganui Distrid Heath Board

Earthquake Commission

- Education New Zeazano

Energy Emclency and Conservation Authorty

Envronmental Protection Authort

Heath Promotion Agency

Heath Qualty and Satery commission

Heath Research Councl of New Zealan

Housing New Zealand Corporation

Martme New Zealand

New Zealand Artarcicic institute

New Zea land Blood Service

New Zealand Fre Service Commission

New Zeaa and Qualffcations Authorthy

New Zealand Tourkm Board

New Zealand Trade and Enterprise
New Zealand Transport Agency

New Zealand Walking Accers Commission

Pharmaceutcal Management Agency

Real Estate Agents Authortty

Soclal Wonters Registration Board

Sport and Recreation New Zealand

Tertiary Education Commlssion

Worksate New Zealano

Autonomous Crown Entities (ACEs)

- Accredtation Councl

- Arts Councl of New Zealind Tol Aotearos

Broadcasting Commission

Familes commission

Govermment Superannuabon Fund Authort

Guardians of New Zealand Superannuaston

Hertage Nea Zealand Pouhere Taonga

Museum of New Zealand Te Papa Tongarewa Board

New Zealand Avtndal Umb Service

New Zealand Flm Commission

New Zealand Lotterles Commission

New Zealand Symphony Cronestra

Public Trust

Retrement Commissioner

Te Reo Whakapuaki Irrang Majorl Broadcasting Funding Agenof

Te Taura Whin I Te Reo Masrn (Maorl Language Commission

Independent Crown Entities (ICEs)

- Broadcasting Stanoards Authorng

Criluren's commissioner

Commerce Commission

Drug Free Sport New Zealand

Electora Commission

Electricly Autiorty

Extemal Reporting Boars

Financia Markets Authorty

Heath and Disabilty Commissione:

Human Rights Commission

Independent Police Conduct Authority

Law Commission

New Zealand Productiviy Commission

Ottce of Fim and Lterasure Classtication

Prvacy Commissioner

Takeovers Pane

Transport Accident Investgation Commission

Crown Entity Companies

Crown Research Institutes (CRls)

- AgResearch Limited

- Instosta of Envronmental Sclence and Research Lumtec

Instinde of Geologcal and Nuclear Sciences Umited

Lanocare Research New Zealand Lmted

Natonal institute of Water and Atmospheric Research Limted

New Zealand Forest Research instute Limter

- The New Zealand institse tor Plart and Food Research Umted

Other companies

- Crosan irigaton Investments Limited

New Zealand Venture investment Fund L Imted

Rasso New Zealand Umilted

Television New Zealand Limited

Crown Entity Subsidiaries

- Approx. 150 Crown entry subsidares

School Boards of Trustees

Approx 2,416 (incuding Te Ano o Te Kura Pounamy-The Comespondence Schooli)

Tertiary Education Institutions

Universities

- Auckiand Universty of Tecinology

- Linoain University

- Massey Unversty

- Universty of Auckiano

- Universty of Cantertury

- Universty of Otago

- Universty of Wakato

- Victora University of Wellington

Polytechnicsilinstitutes of Technology

Bay of Plenty Polytechnic

Crristerures Polylechnic insthde of Technology

Eastem instute of Technology
Manukau instutue of Technoiog

Nelson Marborough Insthte of Technology

Noreland Polytechnic

Open Poytechnic of New Zeazan

Obgo Polytechnic

Southem Insthde of Technology

Ta Poutini Polytechn

- Unltec insthde of Technology

Walarki Bay of Plenty Polytechn

Walankl Instatse of Technolog

Wakato instutute of Technology
Welington insthste of Teconology

Westem institute of Technology

- Whitrea communty Polyechnic

Wananga

- Te Wananga o Aotearo

- Te Wananga o Raskawa

- Te Whare Wananga o Awanularangl

PUBLIC FINANCE ACT SCHEDULE 4 ORGANISATIONS

Fish and Game Councils

New Zealand Flsh and Game Counc

- Fish and Game Counclis (12)

Reserves Boards (22)

Trusts

Agrioutural and Markethg Reserch and Development Trust

- Asla New Zealand Founcation

Leadership Deveiopment Certse Trust

National Pacitc Rado Trus

Ngal Tahu Ancllary Claims Trust

Pacific Co-operation Foundation

Pacinc Island Bushess Development Thust

Te Arik Trust

Other (Bodies Corporate)

- Game Animal Counci

The Marr Trustee

New Zealand Game Bird Hablat Tust Board

New Zealand Govemment Property Corporation

Sentencing Councl (never estabished)

Other (Unincorporated)

- New Zealand Lotery Grants Board

PUBLIC FINANCE ACT SCHEDULE 4A COMPANIES

- Crown Asset Manogement Lmted

Crown Flore Hoidings Lmted

Education Payrol Lmited

- Farway Resolution Limiter

Healith Beneftrs Limited (ceased operations

The Network for Learning LImited

Research and Educaton Adranced Network New Zealens

Inted

- Southem Response Earthquake Services LImted

Tamaki Redevecopment Company Limtec

RESERVE BANK OF NEW ZEALAND

OFFICES OF PARLIAMENT

Once of the Ombudsmen

- The Controller and Audtor-Genera

The Parlamentary Commissicoer for the Envronment

STATE-OWNED ENTERPRISES

- Arways comporation of New Zealand Umtes

Anima Control Produsts Limites

- AsureQually Limted

Electroty Comoration or New Zealand Limted

Kwiral Hoidngs Umiter

Kordia Group Limted

Landcorp Farming Umitied

Leaning Medla Lmted (stuck of Companies Regkter)

Metecrologlical Service of New Zealand LImted

New Zealand Post Limited

New Zealand Ra ways Corporation

Quotable Vaue Limted

Sold Energy New Zeaand Umbed (seling-down assets)

Trappouer New Zearnoumted

\section{MIXED OWNERSHIP MODEL COMPANIES}

- Genesis Energy Umtes

Meriolan Energy Limliz

Mighty River Power Umilied 


\section{Predicted Factors}

\begin{tabular}{|c|c|c|c|c|}
\hline No & Factor & Page & Definition & Literature \\
\hline 01 & Relative advantage & 60 & $\begin{array}{l}\text { The perceived costs and benefits involved in } \\
\text { the adoption of a technology. }\end{array}$ & Rogers (1995) \\
\hline 02 & Compatibility & 60 & $\begin{array}{l}\text { The degree to which XBRL adoption is } \\
\text { perceived as being consistent with existing } \\
\text { information systems, tasks, and the current } \\
\text { needs and objectives of organizations, } \\
\text { including government. }\end{array}$ & Moore and Benbasat (1991) \\
\hline 03 & Complexity & 61 & $\begin{array}{l}\text { The degree to which technology is perceived } \\
\text { as relatively difficult to understand and use. }\end{array}$ & Rogers (1995) \\
\hline 04 & Security & 62 & $\begin{array}{l}\text { Both the perception or judgement and fear of } \\
\text { safeguarding mechanisms for the movement } \\
\text { and storage of data and information through } \\
\text { systems. }\end{array}$ & Lippert and Govindarajulu (2006) \\
\hline 05 & Trialability & 63 & $\begin{array}{l}\text { The degree to which organizations can test } \\
\text { the technology before deciding whether to } \\
\text { adopt it. }\end{array}$ & Rogers (2003) \\
\hline 06 & Human Capability & 64 & $\begin{array}{l}\text { The degree to which the organization } \\
\text { perceives that staff possess a relatively high } \\
\text { level of knowledge and expertise related to } \\
\text { technology. }\end{array}$ & Rogers (1995) \\
\hline 07 & Championship & 65 & $\begin{array}{l}\text { A single person at decision making levels } \\
\text { within an organization, who is committed to } \\
\text { introducing a new technology into its } \\
\text { processes, requirements and laws. }\end{array}$ & Norris (1999) \\
\hline 08 & Financial Support & 66 & $\begin{array}{l}\text { The availability of funds to make a project } \\
\text { possible, particularly investment to enhance } \\
\text { or build the organizational IT-related to new } \\
\text { technology. }\end{array}$ & Rogers (1995) \\
\hline 09 & $\begin{array}{l}\text { Successful Adoption } \\
\text { Stories }\end{array}$ & 67 & $\begin{array}{l}\text { The perception of a favourable experience in } \\
\text { adopting or implementing technology, which } \\
\text { fulfil two criteria, sustainability and the } \\
\text { perspective of different stakeholders. }\end{array}$ & Krishna and Walsham (2005) \\
\hline 10 & $\begin{array}{l}\text { Stakeholder } \\
\text { Involvement }\end{array}$ & 68 & $\begin{array}{l}\text { The degree of effectiveness of stakeholder } \\
\text { participation, which includes encouragement, } \\
\text { support, providing information, funding and } \\
\text { political backing by stakeholders in the } \\
\text { adoption decision process }\end{array}$ & DePietro et al. (1990) \\
\hline 11 & Critical Mass & 68 & $\begin{array}{l}\text { A sufficient number of organizations adopting } \\
\text { XBRL technology so that it reaches a point } \\
\text { where it becomes self-sustaining and creates } \\
\text { further growth. }\end{array}$ & Rogers (2003) \\
\hline 12 & $\begin{array}{l}\text { Trading Partner } \\
\text { Influence }\end{array}$ & 69 & $\begin{array}{l}\text { Two or more participants that have business } \\
\text { or formal relationships on regular basis. The } \\
\text { participants could be a person, company, } \\
\text { country, or region that sells/buys goods or } \\
\text { undertakes project collaborations with one } \\
\text { another. }\end{array}$ & $\begin{array}{l}\text { http://thelawdictionary.org/trading- } \\
\text { partner/; } \\
\text { http://www.macmillandictionary.com/di } \\
\text { ctionary/british/trading-partner } \\
\text { http://www.collinsdictionary.com/dictio } \\
\text { nary/english/trading-partner }\end{array}$ \\
\hline
\end{tabular}




\section{Unpredicted Factors}

\begin{tabular}{|c|c|c|c|c|}
\hline No & Factor & Page & Definition & Literature \\
\hline 01 & Problem solver & 133 & $\begin{array}{l}\text { Whether potential adopters perceive XBRL as a } \\
\text { solution to their problems related to business } \\
\text { reporting matters. }\end{array}$ & $\begin{array}{l}\text { Interviewee } \mathrm{A} \text {, Interviewee } \mathrm{P} \text {, } \\
\text { Interviewee } \mathrm{M}\end{array}$ \\
\hline 02 & Copyright & 131 & $\begin{array}{l}\text { An exclusive legal right either to reproduce, } \\
\text { publish, sell or distribute something. In XBRL's } \\
\text { case it is the right to reproduce the XBRL-based } \\
\text { financial and business information for the } \\
\text { public. }\end{array}$ & $\begin{array}{l}\text { http://www.merriam- } \\
\text { webster.com/dictionary/copyright }\end{array}$ \\
\hline 03 & Stability & 141 & $\begin{array}{l}\text { The ability of an XBRL element such as the } \\
\text { XBRL specification and taxonomy to remain } \\
\text { unchanged under reasonable expected } \\
\text { conditions and use. }\end{array}$ & $\begin{array}{l}\text { http://www.businessdictionary.com/de } \\
\text { finition/stability.html }\end{array}$ \\
\hline 04 & $\begin{array}{l}\text { Availability of tools } \\
\text { and software }\end{array}$ & 148 & $\begin{array}{l}\text { The accessibility of equipment that enables } \\
\text { potential adopters to try a new technology like } \\
\text { XBRL. }\end{array}$ & Rogers (1995) \\
\hline 05 & $\begin{array}{l}\text { Promotion and } \\
\text { communication }\end{array}$ & 132 & $\begin{array}{l}\text { The platform used to share and create XBRL } \\
\text { related information for its stakeholders. }\end{array}$ & Interviewee $\mathrm{E}$, Interviewee $\mathrm{N}$ \\
\hline 06 & Enthusiasm & 132 & $\begin{array}{l}\text { A strong interest in doing XBRL-related } \\
\text { activities among its supporters. }\end{array}$ & $\begin{array}{l}\text { Interviewee A, Interviewee H, } \\
\text { Interviewee J }\end{array}$ \\
\hline 07 & Adoption strategy & 250 & $\begin{array}{l}\text { An approach or method employed to get } \\
\text { stakeholders to start using a new technology } \\
\text { like XBRL. In this thesis, there are two } \\
\text { strategies: voluntary and mandatory adoption. }\end{array}$ & $\begin{array}{l}\text { Hucklesby and Macdonald (2002e), } \\
\text { Interviewee A }\end{array}$ \\
\hline 08 & Leadership & 251 & $\begin{array}{l}\text { The person leads the XBRL project at an agency } \\
\text { or organisational level. As an effective leader, } \\
\text { the person creates an inspiring vision of the } \\
\text { future; motivates people to engage with the } \\
\text { vision; manages the delivery of the vision; and } \\
\text { coaches and builds a team to achieve the } \\
\text { vision. } \\
\text { Leadership and championship are } \\
\text { differentiated based on the degree of influence } \\
\text { the person has in the XBRL project. }\end{array}$ & $\begin{array}{l}\text { https://www.mindtools.com/pages/arti } \\
\text { cle/newLDR_41.htm }\end{array}$ \\
\hline 09 & Programme sponsor & 172 & $\begin{array}{l}\text { The government agency that is responsible for } \\
\text { organizing a particular XBRL initiative in New } \\
\text { Zealand. }\end{array}$ & $\begin{array}{l}\text { http://www.businessdictionary.com/de } \\
\text { finition/sponsor.html }\end{array}$ \\
\hline 10 & Knowledge gap & 135 & $\begin{array}{l}\text { A difference in the level of knowledge and skills } \\
\text { about XBRL technology between those } \\
\text { involved in XBRL initiatives and other } \\
\text { stakeholders. }\end{array}$ & Tichenor et al. (1970) \\
\hline 11 & A change of laws & 143 & $\begin{array}{l}\text { The modifying of laws, rules and regulations } \\
\text { including any change either in rules or } \\
\text { regulations related to XBRL matters. }\end{array}$ & http://thelawdictionary.org/change/ \\
\hline 12 & $\begin{array}{l}\text { The culture of } \\
\text { working } \\
\text { independently }\end{array}$ & 174 & $\begin{array}{l}\text { The way that government agencies operate in } \\
\text { New Zealand, where every agency preferred to } \\
\text { work alone or separately from other agencies. }\end{array}$ & $\begin{array}{l}\text { http://www.merriam- } \\
\text { webster.com/dictionary/culture } \\
\text { http://dictionary.reference.com/brows } \\
\text { e/independently }\end{array}$ \\
\hline 13 & $\begin{array}{l}\text { A change of } \\
\text { government }\end{array}$ & 254 & $\begin{array}{l}\text { A shift of political power from one political } \\
\text { party to another through a general election }\end{array}$ & $\begin{array}{l}\text { https://en.wikipedia.org/wiki/Regime c } \\
\text { hange }\end{array}$ \\
\hline 14 & Global Financial Crisis & 255 & $\begin{array}{l}\text { A period of economic difficulty experienced by } \\
\text { financial markets that has a global impact on } \\
\text { consumers. }\end{array}$ & $\begin{array}{l}\text { http://www.businessdictionary.com/de } \\
\text { finition/global-financial-crisis.html }\end{array}$ \\
\hline
\end{tabular}




\section{Information Sheet}

Re: Invitation to participate in research into the non-adoption of XBRL by government.

I am a PhD student in the School of Accounting and Commercial Law (SACL), Victoria University of Wellington. My PhD thesis is in investigating the factors that influenced the government's decision not to adopt eXtensible Business Reporting Language (XBRL) for internal purposes and external use for business reporting. In addition, this research hopes to determine the implications of government's decision for XBRL stakeholders in New Zealand. Victoria University Wellington Human Ethics Committee approval has been granted for this study.

\section{Desired participants}

I would like to invite you to participate in this research. The research primarily involves interviewing the government and government agencies, business organizations, accounting firms, other external users and other possible stakeholders. Potential interviewees include government personnel, financial accountants, IT staff, internal auditors, external auditors, tax practitioners, shareholders, investment analysts, software vendors and developers and academicians as well as those who have expert knowledge and experience in the decision making process that occurred during the consideration of adopting XBRL in New Zealand.

\section{Interview schedule}

It is envisaged that the interview will last between 40 minutes to one hour. The time and location of the interview session will be arranged at the convenience of interviewee. The interview session will be taped and transcribed afterwards. You will be able to request a copy of your transcript to verify its accuracy.

\section{Data analysis and reporting}

The transcribed interview will be analysed and form the basis of the findings of my research. The interviewee will not be individually identifiable in the thesis. All data will be kept confidential and 
exclusive to me as well as my supervisors, Dr Carolyn Fowler and Dr David Johnstone. You may withdraw from the research at any stage before the data is analysed up until 28 February 2014. Information you have provided and any relevant notes made by myself will be destroyed if you decide to withdraw from the research. The thesis will be deposited in the library of Victoria University of Wellington. It is intended that data and results from the interview will be also used for publications in scholarly journals, presentations at academic conferences and potential reports and discussion papers to disseminate relevant information to XBRL stakeholders about the government's decision and its implication. At the conclusion of this research, a summary of findings will be sent to all interviewees, for those who wish to have it. We hope you will find that this research is beneficial and of value to you. I will contact you in the next few days to see if you are willing to participate.

\section{Contact details}

For future information, please contact me by email at Jasmine.David@vuw.ac.nz or phone 04463 7168, or my supervisor Dr Carolyn Fowler at Carolyn.Fowler@vuw.ac.nz (04 463 6506) and Dr David Johnstone David.Johnstone@vuw.ac.nz (04 463 5877). Alternatively you can mail us at:

School of Accounting and Commercial Law

Victoria University of Wellington

PO Box 600

Wellington 6140 


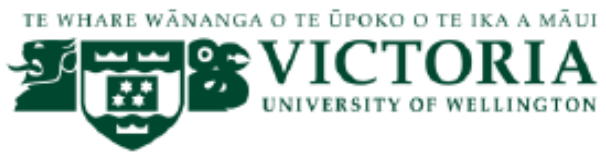

\section{Sample of Interview Questions}

General Questions which apply to all the stakeholders:

1) How would you describe your knowledge of XBRL?

2) Are you aware of developments that use XBRL internationally and in New Zealand? If yes, go to question 3. Otherwise, go to question 4.

3) Based on your knowledge, how long have you been following these XBRL developments? What influenced you to do so?

4) Basically, the US, UK, Australia and most of European countries are adopting and mandating XBRL use for business reporting. In your opinion, should New Zealand follow this? Why?

Specific questions which apply to relevant or selected stakeholder, including those who have expert knowledge and experience in XBRL:

Technological context:

Relative Advantage

1) What do you perceive the benefits of XBRL adoption are?

2) What do you perceive the costs of XBRL adoption are?

3) Based on your knowledge and experience in IT, would you think that cost of XBRL adoption is greater than the benefits it brings?

Compatibility

1) Is your reporting system based on XML (eXtensible Mark-Up Language)? Could you explain more about it?

2) Can you highlight the difference between your reporting system and XBRL technology?

- Would these differences influence your decision to adopt XBRL?

Complexity

1) Based on your knowledge, do you think your organization would face problems using or even understanding XBRL technology?

2) Do you think that implementing XBRL would be difficult when compared to your current reporting system? Can you expand on this?

Security

1) In general, Information Technology (IT) applications can potentially have a security risk. Would there be any security risks that you can highlight if the government adopted or used XBRL?

2) Do you think that security risk affected the decision not to adopt XBRL? Why?

Trialability

1) Have you or your organization trialled an XBRL application? What do you think about the application?

2) Is it important to try the application before deciding to adopt? 


\section{Organizational context:}

Human capacity

1) Do you think your personnel's current knowledge and expertise are relevant and support XBRL adoption? Can you expand?

2) Would a lack of human capabilities influence the decision to adopt XBRL?

- Why?

Championship

1) In general, did you see anybody at the decision making level that was interested in XBRL-related matters?

- Who?

- How do you think these people influenced the decision regarding the non-adoption of XBRL?

Financial Support

1) Do you think funding is important in any technology adoption? What is it for in an XBRL project?

2) How did your organization obtain the funding?

\section{Environmental context:}

Successful adoption

1) Based on your own knowledge, have you ever heard of the successful adoption of XBRL by other organizations or government?

- Where?

- How do you think these stories influence the decision not to adopt XBRL?

Stakeholder involvement

1) Do you think, stakeholder involvement plays an important role in XBRL adoption?

- Can you explain in detail about these stakeholder's roles?

\section{Critical Mass}

1) Based on your opinion, do you think New Zealand will reach the sufficient number of XBRL adopters if XBRL adoption is mandated?

2) If you still remember, how did the stakeholder (accountants, businesses or government agencies) react towards the XBRL projects?

Trading Partner

1) Did you organization trade or have an overseas trading partner? Where?

2) If your trading partners are using XBRL in their business reporting, do you think your organization will adopt XBRL? Why?

The implications of the government's decision

1) What is the implication of the government's decision not to adopt XBRL for your organization/agency?

2) Based on your own knowledge, what could be the consequences of the government's decision to not adopt XBRL?

- To the government itself

- To other stakeholder groups

General questions that apply to all stakeholders:

5) Is there anything that you would like to add? Is there anything that I should ask, but I didn't ask?

6) If you know some other people who might be knowledgeable about XBRL, would you recommend the person and provide me with his/her contact information? 


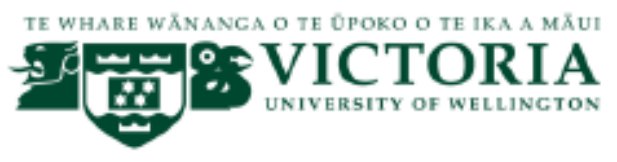

\title{
Consent Form
}

\author{
eXtensible Business Reporting Language (XBRL) in New Zealand
}

I have been provided with adequate information relating to the nature and objectives of this research. I have understood that information and have been given the opportunity to seek further clarification or explanations.

I understand that I may withdraw from this study at any time before the final analysis of data without providing reasons and penalty of any sort, up until 28 February 2014.

I understand that if I withdraw from the research, any data I have provided will be returned or destroyed.

I understand that any information or opinion I provide will be kept confidential and reported only in an aggregated/ non-attributable form.

I understand that the information I have provided will be used only for this research and that any further use will require my written consent.

I understand that when this research is completed the information obtained will be destroyed after 3 years.

I understand that I will have the opportunity to check the transcript of my interview for accuracy and may also request the summary of findings of the final research.

Please tick the following options if appropriate:

$\square$ I understand that this interview is being recorded and consent to this.

$\square$ I would like to receive a summary of the result of this research when it is completed.

I would like to review a transcript of my interview in order to check its accuracy.

\section{I have read the above and consent to take part in the research as described.}

Name:

Signature:

Date: 
WHEN

WHO

WHAT

LEAD TO

EFFECT

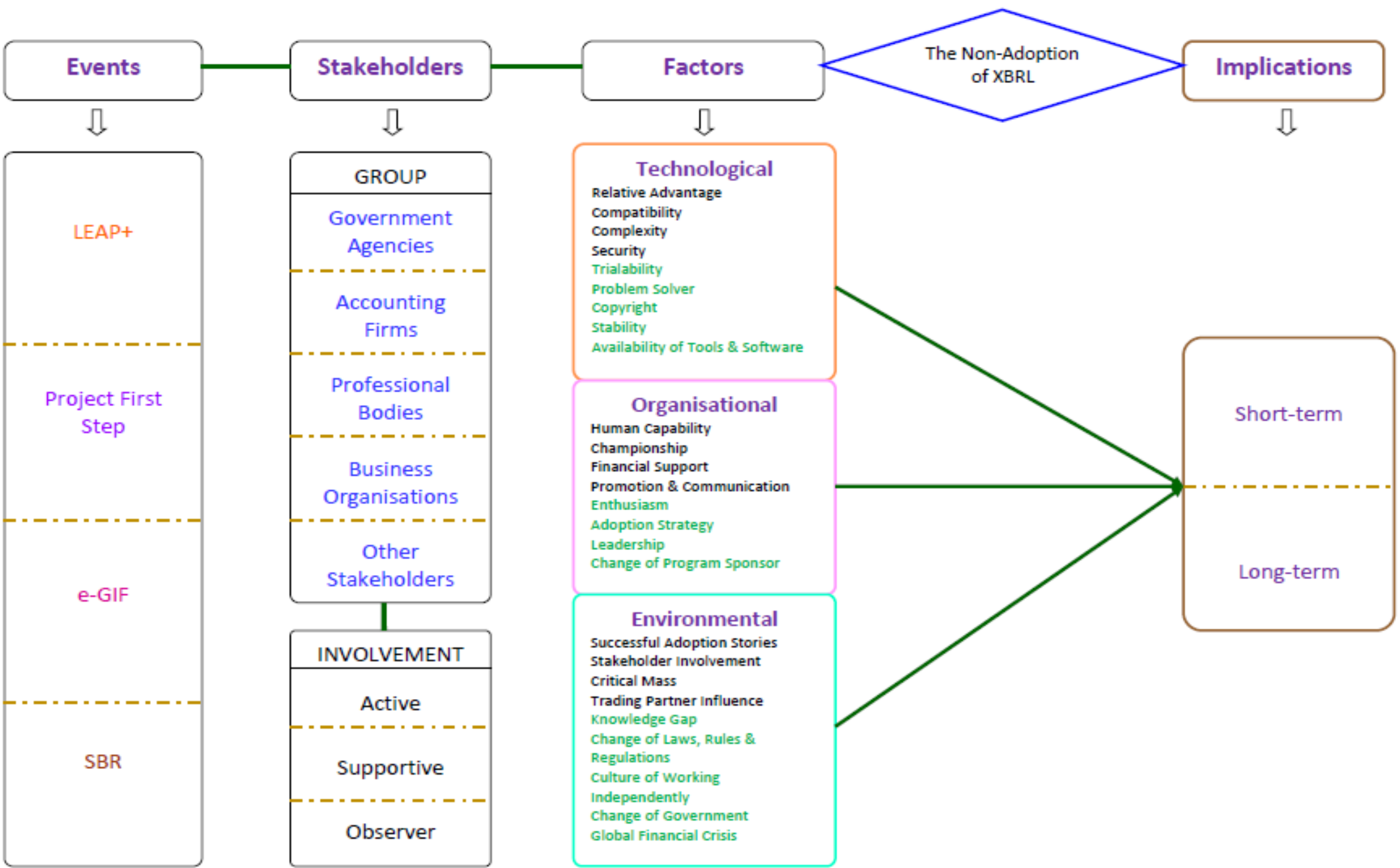




\section{References}

AASB. 1999. Auditing Guidance Statement AGS 1050 - Audit Issues Relating to the Electronic Presentation of Financial Reports. December. Melbourne: Australian Auditing Standards Board, Australian Accounting Research Foundation.

Abdolmohammadi, M., Harris, J., \& Smith, K. (2002). Government financial reporting on the Internet: The potential revolutionary effects of XBRL. The Journal of Government Financial Management, 51(2), 24-24-31.

Abdullah, A., Khadaroo, I., \& Shaikh, J. (2009). Institutionalisation of XBRL in the USA and UK. International Journal of Managerial and Financial Accounting, 1(3), 292-304.

Adhikari, A., \& Tondkar, R. H. (1992). Environmental factors influencing accounting disclosure requirements of global stock exchanges. Journal of International Financial Management \& Accounting, 4(2), 75-105.

Ahrens, T., \& Chapman, C. S. (2006). Doing qualitative field research in management accounting: Positioning data to contribute to theory. Accounting, Organizations and Society, 31(8), 819-841.

Ahrens, T., \& Dent, J. F. (1998). Accounting and organizations: realizing the richness of field research. Journal of Management Accounting Research, 10, 1-40.

Al-Qirim, N. (2007). A Research Trilogy into E - Commerce Adoption in Small Businesses in New Zealand. Electronic Markets, 17(4), 263-285.

Allam, A., \& Lymer, A. (2003). Developments in Internet financial reporting: review and analysis, across five developed countries. The international journal of digital accounting research, 3(6), 165-199.

Alles, M., \& Debreceny, R. (2012). The evolution and future of XBRL research. International Journal of Accounting Information Systems, 13(2), 83-90. doi: http://dx.doi.org/10.1016/i.accinf.2012.03.006

Alles, M. G., Kogan, A., \& Vasarhelyi, M. A. (2002). Feasibility and economics of continuous assurance. Auditing: A Journal of Practice \& Theory, 21(1), 125-138.

Anderson, J. G., \& Aydin, C. E. (1994). Overview: Theoretical Perspectives and Methodologies for the Evaluation of Health Care Information Systems. In J. G. Anderson, C. E. Aydin \& S. Jay, J (Eds.), Evaluation Health Care Information Systems, Methods and Applications (pp. 5-29). Thousand Oaks, CA: Sage Publications.

Arksey, H., \& Knight, P. T. (2002). Interviewing for social scientists: An introductory resource with examples. CA: Sage Thousand Oaks.

Ashbaugh, H., Johnstone, K. M., \& Warfield, T. D. (1999). Corporate reporting on the Internet. Accounting Horizons, 13(3), 241-241-257.

Azam, S., \& Taylor, D. (2011a). Standard Business Reporting in Australia: voluntary take-up issues facing users, preparers and regulators of company financial and business reports. Accountancy Business and the Public Interest, 10(1), 16-41.

Azam, S., \& Taylor, D. (2011b). Adopting standard business reporting (SBR) in Australia: Are CFOs persuaded by technology attributes. Paper presented at the Critical Perspectives on Accounting. Florida, USA.

Baker, J. (2012). The technology-organization-environment framework. In Y. K. Dwivedi, M. R. Wade \& S. L. Schneberger (Eds.), Information systems theory (Vol. 28, pp. 231-245): Springer.

Baldwin, A. A., Brown, C. E., \& Trinkle, B. S. (2006). XBRL: An impacts framework and research challenge. Journal of Emerging Technologies in Accounting, 3, 97.

Barua, A., Konana, P., Whinston, A. B., \& Yin, F. (2004). Assessing internet enabled business value: An exploratory investigation. MIS Quarterly, 28(4), 585-620.

Benbasat, I., Goldstein, D. K., \& Mead, M. (1987). The case research strategy in studies of information systems. MIS quarterly, 369-386.

Bergeron, B. P. (2003). Essential of XBRL: Financial Reporting in 21st Century. Hoboken: John Wiley \& Sons, Inc. 
Bharosa, N., Janssen, M., van Wijk, R., de Winne, N., van der Voort, H., Hulstijn, J., \& Tan, Y.-h. (2013). Tapping into existing information flows: The transformation to compliance by design in business-to-government information exchange. Government Information Quarterly, 30, S9-S18.

Blankespoor, E. (2012a). The Impact of Investor Information Processing Costs on Firm Disclosure Choice: Evidence from the XBRL Mandate.

Boritz, J. E., \& No, W. G. (2005). Assurance for XBRL: XARL (eXtensible Assurance Reporting Language). Journal of Accounting \& Public Policy, 24, 11-35.

Bourgeois III, L. J., \& Eisenhardt, K. M. (1988). Strategic decision processes in high velocity environments: Four cases in the microcomputer industry. Management science, 34(7), 816-835.

Boyd, G. (2003, June). Report From The Amsterdam XBRL Conference. Chartered Accountants Journal of New Zealand, 82, 1.

Boyd, G. (2004a, April). XBRL in New Zealand past, present and future. Chartered Accountants Journal of New Zealand, 83, 3.

Boyd, G. (2004b, June). The 9th International XBRL Conference. Chartered Accountants Journal of New Zealand, 83, 1.

Boyd, G., \& Teixeira, A. (2004a, February). What in the world is XBRL? Chartered Accountants Journal of New Zealand, 83, 2.

Bradbury, M., \& van Zijl, T. (2006). Due process and the adoption of IFRS in New Zealand. Australian Accounting Review, 16(39), 86-94.

Bui, B. T. (2011). Strategy-Driven Implications for the Management Control Systems of Electricity Generators due to Government Climate Change Policies. (PhD), Victoria University of Wellington, Wellington.

Burrell, G., \& Morgan, G. (1979). Sociological Paradigms and Organisational Analysis, Elements of the Sociology of Corporate Life. London: Heinemann Educational Books Ltd.

Callaghan, J., \& Nehmer, R. (2009). Financial and governance characteristics of voluntary XBRL adopters in the United States. International Journal of Disclosure and Governance, 6(4), 321-335.

Chatterjee, B., \& Hawkes, L. (2008). DOES INTERNET REPORTING IMPROVE THE ACCESSIBILITY OF FINANCIAL INFORMATION IN A GLOBAL WORLD? A COMPARATIVE STUDY OF NEW ZEALAND AND INDIAN COMPANIES. Australasian Accounting Business \& Finance Journal, 2(4), 33-33-56.

Chau, P. Y. K. (2001). Inhibitors to EDI adoption in small businesses: An empirical investigation. Journal of Electronic Commerce Research, 2(2), 78-88.

Chau, P. Y. K., \& Hui, K. L. (2001). Determinants of small business EDI adoption: an empirical investigation. Journal of Organizational Computing and Electronic Commerce, 11(4), 229-252.

Chau, P. Y. K., \& Tam, K. Y. (1997). Factors affecting the adoption of open systems: an exploratory study. MIS quarterly, 1-24.

Chong, A. Y. L., \& Ooi, K. B. (2008). Adoption of interorganizational system standards in supply chains: an empirical analysis of RosettaNet standards. Industrial Management \& Data Systems, 108(4), 529-547.

Chua, W. F. (1986). Radical developments in accounting thought. Accounting review, 601-632.

Ciganek, A. P., Haines, M. N., \& Haseman, W. (2006). Horizontal and vertical factors influencing the adoption of Web services. Paper presented at the System Sciences, 2006. HICSS'06. Proceedings of the 39th Annual Hawaii International Conference on.

Clarkson, M. B. E. (1995). A stakeholder framework for analyzing and evaluating corporate social performance. Academy of management Review, 92-117.

Coffin, Z. (2001). The top 10 effects of XBRL. Strategic Finance, 82 (12), 64-67.

Cohen, E. E., Schiavina, T., \& Servais, O. (2005). XBRL: The standardised business language for 21st century reporting and governance. International Journal of Disclosure and Governance, 2(4), 368-394.

Coles, L. C. o. (2006). Review of HMRC Online Services Report. London: HMRC Online Services.

Cordery, C. J., Fowler, C., \& Mustafa, K. (2011). A solution looking for a problem: factors associated with the non-adoption of XBRL. Pacific Accounting Review, 23(1), 69-88. 
Covaleski, M. A., \& Dirsmith, M. W. (1988). An institutional perspective on the rise, social transformation, and fall of a university budget category. Administrative Science Quarterly, 562587.

Creswell, J. (2003). Research Design: Qualitative, Quantitative, and Mixed Methods Approaches (2nd ed.). Thousand Oaks, California: Sage Publications.

Creswell, J. (2007). Qualitative Inquiry and Research Design: Choosing Among Five Approaches (2nd ed.). Thousand Oaks: Sage Publications.

Dalziel, L. (2007). Minister's Announcement: Quality Regulation Review - Final Report. Retrieved from http://www.med.govt.nz/templates/MultipageDocumentTOC 30135.aspx.

Davey, L. (1991). The application of case study evaluations. Practical Assessment, Research \& Evaluation 2(9).

Davidson, A., Robinson, A., \& Malthus, S. (2006, October 2006). Survey of Chartered Accountants shows XBRL slow to catch on. Chartered Accountants Journal of New Zealand, 85, 3.

Davis, F. D. (1989). Perceived usefulness, perceived ease of use, and user acceptance of information technology. MIS Quarterly, 319-340.

Dawes, S. (1996). Interagency information sharing: Expected benefits, manageable risks. Journal of Policy Analysis and Management, 15(3), 377-394.

Dawes, S. S., Pardo, T. A., Connelly, D. R., Green, D. F., \& Mclnerney, C. R. (1997). Partners in state-local information systems: Lessons from the field. Albany, New York: Center for Technology in Government, University at Albany.

Debreceny, R., Farewell, S., Piechocki, M., Felden, C., \& Graning, A. (2010). Does it add up? Early evidence on the data quality of XBRL filings to the SEC. Journal of Accounting and Public Policy, 29(3), 296-306.

Debreceny, R., Felden, C., Ochocki, B., \& Piechocki, M. (2009c). Introduction to XBRL. In R. Debreceny, C. Felden, B. Ochocki, M. Piechocki \& M. Piechocki (Eds.), XBRL for Interactive Data (pp. 35-50).

Debreceny, R., Felden, C., Ochocki, B., Piechocki, M., \& Piechocki, M. (2009a). XBRL for Interactive Data: Engineering the Information Value Chain: Springer Verlag.

Dedrick, J., \& West, J. (2004). An exploratory study into open source platform adoption. Paper presented at the System Sciences, 2004. Proceedings of the 37th Annual Hawaii International Conference on.

Dembla, P., Palvia, P., Brooks, L., \& Krishnan, B. (2003). Adoption of web-based services for transaction processing by organizations: A multilevel contextual analysis. Paper presented at the The 9th Americas Conference on Information Systems, Tampa, Florida, USA.

Denscombe, M. (1998). The Good Research Guide for Small-Scale Social Research Projects. London: The Open University Press.

Denscombe, M. (2010). Ground Rules for Good Research: Guidelines for Good Practice: Buckingham: Open University Press.

Denzin, N. (1989). The research act 3rd ed. Englewood Cliffs, NJ: Prentice Hall.

Denzin, N. (2009). The research act: A theoretical introduction to sociological methods. Piscataway, NJ: Aldine Transaction Publishers

Denzin, N. K. (1970). The research act: A theoretical introduction to sociological methods: Transaction publishers.

Denzin, N. K. (1978). The research act: A theoretical introduction to research methods. New York: McGraw-Hill.

Denzin, N. K., \& Lincoln, Y. S. (2003). The landscape of Qualitative Research: Theories and issues. Thousand Oaks, CA: Sage Publicationa.

DePietro, R., Wiarda, E., \& Fleischer, M. (1990). The Context for Change: Organization, Technology and Environment. In L. G. Tornatzky \& M. Fleischer (Eds.), The Process of Technological Innovation (pp. 151-175). Lexington, MA: Lexington Books.

Deshmukh, A. (2004). XBRL. Communications of the Association for Information Systems, 13, 196-219.

Devonport, B., \& van Zijl, T. (2010). Standard Setting For Financial Reporting in the New Zealand Public Sector. Paper presented at the The sixth Accounting History International Conference, Wellington, New Zealand. 
Doolin, B., \& Troshani, I. (2004). XBRL: a research note. Qualitative Research in Accounting \& Management, 1(2), 93-104.

Doolin, B., \& Troshani, I. (2007). Organizational adoption of XBRL. Electronic Markets, 17(3), 199-209.

Dubé, L., \& Paré, G. (2003). Rigor in information systems positivist case research: Current practices, trends, and recommendations. MIS quarterly, 597-636.

Dunne, T., Helliar, C., Lymer, A., \& Mousa, R. (2009). XBRL: The Views of Stakeholders ACCA Research Report 111. London.

Dunne, T., Helliar, C., Lymer, A., \& Mousa, R. (2013). Stakeholder engagement in internet financial reporting: The diffusion of XBRL in the UK. The British Accounting Review, 45(3), 167-182.

Ebrahim, Z., \& Irani, Z. (2005). E-government adoption: architecture and barriers. Business Process Management Journal, 11(5), 589-611.

Efendi, J., Smith, L. M., \& Wong, J. (2011). Longitudinal analysis of voluntary adoption of XBRL on financial reporting. International Journal of Economics and Accounting, 2(2), 173-189.

Eisenhardt, K. M. (1991). Better stories and better constructs: The case for rigor and comparative logic. Academy of Management review, 16(3), 620-627.

Engel, P., Hamscher, W., Shuetrim, G., Kannon, D., \& Wallis, H. (2003). Extensible Business Reporting Language (XBRL) 2.1 Retrieved April 12, 2011, from http://www.xbrl.org/Specification/XBRLRecommendation-2003-12-31+Corrected-Errata-2005-11-07.rft

Felden, C. (2011). Characteristics of XBRL adoption in Germany. Journal of Management Control, 1-26.

Fetzer, J. (1993). Glossary of Epistemology: Philosophy of Science. New York: Paragon House.

Fisher, L. (2008). The XBRL engine builds speed. Internal Auditor, 65 (4), 50-55.

Flick, U. (1992). Triangulation revisited: strategy of validation or alternative? Journal for the theory of social behaviour, 22(2), 175-197.

Flick, U. (2009). An introduction to qualitative research: SAGE Publications Limited.

Flick, U., Von Kardorff, E., \& Steinke, I. (2004). A companion to qualitative research. London: Sage.

Fountain, J. (2001). Building the Virtual State: Information Technology and Institutional Change. Wishington, D.C.: Brookings Institution Press.

Freeman, R. E. (1984). Strategic management: A stakeholder approach. Marshfield, Massachusetts, USA: Pitman Publishing Inc.

Gable, G. G. (1994). Integrating case study and survey research methods: an example in information systems. European Journal of Information Systems, 3(2), 112-126.

Galliers, R. (1992). Points in understanding information system research. Systemist, 16(1), 32-40.

Garbellotto, G. (2009). Extensible Business Reporting Language (XBRL): What's in it for internal auditor? Institute of Internal Auditors Research Foundation, from http://auditbooks.weebly.com/uploads/4/0/6/9/4069797/extensible business reporting langu age xbrl.pdf

Ghani, E., Laswad, F., \& Tooley, S. (2009). Digital reporting formats: users' perceptions, preferences and performances. The International Journal of Digital Accounting Research, 9, 45-98.

Ghani, E., Laswad, F., \& Tooley, S. (2011). Functional fixation: experimental evidence on the presentation of financial information through different digital formats. The British Accounting Review.

Ghani, E. K., \& Jusoff, K. (2009). Determinants of Preferred Financial Digital Format by New Zealand Accounting Practitioners. International Education Studies, 2(1), P167.

Gillham, B. (2000). The Research Interview. London: Continuum.

Gomes, D., Carnegie, G. D., Napier, C. J., Parker, L. D., \& West, B. (2011). Does accounting history matter? Accounting History, 16(4), 389-402.

Gräning, A., Felden, C., \& Piechocki, M. (2011). Status Quo and Potential of XBRL for Business and Information Systems Engineering. Business \& Information Systems Engineering, 3(4), 1-239.

Gray, G. L., \& Miller, D. W. (2009). XBRL: Solving real-world problems. International Journal of Disclosure and Governance, 6(3), 207-223.

Grgeta, K. (2006). National survey finds nearly one-half of senior finance executives not aware of XBRL Retrieved 16 November, 2011 
Guba, E. G., \& Lincoln, Y. S. (1994). Competing paradigms in qualitative research. In N. K. Denzin \& Y. S. Lincoln (Eds.), Handbook of qualitative research (Vol. 2, pp. 163-194). Thousand Oaks, CA: Sage.

Guilloux, V., Locke, J., \& Lowe, A. (2013). Digital business reporting standards: mapping the battle in France. European Journal of Information Systems, 22(3), 257-277.

Hannon, N. (2002). Accounting Scandals: Can XBRL help? Strategic Finance, 84 (2), 61-62.

Hawkesworth, M. E. (1988). Theoretical Issues in Policy Analysis. Albany, NY: State University of New York Press.

Henderson, K. A. (2011). Post-positivism and the pragmatics of leisure research. Leisure Sciences, 33(4), 341-346.

Hirschheim, R. (1985). Information systems epistemology: An historical perspective. Research methods in information systems, 13-35.

Hodge, F. D., Kennedy, J. J., \& Maines, L. A. (2004). Does search-facilitating technology improve the transparency of financial reporting? The Accounting Review, 79(3), 687-703.

Hodgson, P., Dalziel, L., \& Cosgrove, C. (2008). Standard Business Reporting - Business Case (pp. 1-64).

Hopper, T., \& Hoque, Z. (2006). Triangulation approaches to accounting research. In Z. Hoque (Ed.), Methodological issues in Accounting Research: Theories, Methods and Issues (pp. 477-483): Spiramus Press Ltd.

Hucklesby, M. (2002, September). XBRL New Zealand Gets Serious. Chartered Accountants Journal of New Zealand, 81, 2.

Hucklesby, M. (2010a, 15 March). More investment needed to support Standard Business Reporting. The National Business Review, 2.

Hucklesby, M. (2010b, 9 July). Mind share: compliance costs: a budget cut that will cost more in long run. The National Business Review, 3.

Hucklesby, M., \& Macdonald, J. (2001c, September). XBRL: Past the Point of No Return. Chartered Accountants Journal of New Zealand, 80, 1.

Hucklesby, M., \& Macdonald, J. (2001e, November). XBRL Set to Fly Down Under. Chartered Accountants Journal of New Zealand, 80, 2.

Hucklesby, M., \& Macdonald, J. (2002c, April). <XBRL: Great Attributes>. Chartered Accountants Journal of New Zealand, 81, 3.

Hucklesby, M., \& Macdonald, J. (2002e, June). Financial Reporting: Regulations and XBRL. Chartered Accountants Journal of New Zealand, 81, 4.

Hucklesby, M., \& Macdonald, J. (2003c, December). "Don't change the rules". Chartered Accountants Journal of New Zealand, 82, 1.

Hucklesby, M., \& Macdonald, J. (2004a, March). The three tenets of XBRL- adoption, adoption, adoption! Chartered Accountants Journal of New Zealand, 83, 46-47.

Hucklesby, M., Macdonald, J., \& Teixeira, A. (2003b, July). New Zealand to host international conference. Chartered Accountants Journal of New Zealand, 82, 1.

Hughes, J. (2009). Advisory Committee on Economic Statistics meeting minutes. Retrieved from http://www.stats.govt.nz/browse for stats/economic indicators/balance of payments/adviso ry-committee-on-stats/meeting-minutes/march09.aspx

Hutton, E., Goldstein, J., \& Piemonte, M. (2013). The Adoption of XBRL Reporting: Implications for Industry and Education. The BRC Academy Journal of Education, 3(1), 49-68.

lacovou, C. L., Benbasat, I., \& Dexter, A. S. (1995). Electronic data interchange and small organizations: adoption and impact of technology. MIS quarterly, 19(4), 465-485.

ICT, G. (2011). Government ICT Directions and Priorities Retrieved 10 October, 2011, from http://www.e.govt.nz/guidance-and-resources/standards-compliance/e-gif/xbrl-extensiblebusiness-reporting-language/

IFRS. (2010). XBRL Update Retrieved 8 Septermber, 2011, from http://www.ifrs.org/NR/rdonlyres/DCOFC985-2BB6-4D06-9702-

4D3F358CBD42/0/XBRLUpdateMarch2010.pdf

IFRS. (2011a). XBRL Update Retrieved September, 2011, from http://www.ifrs.org/xbrl

ILIAS, A., RAZAK, Z. M. A., \& RAZAK, S. F. F. A. (2014). The Awareness of the Extensible Business Reporting Language (XBRL) In Malaysia. Journal of Internet Banking \& Commerce, 19(2). 
Irani, Z. (2002). Information Systems Evaluation: Navigating Through the Problem Domain. Information and Management, 40(1), 11-24.

Jankowicz, A. D. (2005). Business research projects (4th ed.). London, UK: Cengage Learning EMEA.

Jick, T. (1979). Mixing Qualitative and Quantative Methods: Triangulation in Action. Aministrative Science Quarterly, 24, 602-611.

Jones, S. R., \& McEwen, M. K. (2000). A conceptual model of multiple dimensions of identity. Journal of college student development, 41(4), 405-414.

Joshi, J., Ghafoor, A., Aref, W. G., \& Spafford, E. H. (2001). Digital government security infrastructure design challenges. Computer, 34(2), 66-72.

Kearns, G. S., \& Lederer, A. L. (2004). The impact of industrial contextual factors on IT focus and the use of IT for competitive advantage Information \& Management 41(7), 899-919.

Kernan, K. (2008). XBRL Around the World. Journal of Accountancy, 206 (4), 62-66.

Kernan, K. (2009, 3 August). XBRL: The Story of Our New Language. Personalities, Cultures, and Politics Combine to Create a Common, Global Language for Business. American Institute of Certified Public Accountants (AICPA), 1-35.

Khan, T. (2006). Financial reporting disclosure on the internet: An international perspective. (PhD), Victoria University, Australia, Victoria, Australia. Retrieved from http://www.adoptifrs.org/uploads/South\%20Africa/Khan\%202006.pdf

Kim, J. W., Lim, J.-H., \& No, W. G. (2012). The effect of first wave mandatory XBRL reporting across the financial information environment. Journal of Information Systems, 26(1), 127-153.

Kimchi, J., Polivka, B., \& Stevenson, J. S. (1991). Triangulation: operational definitions. Nursing research, 40(6), 364-366.

Kochen, M. (1985). Are MIS Frameworks Premature? Journal of Management Information Systems, 2(3), 92-100.

Kock, N., McQueen, R., \& Corner, J. (1997). The nature of data, imformation and knowledge exchange in business process: Implication for process improvement and organizationallearning. The leading Organization. An International Journal, 4(2), 70-80.

Krishna, S., \& Walsham, G. (2005). Implementing public information systems in developing countries: Learning from a success story. Information Technology for Development, 11(2), 123-140.

Kuan, K. K. Y., \& Chau, P. Y. K. (2001). A perception-based model for EDI adoption in small businesses using a technology-organization-environment framework. Information \& Management, 38(8), 507-521.

Kwon, T., \& Zmud, R. (1987). Unifying the fragmented models of information system implementation. In R. Boland \& R. Hirschheim (Eds.), Critical Issues in Information System Research (pp. 227-251). New York: John Wiley \& Sons.

La Rosa, F., \& Caserio, C. (2013). Are Auditors Interested in XBRL? A Qualitative Survey of Big Auditing Firms in Italy. Accounting Information Systems for Decision Making, 8(6), 13-45.

Lai, V. S., \& Guynes, J. L. (1997). An assessment of the influence of organizational characteristics on information technology adoption decision: a discriminative approach. IEEE Transactions on Engineering Management, 44(2), 146-157.

Landsbergen, D., \& Wolken, G. (2001). Realizing the Promise: Government Information System and the Fourth Generation of Information Technology. Public Administration Review, 61(2), 206-218.

Lee, A. S. (1989). A scientific methodology for MIS case studies. MIS quarterly, 13(1), 33-50.

Lee, A. S. (1991). Integrating positivist and interpretive approaches to organizational research. Organization science, 2(4), 342-365.

Lee, C.-P., \& Shim, J. P. (2007). An exploratory study of radio frequency identification (RFID) adoption in the healthcare industry. European Journal of Information Systems, 16(6), 712-724.

Lin, H. F. (2006). Interorganizational and organizational determinants of planning effectiveness for Internet-based interorganizational systems. Information \& Management, 43(4), 423-433.

Lincoln, Y. S., \& Guba, E. G. (1985). Naturalistic inquiry (Vol. 75). Thousand Oaks, CA: Sage.

Lippert, S. K., \& Govindarajulu, C. (2006). Technological, Organizational and Environmental Antecedents to Web Services Adoption. Communications of the IIMA, 6(1), 146-158. 
Locke, J., \& Lowe, A. (2006). Implementation and infusion implications for XBRL. School of Accounting and Commercial Law, Victoria University of Wellington, Wellington, November, 16.

Louwers, T., Pasewark, W., \& Typpo, E. (1998). Silicon Valley Meets Norwalk. Journal of Accountancy, 186, 20-24.

Lowe, A., Locke, J., \& Lymer, A. (2012). The SEC's retail investor 2.0: Interactive data and the rise of calculative accountability. Critical Perspectives on Accounting, 23(3), 183-200.

Lymer, A. (1999). Internet and the future of reporting in Europe. European Accounting Review, 8(2), 289301.

Maharey, S. (2010, 18 June). How New Zealand's universities must cultivate innovative talent. The National Business Review, 3.

Mandilas, A., Maditinos, D., Pipiliagkopoulos, M., \& Passaportis, A. (2009). A Cross Country Assessment of the Determinants of the XBRL Adoption. Paper presented at the 7th Annual Conference Hellenic Finance and Accounting Association, University of Macedonia, Thessaloniki.

Marginson, D. E. (1999). Beyond the budgetary control system: towards a two-tiered process of management control. Management Accounting Research, 10(3), 203-230.

McFarland, K. (2007). Only 59\% of CFO's aware of XBRL; but half believe it will be mandatory SEC filing format Retrieved 16 November, 2011

McGuire, B. L., Okesson, S. J., \& Watson, L. A. (2006). Second-wave benefits of XBRL. Strategic Finance, 88(6), 43-55.

Melvin, M., \& Taylor, M. P. (2009). The global financial crisis: Causes, threats and opportunities. Introduction and overview. Journal of International Money and Finance, 28(8), 1243-1245.

Miles, M., \& Huberman, A. (1994). Qualitative Data Analysis: An Expanded Source Book (2nd ed.). California: Thousand Oaks, Sage Publications.

Miller, G., Dingwall, R., \& Murphy, E. (2004). Using qualitative data and analysis: Reflections on organizational research. In D. Silverman (Ed.), Qualitative research: Theory, Method and Practice (2nd ed., pp. 325-340). London: Sage Publications.

Milner, E. M. (2002). Managing Information and Knowledge in the Public Sector. New York: Routledge.

Mishra, A. N., Konana, P., \& Barua, A. (2007). Antecedents and consequences of internet use in procurement: an empirical investigation of US manufacturing firms. Information Systems Research, 18(1), 103-120.

Moore, G. C., \& Benbasat, I. (1991). Development of an instrument to measure the perceptions of adopting an information technology innovation. Information systems research, 2(3), 192-222.

Morgan, G. (1980). Paradigms, metaphors, and puzzle solving in organization theory. Administrative science quarterly, 605-622.

Morgan, G. (1983). Beyond method: Strategies for social research. Beverly Hills, CA: Sage Publications.

Mousa, R. (2011). E-government adoption process: XBRL adoption in HM revenue and customs and companies house. (Ph.D), University of Birmingham, Birmingham. Retrieved from http://etheses.bham.ac.uk/1752/

Myers, M. D. (1997). Qualitative research in information systems. Management Information Systems Quarterly, 21, 241-242.

Myers, M. D., \& Avison, D. (2002). An introduction to qualitative research in information systems. In D. Myers \& D. Avison (Eds.), Qualitative Research in Information Systems (pp. 3-12). London: Sage Publications.

Napier, C. J. (2006). Accounts of change: 30 years of historical accounting research. Accounting, Organizations and Society, 31(4), 445-507.

Nel, G., \& Steenkamp, L. (2008). An exploratory study of chartered accountants' awareness and understanding of XBRL. Meditari Accountancy Research, 16(1), 79-93.

Norris, D. F. (1999). Leading edge information technologies and their adoption: lessons for US cities.

Oliveira, T., \& Martins, M. F. (2010). Understanding e-business adoption across industries in European countries. Industrial Management \& Data Systems, 110(9), 1337-1354.

Orlikowski, W., \& Baroudi, J. J. (1991). Studying information technology in organizations: Research approaches and assumptions. Information System research, 2 (1), 1-28. 
Oyelere, P., Laswad, F., \& Fisher, R. (2003). Determinants of internet financial reporting by New Zealand companies. Journal of International Financial Management \& Accounting, 14(1), 26-63.

Paré, G. (2004). Investigating information systems with positivist case study research. Communications of the Association for Information Systems, 13(1), 233-264.

Patton, M. Q. (2002). Qualitative Research and Evaluation Methods (3rd ed.). Thousand Oaks, CA: Sage Publication.

Perdana, A., Robb, A., \& Rohde, F. (2015). An integrative review and synthesis of XBRL research in academic journals. Journal of Information Systems, 29(1), 115-153.

Perry, J. L., \& Danziger, J. N. (1980). The Adoptability of Inno Va Tions. Administration \& Society, 11(4), 461.

Pinsker, R. (2003). XBRL awareness in auditing: a sleeping giant? Managerial Auditing Journal, 18(9), 732-736.

Pinsker, R., \& Li, S. (2008). Costs and benefits of XBRL adoption: Early evidence. Communications of the ACM, 51(3), 47-50.

Plumlee, R. D., \& Plumlee, M. A. (2008). Assurance on XBRL for Financial Reporting. Accounting Horizons, 22(3), 353-368.

Polkinghorne, D. (1983). Methodology for the human sciences: Systems of inquiry: Suny Press.

Power, S. (2009). Standard Business Reporting: Report Back to Cabinet Retrieved 4 Aug, 2011, from http://www.med.govt.nz/templates/MultipageDocumentTOC 41220.aspx

Premkumar, G., \& Ramamurthy, K. (1995). The role of interorganizational and organizational factors on the decision mode for adoption of interorganizational systems. Decision Sciences, 26(3), 303336.

Premuroso, R. F., \& Bhattacharya, S. (2008). Do early and voluntary filers of financial information in XBRL format signal superior corporate governance and operating performance? International Journal of Accounting Information Systems, 9(1), 1-20.

Pudjianto, B., Zo, H., Ciganek, A. P., \& Rho, J. J. (2011). Determinants of E-Government Assimilation in Indonesia: An Empirical Investigation Using a TOE Framework. Asia Pacific Journal of Information Systems, 21(1).

Raju, V. (2005). Developments in corporate governance and disclosure regime in Singapore.

Rezaee, Z., \& Turner, J. L. (2002). XBRL-based financial reporting: Challenges and opportunities for government accountants. Journal of Government Financial Management, 51(2), 16-23.

Richards, J., Smith, B., \& Saeedi, A. (2006). An introduction to XBRL. Available at SSRN 1007570.

Richards, J., \& Tibbits, H. (2002). Understanding XBRL. CPA Australia, NSW.

Richards, J., Tibbits, H., \& Campus, B. (2002). CPA AUSTRALIA NSW BRANCH WORKSHOP.

Richards, L. (2014). Handling Qualitative Data: A Practical Guide (3rd ed.). London: Sage Publications.

Rodwell, T. (2001, 14 June). E\& Y, university leap into joint development. Computerworld New Zealand, 3.

Rogers, E. M. (1983). Diffusions of innovations (3rd ed.). New York: The Free Press.

Rogers, E. M. (1995). Diffusion of Innovation. (4th ed.). New York: The Free Press.

Rogers, E. M. (2003). Diffusion of Innovations (4th ed.). New York, NY: The Free Press.

Rondel, M. (2004, June). XBRL - do I need to know more? Chartered Accountants Journal of New Zealand, 83, 4.

Ryan, A. B. (2006). Post-positivist approaches to research Researching and Writing your Thesis: a guide for postgraduate students (pp. 12-26).

Saeedi, A., Richards, J., \& Smith, B. (2006). An Introduction to XBRL. Irainan Accounting \& Auditing Review, 45, 132-158.

Savage, M. (2009). XBRL US Launches Intern Program to Foster Cooperation and Build Community Retrieved from http://www.redorbit.com/news/technology/1667404/xbrl us launches intern program to fo ster cooperation and build/

Schram, D. H., \& Steen, G. (2001). the Psychology and Sociology of Literature. Amsterdam: Johns Benjamin Publishing. 
Scott, W. R. (2004). Institutional Theory. In G. Ritzer (Ed.), Encyclopedia of Social Theory (pp. 408-414). CA: Thousand Oaks.

Sekaran, U. (2000). Research Methods for Business: A Skill-building Approach (3rd ed.). New York: John Wiley \& Sons.

Shan, Y. G., \& Troshani, I. (2014). Does XBRL benefit financial statement auditing? Journal of Computer Information Systems, 54(4), 11-21.

Silverman, D. (2000). Doing Qualitative Research: A practical Handbook. London: Sage.

Smithson, S., \& Cornford, T. (1996). Project Research in Information Systems: A Students' Guide. Basingstoke, UK: Macmillan Press.

Sobh, R., \& Perry, C. (2006). Research design and data analysis in realism research. European Journal of marketing, 40(11/12), 1194-1209.

Srivastava, R. P., \& Kogan, A. (2010). Assurance on XBRL instance document: A conceptual framework of assertions. International Journal of Accounting Information Systems, 11(3), 261-273.

Srivastava, S. C., \& Teo, T. S. H. (2007). What facilitates e-government development? A cross-country analysis. Electronic Government, An International Journal, 4(4), 365-378.

Srivastava, S. C., \& Teo, T. S. H. (2010). E-Government, E-Business, and National Economic Performance. Communications of the Association for Information Systems, 26(1), 14.

SSC. (2008). New Zealand e-Government Interoperability Framework (NZ e-GIF) Version 3.3.

Steenkamp, L. P., \& Nel, G. F. (2012). The adoption of XBRL in South Africa: an empirical study. The Electronic Library, 30(3), 409-425.

Strauss, A., \& Corbin, J. (1990). Basics of Qualitative Research: Grounded Theory Procedures and Techniques. London: Sage Publications.

Tan, K. S., Chong, S. C., Lin, B., \& Eze, U. C. (2009). Internet-based ICT adoption: evidence from Malaysia SMEs. Industrial Management \& Data Systems, 109(2), 224-244.

Tellis, W. (1997b). Information technology in a university: a case study. Campus-Wide Information Systems, 14(3), 78-91.

Teo, H. H., Wei, K. K., \& Benbasat, I. (2003). Predicting Intention to Adopt Interorganizational Linkages: An Institutional Perspective. MIS Quarterly, 27(1), 19-49.

Thompson, M. (2009). The organizational champion: How to develop passionate change agents at every level: McGraw Hill Professional.

Thong, J. Y. (1999). An Integrated Model of Information Systems Adoption in Small Businesses. Journal of Management Information Systems, 15(4), 187-214.

Tichenor, P. J., Donohue, G. A., \& Olien, C. N. (1970). Mass media flow and differential growth in knowledge. Public opinion quarterly, 34(2), 159-170.

Tie, R. (2005). It's Unstoppable. Journal of Accountancy, 200 (2), 32.

Tornatzky , L., \& Klein, K. (1982). Innovation characteristics and innovation adoption implementation: A meta-analysis of findings. IEEE Transaction on Engineering Management, 29(1), 28-45.

Tornatzky, L. G., \& Fleischer, M. (1990). The processes of technological innovation. Lexington, MA: Lexington Books.

Trochim, W. M. (2006). Positivism and post-positivism. Research methods knowledge base. Retrieved from http://www.socialresearchmethods.net/kb/positivism.php

Troshani, I., \& Doolin, B. (2005). Drivers and inhibitors impacting technology adoption: a qualitative investigation into the Australian experience with XBRL.

Troshani, I., \& Doolin, B. (2007). Innovation diffusion: A stakeholder and social network view. European Journal of Innovation Management, 10 (2), 176-200.

Troshani, I., Jerram, C., \& Rao, S. (2011). Exploring the public sector adoption of HRIS. Industrial Management \& Data Systems, 111(3), 470-488.

Troshani, I., \& Rao, S. (2007). Drivers and inhibitors to XBRL adoption. International Journal of E-Business Research, 3(4), 98-111.

Umoren, A., \& Jeremiah, O. (2015). Implications of XBRL Adoption in Nigeria: Perception of Professional Accountants. Research Journal of Finance and Accounting, 6(8), 97-103.

van Burg, H. J., Madden, P., van Hilvoorde, M., \& Farkas, G. (2010). What is SBR? , from http://www.xbisoftware.com/pub/sbr.htm 
Vasarhelyi, M., Chan, D., \& Krahel, J. (2010). XBRL Consequences to Financial Reporting, Data Analysis, Decision Support, and Others: Rutgers University.

Vasarhelyi, M. A., Chan, D. Y., \& Krahel, J. (2012). Consequences of XBRL standardization on financial statement data. Journal of Information Systems, 26(1), 155-167.

Venkatesh, R., \& Armitage, J. (2012). Accountants' Awareness And Perceptions About Assurance On XBRL Financial Statements. Journal of Applied Business Research (JABR), 28(2), 145-154.

Venkatesh, V., \& Davis, F. D. (2000). A theoretical extension of the technology acceptance model: Four longitudinal field studies. Management science, 46(2), 186-204.

Voss, C., Tsikriktsis, N., \& Frohlich, M. (2002). Case research in operations management. International journal of operations \& production management, 22(2), 195-219.

Vun Kannon, D., \& Hannon, N. (2004). Why Is XBRL So Hard? Strategic Finance, 86(2), 49-49.

Walsham, G. (1995). The emergence of interpretivism in IS research. Information systems research, 6(4), 376-394.

Wang, Z., \& Gao, S. (2012). Are XBRL based financial reports better than Non-XBRL Reports? A Quality Assessment. World Academy of Science Research and Innovation, 6(4), 454-459.

Warren, C. A. (2002). Qualitative interviewing. Thousand Oaks, CA: Sage.

Wildemuth, B. M. (1993). Post-positivist research: two examples of methodological pluralism. The Library Quarterly, 450-468.

Willis, M. (2007). Improving investor communications and analysis via standardisation. International Journal of Digital Accounting Research, 7(13), 153-165.

XBRL. (2009). An Introduction to XBRL Retrieved 23 Dec, 2009, from http://www2.xbrl.org/za/frontend.aspx?clk=LK\&val=75

XBRL. (2011). XBRL International Events Retrieved 17 August, 2011, from http://www.xbrl.org/xbrlinternational-events/past-events/

XBRL, I. (2015). An Introduction to XBRL Retrieved 2 Septermber, 2015, from https://www.xbrl.org/thestandard/what/an-introduction-to-xbrl/

Yang, K. H., Lee, S. M., \& Lee, S. G. (2007). Adoption of information and communication technology: impact of technology types, organizational resources and management style. Industrial Management \& Data Systems, 107(9), 1257-1275.

Yin, R. K. (1984). Case Study Research; Design \& Methods. Beverly Hills, California: Sage Publications.

Yin, R. K. (1994). Case Study Research, Design and Methods (2nd ed.). Beverly Hills, CA: Sage Publications.

Yin, R. K. (2003). Case Study Research: Design and Methods, (3rd ed.). California: Sage Publications.

Yoon, H., Zo, H., \& Ciganek, A. P. (2011). Does XBRL adoption reduce information asymmetry? Journal of Business Research, 64(2), 157-163.

Zaltman, G., Duncan, R., \& Holbek, J. (1973). Innovations and Organizations. New York: John Wiley \& Sons.

Zhu, K., Kraemer, K., \& Xu, S. (2003). Electronic business adoption by European firms: a cross-country assessment of the facilitators and inhibitors. European Journal of Information Systems, 12(4), 251-268.

Zhu, K., \& Kraemer, K. L. (2005). Post-adoption variations in usage and value of e-business by organizations: Cross-country evidence from the retail industry. Information systems research, 16(1), 61-84.

Zhu, K., Kraemer, K. L., \& Xu, S. (2006). The process of innovation assimilation by firms in different countries: a technology diffusion perspective on e-business. Management science, 52(10), 15571576.

Zhu, K., Kraemer, K. L., Xu, S., \& Dedrick, J. (2004). Information Technology Payoff in E-Business Environments: An International Perspective on Value Creation of E-Business in the Financial Services Industry. Journal of Management Information Systems, 21(1), 17-54. 